MARIO josé polit

\title{
ESTUDO DA REAÇÃO DE HIDRÓLISE ALCALINA DE IONS N-ALQUIL-4-CIANOPIRIDÍNEOS EM MICELAS
}

Dissertação de Mestrado apresentada ao Departamento de Química do Instituto de Qúmica da Universidade de São Paulo 
Esta dissertação, embora descrita em português de canhoto, é resultado do colaboração de un grupo de pessoas que me ensinaram muito. Agradeço portanto a todas el as.

Agradeço especialmente ao Professor Hernan que re almente entende muito de ciéncia e de vida e que sabe con duziro laboratório e todo pessoal de forma maestral.

A I olanda que sem ela esta dissertação não seria possive7, como também eu nada teria aprendido. Esta menina não é um braço direito, é um mundo inteiro.

A Elisa que apesar de agora longe tem um cantinho todo especial.

Ao Frank que tem uma saūde de ferro em orientar esses iniciantes e é o gringo mais brasileiro que eu conhe ço.

A Regininha que ajudou pacas.

A Dona Benê, Neusa e Clélia que fizeram cafezinhos e como pássaros encantaram o laboratório.

Ao Sërgio, malu e Renato que são companheiros vi gorosos.

Ao Dino, Marconi, Edson, vicente e Ricardo que jun tos enxugamos muitas cervejas.

A Bel que bateu toda a dissertação em tempo recor de.

A Aninha que é una pequera "Chata" menina.

A Wany, Efigênia. Augusto e Sandrinha que torna ram mais fácil o dia a dia. trabalho.

A Isabel que ao meu lado sofrev pelas madrugadas de

A CulCA batucando petas quimicas.

A FAPESP pelo auxitio financeiro.

E findimente dos meus pais, que sempre estáo pre sentes e realmente me ensinarama ser uma pessoa tranquila. 


\section{ND I CE}

$\begin{array}{lr}\text { Simbolos e Abreviaturas } & \text { I } \\ \text { I. Introdução } & 1 \\ \text { II. Micelas } & 1 \\ \text { I.1.1. Definiçao e Estrutura } & 12 \\ \text { I.1.2. Formação } & \end{array}$

1.2. tfeitos de micelas sobre a velocidade de $\begin{array}{ll}\text { reações químicas } & 16\end{array}$

I.3. Sistema em tstudo 22

I.3.1. Esquema Cinético 22

I.3.2. Efeito de constante dielétrica e força iōnica sobre reações entre ions 28

I.4. Alguns conceitos e inovações associados às técnicas empregadas 33

I.4.1. Fotofenōmenos 33

I.4.2. Cromatografia em fase gasosa 35

I.5. Objetivos do estudo 36

II. Materiais, Métodos e Aparelhos 38

II.1. Materiais 38

II.1.1. Detergentes 38

II.1.2. Reagentes Orgānicos 40

II.1.3, Reagentes Inorgānicos 45

II.1.4. Solventes 46

II.2. Mëtodos 47

II.2.1. Dosagens Analiticas 47

II.2.2. Procedimentos de rotina 50 
I I.2.3. Metodos Fluorimétricos

II.2.4. Cromatografia em fase gasosa

Micro - Hoffmann

II.3. Aparelhos

III. Kesultados

III.1. Hidrōlise alcalina dos N-alquil-4-cianopiridineos

I I I.1.1. tm àgua

55

III.1.2. Em micelas

84

I II.2. Anālise de detergentes derivados de sais de amōnio quaternārio por Hoffmann direta (Micro-Hoffmann)

IV. Discussão

IV.l. Reação de Hidrólise Alcalina de N-alquil4-cianopiridíneo (RCP) em àgua

IV.2. Em Micelas

170

IV.3. Anālise de detergentes por Micro-Hoffmann 190

V. Sumārio

V. Summary

194

Notas

Referéncias Bibliográficas 
CMC

CP

0

A

a

$f$

$\mathrm{F}$

$\psi$

R

T

K

Z

e

$\zeta$

$\alpha$

N

D

$\mu$

G

Keq

CT

CD

$\bar{v}$

$k_{x / y}$

$A_{t}$

$A_{b}$ concentração crītica de micelização

centi Poise $\left(\mathrm{g} \times \mathrm{seg}^{-1} \times \mathrm{cm}^{-1} \times 10^{-2}\right)$

Angstron $=10^{-8} \mathrm{~cm}$

atividade

coeficiente de atividade

constante de Faraday $=96.493 \frac{\text { abs.coulombs }}{\text { equivalente }}$

potencial

constante dos gases $=8,317 \times 10^{7} \mathrm{erg} / \mathrm{mol} \cdot \mathrm{K}^{0}$

temperatura absoluta $\left({ }^{0} \mathrm{~K}\right)$

constante de Boltzmann $=1,38 \times 10^{-16} \mathrm{erg} / \mathrm{molec} \cdot \mathrm{k}^{0}$ valência do ĩon

carga do elétron $=4,803 \times 10^{-10}$ e.s.v.

potencial zeta

grau de dissociação da micela

No de àgregação da micela

constante dielétrica

força iōnica

energia livre

constante de equilibrio

concentração total de detergente

concentração de detergente total menos a CMC

volume efetivo por mol de detergente micelizado

constante de troca do ion $x \bar{e}$ o contraion y da mi cela

concentração total de dado ion

concentração de dado ion ligado a micela 


\begin{tabular}{|c|c|}
\hline$A_{f}$ & concentração de dado ion da fase aquosa \\
\hline$k_{\psi}$ & constante de velocidade observada \\
\hline$k_{2}^{0}$ & $\begin{array}{l}\text { constante de velocidade de segunda ordem em fase } \\
\text { aquosa }\end{array}$ \\
\hline$k_{2}^{m}$ & $\begin{array}{l}\text { constante de velocidade de segunda ordem em fase } \\
\text { micelar }\end{array}$ \\
\hline$k 5$ & $\begin{array}{l}\text { constante de partição de reagentes neutros às mi } \\
\text { celas }\end{array}$ \\
\hline$k_{\psi}^{m}$ & $\begin{array}{l}\text { constante de velocidade observada na presença de } \\
\text { micelas }\end{array}$ \\
\hline DTNB & $\bar{a} c i d o 5,5^{\prime}$-dithiobisparanitro benzöico \\
\hline$k_{\psi}^{0}$ & constante de velocidade observada em fase aquosa \\
\hline$k_{2} \psi$ & $\begin{array}{l}\text { constante de velocidade de segunda ordem observa } \\
\text { da }\end{array}$ \\
\hline$R C P$ & $N$-aquil-4-cianopiridineo \\
\hline MCP & $N$-metil-4-cianopiridineo \\
\hline$B C P$ & N-butil-4-cianopiridineo \\
\hline$O C P$ & $N$-octil-4-cianopiridideo \\
\hline UCP & N-dodecil-4-cianopiridineo \\
\hline n & constante de Planck $=6,625 \times 10^{-27}$ erg.seg \\
\hline$\phi_{\text {em }}^{o}$ e $\phi_{\text {em }}$ & $\begin{array}{l}\text { rendimento quāntico da emissão de fluorescência } \\
\text { na ausência e presença de supressor, respectiva } \\
\text { mente }\end{array}$ \\
\hline$k s v$ & constante de Stern-Volmer \\
\hline$C T A B$ & brometo de $N, N^{\prime}$-hexadeciltrimetilamônio \\
\hline SDS & dodecil sulfato de sōdio \\
\hline $50 P$ & 3-(N,N'-dimetildodecilamônio) propano-l-sulfonatc \\
\hline herq-Cl & cloreto de $\mathrm{N}$-dimetilalquilamōnio \\
\hline $\mathrm{Herq}-\mathrm{OH}$ & hidrōxido de $N$-dimetil-N-dialquilamónio \\
\hline D. 0 . & densidade ōptica \\
\hline ᄃ & coeficiente de extinção molar \\
\hline P & $\mathrm{N}-\mathrm{aqu}$ i 1 \\
\hline
\end{tabular}




\begin{tabular}{|c|c|}
\hline A & $N-a q u i 1-4-c a b o x i a m i d o p i r i d i n e o$ \\
\hline$k_{T}^{m o n}$ & constante de troca de monômeros \\
\hline$m f$ & concentraçāo de monōmero livre \\
\hline$\overline{K_{W}}$ & $\begin{array}{l}\text { produto iônico da àgua na interface micela/āgua } \\
\text { na àgua }\end{array}$ \\
\hline$k_{w}$ & produto iōnico da àgua na àgua \\
\hline$\frac{K_{\psi_{m}} \bar{a} x}{K \psi_{0}}$ & fator de aceleração māximo \\
\hline$T \cdot R$. & tempo de retenção \\
\hline $8 \mathrm{NMe}_{2}$ & $N$-dimetil-N'-octil-amina \\
\hline $12 \mathrm{NMe}_{2}$ & $N$-dimetil-N'-dodecil-amina \\
\hline $14 \mathrm{NME}_{2}$ & $N$-dimeti1-N'-tetradecil-amina \\
\hline $16 \mathrm{NMe}_{2}$ & $N$-dimeti1-N'-hexadeci1-amina \\
\hline $18 \mathrm{NMe}_{2}$ & $N$-dimetil-N'-octadecil-amina \\
\hline $\mathrm{C}_{14}$ & $1-$ tetradeceno \\
\hline $\mathrm{C}_{16}$ & 1-hexadeceno \\
\hline $\mathrm{C}_{18}$ & 1 -octadeceno \\
\hline $\mathrm{C}_{16} \mathrm{Cl}$ & 1-cloro-hexadecano \\
\hline $\mathrm{C}_{18} \mathrm{Cl}$ & 1-cloro-octadecano \\
\hline $\mathrm{CTAOH}$ & hidrōxido de $N$-hexadecil-N'-trimetilamōnio \\
\hline CTAC 1 & cloreto de $N$-hexadecil-N'-trimetilamônio \\
\hline TTABr & brometo de $N$-tetratedaci1-N'-trimetilamónio \\
\hline STAC 1 & cloreto de $N$-octadecil-N'-trimetilamônio \\
\hline
\end{tabular}


Esta introdução serā composta de quatro partes. Na primeira parte serão revisados os modelos estruturais e as teo rias de formação de micelas e efeitos destas sobre a velocidade de reações químicas. Na segunda parte apresenta-se o siste ma de reação estudado e tratamentos teōricos (1) desenvolvidos pa ra anālise do mesmo. Na terceira parte desenvolvem-se concei tos utilizados em algumas têcnicas empregadas e na quarta par te expõe-se os objetivos deste trabalho.

I. Micelas

I.1.1. Definição e Estrutura

Dissolvendo-se substāncias anfifịicas (compostos de duplo carāter), que apresentam na parte hidrofōbica.(2) uma cadeia alquila não ramificada com 8 a 18 grupos metilénicos e na parte hidrofilica um grupamento iōnico, observa-se a partir de certa faixa de concentração (denominada concentração críti ca de micelização) variações bruscas em algumas das propriedades físicas do sistema. Medindo-se algumas destas proprieda des (tensão superficial, condutividade, espalhamento de luz, etc. Shinoda et al, 1963) em função da concentração da substāncia anfifilica, ou, detergente observa-se o comportamento re presentado na Figura 1 (Fendler \& Fendler, 1975; Shinoda et al 1963).

As mudanças observadas a partir da CMC estão associa das à formação de agregados denominados micelas.

Existe uma exaustiva série de trabalnos e revisões, 


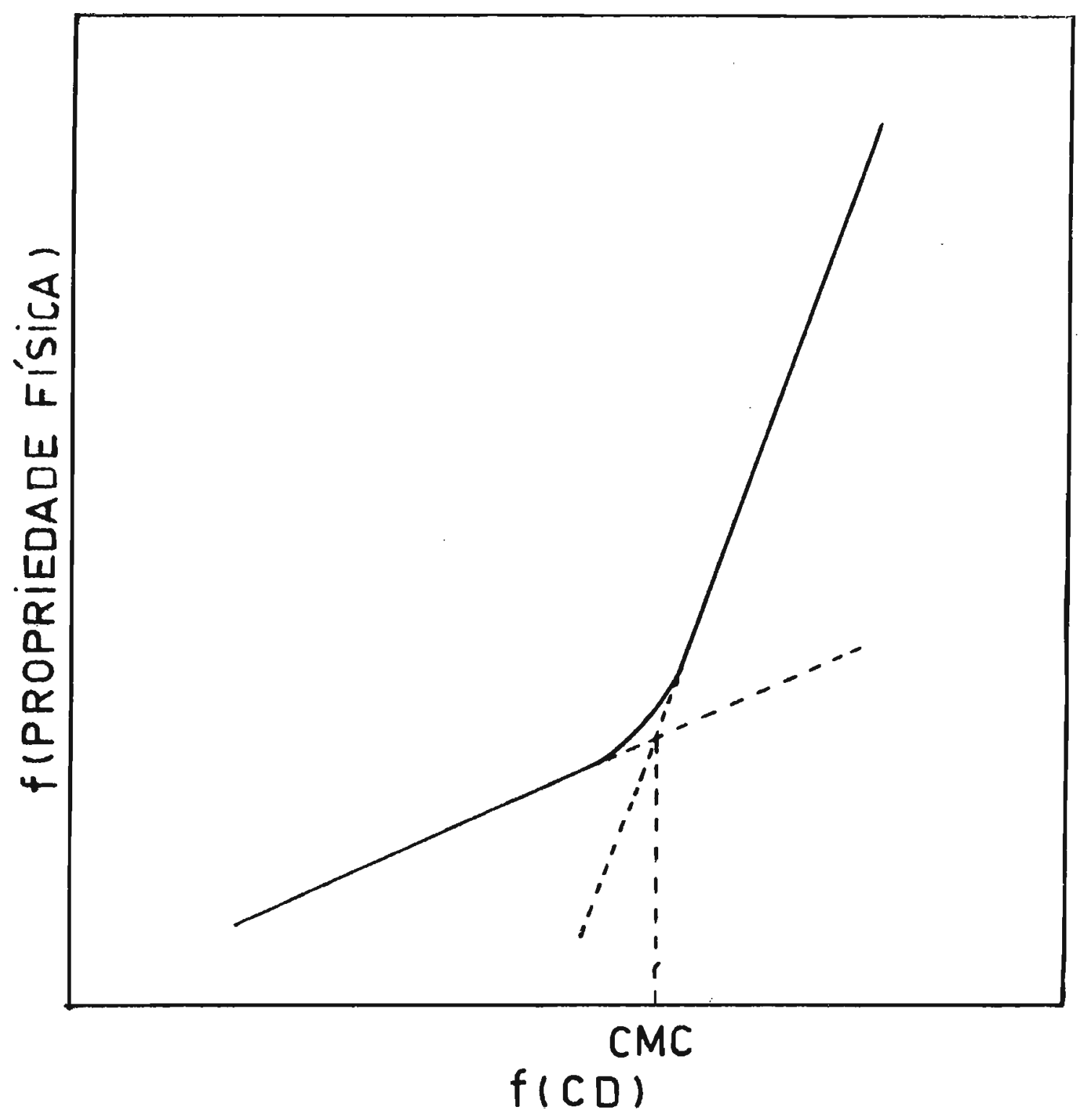

Figura 1 - Efeito na propriedade fisica observada em função da concentração de detergente (Reproduzido de Fendler \& Fen dler, 1975). 
- relacionados às propriedades das entidades formadas a partir da CMC (Fig. 1) (Hartley, 1936; M.CBain, 1955; Shinoda et al, 1963 e 1965; Schick , 1967; Elworthyet a1, 1968; Jungermann, 1970; Mukerjee e Mysels, 1971; Berezin et a1, 1973; Bunton, 1973; Tanford, 1973 e 1980; Fendler e Fendler, 1975; Romsted 1975 ; Mitta1, 1977 e 1979).

Quanto à forma das micelas, salientamos alguns dos mo delos descritos: o modelo laminar de McBain (McBain, 1942), o esfērico de Hartley (Hartley, 1936), o intermediārio aos dois anteriores de Harkins (Harkins, 1946) e o em forma de "cacho de uvas" de Menger (Menger, 1979). Pode-se apreciar que exis te uma variedade de modelos para descrever a forma das micelas .

Na falta de dados precisos que impliquem na determinação inequívoca da forma das micelas apresentamos o modelo de micelas esfēricas (3).

A estrutura do agregado esférico pode ser esquematizada como apresenta a figura 2, que mostra a micela composta das seguintes regiões:

- uma região central constituída pelas cadeias alqui las do detergente, formando um núcleo esférico, cujo raio, pe las dimensões da cadeia, pode ser estimado em 10 a $28 \AA$ (4) (Fen dler e Fendler, 1975; Pauling, 1960). Dados de ressonāncia paramagnētica eletrōnica (Nakagawa e Jizimoto, 1972), ressonān cia magnética nuclear (Muller e Birkhahn, 1967; Muller, 1963)e emissão de sondas fluorescentes (Shinitzky et al, 1971) mostram que o interior das micelas têm uma viscosidade entre 8,3 a 50 $C P$, semelhante a liquidos parafínicos. 0 estado líquido, para os grupos metilênicos próximos à superfĩcie, não deve ser real, 


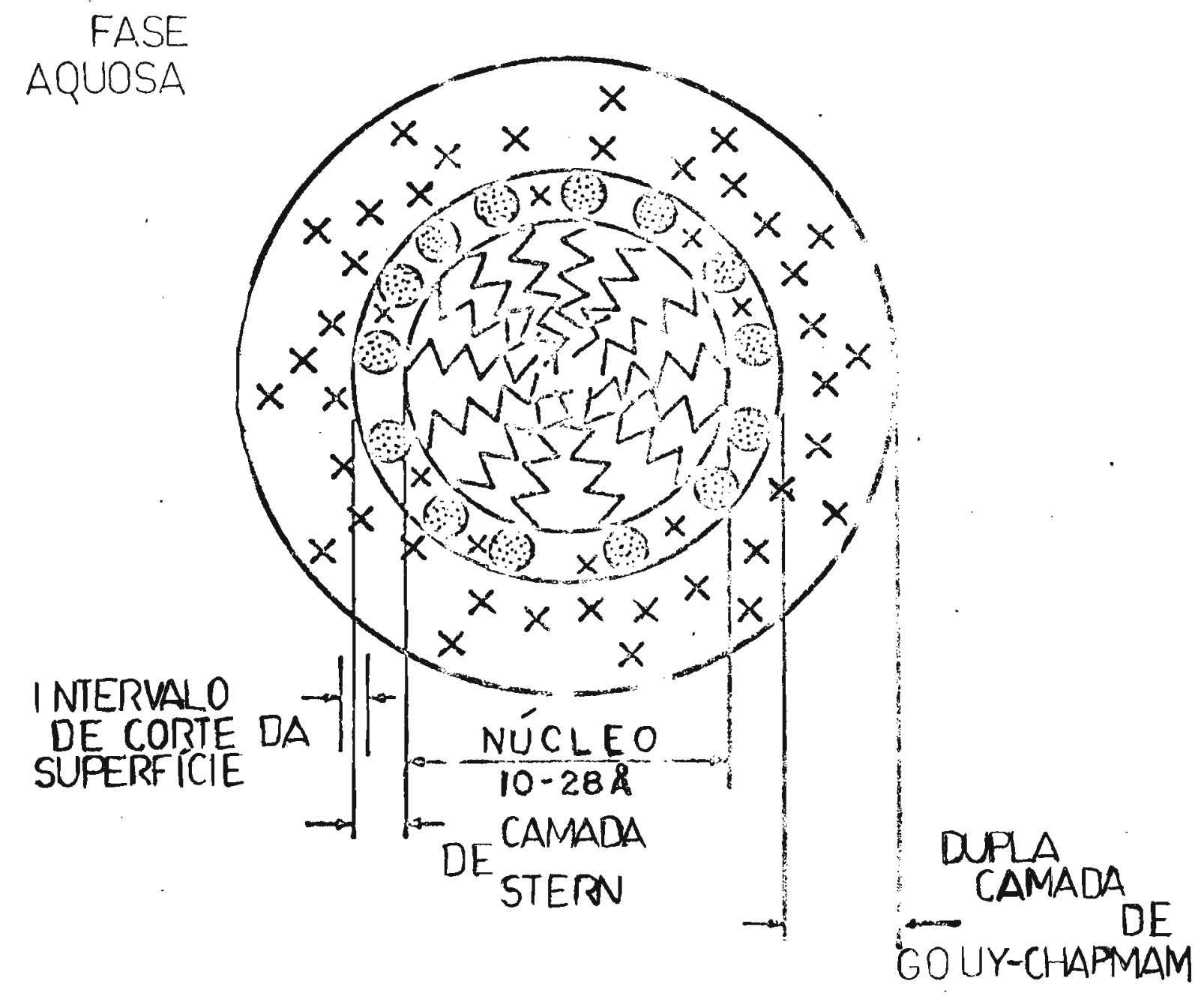

Figura 2 - Corte transversal da micela esférica $x$ = contraton $x=$ contraion

(2)

(Reproduzido de Fendler e Fendier, 1975) 
uma vez que os monômeros dispõem-se perpendiculamente à super ficie. 0 movimento dos grupos metilénicos prōximos da superfi cie da micela deve ser mais restrito do que o dos grupos do in terior da micela. Dados de $T_{1}$ (tempo de relaxação "spin-lattice ") de $\mathrm{c}^{13}$ mostram que $n$ grau de ordem decresce para o interior di micela (Williams et al, 1972). Medidas de microviscosidade: (Kalyanasundaram, 1978; Turro et a 1, 1979) estabelecem que a viscosidade do interior da micela está entre 15 a 30 CP.

- A seguir define-se acamada de Stern (Overbeek, 1952),

região na qual encontram-se a parte hidrofỉlica do composto anfifilico, os ions de carga oposta a do anfifilico, isto é,os contratons ligados (como veremos mais a frente só uma parte dos contraions estäo ligados nesta região), juntamente com àgua de hidratação. A definição desta camada, assim como as proprieda des geométricas da mesma são dependentes do modelo escolhido. No modelo mais recente que sugere a micela em forma de "cacho de uvas" (Menger, 1979), não é possível definir-se fisicamente tal região, porēm, a existência da mesma ê indiscutível. Para o modelo esférico, baseado no tamanho da parte polar dos anfifílicos comumente empregados, estima-se a largura da camada em cerca de $8 \AA$ (c1iford e Pethica, 1964; Stigter, 1974).

- Após a camada de Stern temos a dupla camada difusa de Gouy-Chapman (Myse1s, 1967 ;MacLaugh1in, 1977). Nesta encon tram-se os contraions livres. 0 nümero e a organização destes ions obedecem, segundo o modelo de Gouy-Chapman MacLaughtin, 1977), a uma distribuição do tipo Poisson-Boltzmann (Stigter, 1964; Fernandez e Fromherz, 1977; Hartley e Roe, 1940), isto $\overline{\mathrm{e}}$

$$
a_{i G . C .}=a_{i H_{2}} 0 \cdot e^{-(F \psi / R T)}
$$


(onde: a ${ }_{i G . C .}=\bar{e}$ atividade do ion $i$ na camada de Gouy-Chap man; $a_{i H_{2}} \mathrm{O}=$ atividade de 1 em água; $\psi$ é o potencial eletros tātico superficial?.

Considerando o potencial na superficie de corte en tre as camadas de Stern e de Gouy $\left(\Psi_{D}\right)$, a expressão do po tencial (Mysels, 1967:MacLaughlin, 1977) indica que este dimi nui na direção radial. Consequentemente a concentração dos contrąons diminui na direção do meio aquoso. Devemos ressal tar ainda que a expressão do potencial é dependente da farça' iônica do meto (Mysels, 1967;Maclaughtin, 1977). No intuito de dar um maior esclarecimento sobre o assunto acima tratado. apresentamos a expressão do potencial, obtida da releção de Poisson-Boltzmann Maclaughlin, 1977), admitidas as seguintes condiçöes de contorno.

$$
\begin{aligned}
& \psi(x)=\psi_{0} \text { para } x=0 \\
& \frac{d \psi}{d x}(x)=\psi(x) \text { e } \psi(x)=0 \operatorname{para} x=\infty
\end{aligned}
$$

o potencial (\$). $\bar{e}$ dado por

$$
\psi(x)=\frac{2 k T}{2 e} \quad \ln \frac{1+\alpha e^{-k x}}{1-\alpha e^{-k x}}
$$

onde

$$
\begin{aligned}
& \alpha=\frac{e^{(\operatorname{le} \psi o / 2 k T)}}{e^{(Z e \psi o / 2 K T)}+1} \\
& k=\frac{2 e^{2} n_{\infty} z^{2} 1 / 2}{E_{r} E_{0} K T}
\end{aligned}
$$


Jonde $K=$ constante de Boltzmann

$$
\begin{aligned}
z & =\text { valéncia do ion } \\
e & =\text { carga do eletron } \\
n_{\infty} & =\text { nọ de íons à distāncia infinita } \\
E_{r} & =\text { constante dielëtrica do meio } \\
E_{0} & =\text { permissividade do espaço livre) }
\end{aligned}
$$

Graficando-se o potencial expresso pela equação (4) em função da distāncia observa-se o perfil apresentado na $\mathrm{F} \underline{\mathbf{i}}$ gura 3 .

Dados de mobilidade eletroforētica de micelas (Stig ter e Mysels, 1955; MacDonald e Banghan, 1972) permitem a ob tenção do denominado potencial zeta $(\zeta)$, calculado pela equa ção de Helmholtz-Smoluchowski MacLaughtin, 1977)

$$
\zeta=\frac{n \mu}{E_{r} E_{0}}
$$

(onde $\mu=$ mobilidade eletroforética; $n=$ viscosidade). Os poten ciais acima ( $\psi_{0}$, potencial de superficie; $\psi_{D}$, potencial na su perficie de corte entre a camada de Stern e Gouy-Chapman e $\zeta$, potencial hidrodinâmicol estão indicados na figura 4.

o potencial zeta tem sido obtido de outras formas, como por exemplo, de estudos relativos à dināmica de micelização (Aniansson 1975; Aniansson e Wa11, 1974,1975,1977; Anias son et al, 1976). Os parāmetros de relaxação relativos à en trada e saida de monômeros de micelas carregadas obtidos atra vēs desses estudos (Chan e Kulweit, 1977; Almgreen et al, 1977) demonstram a existēncia e a magnitude deste potencial.

Para termos uma visão da origem do potencial de Stern Lou zeta admitindo que a separação entre eles ē minima, veja Figura 4), podemos apreciar a expressão do efeito de sais na 


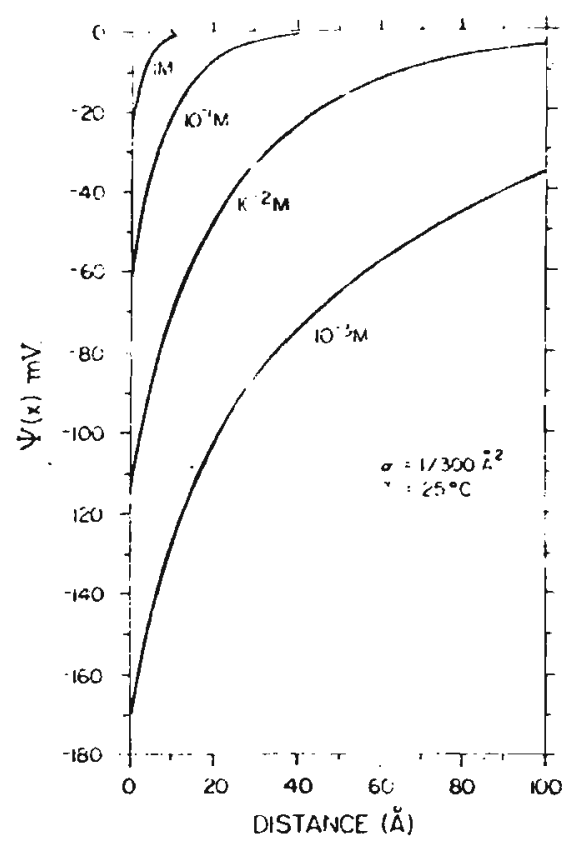

Figura 3 - Curvas de potencial preditos pela teoria de Gony Chapman para diferentes valores de concentração de íons univa lentes em solução. Note que a medida que a concentração de ions na àgua diminui, o potencial aumenta (Reproduzido de Mac Laugh1 in, 1977).

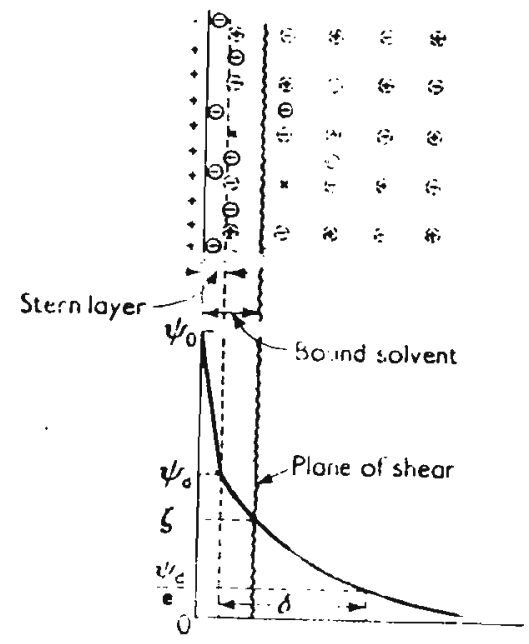

Figura 4 - Estrutura da dupla camada e potenciais corresponden tes. $\psi \circ \bar{e}$ o potencial na superficie; $\psi D$ potencial na superfi cie de corte entre a camada de Stern e Gony-Chapman, S potencial hidrodinámico do plano de corte. Na dupla camada digusa(Go ny-Chapman o potencial decai por um fator de l/e na distância $1 / K$ para potenciais pequenos. 
CMC. 0 resultado experimental deste efeito (Shinoda,etal 1963; Barry e Russel, 1973) pode ser expresso pela equação

$$
\log C M C=-\left(\frac{q}{p}\right) \log \text { sal }+c
$$

(onde q è onūmero de contraĩons ligados; p nūmero de monóneros e C è um parāmetro da equação).

A relação $q / p$ da expressão 8 reflete a fração de car ga da micela, ou seja o seu grau de dissociação ( $\alpha$ ) (vide in fra). Utilizando-se o modelo de ação de massas para o proces so de micelização (Shinoda,et al, 1963; Aniansson e Wall, 1974 , 1975, 1977), ou de separação de fases (Corrin, 1948; Berezin et al, 1973) (vide infra), obteve-se expressões anālogas à ex perimental (Equação 8) no sentido que por ambos os formalis mos chega-se ao fator constante relacionado a $\alpha .0 \alpha$ pode ser definido como (Romsted, 1975):

$$
\begin{aligned}
& \alpha=\frac{\text { concentração de contraĩons livres - CMC }}{\text { concentração total de contraĩons - CMC }} \\
& \alpha=\frac{\text { carga da micela }}{\text { nọ de agregação }} \quad(10)
\end{aligned}
$$

A base experimental para a constāncia do valor de $\alpha$ (numa faixa de concentração de detergente e sal (5)) ē bastan te grande (Romsted, 1975).

Outro fator importante para a definição do sistema' de micelas é o denominado nümero de agregação (N). Värios au tores têm se preocupado em determinar este parāmetro utilizan do-se para tal técnicas variadas como: técnicas de lumines. cência, velocidade de difusão e sedimentação, ressonância mag 
nētica nuclear, etc. (Grätzel e Thomas 1976; Thomas, 1977 ; Ka lyanasundaram, 1978; Turro et al 1979; Infe1ta, 1979; Yekla et al,1979; Elworthy et al, 1968; Kirschbaum, 1974). A con clusão principal é que as micelas são sistemas poilidispersos, cuja dispersão não é muito grande, podendo assim ser definıdo um nūmero médio (N) que representa bastante bem o sistema.

Com base nas dimensöes da camada de Stern (vide supra) e no $\mathbb{N}$ fica definido o volume da camada citada (6). A partir do valor de $\alpha$ e $\bar{N}$ obtem-se o no de ions presentes na ca mada e consecutivamente a concentração iônica aî presente. As estimativas deste cālculo indicam a existência de uma concentração salina da ordem de 3M (Mukerjee, 1962) (este valor é dé pendente do modelo escolhido para a forma da micela)(6).

0 modelo da micela aqui apresentado, basicamente 0 descrito por Stigter (Stigter, 1964, 1974 a e b; 1975 a e b), e bastante rigido, com camadas bem delimitadas assim como as constantes de cada região bem definidas. E claro que tal mo delo é sujeito a vārias crïticas, como por exemplo, a que diz respeito à penetração de āgua. Os dados da literatura indicam que a ägua penetra até pelo menos o sexto carbono da cadeia alquila (Clifford,1965; Podo et a1, 1973; Menger et a1, 1978).

Outro fator a ser analisado, continuando a descriçäo da estrutura das micelas, è relativo â polaridade efetiva das diferentes regiões. Como anteriormente indicamos, o nū cleo da micela constitui-se de hidrocarboneto líquido ao qual pode-se assinalar o valor de constante dielétrica (D) de 2(1 quidos parafinicos semelhantes à octana; Fendler, 1980; Shino da, 1963; Muller e Birkhahn, 1967; Shinitzkyetal, 1971). No 
outro extremo temos água cuja constante dielētrica é da ordem de 80 (Stigter, 1974; Robinson e Stokes, 1955). A questão é determinar a constante dielëtrica na região intermediāria en tre estes dois extremos.

os estudos para determinação do valor da constante dielētrica na interface ägua-micela tēm envolvido a utịizaça de algumas sondas. Uma vez que a localizaçäo exata da sonda nem sempre è conhecida e a presença da pröpria sonda pode alte rar o micro ambiente, os resultados devem ser analisados com cuidado. Alguns dados relativos à medida da constante diele trica säo apresentados a seguir (Tabela 1).

Tabela 1 - Valores da constante dielëtrica em diferen tes sistemas micelares

\section{Micela}

- Iodeto de Dodecil Piridíneo

- Dodecil N-betaina

- Octilsulfato de sōdio

- Dodecanoato de sōdio

- Cloreto de Dodecil Amōnio

- Brometo de Hexadeciltrimetil Amônio

- Dodecil sulfato de sōdio
Constante dielêtrica

$$
\begin{aligned}
& 36^{a} \\
& 37^{a} \\
& 49^{b} \\
& 39^{b} \\
& 26^{b} \\
& 18^{b}, 32^{c} \\
& 32^{c}
\end{aligned}
$$

a - valores obtidos de Mukerjee et al, 1977

b - valores obtidos de Kalyanasundaram e Thomas, 1977

c - valores obtidos de Fernandez e Fromherz, 1977

Aos valores da Tabela 1 poderiam ser acrescentados 1 uma série bastante extensa de dados (Pottel et al, 1978).

Deve-se notar que apesar dos detergentes estudados serem diferentes, os valores de constante dielëtrica situam-se 
numa faixa pequena $(\bar{D}=36 \pm 7)$. Näo $\bar{e}$ nossa intenção uma a nálise exaustiva desses valores; queremos apenas indicar que a constante dielétrica da interface (Tabela 2), pode ser com parada a de metanol ( $D_{\mathrm{MeOH}}=32$, a $30^{\circ} \mathrm{C}$ ) (Fernandez e Fromherz, 1977). No presente trabalho assumiremos $D=32$ (7).

A definição dos valores anteriormente assinalados, assim como a descrição matemātica de certas funções, estā na dependência da forma da micela por um lado e por outro na prō pria estrutura da āgua líquida. No momento os dados existentes são insuficientes para justificar a opção por um dado mo delo. Vale ressaltar que, do ponto de vista de cinētica de reações (onde o que importa $\vec{e}$ a concentração local das espécies se a reação ocorre na interface, vide infra), a forma da micela pouco vai influir.

\section{†.1.2. Formação}

Colocando-se em contato com o meio aquoso, as moléculas anfifílicas, dois fenômenos opostos ocorrem. Em primei ro lugar a tendēncia de dissolução da parte hidrofîlica junta mente com o contraion (considerando-se ions pequenos como $\mathrm{Na}^{+}$, $\mathrm{Br}^{-}, \mathrm{Cl}$, etc.), devido ao aumento de entropia resultante da se paração dos ions (evidentemente o componente elétrico, atratị vo opera em sentido oposto). Em segundo lugar a "antipatia" devido a cadeia alquila, hidrofóbica, pela āgua que implica numa diminuição de entropia do sistema, decorrente da alta es truturaçãodaāgua 1 íquida necessāria para acomodar a parte orgānica. A representação de Tanford ilustra bastante bem a dif 
culdade de solubilização da parte hidrocarbonada

$$
2 \mathrm{H}_{2} \mathrm{O}+\mathrm{S}-\mathrm{S} \longrightarrow 2 \mathrm{H}_{2} \mathrm{O}-\mathrm{S}-\mathrm{H}_{2} \mathrm{O}
$$

(Tanford, 1973, 1980) (onde $S$ è um hidrocarboneto parafinico). A presença de $S$ irā distorcer as pontes de hidrogēnio da àgua. Considerando-se a estrutura de àgua (Hasted, 1973; Eisenberge Kauzmann, 1969) quer seja em termos de "flickering-clusters", ou o modelo intersticial, ou ainda o modelo de ponte de hidrogēnio distorcido, os monômeros ao anfifîlico aumentam a ordenação de água (Némethy e Scheraga, 1962; Frank e Evans, 1945; Frank, 1963, 1965; Kava nau, 1965; Sheraga, 1974) pela formação de cavidades ao redor da qual a āgua deve ordenar-se.

A micelização é decorrente do decrēscimo de energia livre resultante da desidratação das cadeias, que agora constituem um nücleo hidrocarbonado (efeito hidrofōbico)(Tanford, 1973, 1980). A estabilidade desse sistema envolve o balanço de forças opostas. A alta coesão interna da ägua (Eisenberg e Kauzman, 1969) promove a agregação de substâncias hidrofóbị cas em solução. Por outro lado a associação de detergentes ' iōnicos conduz à formação de um agregado onde a repulsão ele trostātica limita o crescimento (Chaimovich, 1979; Tanford, 1973, 1980). $0 \Delta G_{m}^{0}$ (energia livre de micelização padrão) po de ser dado por (Tanford, 1973, 1980):

$$
\Delta G_{m}^{0}=\Delta V_{m}^{0}+W_{m}
$$

(onde $\Delta V_{m}^{0}$ é a contribuição atrativa devido ao efeito hidroföbico e $W_{m}$ o componente repulsivo devido aos grupos hidrofilicos da superficie). 
Dois modelos tentam explicar a micelização: a apli cação da lei da ação de massas (modelo de ação de massas cor rin, 1948; Aniansson e Wa11, 1974) e o modelo de separação de fases (Shinodaet a 1,1963;Berezin et al, 1973). Primeiramente a nalisamos o modelo de ação de massas considerando o equilíbrio abaixo, aplicado a dodecil sulfato de sōdio (SDS) (Sasaki et a 1, 1975):

$$
\mathrm{pDS}^{-}+\mathrm{qNa}^{+} \stackrel{\mathrm{keq}}{\rightleftharpoons} \mathrm{NaqDSp}-(\mathrm{p}-\mathrm{q})
$$

(onde $\mathrm{DS}^{-} \overline{\mathrm{e}}$ um monômero de SDS, $\mathrm{Na}^{+} \overrightarrow{\mathrm{e}}$ o contraion e $\mathrm{p}$ e q são o nūmero de ions $\mathrm{DS}^{-}$e $\mathrm{Na}^{+}$que fazem parte da micela)(8).

A constante referente ao equilibrio representado pe la Equação 12 é formalmente expressa por

$$
\text { Keq }=\frac{a_{m}}{a_{D S}^{p} a_{N a}^{q}}
$$

(onde a representa a atividade das espēcies DS $^{-}$e $\mathrm{Na}^{+}$e $a_{m} \bar{e}$ a atividade da micela $\left(\mathrm{Na}_{q} \mathrm{DS}_{\mathrm{p}}-(\mathrm{p}-\mathrm{q})\right)$. Empregando-se as def $\underline{i}$ nições de $\alpha$ (equações 9 e 10) e $\bar{N}$, a expressäo 13 pode ser re escrita como:

$$
\text { Keq }=\frac{a_{m}}{a_{D S} a_{N a} N(1-\alpha)}
$$

na forma logarỉtmica a expressão 14 fica

$$
\begin{aligned}
& \log a_{D S}=-(1-\alpha) \log a_{N a}-\frac{\log a_{m}}{\bar{N}}-\frac{\log K e q}{\bar{N}} \text { (15) } \\
& 0 \text { modelo de separação de fases considera a micela } \\
& \text { como uma fase carregada separada (9) (Shinoda et al, 1963; Cerezin } \\
& \text { et a 1, 1973; Tanford, 1973, 1980; Sasaki et al, 1975). 0 equi } \\
& \text { lỉbrio de formação pode ser representado por: }
\end{aligned}
$$




$$
\mathrm{pDS}^{-}+\mathrm{qNa}^{+} \rightleftharpoons \mathrm{Naq}_{\mathrm{DS}}^{-(p-q)} \text { (16) fase separada }
$$

onde

$$
\underset{\mathrm{Na}}{\mathrm{q}} \cdot \stackrel{\mathrm{p}}{\mathrm{a}_{\mathrm{DS}}}=\text { constante (17) }
$$

ou utilizando-se $\alpha$ e $\bar{N}$

$$
a_{N a}^{\bar{N}(1-\alpha)} \cdot \quad a_{D S}^{\bar{N}}=\text { constante }(18)
$$

A forma logarîtmica da equação $18 \bar{e}$

$$
\log \mathrm{a}_{D S}=-(1-\alpha) \log \mathrm{a}_{\mathrm{Na}}+\text { constante }
$$

Ambas as equações (15 e 19) predizem no limite da CMC $\left(\frac{\log a_{m}}{N} \rightarrow 0\right)$ que existe uma relação inversa entre a atividade do monômero livre ( $\left.{ }_{D S}\right)$ e do contraion ( $a_{N a}$ ), fato este jä experimentalmente conhecido (veja Equação 8) (10).

A relação de Keq com o $\Delta G^{0} m$ pode ser feito da maneira usual, isto $\bar{e} \Delta G_{m}^{0}=-R T$ In Keq (20).

Assim temos, para o caso do modelo de açäo de massas (Fendler e Fendler, 1975; Shinoda, 1963):

$$
\frac{\Delta G_{m}^{0}}{R T}=-\log N a \text { a } p+\log D S+(1-\alpha) \log N a
$$

Para o modelo de separação de fases (Fendler e Fendler, 1975; Shinoda, 1963), sendo a CMC o ponto de partida da nova fase, podemos escrever

$$
\Delta G^{0}=R T \ln C M C
$$

As relações expressas nas equações $15,19,21$ e 22 jun tamente com equações usuais de termodināmica (Guggenheim, 1949) permitem tratar e prever uma série de dados relativos à solub 
lização, efeitos de temperatura, adição de sais, etc.

Devemos acrescentar que as micelas são entidades di námicas, existindo um equilïbrio de troca de monōmeros entre a àgua e o meio micelar e outro de rompimento e formação de micelas. Cinéticas desse processo têm sido investigadas por cinética de fluxo detido, salto de temperatura e de pressão, absorção ultrassōnica, ressonāncia magnētica nuclear e para magnētica eletrônica (Fendler e Fendler, 1975; Fisher e Oaken ful1, 1977; Quina, 1978). Determinou-se que o primeiro fenōmeno (troca de monōmeros) ocorre na faixa de microsegundos e o segundo (distruiçäo) na faixa de milisegundos (Muller, 1972, 1979). Do ponto de vista da cinētica de reações empregadas em meio micelar ( $\frac{1}{2}>1$ segundo) a micela está estātica.

I.2. Efeitos de micelas sobre a velocidade de reações químicas

Historicamente foram-se desenvolvendo modelos ciné ticos que tentaram explicar o efeito de micelas sobre a velocidade de rea çöes quỉmicas na presença de micelas (Fendler \& Fendler, 1975; Mitta1, 1978, 1980). Os modelos que merecem des taque são os de Menger e Portnoy (1967), Berezin et al (1973), Romsted (1975) e Quina e Chaimovich (1979).

Não $\vec{e}$ intenção deste trabalho a discussão destes mo delos(encontra-se uma boa discussão em Cuccovia, 1980). Con vëm no entanto citar que de todos os modelos, o que melhor se ajusta aos dados experimentais (como efeitos no pk de ācidos fracos, efeitos na velocidade de reações químicas em presença de tampão e outros) é o modelo de troca iônica aplicado à 
micelas de Quina e Chaimovich (1979) (maiores detalhes a res peito deste e outros modelos podem ser encontrados em publica ções recentes: (Mitta1, 1978,1980; Fendler \& Fendler, 1975; Chaimovich, 1979; Cuccovia, 1980).

Apresentamos a seguir uma das aplicações do modelo de troca iōnica, conduzindo-o ao interesse de nossa posterior anālise.

As suposiçōes bāsicas do modelo são as seguintes:

i) Existe um equilibrio de troca entre os ions da si perficie da micela (ligados) e os ions da fase aquosa (livres) (Romsted 1975).

ii) A velocidade de troca entre os jons é rápida quando comparada à velocidade das reações estudadas em meio micelar (Grunhagem, 1975).

iii) O grau de ionização $(\alpha)$ da micela ē constante(5), estando relacionado com o nọ de contraions ligados pela expres säo: $m=\bar{N}(1-\alpha)$ (23) (onde $m=n$ e de contrajons ligados) (Romsted, 1975; Sasaki et a 1, 1975; Funasaki, 1979).

iv) As atividades das vārias espécies iónicas presen tes são tratadas em termos de suas concentrações analīticas.

0 equilíbrio de troca iōnica pode ser representado

por

$$
x_{f}+y_{b} \stackrel{K_{x / y}}{\rightleftarrows} x_{b}+y_{f}
$$

da qualk $x / y$ é dado por

$$
k_{x / y}=\frac{x_{b} \cdot Y_{f}}{x_{f} \cdot Y_{b}}=\frac{\overline{x_{b}} \cdot \gamma_{f}}{x_{f} \cdot \overline{Y_{b}}}
$$

conde $Y$ representa o contraion original do monomero anfifilico, X o ion adicionado que irā trocar, os indices b e $f$ ind 
cam o ion ligado e livre respectivamente e as barras repre sentam a concentração local das espëcies na micela; vide in fra).

As espécies assinaladas com barra na equação 25 re presentam a concentração local do íon ligado à fase micelar. Este fato é devido à diferença entre as concentraçōes efetivas e analiticas, uma vez que ocorre exclusão de volumes. De signando $x^{\prime}{ }_{f} \bar{a}$ concentração efetiva no meio aquoso temos

$$
x_{f}^{\prime}=\frac{x_{f}}{1-\operatorname{CD} V \text { excluido }}
$$

(onde CD, representa a concentração de detergente micelizado, isto $\bar{e}, C T$ (detergente total) - CMC).

Sendo o volume excluído da solução, fase micelar, pequeno em relação ao volume aquoso (CD é no māximo $0,1 \mathrm{M}$ e $\bar{V}$ $=0.2-0.4 \mathrm{M}^{-1}$, Mukerjee, 1962; Shinoda e Soda, 1963; Corkill et al, 1967; Yatsimirski et al, 1971), aproxima-se, sem erros significativos, $X_{f} \bar{a} x_{f}{ }_{f}$.

Para a fase micelar, designando-se concentração efe tiva de $\overline{X_{b}}$; temos:

$$
\frac{x_{b}}{x_{b}}=\frac{x_{b}}{c D \bar{V}}
$$

(onde $\bar{V} \bar{e}$ o volume efetivo por mol de detergente micelizado). $\mathrm{Na}$ expressão que define $K_{x / y} \bar{e}$ indiferente a utilização de $X_{b}\left(o u Y_{b}\right)$ ou $\overline{X_{b}}\left(o u \overline{Y_{b}}\right)$ pois o termo cDV é automaticamente cancelado.

Entre os fatores que poderiam contribuir na magnitu de do valor de $k_{x / y}(5)$, devemos apontar: a contribuição da parte não eletrostātica de certos ions no potencial de ad sorção (Chaimovich et al, 1980) e diferenças nos coeficientes 
de atividade das espécies 1 igadas, uma vez que na fase aquosa considera-se estes coeficientes unitärios (Fernandez e From herz, 1977; Chaimovich et a1, 1979).

Considerando-se a ligação de um ĩon reativo à micela (como por exemplo hidrōxido a micelas de brometo de hexade ciltrimetilamōnio) são vālidas as equações abaixo para uma so lução micelar $\left(D^{+} Y^{-}\right.$) e um ion reativo $\left(X^{-}\right)$(assume-se que 0 cätion de $x^{-}$não interfere):

$$
C T=D^{+} Y^{-}=C D+C M C=Y_{t}
$$

(onde $Y_{t} \bar{e}$ o $Y$ total)

$$
Y_{f}=\alpha C D+C M C+X_{b}
$$

A quantidade $Y_{f} \bar{e}$ dada pela dissociação da micela ( $\alpha$ CD), mais o valor da CMC e o valor da concentração de $Y$ trocado (Equação 25) por $x$

$$
Y_{b}=(1-\alpha) C D-X_{b}
$$

A quantidade de $Y_{b} \bar{e}$ o $Y$ que permanece ligado $((1-\alpha)$ CD) menos aquele que foi trocado.

$$
x_{T}=x_{f}+x_{b}
$$

usbstituindo-se os valores de $X_{b}, Y_{f}, X_{f}$ e $Y_{b}$ na expressào 25 obtemos

$$
k_{x / y}=\frac{x_{b}}{\left(x_{t}-x_{b}\right)}-\frac{a C D+C M C+x_{b}}{(1-a) C D-x_{b}}
$$

0 comportamento da expressão 32 , no 1 imite da alta concentração de detergente é expresso por

$$
\lim _{c_{T} \rightarrow \infty} k_{x / y}=\frac{x_{b}}{x_{T}-x_{b}} \frac{\alpha}{(1-\alpha)}=\frac{x_{b}}{x_{f}} \frac{\alpha}{(1-\alpha)}
$$


Uma vez conhecido $x_{t}$, pode-se determinar $x_{f}$ ou $x_{b}$ (Chaimovich et al, 1979) e assim conhecido o a(Romsted, 1975) pode-se avaliar $K_{x / y}$ aplicando-se a expressão 33 . A expres são 33 mostra que a relação $x_{b} / x_{f}$ tende, no limite de CT alto, a um valor definido(11).A expressão 33 pode ser resolvida para $x_{b}$ e, pelo uso de métodos matemäticos, pode-se optimizar o re sultado em função do valor experimental (Chaimovich et al, 1979).

Estudando-se uma reação em condiçōes de pseudo-primeira ordem, com o ion reativo $x^{-}$em excesso com relação ao outro reagente ( $R$ ) (suposto neutro), o tratamento cinético $\underline{u}$ sual é dado por: (Bunton, 1973; Romsted, 1975; Martinek et al, 1977; Fendler e Fendler, 1975) (12).

$$
k \psi=k_{2}^{0} \quad x_{f} \frac{R_{f}}{R_{T}}+k_{2}^{m} x_{b} \frac{R_{b}}{R_{T}}
$$

(onde $k \psi$ è a constante de velocidade observada de pseudo pri meira ordem, $k_{2}^{0}$ e $k_{2}^{m}$ as constantes de velocidade de segunda ordem na ăgua e na micela) e $\frac{R_{f}}{R_{T}}, \frac{R_{b}}{R_{T}}$ as fraçöes de $R$ na ägua e na micela).

Utilizando-se a expressão de $K_{x / y}$ (Equação 25), po de-se demonstrar que

$$
k_{\psi}=\frac{x_{T} \frac{k_{2}^{m}}{\bar{V}} k_{s} k_{x / y} \frac{y_{b}}{y_{f}}+k_{2}^{0}}{\left(1+k_{s} C D\right)\left(1+k_{x / y} \frac{y_{b}}{y_{f}}\right)}
$$

(onde $K_{s}$ refere-se à partição de $R$, isto ē, $C D+R_{f} \stackrel{K_{s}}{\rightarrow} R_{b}$; Martinek et al, 1973).

Graficando-se $k_{\psi}^{m}$ ( $k_{\psi}$ na presença de micelas) sobre $k_{\psi}^{0}$ ( $k_{\psi}$ em ägua) vs CT obtem-se as curvas da Figura 5. 


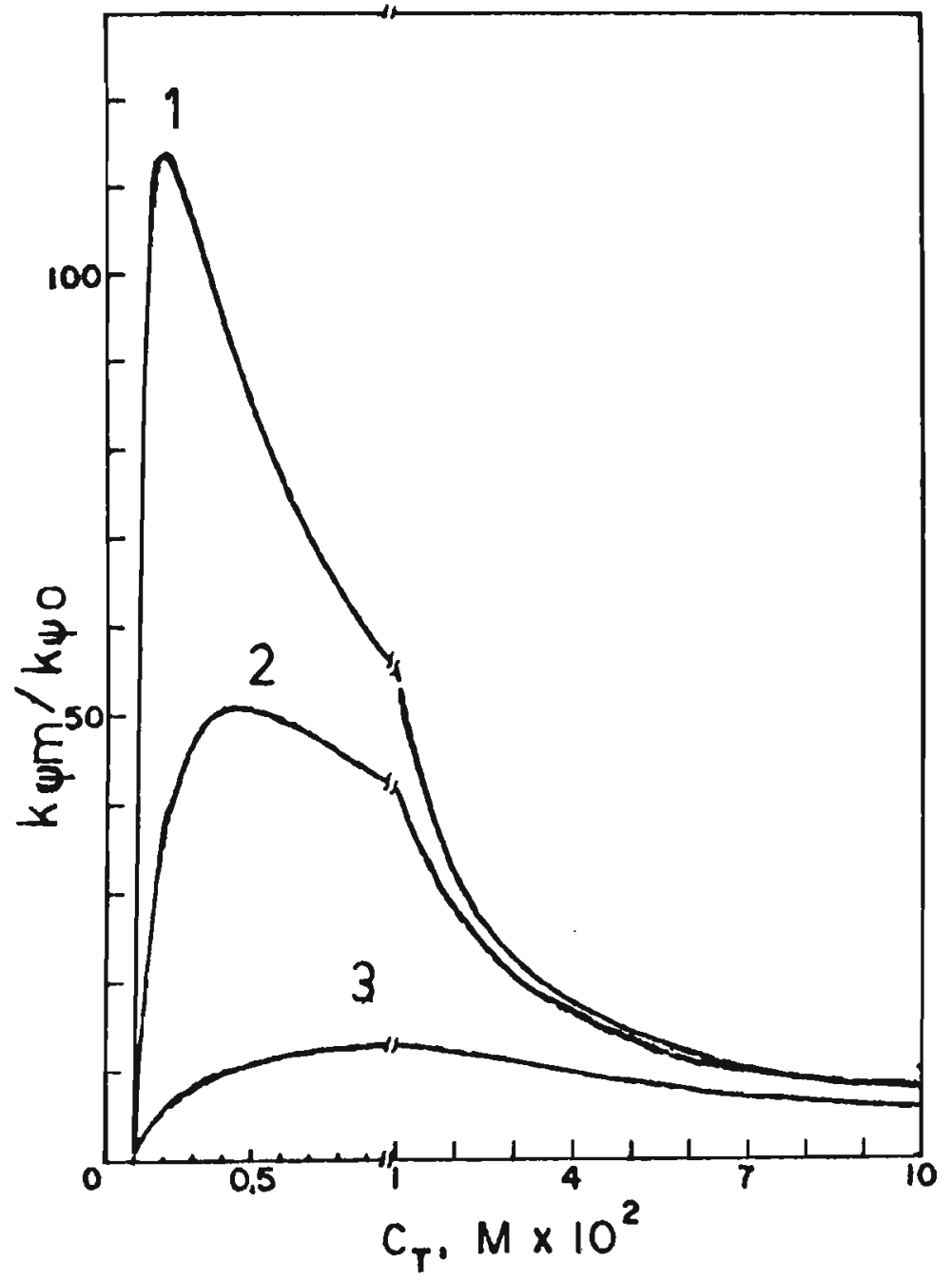

Figura 5 - Variação de $k \psi m / k \psi_{0}\left(=k \psi / k_{2}^{0}-X T\right)$ em função de CT, para $X T=1 \times 10^{-3} \mathrm{M}$; curva $1 \mathrm{~K}_{\mathrm{S}}=3 \times 10^{3} \mathrm{M}^{-1} ;$ curva $2 \mathrm{~K}_{\mathrm{S}}=3 \mathrm{X}$ $10^{2} \mathrm{M}^{-1}$; curva $3 \mathrm{~K}_{\mathrm{S}}=30 \mathrm{M}^{-1}$. (Reproduzido de Chaimovich, 1979) 


\section{I.3. Sistema em Estudo}

\section{I.3.1. Esquema Cinētico}

O sistema de estudo é a reaçăo de hidrōlise alcalina dos ions N-alquil-4-cianopiridineos (RCP) (Kosower e Patton, 1966). A escolha de tal sistema deveu-sea algumas características desses compostos, entre as quais vale notar:

i) permite obter a relação $R_{b}$ e $R_{f}$. Os ĩons RCP são supressores de fluorescéncia de alguns ions emissores, como o Ru(bipy) ${ }_{3}^{2^{+}}$(Quina, 1978). Uma vez que esse emissor reside ex clusivamente na fase extra-micelar de sistemas micelares catiō nico (como CTAB) (Quina, 1978), a medida da quantidade de RCP que permanece na água em soluções micelares cationicas e dire ta.

ii) variando-se o comprimento da cadeia $\mathrm{N}$-alquila $\vec{e}$ de se esperar que o grau de incorporação seja diferente, uma vez que sabe-se que a energia requerida para transferir um gru po metilênico de uma solução parafinica para água é cerca de $0,7 \mathrm{Kcal} / \mathrm{CH}_{2}$ (Tanford, 1973,1978). Assim é presumivel que do composto N-metila (MCP) para o N-dodecil (DCP), O equilibrio de partição entre a fase aquosa e micelar seja deslocado por um fator energētico (cerca de $77 \mathrm{Kcal}$ ) para O DCP.

iii) a velocidade da reação ē bastante sensĩvel às mu danças de pH (Kosower e Patton, 1966), permitindo visualizar efeitos devido à concentração ou diluiçào de hidróxido.

iv) a hidrólise dos RCP (Figura 6) leva a dois produ 


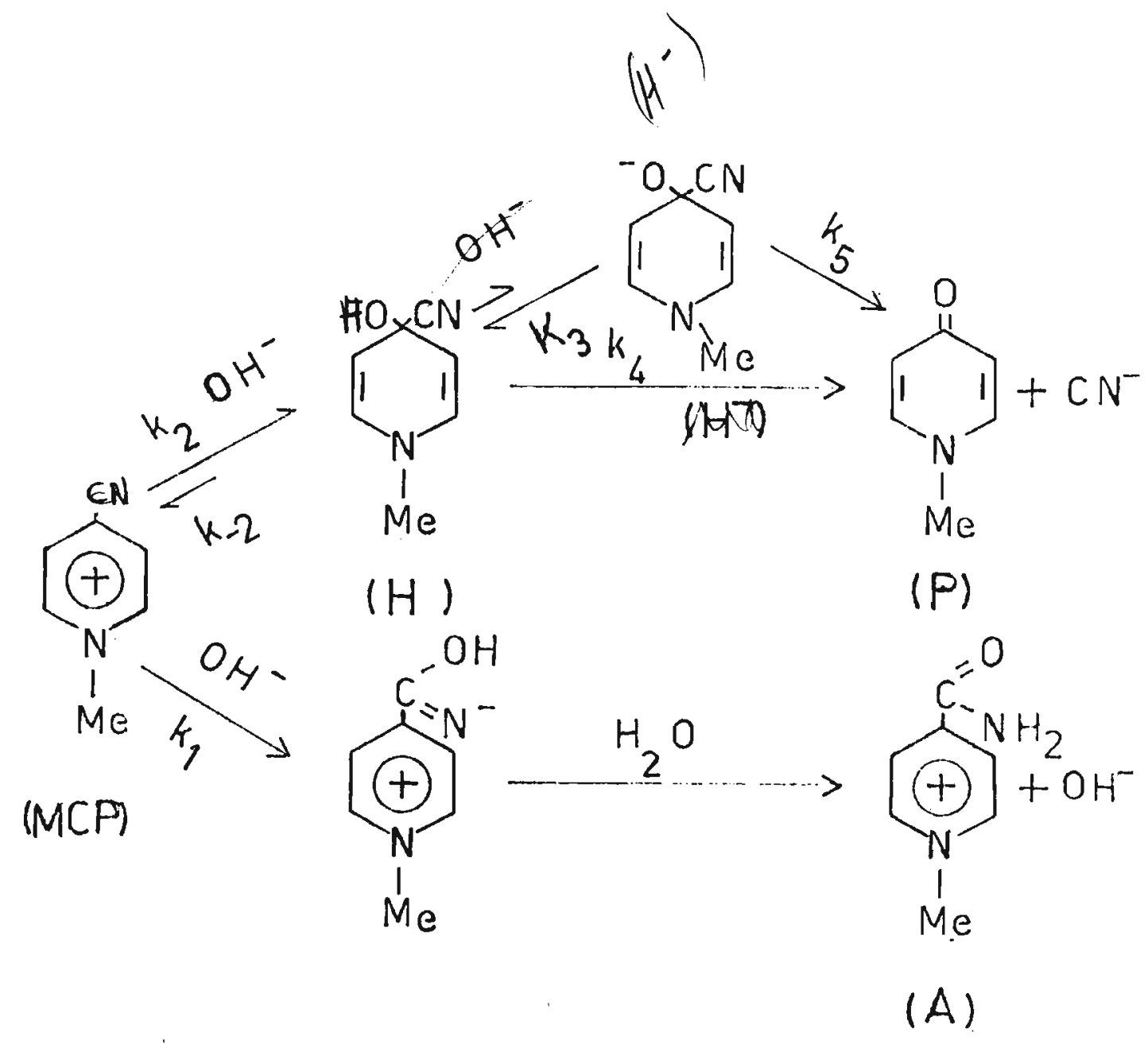

Figura 6 - Esquema cinético da hidrôlise alcalina do MCP; He $\mathrm{H}^{-}$derivados cianohidrínicos intermediārios; $\mathrm{P}=\mathrm{N}-\mathrm{meti1}-4-\mathrm{L}$ dnopiridineo; $A=N$-metil-4-carboxiamidopiridineo.

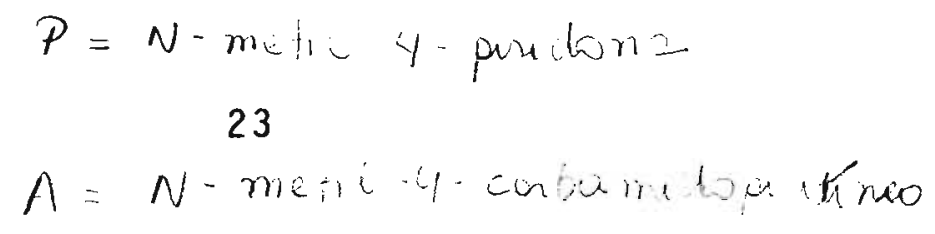


tos facilmente reconhecidos (Kosower e Patton, 1966), sendo um neutro (piridona) e outro positivo (amida). A relação piridodà $(P / A)$ é função do pH e eventualmente pode ser função do meio.

Foi proposto o mecanismo apresentado na Figura 6 para a hidrólise alcalina do ion N-metil-4-cianopiridineo (MCP) em àgua (Kosower e Patton, 1966).

Para o desenvolvimento desta introdução ē conveniente reproduzir aqui o tratamento proposto para a anālise cinéti ca desta hidrölise (Kosower e Patton, 1966).

Para obter-se a expressão de velocidade assume-se que

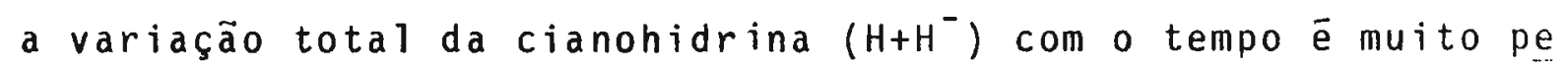
quena, isto $\bar{e}, d H t o t a l / d t=0$, agrupando-se as equações refe rentes aos vārios passos, obtem-se:

$$
\frac{-d(M C P)}{d t}=\frac{d(P)}{d t} \frac{d(A)}{d t}=\left[k_{2} \frac{k_{4}+k_{3} k_{5}\left(\mathrm{OH}^{-}\right)}{k_{-2}+k_{4}+k_{3} k_{5}\left(\mathrm{OH}^{-}\right)}+k_{1}\right] \cdot M C P . \mathrm{OH}^{-}
$$

E interessante notar os limites da expressão acima.

a) em alta concentraçāo de hidrōxido $\mathrm{K}_{3} \mathrm{k}_{5}\left(\mathrm{OH}^{-}\right)>>$ $k_{4}+k-2$ e assim temos:

$$
-\frac{d(M C P)}{d t}=\left(k_{1}+k_{2}\right)(M C P)\left(\mathrm{OH}^{-}\right)
$$

b) em baixa concentração de hidröxido reciprocamente temos:

$$
\mathrm{k}_{5} \mathrm{~K}_{3}\left(\mathrm{OH}^{-}\right)<<\mathrm{k}_{4}+\mathrm{k}_{2} \text { e } \mathrm{k}_{5} \mathrm{~K}_{3}\left(\mathrm{OH}^{-}\right)<<\mathrm{k}_{4} \text {, assim te }
$$

mos:

$$
\frac{-d(M C P)}{d t}=\left[k_{1}+k_{2} \frac{k_{4}}{k_{-2}+k_{4}}\right](M C P)\left(\mathrm{OH}^{-}\right)
$$


A baixa concentração de hidróxido a velocidade de formação de $P$ necessariamente diminui pois o fator $\frac{k_{4}}{k_{-2}+k_{4}}$ $\bar{e}$ sempre menor que um. Desmembrando-se a expressäo 36 , obtemos:

$$
-\frac{d(M C P)}{d t}=\frac{d P}{d t}+\frac{d A}{d t}=k_{2} \frac{k_{4}}{k_{-2}+k_{4}} \quad(M C P)\left(O^{-}\right)+k_{7}(M C P)\left(O H^{-}\right)
$$

por comparação temos:

$$
\begin{aligned}
& \frac{d P}{d t}=k_{2} \frac{k_{4}}{k_{-2}+k_{4}}(M C P)\left(\mathrm{OH}^{-}\right) \\
& \frac{d A}{d t}=k_{1}(M C P)\left(\mathrm{OH}^{-}\right)
\end{aligned}
$$

Pode-se predizer em base nas equaçōes acima e nos 1 i mites que a relação $P / A$ tende a valores crescentes com aumento de pH (Kosower e Patton, 1966). A relação P/A é dada por:

$$
\frac{d P}{d A}=\frac{P}{A}=\frac{k_{2}}{k_{1}} \quad \frac{k_{4}+k_{5} k_{3}\left|\mathrm{OH}^{-}\right|}{k_{-2}+k_{4}+k_{5} k_{3} \mid O H-1}
$$

Nas equações seguintes apresentamos um desenvolvimen to analitico que se mostrou adequado para o tratamento de nos sos dados experimentais. Designando-se

$$
\frac{k_{4}+k_{5} k_{3}\left(\mathrm{OH}^{-}\right)}{k_{-2}+k_{4}+k_{5} k_{3}\left(\mathrm{OH}^{-}\right)}=\delta
$$

a expressão de velocidade pode ser simplificada para

$$
\frac{-d M C P}{d t}=\left(k_{2} \delta+k_{1}\right)\left(O H^{-}\right)(M C P)
$$

en condições de pseudo-primeira ordem onde $\mathrm{OH}^{-}>>>M C P$ ou ell 
presença de sistema tampäo onde $\left(\mathrm{OH}^{-}\right)=$constante, a constan te de velocidade $\left(k_{\psi}\right)$ serà

$$
\mathrm{k}_{\psi}=\left(\mathrm{k}_{2} \delta+\mathrm{k}_{1}\right)\left(\mathrm{OH}^{-}\right)
$$

e a constante de segunda ordem $\left(k_{2 \psi}\right)$

$$
k_{2 \psi}=\frac{k_{\psi}}{O H^{-}}=k_{2} \delta+k_{1}
$$

Uma anālise do efeito de força iónica sobre a reaçăo em meio aquoso è necessāria para entender qualquer eventu al modificação na reatividade intrīnseca na fase micelar, jā que a força iônica na camada de Stern é alta (vide supra). Co mo se sabe a velocidade de reação entre ions é dependente da força iōnica do meio (Weston e Schawrz, 1972). Esta dependên cia pode ser induzida tanto pelo desvio das concentrações dos prōprios ions reativos (13), como tambēm pela adição de outros sais não reativos (eletrōlitos inertes) (Weston e Schawrz, 1972). Este efeito pode ser traduzido da seguinte forma:quan to maior a concentração salina do meio, tanto menor serā a constante para reações entre ions de carga oposta e maior pa ra Tons de carga igual (Permutter e Hayman, 1972). 0 efeito de força iônica na velocidade de reações é analisado pormenorizada mais à frente.

Conforme o tratamento de Bronsted-Bjerrum (Robinson e Stokes, 1955 ; Harned e Owen, 1943) o efeito de força iônica pode ser representando por (as deduções e detalhes das equações encontram-se em I.3.2):

$$
k=k^{0} \cdot 10^{-f(\mu)}
$$

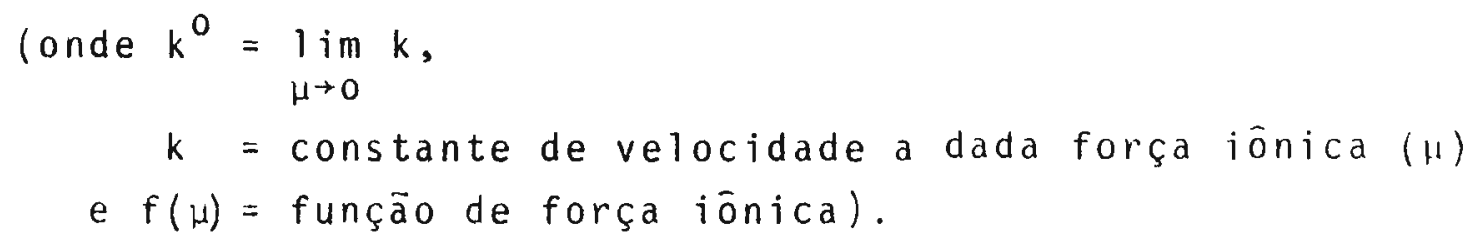


Investigando-se o efeito de força iónica sobrea reaçăo de hidrōlise alcalina dos RCP, observou-se que a relação P/A não é afetada por força iōnica, enquanto as constantes de velocidade $k_{1} e k_{2}$ são. Estes fatos fazem com que derivemos expressōes que permitam analisar quantitativamente este efeito.

A expressão que descreve a relação $P / A$ em funçäo de $\delta \bar{e}$ dada por:

$$
\frac{P}{A}=\frac{k_{2}}{k_{1}} \quad \delta
$$

Aplicando-se a equação 47 às equações 46 e 48 temos que:

$$
\begin{aligned}
& k_{2 \psi}^{0}=k_{2}^{0} \delta+k_{1}^{0} \\
& \frac{P}{A}=\frac{k_{2}^{0}}{k_{1}^{0}} \delta
\end{aligned}
$$

Resolvendo-se o sistema para $k_{1}^{0}$ obtemos:

$$
k_{1}^{0}=\frac{k_{2 \psi}^{0}}{(P / A+1)}
$$

sendo $k_{2 \psi}$ e P/A dados experimentais, obtemos $k_{2 \psi}^{0}$ através da quação 47 e então $k_{1}^{0}$ através da equação 51 . A alta concentra ção de hidrōxido $(\mathrm{pH} \geqslant 12,8)$ a relação $\mathrm{P} / \mathrm{A}$ tende a um valor má ximo (Kosower e Patton, 1966). Da expressäo 50 utilizando-se - limite de alta concentração de hidrōxido (Equação $37 ; s=1$ ) pode-se obter $k_{2}^{0}$.

Rearranjando a expressão 43 , obtemos

$$
\frac{\delta}{1-\delta}=\frac{k_{4}}{k-2}+\frac{k_{5} k_{3}}{k_{-}-2}\left(\mathrm{OH}^{-}\right)
$$

que traduz uma relação linear entre $\left(\frac{\delta}{1-\delta}\right)$ e $\mathrm{OH}^{-}$. O gräfico $\left(\frac{\delta}{T-\delta}\right)$ vs $\left(\mathrm{OH}^{-}\right)$será portanto uma reta na qual o intercepto 
com o eixo da ordenada e a inclinação traduzem relações entre $k_{4}, k_{-2}, k_{5}$ e $k_{3}(14)$.

1.3.2. Efeito de constante dielétrica e força iônica sobre reações entre ions

Desde que a constante dielétrica da micela é seme lhante a de metanol (Fernandez e Fromherz, 1977; vide supra) a anălise deste efeito assim como o de força iōnica (vide supra) sobre a velocidade da reação é essencial. Estes efeitos têm sido amplamente discutidos (Robinson e Stokes, 1955;Harned e Owen, 1943; Pitzer, 1973, 1977; Pitzer e Mayorga, 1973;Pitzer e Kim, 1974; Amis, 1949, 1966; Frank e Thompson, 1959; Patey e Valleau, 1975; Laidler, 1963).

Analisamos inicialmente o efeito de força iōnica. 0 tratamento usual pode ser visto como se segue:

Considere-se o equilibrio:

$$
A+B \stackrel{K}{\longrightarrow} x \longrightarrow C+D
$$

(onde A e B são os reagentes; C e D produtos e X equivale ao estado de transição). A constante $K \bar{e}$ dada por

$$
k=\frac{C_{X} \cdot f_{X}}{C_{A} f_{A} C_{B} f_{B}}
$$

(onde $C=$ concentração e $f=$ coeficiente de atividade). Sendo a velocidade da reação proporcional à concentração da espē cie de transição $x$, isto $\vec{e}$

$$
V=k^{\prime \prime} c_{x}
$$

(onde $k "=$ constante de proporcionalidade)

Substituindo-se 55 em 54 vem 


$$
v=k " k C_{A} C_{B} \frac{f_{A} f_{B}}{f_{X}}
$$

denominando-se $k^{\prime \prime} k=k_{0}^{\prime}$ (57) e substituindo em 56 temos;

$$
v=k_{0}^{\prime} C_{A} C_{B} \frac{f_{A} f_{B}}{f_{x}}
$$

Para reaçōes bimoleculares a velocidade pode ser dada por:

$$
v=\frac{-d C_{i}}{d t}=k^{\prime} C_{A} C_{B}
$$

aplicando-se 59 em 58 temos:

$$
k^{\prime}=k_{0}^{\prime} \cdot \frac{f_{A} f_{B}}{f_{X}}
$$

Considerando-se $A$ e $B$ iônicos temos:

$$
A^{Z} A+A^{Z} B X^{\left(Z_{A}+Z_{B}\right)}
$$

(onde $Z \bar{e}$ a carga do ion). Aplicando-se a Teoria de Debye-Hü cke1 (Robinson e Stokes,1955; Harned e Owen, 1943) o coeficiente de atividade de um eletrōlito simples è dado por:

$$
\ln f_{i}=\frac{-Z_{i}^{2} A \sqrt{\mu}}{1+\beta a_{i} \sqrt{\mu}}
$$

(onde $f_{i} \bar{e}$ o coeficiente de atividade do ion $i$ );

$$
\begin{aligned}
A & =\frac{e^{3}}{\text { DKT }} \frac{2 \pi N}{1000 \text { DKT }} \\
\text { com, } & =\text { carga do elētron, } \\
D & =\text { constante dielētrica, } \\
K & =\text { constante de Boltzmann, } \\
N & =n o \text { de Avogadro; }
\end{aligned}
$$




$$
\begin{aligned}
\beta & =\frac{8 \pi N \mathrm{e}^{2}}{1000 \text { DKT }} \quad(64) \\
\text { e } a_{i} & =\text { distãncia de encontro māximo (15)) }
\end{aligned}
$$

No desenvolvimento de Debye-Hückel são feitas apro ximaçöes que nem sempre são vālidas. Uma das crïticas que tell sido feita ao modelo é não levar em conta potenciais de curto alcance entre os ions (MacIness, 1939; Frank e Thompson,1959; Pitzer, 1977). Tém sido propostos modelos mais ou menos com pletos para explicar o comportamento de atividade em regiōes de atē pelo menos 6M (Pitzer, 1979). Tais modelos envolvem funções de distribuição radial e outros parāmetros como o decaimento do potencial de curto alcance. No caso de um sistema onde a determinação dos parāmetros acima indicados ē inexe qüivel, a solução comumente empregada è estender empiricamente a expressão de Hückel, como por exemplo:

$$
\begin{aligned}
& \ln f_{i}=\frac{-z_{i}^{2} A \sqrt{\mu}}{1+\beta a_{i} \sqrt{\mu}}+b \mu \\
& \text { (Robinson e Stokes, } 1955 \text { ) }
\end{aligned}
$$

ou

$$
\ln f_{i}=\frac{-z_{i}^{2} A \sqrt{\mu}}{1+B a_{i} \sqrt{\mu}}+\frac{2}{b} \ln (1+b \sqrt{\mu})
$$

$$
\text { (Pitzer, 1973) }
$$

onde os termos adicionados empiricamente contêm os desvios da expressão não passivel de anālise.

Utilizando a expressão de Hückel para resolver o fá tor $f_{A} f_{B} / f_{x}$ (equação 56 ) obtemos: 


$$
\ln k^{\prime}=\ln k_{0}^{\prime}+\frac{2 Z_{A} Z_{B} A \sqrt{\mu}}{1+\beta a_{i} \sqrt{\mu}}
$$

(poderiamos utilizar as expressões 65 ou 66 e neste caso em 67 apareceriam fatores adicionais).

Trataremos agora do efeito de constante dielëtrica sobre a velocidade de reaçôes. Para um sistema de esferas rị gidas (na qual o potencial entre os ions è prontamente estabe lecido), pode ser demonstrado que a energia livre do estado de transição serā dada por uma expressão do tipo (Laidler, 1963)

$$
\frac{\Delta G^{*}}{N}=\frac{\Delta G^{\neq}}{N} \frac{Z^{2} e}{N}+\frac{Z_{A} Z_{B} e^{2}}{D\left(r_{A}+r_{B}\right)}
$$

(onde $\Delta G^{\neq}$é a contribuição não eletrostātica; lembre-se que es tamos tratando de um sistema iōnico $\left.A^{ \pm}+B^{ \pm} \quad x\right)$. Substituin do-se a equação 68 na expressão de velocidade derivada da teo ria do estado de transição (Benson, 1960; Weston e Schawrz. 1972; Lefler e Grunwald, 1963 ; Laidler, 1963)

$$
k=\frac{K T}{h} \text { e }-\Delta G^{\neq} / R T
$$

(onde $h$ è a constante de Planck), obtemos:

$$
\operatorname{lnk}=\ln \frac{K T}{h} e^{-\Delta G^{*} \eta \cdot e / R T}-\frac{Z_{A} Z_{B} e^{2}}{D\left(r_{A}+r_{B}\right) K T}
$$

que pode ser simplificada para

$$
\ln k=\ln k_{0}-\frac{z_{A} z_{B} e^{2}}{D\left(r_{A}+r_{B}\right) k T}
$$

Scactchard obteve uma expressão semelhante à 71 (Amis, 1949 ; 
1966), ná qual explocitou um estado de referência ( $D=1$, vācuo) e condicionou a relação ao limite de zero de força iônica. A expressão de Scactchard é:

$$
\operatorname{lnk} k_{0}^{\prime} \text { 'Dmeio }=\ln k_{0}^{1}, D=1+\frac{Z_{A} Z_{B} e^{2}}{K T\left(r_{A}+r_{B}\right)}\left(1-\frac{1}{D}\right)
$$

Aplicando-se a expressão 72 para dois meios de cons tante dielétrica diferentes e subtraindo as expressões obtemse

$$
\operatorname{lnk} k_{0}^{\prime} \text { 'Dmeiol }=\operatorname{lnk} k_{\text {oDmeio } 2}^{\prime}-\frac{Z_{A} Z_{B} e^{2}}{k T\left(r_{A}+r_{B}\right)}\left(\frac{1}{\text { Dmeio } 1}-\frac{1}{\text { Dmeio } 2}\right)
$$

Da expressão 73 pode-se prever que, para una reação entre ions de carga oposta,quando Dmeio 1 < Dmeio 2 obtem-se $k_{\text {o Dmeio } 1}^{\prime}>k_{\text {o Dmeio }}^{\prime}$.

Se os ions reagentesforem de mesma carga o efeito será oposto.

Poderíamos escrever uma expressão geral que englobas se efeito de constante dielétrica e força ionnica que è a equa ção de Brönsted-Christiansen-Scatchard (Amis, 1949). Para efeito deste trabalho achamos conveniente utilizar separada mente as equações 67 e 73 . 
I.4. Alguns conceitos e inovaçöes associados às tëcnicas empregadas

\section{I.4.1. Fotofenômenos}

A aplicações de fotofenômenos em soluções micelares tem sido correntemente utilizada (Quina et al, 1977; Turro et al, 1979; Grätzel e Thomas, 1976; Miola, 1979; Bonilha; Fendler, 1980). Apresentamos abaixo um breve desenvolvimento, aplicado ao ponto de vista deste estudo. Maiores detalhes so bre as equações, modelos e suposições podem ser encontradosem Quina (1978) ou Miola (1979).

0 fotofenōmeno empregado foi o da supressão da emis são de fluorescéncia, para o qual utilizamos o íon emissor de fluorescència Ru(bipy) ${ }_{3}^{2^{+}}$

A supressão da emissão deste íon pelos ions RCP dáse por um mecanismo de transferēncia de carga (Miola, 1979), como esquematizado na figura 7.

Na ausência de micelas a supressão é descrita pela equação de Stern-Volmer (Quina, 1978)

$$
\left(\frac{\phi_{\mathrm{em}}^{0}}{\phi_{\mathrm{em}}^{\mathrm{m}}}\right)_{0}=1+k_{\mathrm{s} \cdot \mathrm{v}} \text { St }(74)
$$

(onde $\emptyset_{\text {em }}$ e $\phi_{\text {em }}^{0}$ são os rendimentos quânticos da emissão na pre sença e ausência, respectivamente, de uma concentração total de supressor (St) e $K_{S . v} \bar{e}$ a constante de Stern-Volmer).

Na presença de micelas cationicas (como de brometo de hexadeciltrimetilamōnio, a supressão deve-se somente au supressor da fase aquosa, uma vez que o ion emissor (Ru(bipy) ${ }_{3}^{2+}$ 
năo se incorpora às micelas positivas (Quina, 1978). A equaçäo correspondente é

$$
\left(\frac{\phi_{\mathrm{em}}^{0}}{\phi_{\mathrm{em}}}\right)_{\mathrm{CD}}=1+k_{\mathrm{sv}} \cdot \mathrm{S}_{\mathrm{f}}
$$

Conde o īndice CD refere-se à presença de micelas e $S_{f} \bar{e}$ o sü pressor livre, sendo $S_{f}=S_{t}-S_{b}(76)$. 0 equilibrio de dis tribuição dos RCP pode ser representado por:

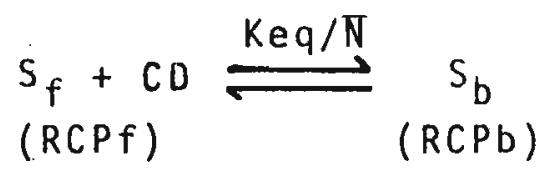

A constante de equilibrio.(Keq/N) è dada por

$$
\frac{K e q}{N}=\frac{S_{b}}{S_{f} C D} .
$$

Substituindo 76 em 78 , obtemos

$$
\frac{S_{t}}{S_{f}}=1+\frac{K e q}{\bar{N}} C D
$$

Combinando-se as expressōes 74,75 e 79 obtemos por fim

$$
\gamma=\frac{\left(\frac{\phi_{\mathrm{em}}^{0}}{\phi_{\mathrm{em}}}\right)_{0}-\left(\frac{\phi_{\mathrm{em}}^{0}}{\phi_{\mathrm{em}}}\right) C D}{\left(\frac{\phi_{\mathrm{em}}^{0}}{\emptyset_{\mathrm{em}}}\right)_{D}-1}=\frac{\mathrm{Keq}}{\bar{N}} \operatorname{CD}(80)
$$

A distribuição de compostos como os RCP entre a fa se aquosa e micelar, como o comportamento de CMC, são depen dentes da força iōnica do meio (veja equação 8). O efeito de sal sobre o valor Keq/ $\bar{N}$ tem sido descrita por una expressãodo tipo (Quina, 1978): 


$$
\text { - } \log \frac{\text { Keq }}{\bar{N}}=c_{1}^{\prime}+c_{2}^{\prime} \log (\text { s.a } 1)
$$

(onde $C_{i}^{\prime}$ e $C_{2}^{\prime}$ são parāmetros lineares da equação).

\section{I.4.2. Cromatografia em fase gasosa}

- Anālise de detergentes derivados de sais de tetraalquilamōnio - Micro-Hoffmann

A anālise correta de resultados obtidos em soluções micelares dependem da pureza do detergente. E importante ter se portanto um bom mëtodo de dosagem analitica desses compos-. tos.

Tratando-se da constante de distribuição de compos tos em micelas, de forma geral, $\bar{e}$ sabido que tais constantes são sensîveis ao comprimento da cadeia do detergente (Fendler e Fendler, 1975; Mitta1, 1977; Romsted, 1975), uma vez que séries homólogas de detergentes apresentam CMC, nọ médio de agregação e grau de dissociação distintos.

Dados anterioresobtidos neste laboratōrio (Bonilha, 1979; Chaimovich et a 1, 1979), mostraram que lotes de cloreto de cetiltrimetilamónio (CTACl) eram na realidade cloreto de tetradecilamōnio (TTAC 1).

Rotineiramente temostrabalhado com anfifilicos deri vados de sais de amōnio quaternārio. A tēcnica usual para de terminar-se os componentes de um composto desta espēcie (Cuccovia, 1980) é através da eliminação de Hoffmann (Fuson, 1962), a qual pode ser esquematizada como mostra a Figura 3.

Resumidamente temos: o haleto de tetralquilamõnio é transformado no hidróxido correspondente, o qual por decompo- 
sição tērmica dā origem aos compostos I, II, III e IV V.

A problemâtica que ocorre na operaçāo ē relativa à fase de eliminação, a qual é bastante demorada envolvendo des tilação, aquecimento em banho de öleo, etc.

A variação do método que propomos $\vec{e}$, uma vez obtido o hidrōxido de tetralquilamōnio, injetar-se o composto numcro matógrafo a gās a uma temperatura de injeção alta (cerca de $250^{\circ} \mathrm{C}$ ) fazendo com que a eliminação ocorra no pröprio cromatō grafo.

I.5. Objetivos do estudo

As proposições deste trabalho são:

1) Estudar a reação de hidrōlise alcalina de N-alquil4-cianopiridineos em fase aquosa e descrevero efeito de varia çōes no meio (força iōnica e constante dielētrica) sobre a ve locidade e produtos da reação.

2) Estudar sistemas micelares iōnicos (catiōnicos, aniōnicos e zwitteriōnicos), empregando como sonda a reaçãode hidrólise alcalina dos RCP, utilizando a sensibilidade desta reação a mudanças de meio.

3) Verificar a aplicabilidade do modelo de troca iónica em micelas à anāilise do sistema em estudo (ver ítem I.2).

4) Analisar os dados obtidos ao se estudar o efeito de detergentes sobre a velocidade (e/ou prudutos) da reação uti lizando as informações sobre os efeitos do meio na reação não modificada por adição de micelas, isto ë, em āgua. 


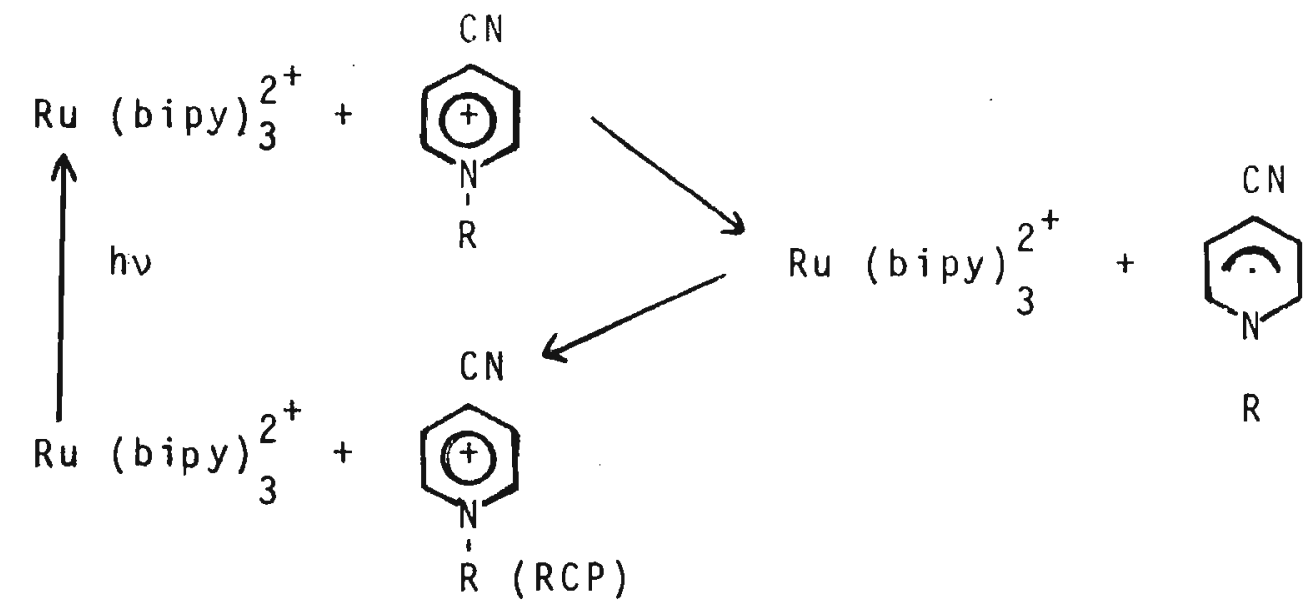

Figura 7 - Mecanismo de transferência de car ga de ions (Ru (bipy) ${ }_{3}^{2+}$ pelos RCP.

$$
\begin{aligned}
& 2 \mathrm{R}_{4} \mathrm{~N}^{+} \mathrm{X}^{-}+\mathrm{Ag}_{2} \mathrm{O} \stackrel{\mathrm{H}_{2} \mathrm{O}}{\longrightarrow} 2 \mathrm{RN}^{+} \mathrm{OH}^{-}+2 \mathrm{AgX} \\
& \left(X=\mathrm{Cl}^{-}, \mathrm{Br}^{-} ; \mathrm{R}_{4}=\text { grupos alquila }\right)
\end{aligned}
$$

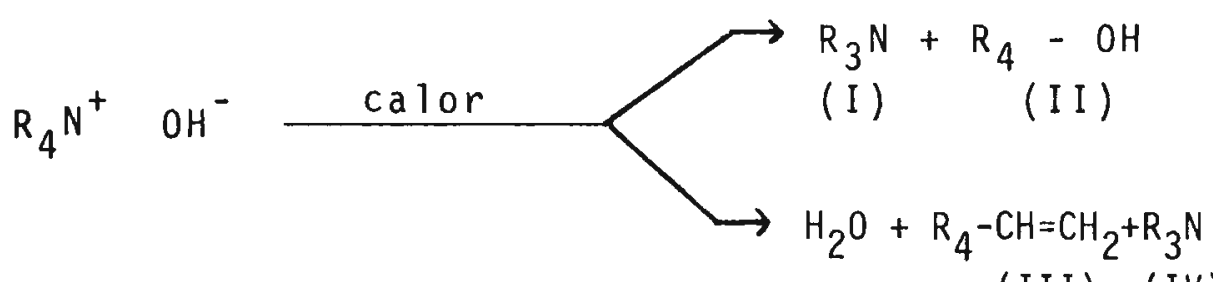

Figira 8 - Esquema de eliminação de Hoffmann 
II. Materiais, Métodos e Apararelhos

II.1. Materiais

Os materiais serão descritos na ordem seguinte: deter gentes, reagentes orgānicos, reagentes inorgānicos e solventes.

\section{1.1. Detergentes}

- Brometo de Hexadeciltrimetilamônio (CTAB)

0 CTAB (E.Merck, Darmstadt) foi purificado por trés recristalizações de acetona/etanol $(85: 15 \mathrm{v} / \mathrm{v})$ e seco sob vácuo.

\section{- Dodecilsulfato de sōdio (SDS)}

o SDS (BDH Chemicals Ltd) foi utilizado sem purificação prévia uma vez que não apresentou minimo nas curvas de ten são superficial em função da concentração de detergente (Harrold, 1960). A pureza deste composto foi ainda confirmada pela medida por cromatografia gasosa da composição dos alcoōis deri vados da hidrōlise àcida (Kurz, 1962). Tal medida mostrou a existēncia de $99 \%$ de dodecanol no extrato etéreo obtido apōs a hidrōlise.

- 3-(N,N-dimetil dodecil amōnio) propano-1-sulfonato (SDP)

O SDP foi cedido pelo Prof.Dr. Omar El Seoud (USP-Sac Pau10) 
Paulo). Apōs vārias purificações do composto, feitas por El Seoud, as medidas de CMC não mostraram minnimos nas curvas de tensão superficial. Portanto, utilizamos o composto como rece bido.

- cloreto de Hexadeciltrimetilamónio (CTACl)

- cloreto de Octadeciltrimetilamônio (STACl)

- Brometo de Tetradeciltrimetilamónio (TTABr)

o CTAC1, o STACl e o TTABr foram sitetizados e cedidos pelo Prof.Dr. J.B.S. Bonilha (USP, Ribeirão Preto), sendo $\underline{u}$ tilizados como recebidos.

- Hidrōxido de Hexadeciltrimetilamōnio (CTAOH)

o CTAOH foi sintetizado e cedido pelo Prof.Dr. Luis Sepulveda (Universidade Catōlica do Chile) sendo utilizado como recebido.

- Herquat $2 \mathrm{HT}-75$

0 Herquat 2 HT-75 (Herga S.A.), uma mistura de cloreto de dialquildimetilamōnio (75\% de $\mathrm{C}_{18} \mathrm{H}_{37}$ e $25 \%$ de $\mathrm{C}_{16} \mathrm{H}_{33}$ ) foi recristalizado seis vezes de acetona e trés vezes de acetato de etila e seco sob vācuo. 
II.1.2. Reagentes orgānicos

\section{- Padrões cromatogrāficos}

Utilizou-se como padrões para cromatografia gasosa:

1- Hexadeceno (Aldrich)

1- Octadeceno (A1drich)

1 - Clorohexadecano (Aldrich)

1 - Dodecanol (Merck)

Os compostos acima são de grau analitico, sendo utilizados sem tratamento prēvio para purificação; a resolução obtida nos cromatogramas (ver Resultados) garante a pureza des ses compostos.

$$
\begin{aligned}
& \text { N-dimetil-N-dodecilamina } \\
& N \text { - dimetil-N-nexadecilamina } \\
& \text { N-dimetil-N-octadecilamina }
\end{aligned}
$$

Estas aminas foram sintetizadas e cedidas pelo Prof. Dr. Omar El Seoud (USP, São Paulo), sendo utilizadas como rece bidas. A pureza destas pode ser verificada nos cromatogramas (ver Resultados).

- N-alquil-2-ciano e 4-cianopiridíneos:

Cloreto de $\mathrm{N}$-metil-4-Cianopiridineo (MCPCI)

0 MCPC1 foi sintetizado (Bock, 1974; Kosower, 1960)a partir do iodeto de metila (Aldrich Chemical, Inc., previamente purificado por cromatografia de coluna de aluminal e 4-cianopiridina (Aldrich Chemical, Inc.; 99\%). Adicionou-se a cercá 
de 0,04 moles de 4-cianopiridina, um ligeiro excesso de iodeto (- 0,045 moles) em cerca de $15 \mathrm{ml}$ de acetonitrila (Aldricr Chemical co., Inc., 99\%) em baläo de vidro de tampa esmerilhada. Deixou-se a mistura de reação, protegida de luz, por vir te quatro horas à temperatura ambiente. 0 iodeto de $\mathrm{N}$-metil 4-cianopiridineo (MCPI) formado. cristaliza. Ao MCPI forani a dicionados cerca de 0,07 moles de cloreto de prata, preparado' a partir de quantidades equimolares de nitrato de prata (E.Mer ch, Darmstadt) e cloreto de sōdio (Analar, BdH Chemical Ltd) filtrado e lavado com àgua. Adicjonou-se o cloreto de prataent meio aquoso levemente àcido (pela adição de HCl, Carlo Erba P.A-ACS. Sepa rou-se a seguir o iodeto de prata formado por filtraçäo. 0 filtrado foi liofilizado e o pö resultante lavado exaustivamente com acetonitrila.

- Cloreto de $\mathrm{N}$-metil-2-cianopiridineo (MC2PCl)

0 MC2PCl foi sintetizado pelo mesmo procedimento des crito para o MCPC1, exceto que neste caso partiu-se de 2-ciano piridina (Aldrich Chemical, Co., Inc., 99\%).

- Brometo de $N$-Butil-4-cianopiridineo (BCPBr)

O BCPBr foi sintetizado (Landquist, 1976) a partir a، 4-cianopiridina e Brometo de n-butila (Aldrich Chemical Co. Inc., 99\%). Adicionou.se a cerca de 0,04 moles de 4-cianopiri dina, um ligeiro excesso de brometo de n-butila ( - 0,05 moles) eill cerca de $15 \mathrm{ml}$ de acetonitrila num baläo de vidro de boca esmerilhada. Refluxou-se a mistura sob aqitação con barra magnética por 24 ho - 
ras a temperatura de $82,0^{\circ} \mathrm{C}$. Apōs resfriamento recristalizoulse o precipitado pelo menos quatro vezes em acetonitrila. 0 produto obtido foj seco sob vācuo à temperatura ambiente.

\section{- Brometo de $\mathrm{N}$-octil-4-Cianopiridineo (OCPBr) \\ - Brometo de $\mathrm{N}$-decil-4-cianopiridineo (DeCPBr) \\ - Brometo de $N$-dodecil-4-cianopiridineo (DCPBr)}

Estes piridineos foram sintetizados por processo ana logo ao BCPBr, exceto que em cada caso parte-se do brometo de alquila correspondente. Os brometos de n-octila e de n-decila são da Aldrich (Aldrich Chemical Co., Inc., 99\%) e o brometo de $n$-dodecila, da Merck (E. Merck, Darmstadt).

A pureza dos compostos piridineos preparados foi ve rificada pelo peso equivalente obtido pela titulação de cloreto ou Brometo (vide Mëtodos), juntamente com os coeficientes' de extinção molar comparados aos valores descritos (Kosower e Patton, 1966) (Tabela 2)e pelas anālises elementares (feitas por Riva Moscovia, IQ-USP, Säo Paulo), de MCPC1, MC2PC1,BCPBr,OCPBr e DCPBr (Tabela 2A).

\section{Outros reagentes orgänicos}

- Acido 5-5' Dithiobis:paranitro benzóico (DTNB)

O DTNB (BDH Biochemicals) foi utilizado como recebido, sendo dissolvido em solução tampão Tris $0,1 \mathrm{M}$ a $\mathrm{pH}=8,00$ / (concentração da solução estoque de $0,01 \mathrm{M}$ ) e conservado a baixa 
Tabela 2 - Coeficientes de extinção molar, $\varepsilon(a=$ descrito, $b=$ obtido) dos RCP

composto

MCP

MC 2P

$B C P$

OCP

DeCP

DCP $\lambda \max , n m$

278

233

297

271

278

233

278

233

278

233

278

233 $\varepsilon, \mathrm{M}^{-1} \mathrm{Cm}^{-1}$

$4825^{\mathrm{a}}$
$4750^{\mathrm{b}}$

$12100^{\mathrm{a}}$
$11800^{\mathrm{b}}$

$68200^{\mathrm{a}}$
$6400^{\mathrm{b}}$

$7950^{\mathrm{a}}$
$7725^{\mathrm{b}}$

$4620^{b}$
$13520^{b}$

$4280^{b}$

$12200^{b}$

$4500^{b}$

$12300^{b}$

$4380^{b}$

$12420^{b}$

* Os valores acima obtidos são mëdias de dez valores para cada composto, cuja análise estatistica mos tra um desvio máximo de (5\% Os compostos BCP, OCP DeCP e DCP não são descrttos na literatura.

errostiunodot pengue tem difenuss de 10-15\% entre a possojome a titulogarde bumeto

43 
Tabela $2 A$ - Porcentagem de $C, H$ e $N$ obtidas por anālise elementar (Riva Moscovia, IQ USP, São Paulo) $(a=c a l c u l a d o, b=o b t i d o)$.

\begin{tabular}{c|ccc} 
Composto & $C$ & $H$ & $N$ \\
\hline$M C P$ & $a=55,01$ & 3,96 & 18,36 \\
$\left(C_{7} H_{6}{ }_{2} C 1\right)$ & $b=55,38$ & 3,88 & 18,70 \\
$M C 2 P$ & $a=55,01$ & 3,96 & 18,36 \\
$\left(C_{7} H_{6}{ }_{2} C 1\right)$ & $b=54,43$ & 4,56 & 18,32 \\
${ }_{B C P}$ & $a=49,81$ & 6,43 & 11,61 \\
$\left(C_{10}{ }^{H} 13^{N} 2^{B r}\right)$ & $b=50,76$ & 5,67 & 11,47 \\
$0 C P$ & $a=54,74$ & 7,42 & 9,82 \\
$\left(C_{14}{ }^{H} 21^{N} \mathrm{Br}\right)$ & $b=55,32$ & 7,43 & 9,49 \\
${ }_{D C P}$ & $a=61,20$ & 8,30 & 7,91 \\
$\left(C_{18}{ }^{H} 29^{N} \mathrm{Br}\right)$ & $b=60,75$ & 8,30 & 7,80
\end{tabular}


temperatura (cerca de $-10^{\circ} \mathrm{C}$ ).

- Cloreto de tris $\left(2,2^{\prime}-\right.$ bipiridina) Ruténio I I Hexahi
dratado (Ru(bipy) $\left.{ }_{3}^{2+} \mathrm{Cl}_{2} .6 \mathrm{H}_{2} \mathrm{O}\right)$

o cloreto de tris (2,2'-bipiridina) Rutēnio II (G. Frederich Smith Company), emissor de fluorescência, foi utilizado sem prëvio tratamento.

- Brometo de tetrametilamōnio (BTMA)

0 BTMA foi sintetizado a partir do hidróxido correspondente (E. Merck, Darmstadt, p.ap) e àcido bromỉdrico (Carlo Erba, PA-ACS). Tratou-se cerca de 3 gramas do hidröxido com quantidade suficiente do ācido para atingir pH 4,0; evaporou se o solvente $\left(\mathrm{H}_{2} \mathrm{O}\right)$ sob pressão reduzida e o cristalizado en tão formado foi recristalizado três vezes de acetona/älcool / àgua $(70: 25: 5)$. Secou-se o produto sob vācuo à temperatura am biente.

II.1.3. Reagentes inorgānicos

- Padrões de pH

Utilizamos rotineiramente soluçöes titrisol (Merck) $\mathrm{NaOH}$ ou HCl que foram diluĩdas para a concentração desejada com ägua bidestilada e deonizada (vide intra). 


\section{- Soluções tampão}

As soluçōes tampäo utilizadas foram preparadas a par tir de:

Tris (Hidroximetil) amino metano (Tris, $\mathrm{C}_{4} \mathrm{H}_{1}{ }_{1} \mathrm{NO}_{3}$. E. Merck, Darmstadt, p.a.)

Acido Bōrico $\left(\mathrm{H}_{3} \mathrm{BO}_{3}\right.$, Baker, Gen. Chem.Co.)

Carbonato de södio ( $\mathrm{Na}_{2} \mathrm{CO}_{3}$, Baker, Gen. Chem. Co.)

Fosfato dissödico dihidratado $\left(\mathrm{Na}_{2} \mathrm{HPO}_{4} \cdot 2 \mathrm{H}_{2} \mathrm{O}\right)$ (Analar, BdH Chemical Ltd)

\section{- outros}

Todos os demais reagentes eram de grau analitico.

II.1.4. Solventes

\section{- Agua $\left(\mathrm{H}_{2} \mathrm{O}\right)$}

A āgua utilizada foi dionizada, bi-destilada em vi dro, fervida e esfriada sob argōnio ou nitrogénio.

\section{- 1,4-Dioxana (Diox)}

A 1,4-dioxana (Carlo Erba, R,A,-ACS) foi purificada (Vogel, 1971) como se segue: um litro de dioxana, 14 ml de àci do cloridrico (37\%, Carlo Erba, P.A.-ACS) e $100 \mathrm{ml}$ de ägua fo ram colocados sob refluxo por sete horas, na qual borbulhou-se nitrogénio para remover o acetaldeidofor mado. A solução fria foi tratada com hidröxido de potássio em 
lentilhas (E. Merck, Darmstadt) sob agitação e separa-se a camada aquosa. A seguir deixou-se a mistura em repouso com nova porçāc de hidrōxido por 24 horas; seguiu-se num refluxo sobre excesso de sōdio metälico por 7 horas. Finalmente destilou-se, recolhendo-se uma fração que destilou a cerca de $99^{\circ} \mathrm{C}$ (P. E. des crito $=101^{\circ} \mathrm{C}$ à $\left.760 \mathrm{~mm} \mathrm{Hg}\right)$; guardou-se a dioxana sob atmosfera inerte e em frasco ambar.

\section{2. Mētodos}

II.2.1. Dosagens analiticas

Titulação de Cloreto e Brometo

As concentrações de cloreto ou brometo, componentes' das soluções dos ĩons piridínicos (MCPC1, DCPBr, etc.) ou dos detergentes (CTAB, Herquat, etc.), foram determinadas por titu lação (Schales e Schales, 1941) com solução padronizada de nị trato mercūrico $\left(\mathrm{Hg}\left(\mathrm{NO}_{3}\right)_{2}\right)$ (Riedel - De Haénag Seelze - Hannover) e difenilcarbozona (E. Merck, Darmstadt) como indicador. Atravēs dessa titulação podemos obter a concentração das solu çöes estoques e pesos equivalentes dos compostos sintetizados.

\section{Titulação de Cianeto}

A reação de hidrōlise (Figura 6) conduz à liberação de cianeto (formação de piridona). Assim sendo, a dosagen deste ūitimo é uma ferramenta importante para se determinar a estequiometria da reação. A determinação do cianeto ë efetuada a travēs da reação deste com DTNB (Spurlin et col., 1977). O cia 
neto ataca a ligação "S-S-" do DTNB liberando o anion RS $^{-} 0$ qual apresenta um pico de absorção em 412 nm em āgua e $430 \mathrm{~nm}$ em solução de CTAB. A medida é feita da seguinte maneira:

apōs o tërmino da reação adiconamos: i) tampão Tris $1 \mathrm{M}$ pH 8,0 (concentração final $20 \mathrm{mM}$ ); ii) CTAB $0,1 \mathrm{M}$ (concentraçäo final $10 \mathrm{mM})$; iiil prepara-se um branco da mesma maneira que a cela de reação exceto pela ausēncia de substrato (RCP); iv) adicio na-se $50 \mu 1$ de DTNB $10 \mathrm{mM}$ no branco e na amostra; v) registrase o mäximo de densidade öptica. Pela densidade ōptica obtida e curva padrão (pré-estabelecida nas condições do experi mento) de concentração de cianeto em função de densidade öptị ca obtem-se a quantidade de cianeto liberada.

Nos casos onde a reação foi estudade em meio de SDS, foi necessārio desenvolvermos uma marcha sistemätica original, abaixo descrita, uma vez que o SDS interfere na medida. Após término da reação em presença de SDS adiciona-se 0,5 ml de c.10 reto de bārio na concentração adequada para precipitar todo SDS, separa-se o precipitado (dodecilsulfato de bārio) por centrifugação. Toma-se uma alĩquota de $2,3 \mathrm{ml}$ do sobrenadante adicionando-se em seguida o tampão, CTAB e DTNB. A partir de então segue-se a rota normal (como explicada anteriormen te).

\section{Determinação e dosagem dos produtos da reação}

Os espectros de absorção regiäo de luz ultra-violeta (360 nm à $20 \mathrm{~nm}$ ) dos produtos da hidrōlise alcalina (Figura 6) do MCP e MC2P são conhecidos (Kosower e Patton, 1966). Com base nos valores de coeficiente de extinçäo molar destes 
compostos (no גmax, descrito, Kosower e Patton, 1966), titula ção de cloreto ou brometo e medida de cianeto (mede-se diretamente a piridona respectiva formada) obtivemos os valores de coeficiente de extinçäo molar dos produtos da reação de hidrólise alcalina dos ions RCP (Tabela 3 ).

Tabela 3 - Coeficiente de extinção molar ( $\varepsilon$, $a=$ descrito, $b=$ obtido) dos produtos de rea ção dos RCP (Figura $6, A=$ amida e $P=$ piridona respectivas)*

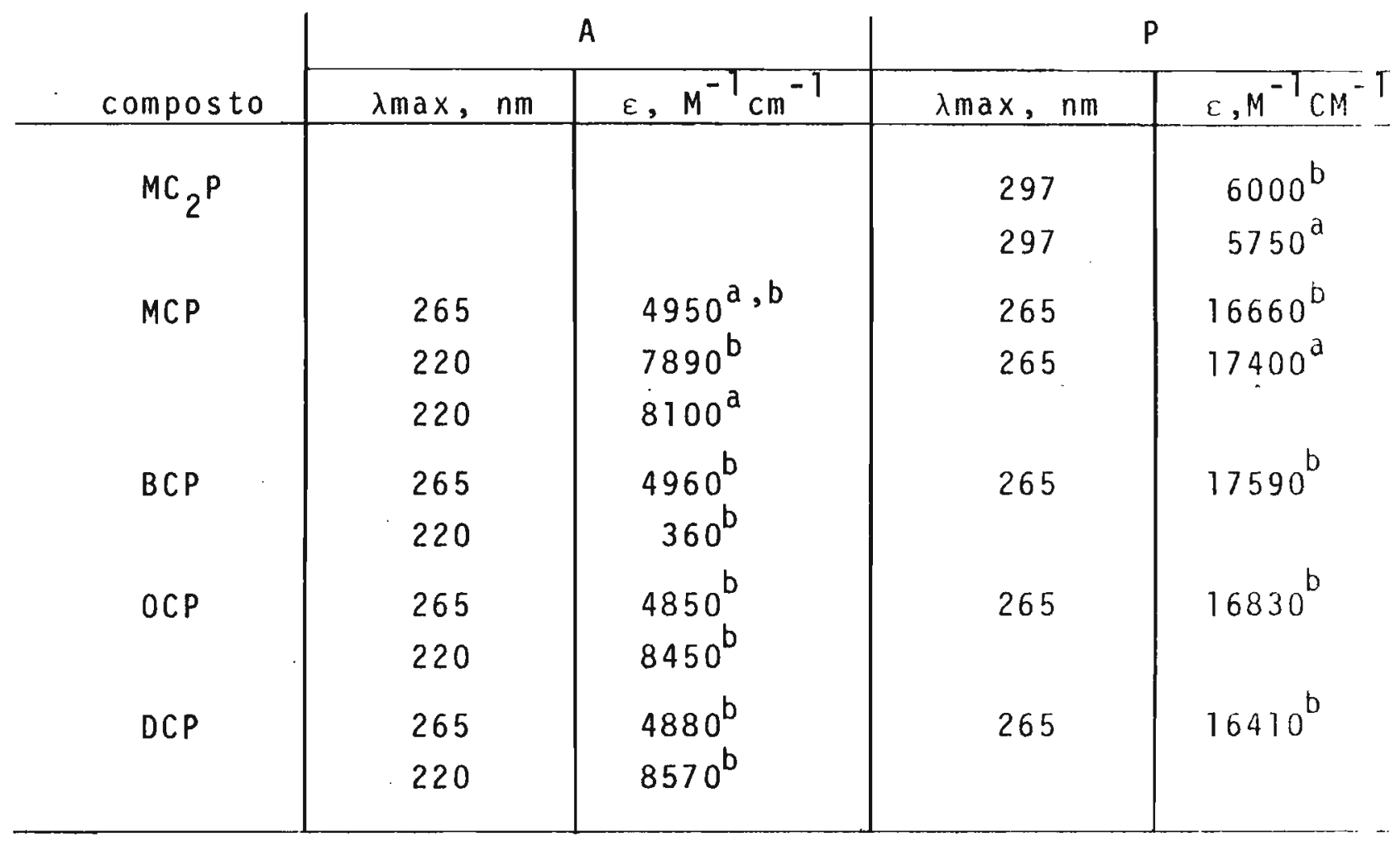

*os valores acima säo mêdia de dez valores cada. A anälise estatistica dos mesmos mostra um desvio mäximo de $5 \%$ -

Sendo conhecidos os coeficientes de extinção molar dos produtos ( $P$ e $A$ ) da reação (Figura 6) e a concentração do composto reagente (RCP), determina-se a relação P/A (via espec tro de absorção) fazendo-se uso das expressões abaixo: 


$$
\begin{gathered}
{[P]+[A]=[R C P] \quad(81)} \\
D .0_{265 \mathrm{~mm}}=[P] \varepsilon_{\mathrm{p} 265 \mathrm{~nm}}+[A] \varepsilon_{A} 265 \mathrm{~nm}
\end{gathered}
$$

(onde

$$
\text { D.0. = densidade ōptica }
$$$$
\begin{aligned}
\varepsilon_{p}, \varepsilon_{a}= & \text { coeficientes de extinção molar de } P \text { e } A \\
& \text { respectivamente) }
\end{aligned}
$$

o sistema pode ser resolvido para $P$ e A. No caso do MC2P observando-se o espectro de absorção dos produtos da rea ção, temos 297 nm absorção devido somente à piridona (Kosower e Patton, 1966). Assim a concentração de $\mathrm{P}$ é determinada direta mente por

$$
[P]=\frac{D .0 .297 \mathrm{~nm}}{6000}
$$

As concentrações de $P$ ou $A$ obtidas pelas equações acima comparadas àquelas pela dosagem de DTNB (vide supra) de monstram a vāilidade das mesmas (ver resultados, item III.1).

\section{II.2.2. Procedimentos de rotina}

\section{Cinētica}

Os dados cinēticos foram obtidos em espectrofotōme tro com registrador acoplado e cela termostatizada. Invariavelmente trabalhou-se $\bar{a} 30.0^{\circ} \mathrm{C}$, tomando-se o cuidade de prëequilibrar as soluções em uso em banho de ägua à $30,0^{\circ} \mathrm{C}$.

Rotineiramente procedemos da seguinte maneira:

i) tira-se a linha base de uma cubeta de quartic de $1 \mathrm{~cm}$ de caminho ōptico e $3,3 \mathrm{ml}$ de volume total), (varredura 
de $350 \mathrm{~nm}$ a $220 \mathrm{~nm}$ ). Adiciona-se em seguida $0.025 \mathrm{ml}$ de stabs trato (RCP) e registra-se novemente o espectro.

ii) despreza-se a soluçäo acima, lava-se bem a cubeta e adiciona-se então detergente, tampão, hidrōxido, etc., depen pendendo do caso a ser estudado para um volume de 2,475 m1, (convēm notar que as cubetas de uso säo providas de tampa de teflon; em geral borbulhou-se nitrogēnio ou argōnio ümidos pa ra manter-se atmosfera inerte na cubeta).

Registra-se então a linha base e introduz-se na cube ta por meio de um bastão de tefion 0,025 $\mathrm{ml}$ de substrato (RCP) com agitação. Acompanha-se a cinëtica de reação a $260 \mathrm{~nm}$ (apa recimento de produtos) ou $230 \mathrm{~nm}$ (desaparecimento de substra to). No caso do MC2P acompanhou-se a cinētica da reação a 297 $n m$ (aparecimento da piridona). Completada a reação (pelo me nos dez meias vidas) registra-se o espectro final (absorção de produtos).

iii) mede-se o pH final (vide infra).

iv) mede-se, às vezes, a quantidade de cianeto libera da (vide supra).

\section{Medida de $\mathrm{pH}$}

Inicialmente afere-se a pHmetro por meio de soluçōes - tampão padronizadas à temperatura ambiente $(25-3)^{\circ} \mathrm{C}$. Mede-se - pH da reação. Duas notas são importantes aqui:

i) A reação ē feita em condições onde a concentração de hidröxido é muito maior que a do RCP empregado ou é constan te (tampão), isto $\bar{e}$, a reação è de pseudo primeira ordem (vide 1.3.), portanto, näo deve apresentar variação de $\mathrm{pH}$ mensurävel 
do início ao final da reação. Isto foi comprovado medindo- si por vezes o pH inicial e final.

ii) A correção de $\mathrm{pH}$ que poderia ser efetuada entre $0 \mathrm{pH}$ medido $\left(t=25^{\circ} \mathrm{C}\right)$ e o $\mathrm{pH}$ de reação $\left(t=30^{\circ} \mathrm{C}\right)$ é desnecessäria, uma vez que a sensibilidade de leitura de $\mathrm{pH}( \pm 0,05)$ maior que a possĩvel correção.

\section{I1.2.3. Mëtodos fluorimëtricos}

As medidas das constantes de distribuiçäo dos RCP en tre a fase aquosa e micelar foram realizadas pela supressão da fluorescēncia do ion Ru(bipy) ${ }_{3}^{2}$ pelos RCP. A sequēncia experi mental utilizada foi:

Partiu-se de uma solução de Ru(bipy) $2_{3}^{+}(\sim 0,4 \mathrm{mM})$ a dada concentração salina, excitou-se o emissor de fluorescèn cia Ru(bipy) ${ }_{3}^{+}$com 1 luz de $450 \mathrm{~nm}$ de comprimento de onda e fen da de $4 \mathrm{~mm}$. Os espectros de emissão (com supressão ou não) fo ram registrados na faixa de $460 \mathrm{~nm} \bar{a} 540 \mathrm{~nm}$ com fenda de $10 \mathrm{~mm}$.

A partir da emissão inicial adicionaram-se, sequenci almente, aliqquotas de RCP, obtendo-se então emissões cada vez menos intensas (tomamos a precaução de iniciar a supressão com solução estoque de RCP concentrada para evitar grandes di luições de emissor). A uma dada concentração de supressor,pre viamente estabelecida passamos a adicionar detergente (CTAB). Quando os RCP incorporam-se às micelas a supressão diminui. 
II.2.4. Cromatografia em fase gasosa Micro Hoffmann

Para analisar os detergentes amino-derivados (CTAB, Herquat, etc.) utilizou-se a reação de eliminação de Hoffmann (Figura 8 ).

Preparou-se o ōxido de prata da maneira usual, ou se ja, a uma solução de nitrato de prata (proporcional à quantida de de ōxido que deseja-se formar) adicionou-se, gota à gota, hidrōxido de sōdio $(0,1$ M) sob intensa agitação. o öxido forma do foi lavado vārias vezes com acetona (Cope e Trumbul1, 1960). Adicionou-se às soluções de detergente em anālise (preparadas na concentração de $0,1 \mathrm{M}$ e no volume de $2 \mathrm{ml}$ ) cerca de $46 \mathrm{mg}$ do oxido preparado (observe que a quantidade de $\mathrm{Ag}^{+} \bar{e}$ mais que suficiente para precipitar todo o haleto do detergente). Em se guida atravēs de filtração ou centrifugação recolheu-se um pe queno volume (na faixa de 2 a $6 \mu 1$ ) do filtrado ou do sobrenadante atravēs de microseringa (Hamilton) e injetou-se no croma tōgrafo à gās.

- A temperatura de injeção foi $250,0^{\circ} \mathrm{C}$ (excepto en a 1 guns casos onde empregou-se $180,0^{\circ} \mathrm{C}$ ).

- A coluna foi operada a $207,0^{\circ} \mathrm{C}$ sob pressão de $\mathrm{N}_{2}$ de cerca de $1,71 \mathrm{ibras} / \mathrm{cm}^{2}$. Empregou-se uma coluna de aço inoxidāvel (6" $x$ 1/8") com 10\% de UCW-9 em cromosorb (60-80 mesh) aw dmcs.

- o detetor foi previamente estabilizado à $250,0^{\circ} \mathrm{C}$.

- Empregou-se padrões como parámetro de comparaçäo (vi de infra). 
Para obtençäo dos dados cinéticos utilizamos um espectrofotômetro Beckmann modelo 25, com registrador, cela ter mostatizada e trocador de celas automātico.

Para registros dos espectros de absorçäo em U,V. além do espectrofotômetro acima utilizamos tambēm um Cary modelo 14.

Os espectros de emissão de fluorescência foram regis trados em espectrofluorimetro MPF-4 da Hitachi-Perkin.Elmer trabalhando em "ratio", com cubetas de fluorescência de quartzo (Helma) de $1 \mathrm{~cm}$ de caminho öptico.

As medidas de pH foram obtidas em um pHmetro Metrohm Herisau E 388 equipado com um eletrodo semi-micro de combina ção (Beckmann Inc.).

A cromatografia gasosa foi feitanum Research Cromato graph 5750 daHelwelltt Packard, atravēs da injeção por microseringa.

os cālculos e simulação de dados foram obtidos em calculadora programāvel de mesa da Helwelltt Packard modelo $9820 \mathrm{~A}$. 


\section{III - Resultados}

III. H. Hidrōlise alcalina dos N-alquil-4-cianopiridineos

III.1.1. Em ägua

- Efeito de pH

Conforme apresentado na Figura 6 a reação de hidrōli se alcalina dos RCP conduz a dois produtos: a piridona e a ami da correspondentes. Empregando os valores coeficiente de extinção molar do reagente (MCPC1, Tabela 2) e dos produtos de hidrólise alcalina ( $P$ e A, Tabela 3 ) no comprimento de onda de absorção mäxima descritos (MCPC1, $\lambda \max =275 \mathrm{~nm}$ e $230 \mathrm{~nm} ; \mathrm{P}$, $\lambda \max =265 \mathrm{~nm} ; A, \lambda \max =265 \mathrm{~nm}$ e $220 \mathrm{~nm}$ ) (Kosower e Patton, 1966), juntamente com o valor de concentração de piridona for mada (atravēs da medida de cianeto liberado pela reação, veja métodos) podemos reproduzir o valor da densidade óptica a 265 nm no fim da reação.

$$
\begin{gathered}
D .0_{265 \mathrm{~nm}}=\varepsilon_{\mathrm{p}, 265 \mathrm{~nm} \cdot[\mathrm{P}]+\varepsilon_{A}, 265 \mathrm{~nm}}[\mathrm{~A} \\
{[\mathrm{A}]=[\mathrm{MCPC} 1]-[\mathrm{P}]}
\end{gathered}
$$

Por outro lado, efetuando-se a hidrólise a $\mathrm{pH}$ fracamente alcalino (por volta de nove) a proporção de piridona for mada pode ser desprezada (vide infra, Tabela 4, Kosower e Pat ton, 1966). Assim sendo, nesse pH a densidade öptica a $265 \mathrm{~nm}$ serā devida basicamente à absorção da amida formada.

$$
0.0_{265 \mathrm{~nm}}=\varepsilon_{\mathrm{A}, 365 \mathrm{~nm}}[\mathrm{~A}]
$$




$$
[A]=[M C P C 1]
$$

A existência de um pico de absorção com māximo em $220 \mathrm{~nm}$ devido à amida, permite, juntamente com os anteriores formar os alicerces deste estudo. Não foi necessário isolar os produtos de reação, uma vez que estes produtos estão des critos (Kosower e Patton, 1966) e os valores apresentados de coeficiente de extinção molar, assim como o comprimento de on da dos māximos de absorção são concordantes com os valores por nós obtidos (Tabela 2 e 3 ).

A Figura 9 mostra a mudança no espectro de absorção em função do tempo, para a reação de hidrólise alcalina do MCPC1. Da Figura 9 podemos observar:

- Inicialmente o espectro de absorção do reagente (MC PC1) (espectro 1)

$$
\begin{array}{lll}
\text { D. } 0_{\max 275}=0.237 & {[\mathrm{MCPC} 1]} & =4,91 \times 10^{-5} \mathrm{M} \\
\text { D. } 0_{\max 230}=0.575 & {[M C P C 1]} & =4,78 \times 10^{-5} \mathrm{M}
\end{array}
$$

- Em seguida a diminuição da densidade öptica à 275 nm e $230 \mathrm{~nm}$ com a adição de $\mathrm{NaOH}$ e aparecimento de um pico a $265 \mathrm{~nm}$. Ao final da reação (o espectro não varia mais com o tempo (espectro 2) o comprimento de onda do mäximo de absor ção dos produtos fica definido (265 nm e $220 \mathrm{~nm})$.

D. $0_{\max 265}=0.326$

Utilizando as Equações 81 e 82 obtemos [P] $=0,66 \times$ $10^{-5} \mathrm{M}$ que implica $[\mathrm{A}]=4,34 \times 10^{-5} \mathrm{M}$

$$
\begin{aligned}
& \text { D. } 0_{\max } 220=0.355=\varepsilon_{\max A, 220} \\
& {[A]=4,38 \times 10^{-5} \mathrm{M}}
\end{aligned}
$$

Note a concordäncia entre ovalor de concentraçá d. tido para a amida através das Equações 81 e 82 e o valor cal- 
culado pela D. $0_{\max }$ a $220 \mathrm{~nm}$.

A sequéncia acima apresentada permite a aplicaçà do esquema proposto por Kosower e Patton (Figura 6), justificada' pela concordāncia entre nossos dados e dos autores acima e ain da pela reprodutibilidade de nossos valores (vide infra).

0 estudo do efeito de pH sobre a constante de veloci dade de reação de hidrölise foi realizado em condições de pseu do primeira ordem acompanhando-se a cinētica de reação, quer seja pelo desaparecimento do pico do reagente (RCP) à $230 \mathrm{~nm}$, quer pelo aparecimento de produtos $\bar{a} 260 \mathrm{~nm}$.

Devemos notar ainda que o espectro de absorção do reagente e produtos $\vec{e}$ análogo para os quatro RCP utilizados ( MCP, BCP, OCP e DCP), ocorrendo uma ligeira variação no coeficiente de extinção molar nos comprimentos de onda māximos de absorção de cada composto (vide materiais e métodos, Tabelas 2 e 3).

As Tabelas 4,5,6 e 7 compõem o efeito da mudança de pH na velocidade da reação de hidrōlise alcalina dos RCP.

Com os dados das Tabelas $4,5,6$ e 7 construimos as F guras $10,11,12$ e 13 relativas ao efeito de pH constante de ve locidade da reação de hidrōlise dos RCP MCP, BCP, OCP e DCP ' respectivamente $\left(\log k_{\psi} v s \mathrm{pH}\right)$ e as Figuras $14,15,16$ e 17 rela tivas ao efeito de $\mathrm{pH}$ constante de velocidade de segunda ordem $\left(k_{2 \psi}=k_{\psi} /\left|\mathrm{OH}^{-}\right|\right)$e na relação P/A.

As inclinações obtidas pelo mëtodo de regressão line ar simples dos pontos das Figuras 10 a 13 são:

\footnotetext{
Figura $10-$ inclinação $=1,0570$

Figura 11 - inclinação $=1,0702$

Figura 12 - inclinaçao $=1,0678$

Figura 13 - inclinação $=1,0858$
} 


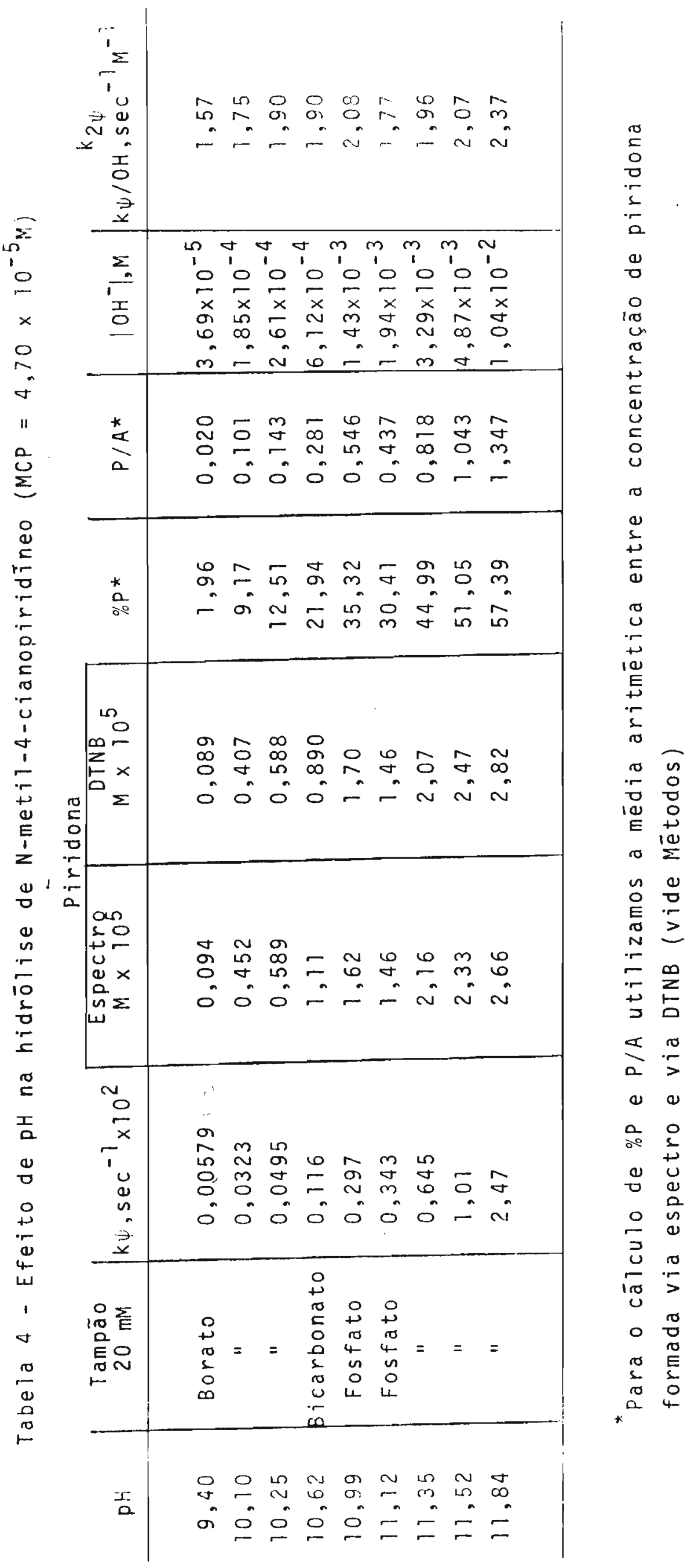




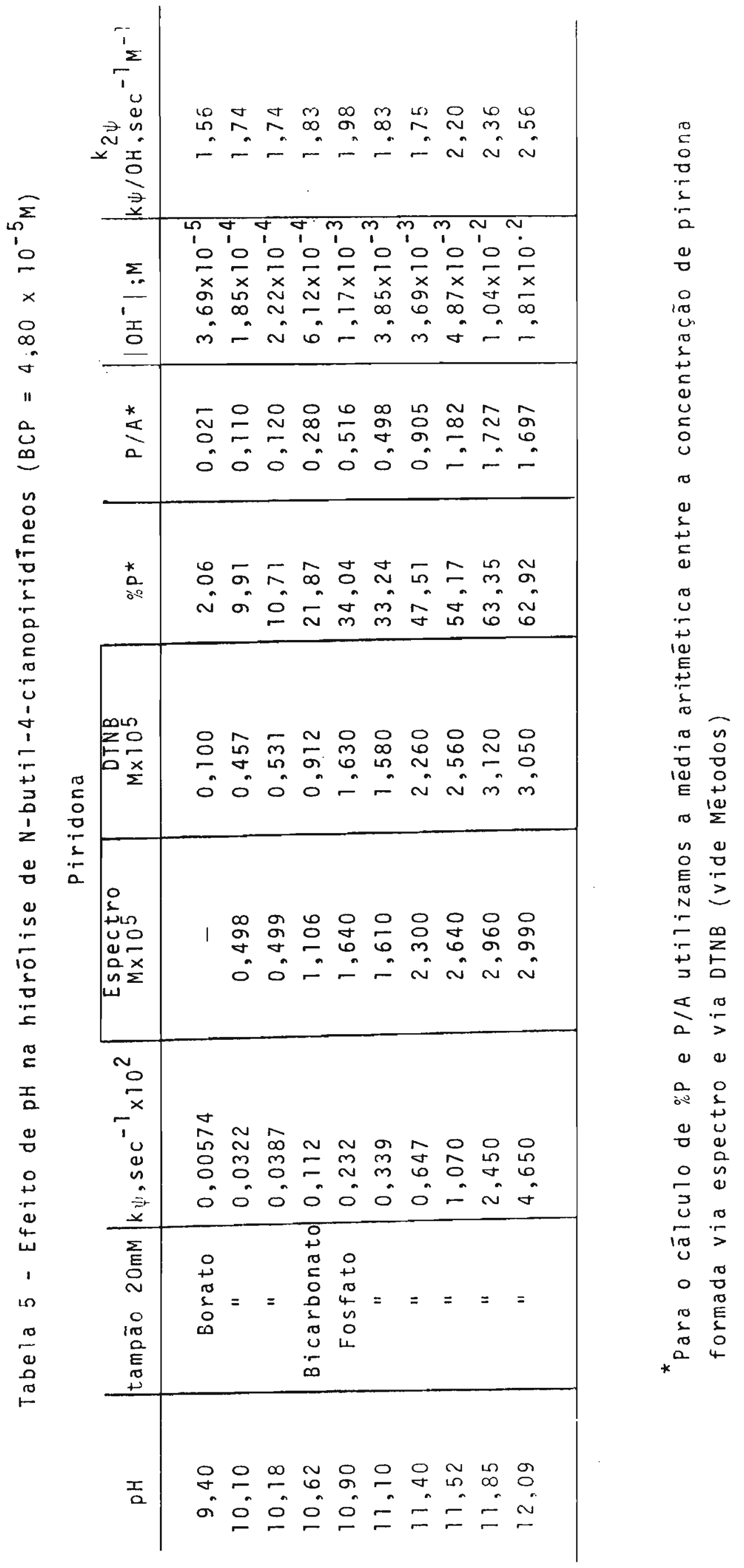




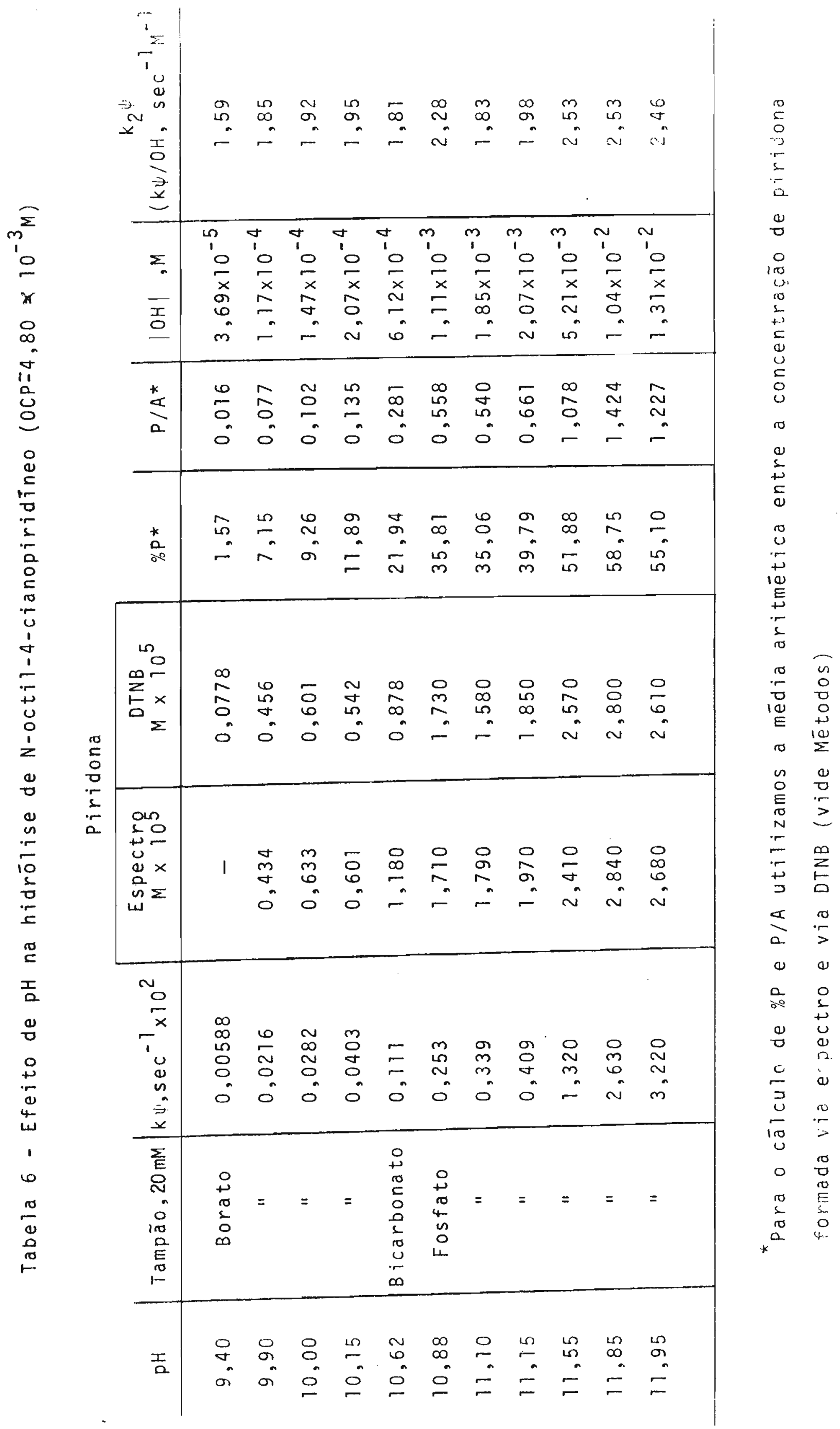




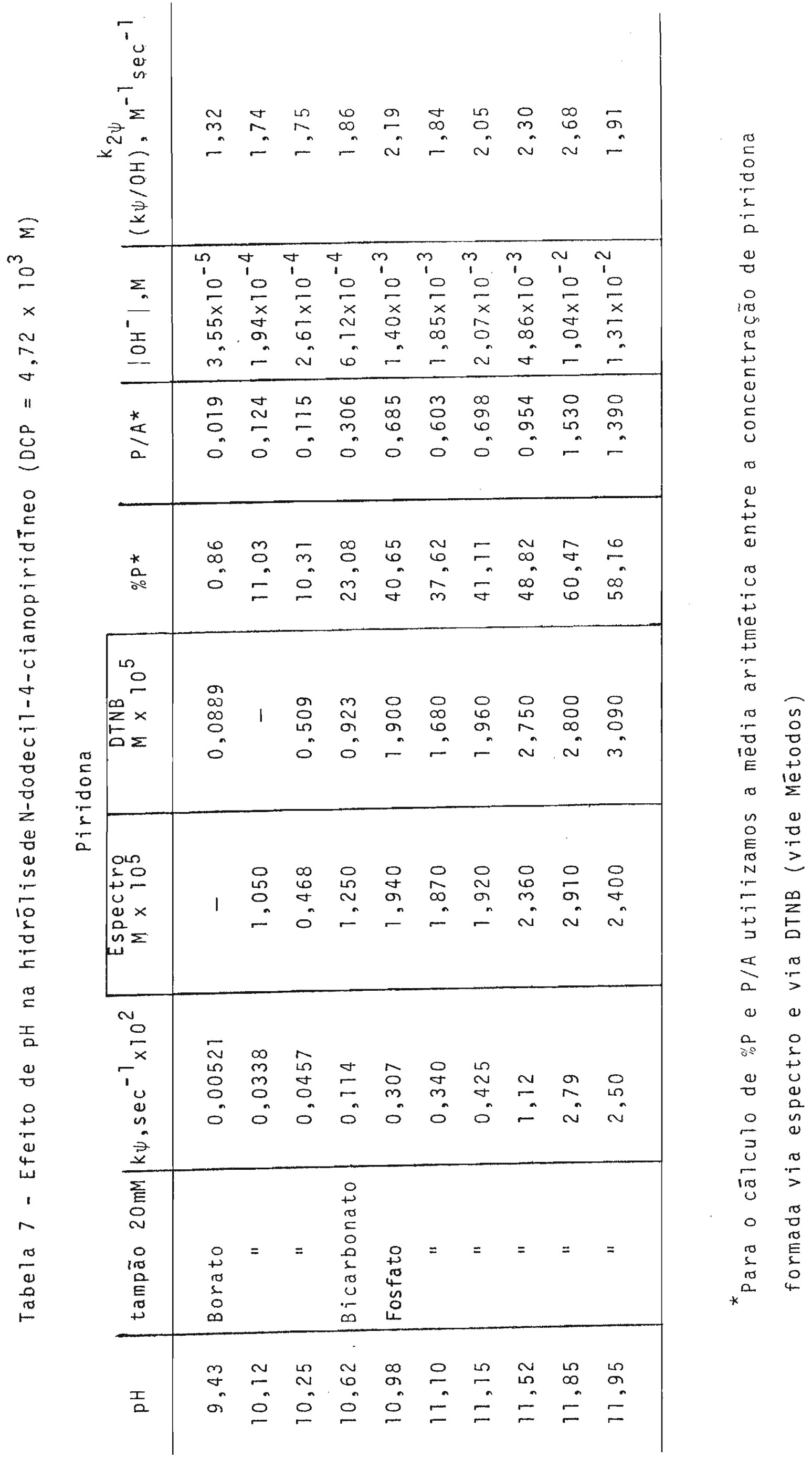




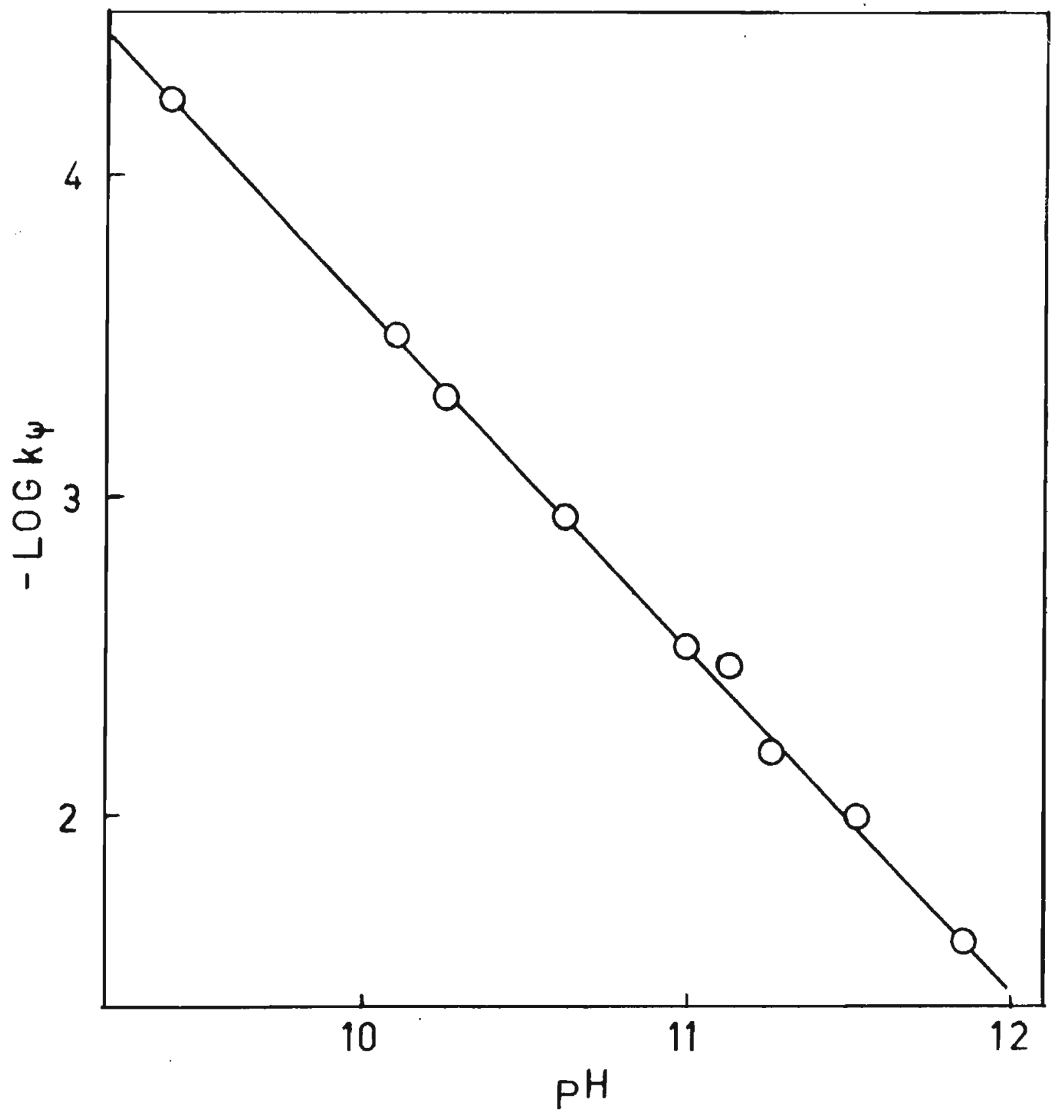

Figura 10 - Efeito de pH na constante de velocidade de hidrôlise no $\mathrm{N}$-metil-4-Cia nopiridíneo ( $M C P=4,70 \times 10^{-5} \mathrm{M}$ )

(veja condições na Tabela 4)

inclinaçäo $=1,0570$

intercepto $=14,17$ 


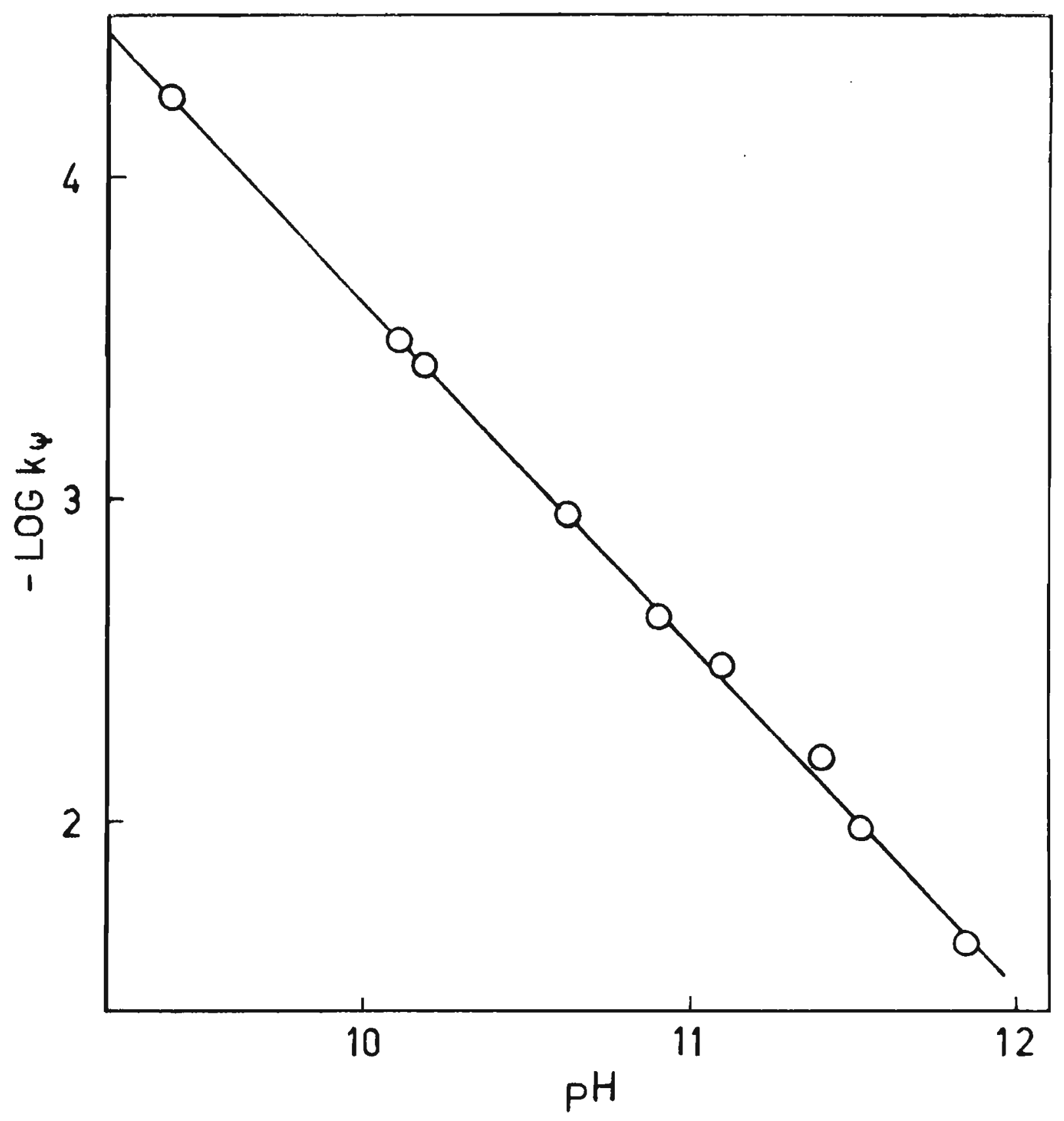

Figura 11 - Efeito de pH na constante de velocidade de hidrōlise do N-butil-4-cia nopiridineo ( $B C P-4,80 \times 10^{-5} \mathrm{M}$ )

(veja condições na Tabela 5)

inclinação $=1,0702$

intercepto $=-14,31$ 


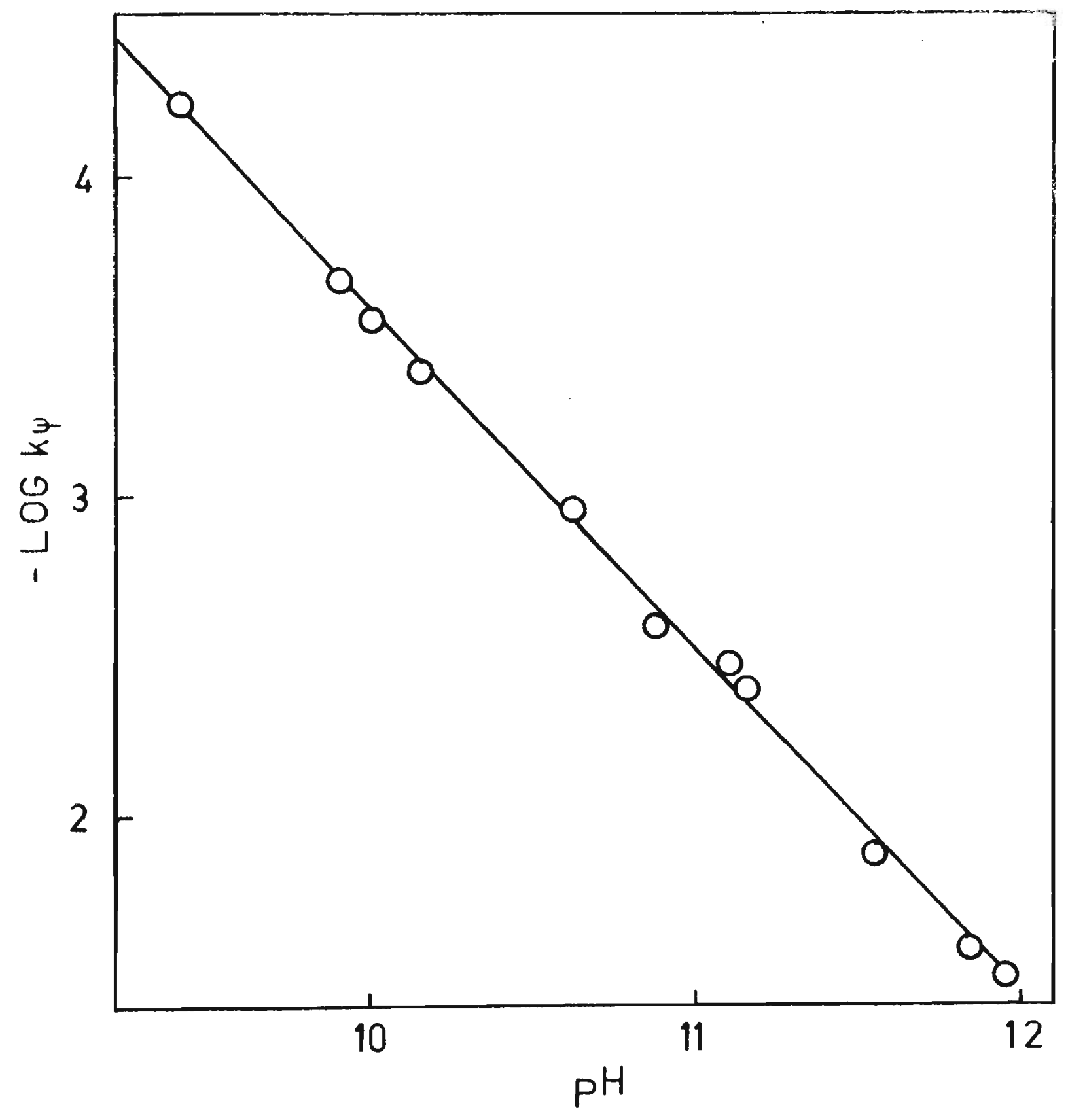

Figura 12 - Efeito de pH na constante de velocidade de hidrólise do N-octil-4-cia nopiridineo $\left(\mathrm{OCP}=4,80 \times 10^{-5} \mathrm{M}\right)$

(veja condições na Tabela 6)

inclinação $=1,0678$

intercepto $=-14,25$ 


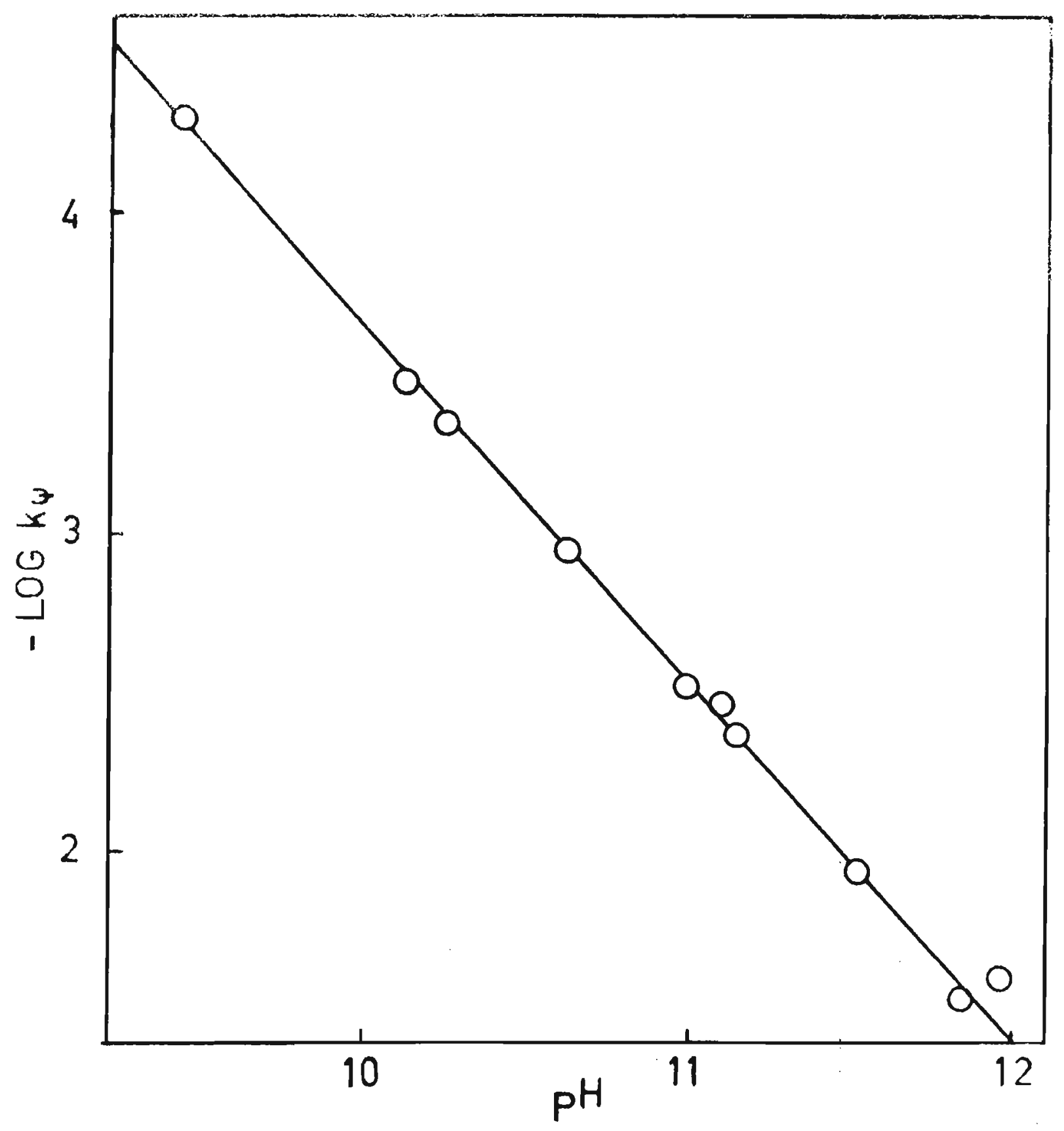

Figura 13 - Efeito de pH na constante de velocidade de hidrōlise do N-dodecil-4cianopiridineo ( $D C P=4,72 \times 10^{-5} \mathrm{M}$ ) (veja condiçōes na Tabela 7 ) inclinação $=1,0858$ intercepto $=-14,48$ 


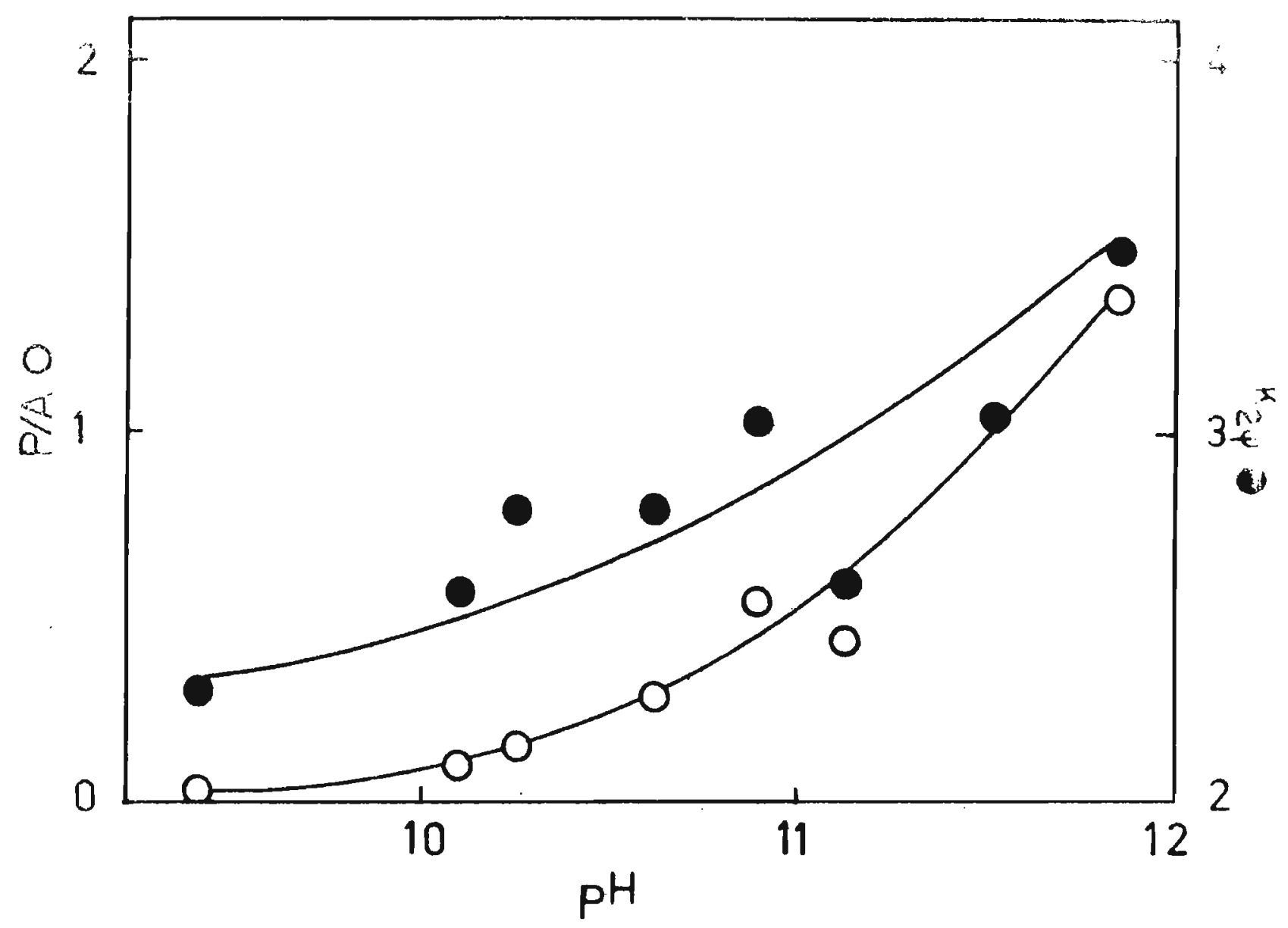

Figura 14 - Variação na relação de produtos P/A O e constante de velocidade $k_{2 \psi}$ em fun ção do pH. Hidrōlise do N-metil-4-cianopiridineo ( $M C P=4,70 \times 10^{-5} \mathrm{M}$ ) (veja condições na Tabela 4) 


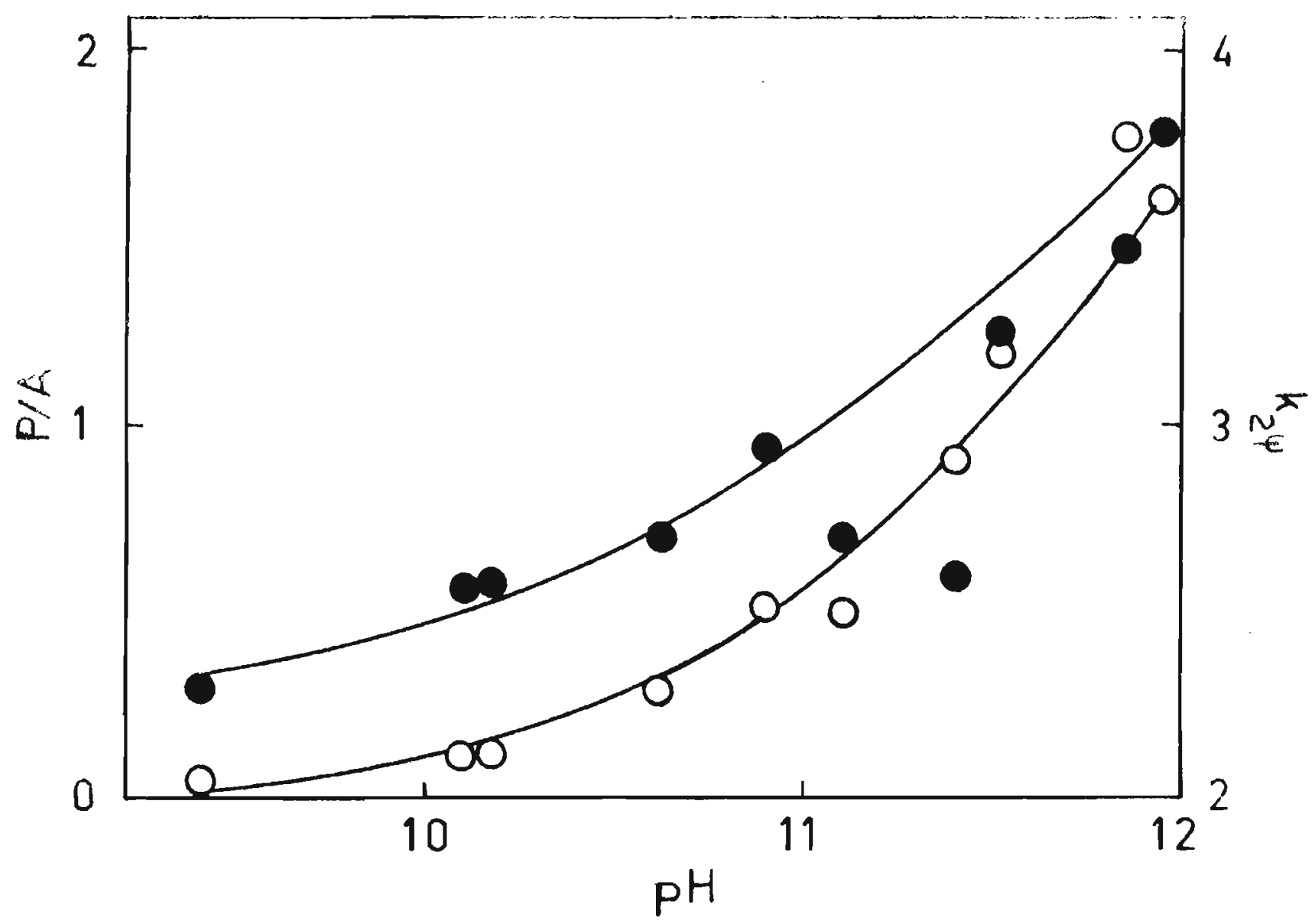

Figura 15 - Variação na relaçäo de produtos $P / A$ O e constante de segunda ordem $k_{2 \psi}$ em funçäodo $\mathrm{pH}$ para a hidrōlise do $\mathrm{N}$-butil-4-cianopiridineo $\left(B C P=4,80 \times 10^{-5} M\right)(v e j a$ condiçōes na Tabela 5$)$ 


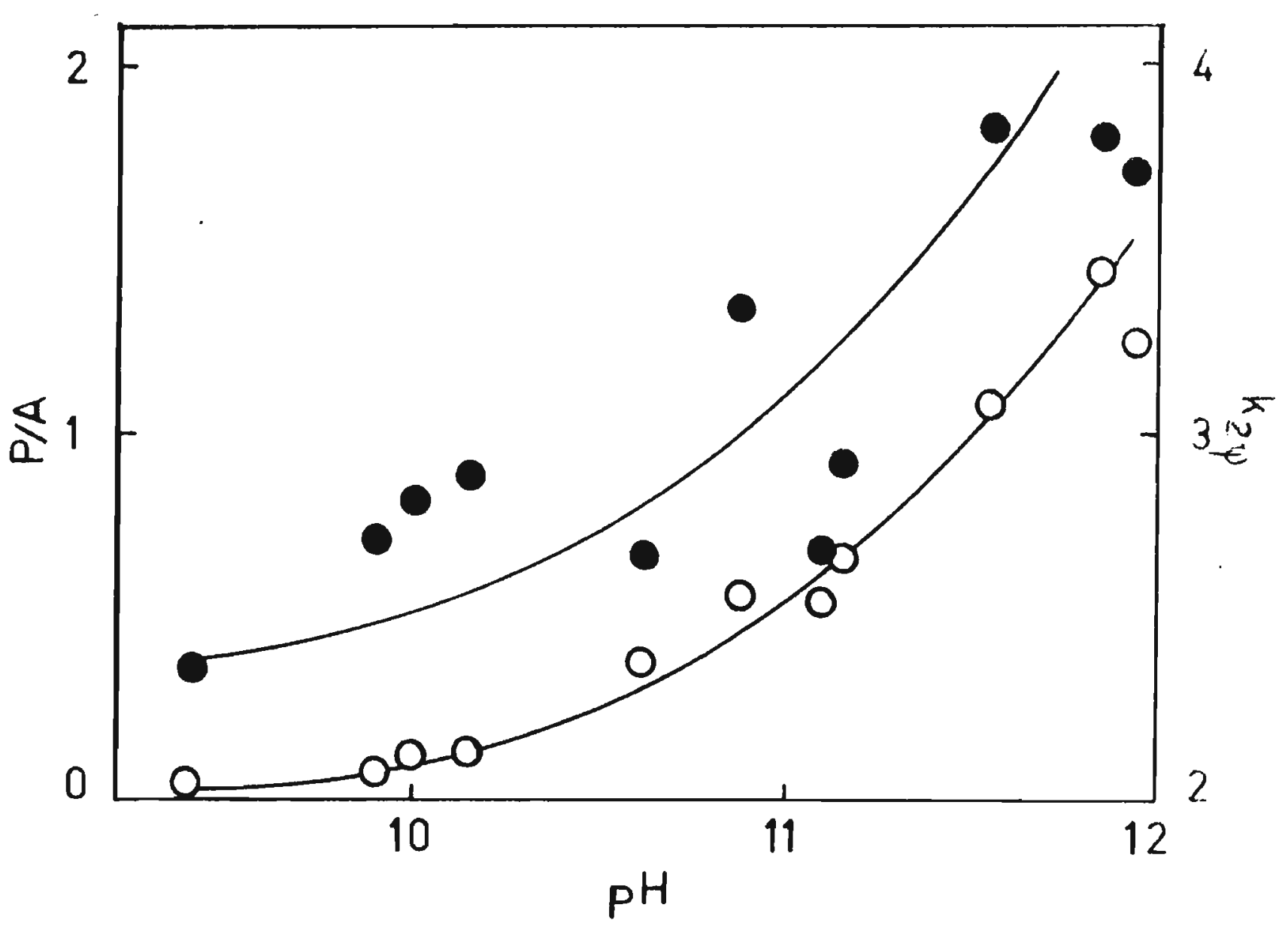

Figura 16 - Variação na relação de produtos $P / A$ Oe constante de segunda ordem $k_{2 \psi}$ em funçäo do pH para a hidrōlise do N-octil-4-cianopiridí neo $\left(D C P=4,80 \times 10^{-5} M\right)$ (veja condiçōes na Tabe 1a 6) 


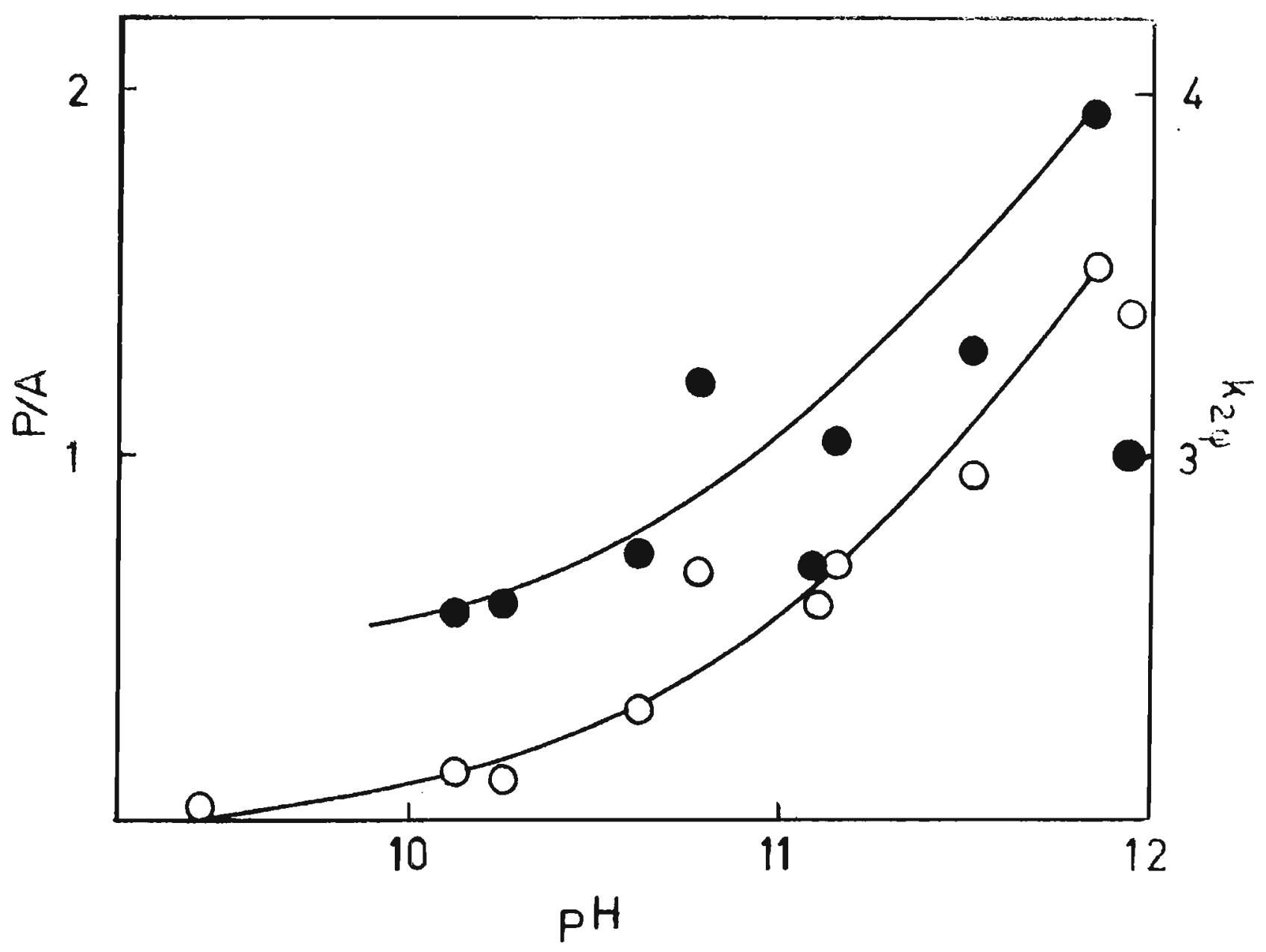

Figura 17 - Variação na relação de produtos $P / A O$ e constante de segunda ordem $k_{2 \psi}$ em funçäo do pH para a hidrölise do N-dodecil4-cianopiridineo ( $\left.D C P=4,72 \times 10^{-5} M\right)$ (veja condiçöes na Tabela 7). 
A mēdia entre as inclinaçōes acima ê 1,0702 , a qual com um desvio de $2 \%$ (calculado pela diferença.entre os valores extremos dividida pela mëdia), abrange os valores obtidos para todos os RCP.

o intercepto obtido, analogamente a inclinação, tem como valor mëdio $-14,30$.

Construimos então a equação linear que dã o valor da constante de velocidade de hidrōlise alcalina em ägua em fun ção do pH.

$$
\log k_{\psi}=1,0702 \mathrm{pH}-14,30
$$

O fator 1,0702 pode ser explicado com auxilio da ex pressäo 36, generalizada para os RCP

$$
-\frac{d(R C P)}{d t}=\left(k_{2} \frac{k_{4}+K_{3} k_{5}\left(\mathrm{OH}^{-}\right)}{k-2+k_{4}+k_{3} k_{5}\left(\mathrm{OH}^{-}\right)}+k_{1}\right)\left(\mathrm{OH}^{-}\right) R C P,
$$

Da expressäo 36 (geral) fica claro que em condições' de pseudo-primeira ordem $\left(\left|\mathrm{OH}^{-}\right|>>|R C P|\right)$, o gräfico log $k_{\psi}$ vs pH não terā a inclinação idēntica a unidade devido ao fator en tre parenthesis, na qual aparece $(\mathrm{OH})$ no numerador e denominador.

As Figuras 14 a 17 referentes a relação $P / A$ e $k_{2 \psi}$ com $\mathrm{pH}$ denotam o aspecto sigmoidal destas curvas que $\bar{e}$ comparāiel ao obtido por Kosower (Kosower e Patton, 1966). Fica aparente o comportamento anālogo entre os quatro compostos (MCP, BCP, OCP e DCP) perante a hidrōlise alcalina em àgua.

Deve-se observar ainda nas Tabelas $4,5,6$ e 7 a concordância entre as medidas de dosagem de piridona via espectro e via DTNB (veja Materiais e Mètodos).

0 limite superior da relação $P / A$ foi obtido indepen- 
dentemente de dados cinéticos (Tabela 8), uma vez que, a alta concentração de hidróxido $(|\mathrm{NaOH}|>0,1 \mathrm{M})$, o tempo de vida da reaçäo $\left(t \frac{1}{2} \leqslant 1 S\right)$ é inferior ao tempo de resposta da aparelhagem empregada (ver Aparelhos).

Tabela 8 - Limite superior da relação $P / A$

\begin{tabular}{|c|c|c|c|}
\hline Composto* & $\mathrm{pH} * *$ & $P / A$ & $\% P$ \\
\hline$M C P$ & 13,00 & 1,667 & 62,50 \\
\hline$"$ & 13,00 & 1,654 & 62,32 \\
\hline$"$ & 13,00 & 1,538 & 60,60 \\
\hline$"$ & 13,00 & 1,618 & 61,80 \\
\hline$"$ & 13,00 & 1,611 & 61,70 \\
\hline$B C P$ & 13,00 & 1,606 & 61,63 \\
\hline$O C P$ & 13,00 & 1,609 & 61,67 \\
\hline$M C P$ & 13,13 & 1,732 & 63,40 \\
\hline$"$ & 13,30 & 1,856 & 64,98 \\
\hline$"$ & 13,30 & 1,801 & 64,30 \\
\hline$"$ & 13,35 & 1,677 & 62,64 \\
\hline$"$ & 13,35 & 1,700 & 63,96 \\
\hline$"$ & 13,43 & 1,470 & 59,51 \\
\hline$"$ & 13,43 & 1,800 & 64,28 \\
\hline$"$ & 13,60 & 1,732 & 63,40 \\
\hline$"$ & 13,60 & 1,790 & 64,15 \\
\hline$"$ & 13,60 & 1,520 & 60,32 \\
\hline$" 1$ & 13,73 & 1,800 & 64,28 \\
\hline$"$ & 13,73 & 1,750 & 63,64 \\
\hline " & 13,83 & 1,740 & 63,50 \\
\hline$"$ & 13,83 & 1,700 & 62,96 \\
\hline
\end{tabular}

* RCP $\sim 5 \times 10^{-5} \mathrm{M}$

* 0 pH da solução foi obtido pela adição de $\mathrm{NaOH}$

Devido ao comportamento idéntico (praticamente) dos RCP frente a reaçäo de hidrölise alcalinia em água, podemos ge 
neralizar a variação da relaçăo P/A (como foi feito com k!", vide supra) em função do pit (Tabela 9 e Figura 18).

Tabela 9 - Hidrōlise alcalina em ägua dos ĩons RCP. Valores médios de $P / A(P / A m)$ e \%P(\%Pm) em funçäo do $\mathrm{pH}$ londe o indice $m$ refere- se a media aritmetica dos valores).

\begin{tabular}{c|c|r}
$\mathrm{pH}$ & $\mathrm{P} / \mathrm{Am}$ & $\% \mathrm{Pm}$ \\
\hline 9,40 & 0,020 & 1,96 \\
10,00 & 0,097 & 8,84 \\
10,40 & 0,185 & 15,61 \\
10,80 & 0,395 & 28,31 \\
11,20 & 0,745 & 42,69 \\
11,40 & 0,940 & 48,45 \\
11,60 & 1,140 & 53,27 \\
11,80 & 1,335 & 57,17 \\
12,00 & 1,465 & 59,43 \\
12,50 & 1,625 & 61,90 \\
12,80 & 1,680 & 62,69 \\
13,10 & 1,750 & 63,64 \\
13,40 & 1,750 & 63,64 \\
13,60 & 1,750 & 63,64 \\
13,80 & 1,750 & 63,64
\end{tabular}

- Efeito de força iōnica $(\mu)$

Para a anālise numérica dos dados referentes à reação de hidrōlise alcalina dos RCP em āgua discriminamos o efei to de variação de força iônica $(\mu)$ do meio. Aplicando-se o mo delo de Brönsted-Bjerrum (equaçöes 47 e 67 ) obtemos o valor da constante de velocidade extrapolado à diluição infinita, isto é, zero de força ionnica. Pode-se observar que a relação $P / A$ é independente de força iōnica (Tabela 10), e purtanto as equa - 


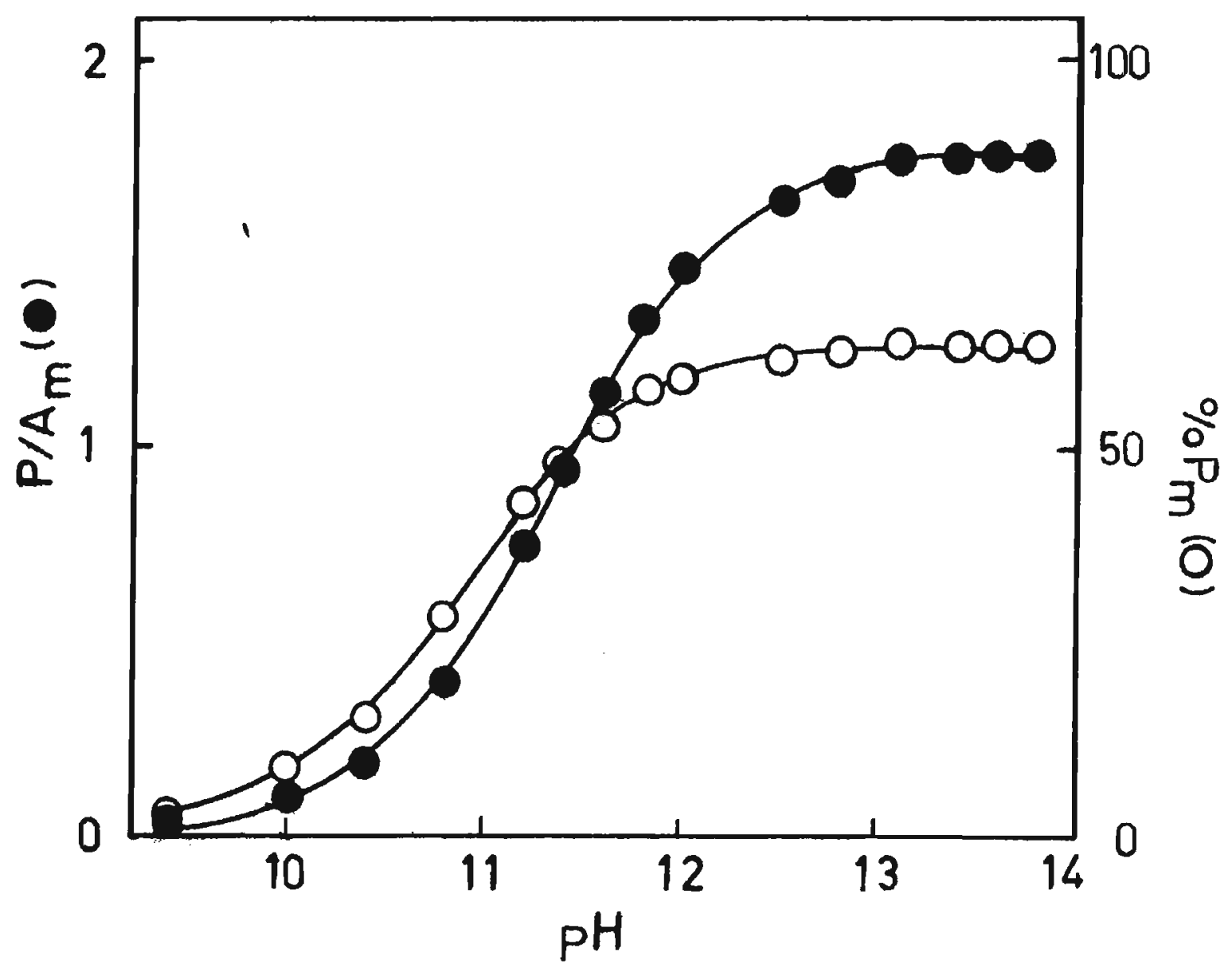

Figura 18 - Relação $\mathrm{P} / \mathrm{Am}$ e \%.Pm em funçāo de $\mathrm{pH}$ para a rea ção de hidrólise alcalina dos ions RCP (MCP, BCP, OCP e DCP) 
çōes (48 a 51) são aplicāveis.

Para simular o efeito de força iônica empregamos bro meto de tetrametilamônio (BTMA). Utilizou-se este sal devido a semelhança com a parte polar de CTAB (vide infra).

Na Tabela 10 apresentamos o resultado deste estudo.

Tabela 10 - Efeito de força iōnica sobre a constante de velocidade e relação de produtos da hi drólise do MCP (|MCP|= $5 \times 10^{-5 M}$ ) sal uti1 izando brometo de tetrametilamónio (BTMA)

\begin{tabular}{c|c|c|c}
$\mathrm{pH}^{*}$ & $|\mathrm{BTMA}| \mathrm{M} \times 10^{3}$ & $\mathrm{k} \psi, \mathrm{sec}^{-1} \times 10^{2}$ & $\mathrm{P} / \mathrm{A}$ \\
\hline 12,30 & - & 7,90 & 1,53 \\
11 & 1 & 7,63 & 1,45 \\
12,25 & 2 & 7,58 & 1,45 \\
12,30 & 4 & 7,57 & 1,47 \\
12,25 & 6 & 8,23 & 1,52 \\
12,30 & 8 & 7,00 & 1,37 \\
12,25 & 10 & 6,40 & 1,48 \\
12,30 & 10 & 7,27 & 1,42 \\
11 & 20 & 6,92 & 1,39 \\
$1 "$ & 40 & 6,74 & 1,38 \\
$" 1$ & 60 & 6,59 & 1,45 \\
10,85 & 80 & 6,19 & 0,42 \\
11 & - & 0,243 & 0,39 \\
$"$ & 1 & 0,227 & 0,37 \\
$" 1$ & 2 & 0,191 & 0,43 \\
10,90 & 4 & 0,183 & 0,40 \\
10,85 & 6 & 0,185 & 0,39 \\
10,90 & 8 & 0,166 & 0,39 \\
10,80 & 10 & 0,186 & 0,17 \\
10,85 & 20 & 0,196 & 0,42 \\
10,80 & 30 & 0,177 & 0,39 \\
10,88 & 40 & 0,167 & 0,38 \\
& 50 & 0,177 & \\
\hline
\end{tabular}

*pH obtido pela adição de $\mathrm{NaOH}$

Deve-se notar na Tabela 10 a constāncia da relaçăo' $P / A$ enquanto $k \psi$ descreve:

Aplicando-se a equação 51 , na sua forma dependente' de força iônica isto $\bar{e}$, 


$$
k_{1}=\frac{k_{2 \psi}}{P / A+1}
$$

Podemos calcular segundo os valores de P/Am (Tabela 9) e de $k_{2} \psi$ (Tabela 4,5,6 e 7) o valor de k e pelo efeito de força iônica (equação 47,67, Tabela 10) o valor de $k_{7}^{0}$, confor me apresentado a Tabela 11.

Tabela 11 - Valores de $k_{1}$ (em função de $\mathrm{pH}$ ) e de $k_{1}^{0}$

\begin{tabular}{c|c|c|c|c|c}
$\mathrm{pH}$ & $\mathrm{P} / \mathrm{Am}$ & $\mathrm{k} \psi, \mathrm{sec}^{-1} \times 10^{5}$ & $\mu \times 10^{2}(\mathrm{mM})$ & $\mathrm{k}_{1}$ & $\mathrm{k}_{1}^{0}$ \\
\hline 9,41 & 0,020 & 5,6 & 1,24 & 1,48 & 1,85 \\
10,11 & 0,095 & 32,8 & 1,79 & 1,57 & 2,04 \\
10,16 & 0,120 & 39,5 & 1,82 & 1,65 & 2,14 \\
10,25 & 0,140 & 47,6 & 1,86 & 1,61 & 2,10 \\
10,62 & 0,282 & 113,2 & 3,16 & 1,44 & 2,01 \\
10,89 & 0,465 & 242,5 & 6,23 & 1,45 & 2,22 \\
11,10 & 0,632 & 340,2 & 6,37 & 1,10 & 1,68 \\
11,37 & 0,913 & 646,0 & 6,69 & 0,97 & 1,50 \\
11,53 & 1,076 & 1130,0 & 6,98 & 1,09 & 1,70 \\
11,85 & 1,377 & 2585,0 & 8,03 & 1,03 & 1,65 \\
11,95 & 1,430 & 2860,0 & 8,41 & 0,88 & 1,47 \\
12,09 & 1,500 & 4650,0 & 9,28 & 1,00 & 1,63 \\
& & & & & \\
\hline
\end{tabular}

Tomando-se a mëdia dos valores de $k_{j}^{0}$, obtem-se

$$
k_{1}^{0}=1,83 \pm 0,27 \mathrm{sec}^{-1} \cdot \mathrm{M}^{-1}
$$

A relação $\mathrm{P} / \mathrm{A}$ acima de $\mathrm{pH} 12,8$ ē constante (Tabela 8) e alcança um valor limite de 1.75 (Tabela 9 e Figura 13).

No limite de $p / A=1,75$, aplicando-se a equação 42 , chega-se a um valor de $\delta$ igual a um. Aplicando-se a equação 50 , podemos calcular $k_{2}^{0}$ :

$$
k_{2}^{0}=(P / A)_{m} \cdot k_{1}^{0}(P / A \text { no limite superior) e portan- }
$$

to 


$$
k_{2}^{0}=3,20 \pm 0,27 \sec ^{-1} \cdot \mathrm{M}^{-1}
$$

Aplicando-se a equação 50 em toda extensão da Figura 18, obtemos $\delta$ e $\delta / 1-\delta($ Tabela 12).

Tabela 12 - Valores de e $\delta / 1-\delta$ em funçäo da concencra ção de $\mathrm{OH} \delta / 1-\delta$

\begin{tabular}{|c|c|c|c|c|c|}
\hline $\mathrm{pH}$ & ${ }^{\circ} \mathrm{OH}$, & , $M$ & $P / A_{m}$ & $\delta$ & $\frac{\delta}{1-\delta}$ \\
\hline $\begin{array}{r}9,41 \\
10,11 \\
10,16 \\
10,25 \\
10,62 \\
10,89 \\
11,10 \\
11,37 \\
11,53 \\
11,85 \\
11,95 \\
12,09\end{array}$ & $\begin{array}{ll}3,75 & \times \\
1,88 & x \\
2,12 & x \\
2,61 & x \\
6,12 & x \\
1,14 & x \\
1,87 & x \\
3,48 & x \\
4,94 & x \\
1,04 & x \\
1,31 & x \\
1,81 & x\end{array}$ & $\begin{array}{ll}\times & 10^{-5} \\
\times & 10-4 \\
\times & 10-4 \\
\times & 10-4 \\
x & 10-4 \\
x & 10-3 \\
x & 10-3 \\
x & 10-3 \\
x & 10-3 \\
x & 10-2 \\
x & 10-2 \\
x & 10-2\end{array}$ & $\begin{array}{l}0,020 \\
0,095 \\
0,120 \\
0,140 \\
0,282 \\
0,465 \\
0,632 \\
0,913 \\
1,076 \\
1,377 \\
1,430 \\
1,500\end{array}$ & $\begin{array}{l}0,0114 \\
0,0543 \\
0,686 \\
0,0800 \\
0,161 \\
0,266 \\
0,361 \\
0,522 \\
0,615 \\
0,788 \\
0,818 \\
0,858\end{array}$ & $\begin{array}{l}0,0115 \\
0,0574 \\
0,0736 \\
0,0870 \\
0,192 \\
0,362 \\
0,565 \\
1,09 \\
1,60 \\
3,72 \\
4,49 \\
6,04\end{array}$ \\
\hline
\end{tabular}

0 grāfico de $\delta / 1-\delta$ em função da concentração de hi drōxido (Figura 19), tem como intercepto arelação $k_{4} / k-2$ (equa ção 52) e inclinação $k_{5} k_{3} / k_{-2}$.

Aplicando-se uma regressão linear simples aos pon tos da Tabela 12, obtem-se para o intercepto e a inclinaçäo' os valores:

$$
\begin{array}{l|l}
\text { intercepto }=-0,018 & 0.352 \\
\text { inclinação }=340,81 & 313.67
\end{array}
$$

os quais pela equação 52 , correspondem a:

$$
\text { intercepto } \frac{k_{4}}{k_{-2}}=\text { zero }
$$

is to $\vec{e} k_{4}<k-2$ 


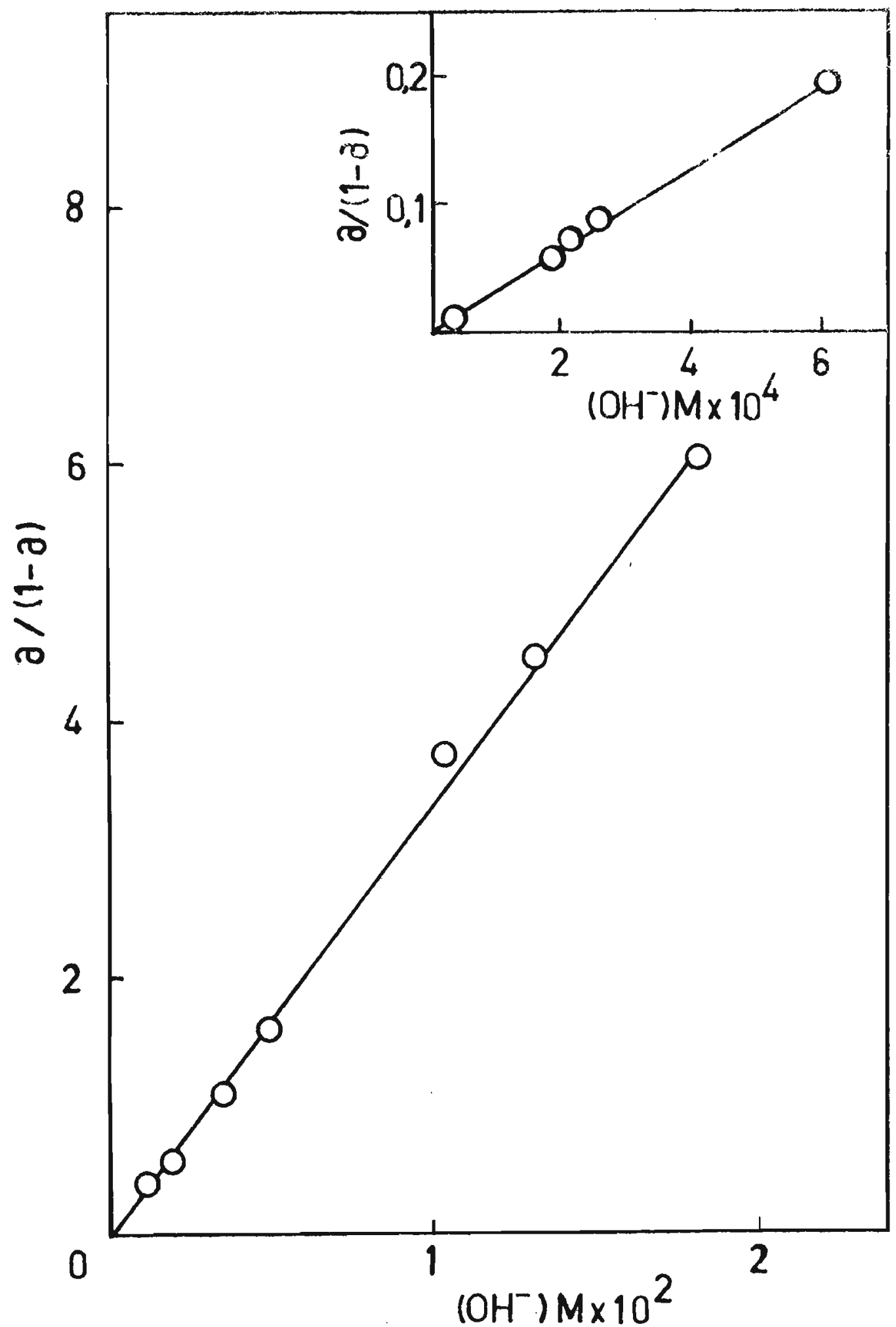

Figura $19-\delta / 1-\delta$ em função de $\left|\mathrm{OH}^{-}\right|$(equação 52)

inclinação $=340,81$

intercepto $=-0,018$ 


$$
\text { inc] inação } \rightarrow \frac{k_{5} k_{3}}{k_{-2}}=340,8
$$

- Efeito de constante dielétrica (D)

Utilizamos, para variar a constante dieletrica do meio, misturas dioxana ägua nas proporções abajxo indicadas.

Tabela 13 - Porcentagem de dioxana e constante dielétrica (D) (Temperatura $=30,0^{\circ} \mathrm{C}$ )

\begin{tabular}{c|c|c}
$\begin{array}{c}\% \text { volume } \\
1-4 \text { dioxana }\end{array}$ & $\begin{array}{c}\% \text { peso } \\
1-4\end{array}$ & $D^{a}$ \\
\hline 0 & 0 & 76,72 \\
10 & 10,22 & 67,79 \\
30 & 30,49 & 50,11 \\
50 & 50,60 & $32,81^{\mathrm{b}}$
\end{tabular}

a. As constantes foram calculadas pela equação $\log D=$ $\log a-b t$ (Akérlof e Short, 1936)

b. Valor obtido de Robinson e Stokes (1955, apêndice A.1)

Nas Figuras 20,21 e 22 mostramos os resultados relativos ao efeito de $D$ sobre a constante de velocidade observa da. As linhas são calculadas utilizando as equações 67,72 e 73 e os pontos são experimentais.

Pode-se notar que o modelo teōrico (equaçōes 67,72 . 73) ê prōximo dos pontos experimentais. Devemos acrescentar que a relação P/A (Figura 23) acompanha o observado para $k \psi$. 


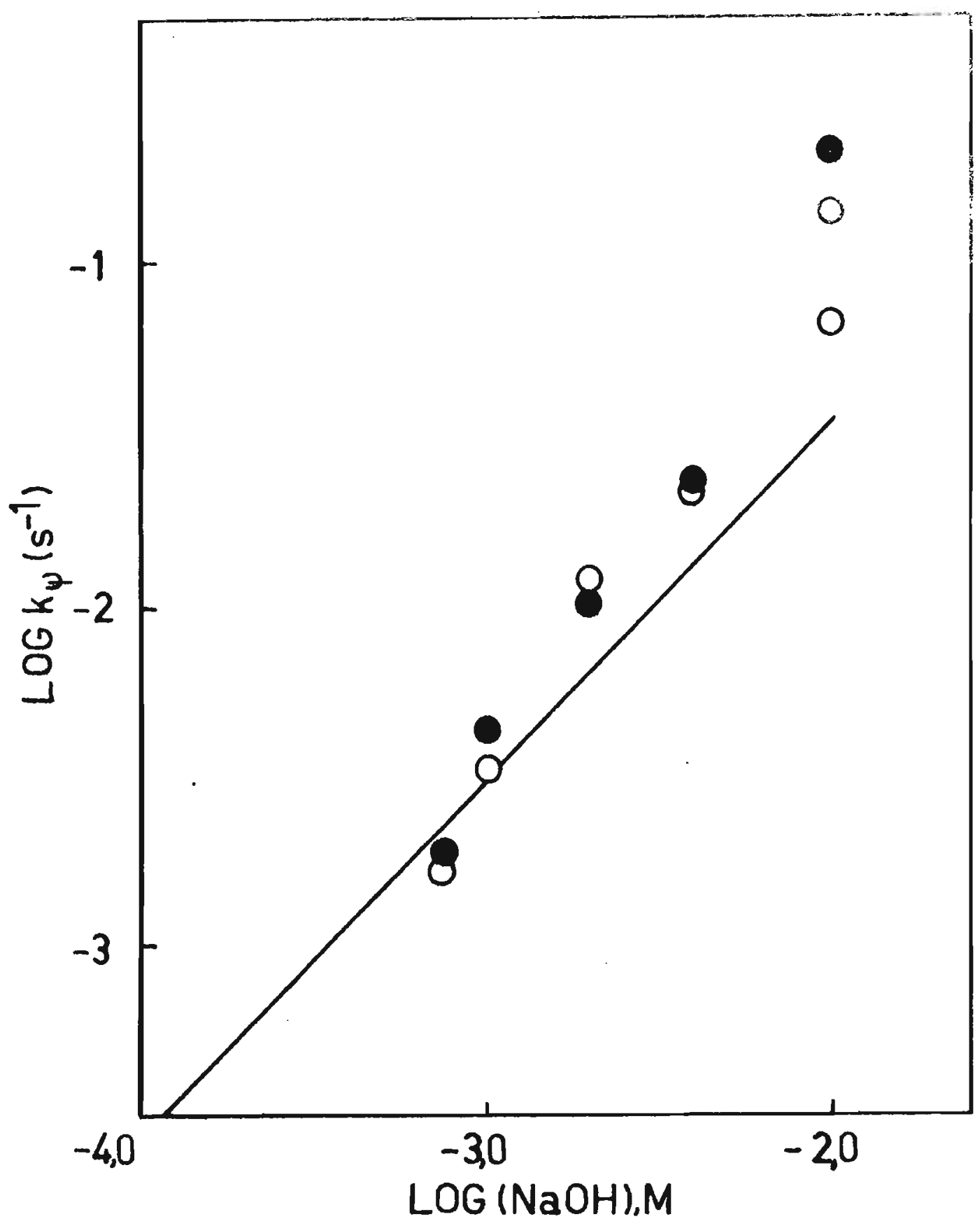

Figura 20 - Constante de velocidade da reação de hidrôlise alcalina de RCP (Figura 6) em funçâo de $\log \mathrm{OH}^{-}$para $10 \% \mathrm{~V} / \mathrm{V}$ de dioxana. - N-metil-4-cianopiridineo ( $M C P=5,17 \times 10^{-5} \mathrm{M}$ ) O -N-dodecil-4-cianopiridineo (DCP $=5,45 \times 10^{-5} \mathrm{M}$ ) 


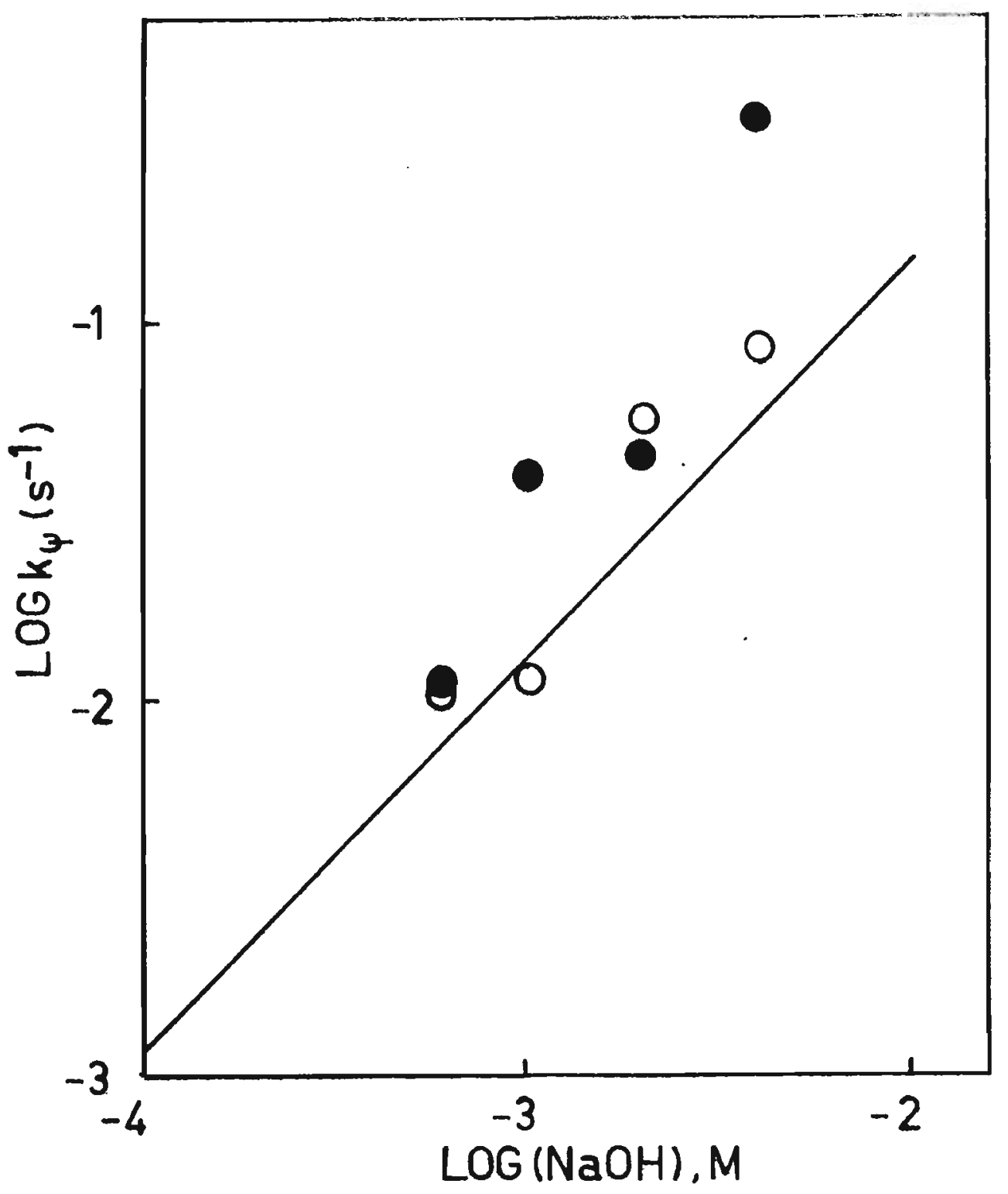

Figura 21 - Constante de velocidade da reação de hi drôlise (Figura 5) em função de $\log \mathrm{OH}^{-} \mid$pa $30 \%$ de dioxana. N-metil-4-cianopiridineo

- $N$-metil-4-cianopiridineo ( $M C P=5,17 \times 10^{-5} M$ )

O-N-dodecil-4-cianopiridineo ( $D C P=5,45 \times 10^{-5} \mathrm{M}$ ) 


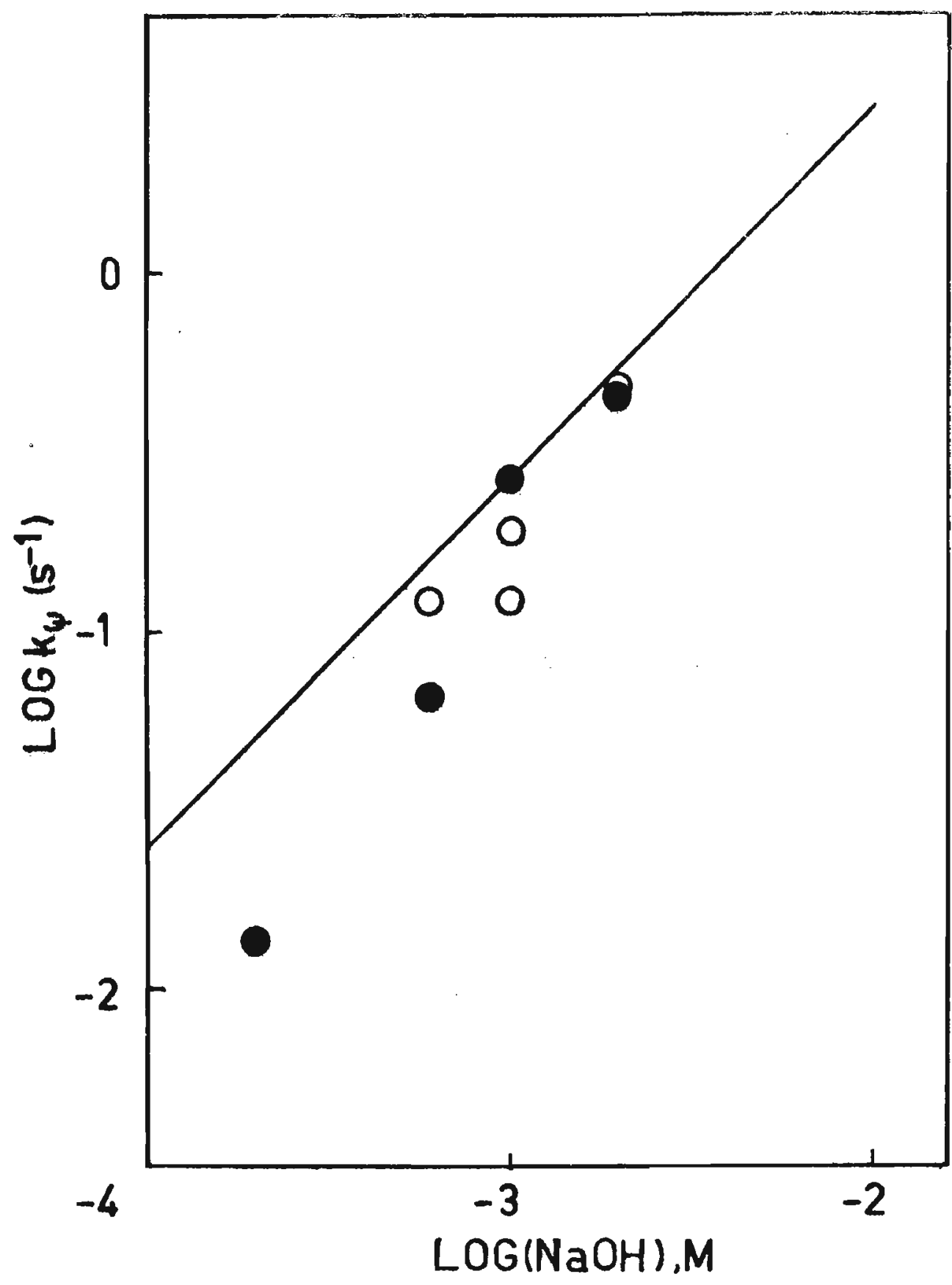

Figura 22 - Constante de velocidade da reação de hidrōise (Figura 6) em função de $\log \mathrm{OH}^{-}$para 3 (3) $v / v$ de dioxana.
-N-metil-4-cianopiridineo ( $M C P=5,17 \times 10^{-5} M$ )
O-N-dodecil-4-cianopiridineo ( $D C P \approx 5,45 \times 10^{-5} \mathrm{M}$ ) 


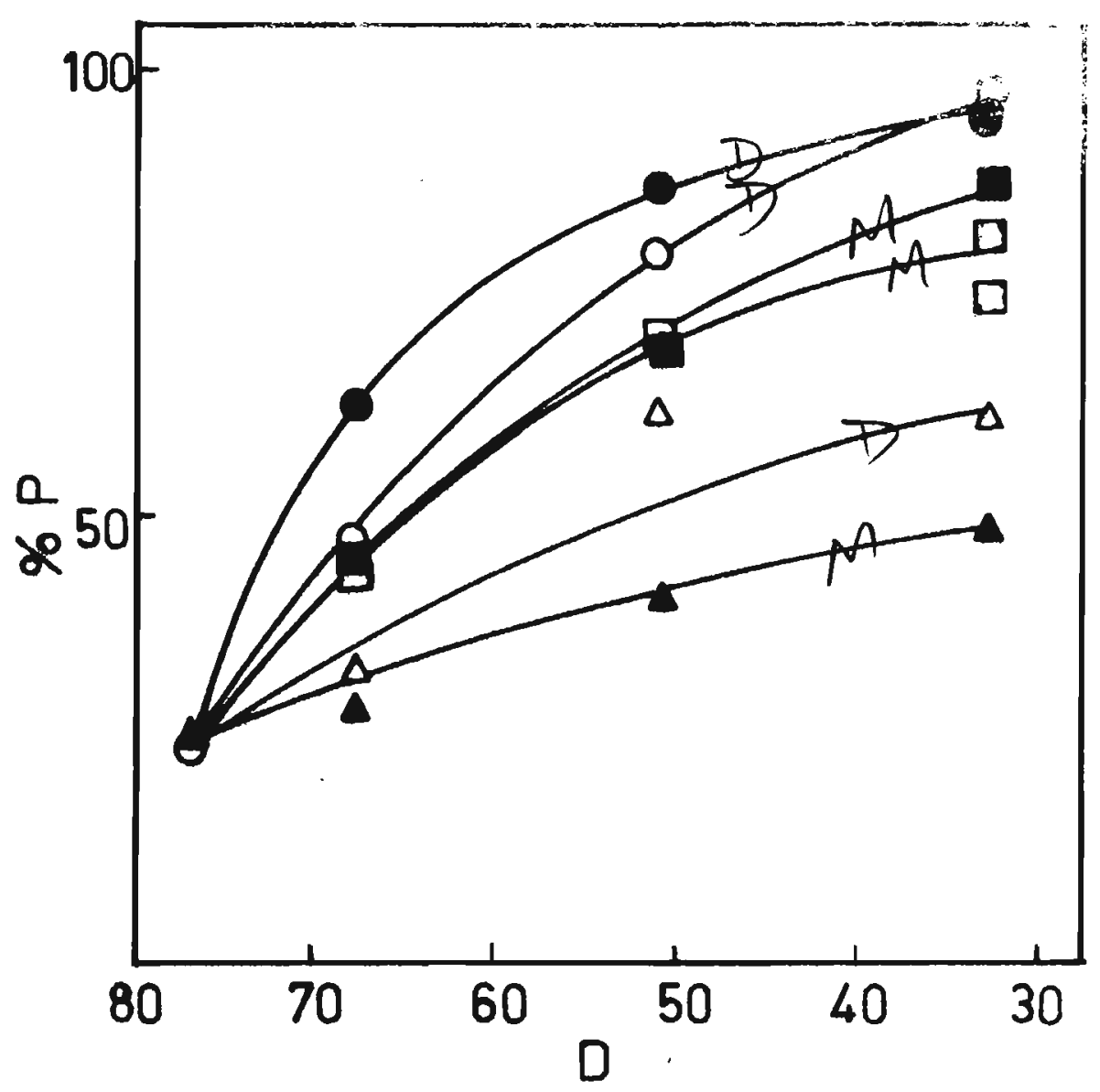

Figura 23 - \% de piridona em função de D para: N-metil-4-cianopiridfneo ( $M C P=5,17 \times 10^{-5} \mathrm{M}$ ) NaOH $(0,1 \mathrm{M}) \square 50 \mathrm{U}$;

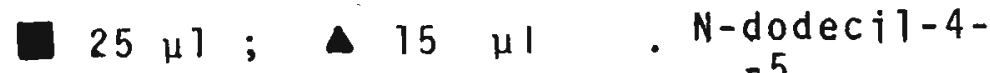
clanopiridineo ( $\left.D C P=5,45 \times 10^{-5} \mathrm{M}\right) \mathrm{NaOH}$ $(0,1 M) \bigcirc 50 \mu 1 ; 025 \mu 1 ; \Delta 15 \mu 1$ 
IIl.1.2. Em micelas:

- Brometo de hexadeciitrimetilamônio (CTAB)

Constantes de incorporação dos RCP a micelas deCTAB

As constantes de incorporação (Keq/N) dos RCP (equa ção 77,78 ) entre a fase aquosa e micelar foi obtida por supres são da emissão de fluorescencia do ion Ru(bipy) ${ }_{3}^{2^{+}}$(vide Materiais e Métodos) pelos RCP.

Inicialmente listamos os resultados relativos à supressão de fluorescência por DCP. Primeiramente aparecem os valores de rendimento quāntico $\left(\phi^{\circ}\right.$ em/ $\phi$ em onde $\phi^{\circ} \mathrm{em} \bar{e}$ o ren dimento quāntico de fluorescéncia devido ao emissor e $\phi$ em $\bar{e}$ o rendimento quāntico na presença de certa quantidade de supressor) na ausência de detergente a vārias concentraçōes de sal (Tabela 14 , veja equação 74 ).

Aparecem em seguida os valores de $\left(\phi^{\circ} \mathrm{em} / 6 \mathrm{em}\right)$ na pre sença de concentrações crescentes de detergente (Tabela 15, ve ja equação 75) e, finalmente, os valores de $\gamma(v e j a$ equação 80 ) da qual obtemos o valor de Keq/N (Tabela 16) da inclinação.

Utilizando os dados das Tabelas 14,15 e 16 construimos os gräficos de $\gamma$ vs CT (vide equação 74,75 e 80 ) (figuras 24 a 30). Vale notar que o fator CD presente na equação 80 ē passivel de simplificação, conforme se demonstra a seguir:

$$
C D=C T-C M C
$$

para concentrações salinas entre $10 \mathrm{mM}<\mathrm{sa} 1<100 \mathrm{mM}$ as CMCs correspondentes ficam na faixa $0,23 \mathrm{mM}>C M C>0,057 \mathrm{mM}$ (Funasa- 
Tabela 14 - Vaiores de $\left(\phi^{0} \text { em/ } \phi \text { em) } 0 \text { para supressão da fluorescēncia de Ru(bipy }\right)_{3}^{2^{+}}\left(0,4 \times 10^{-5} \mathrm{M}\right)$ por $\mathrm{C}_{12} \mathrm{CP}$ em $\mathrm{H}_{2} \mathrm{O}\left(30^{\circ} \mathrm{C}\right)$ na presença de vārias concentrações de $\mathrm{KBr}$.

\begin{tabular}{c|cccccccc}
\multicolumn{1}{c}{$\left(\phi^{\circ} \mathrm{em} / \phi \mathrm{em}\right)_{0}$} \\
\cline { 2 - 11 }$\left|\mathrm{C}_{12} \mathrm{CP}\right|, \mathrm{Mx} 10^{4}$ & $10 \mathrm{mM} \mathrm{KBr}$ & $20 \mathrm{mM} \mathrm{KBr}$ & $30 \mathrm{mM} \mathrm{KBr}$ & $40 \mathrm{mM} \mathrm{KBr}$ & $60 \mathrm{mM} \mathrm{KBr}$ & $80 \mathrm{mM} \mathrm{KBr}$ & $100 \mathrm{mM} \mathrm{KBr}$ \\
\hline 0 & 1 & 1 & 1 & 1 & 1 & 1 & 1 \\
1,10 & 1,084 & 1,062 & 1,069 & 1,092 & 1,156 & 1,067 & 1,125 \\
2,17 & 1,132 & 1,126 & 1,128 & 1,203 & 1,182 & 1,130 & 1,203 \\
3,22 & 1,251 & 1,184 & 1,204 & 1,252 & 1,260 & 1,205 & 1,283 \\
4,26 & 1,238 & 1,227 & 1,258 & 1,323 & 1,313 & 1,268 & 1,347 \\
6,25 & 1,346 & 1,335 & 1,377 & 1,409 & 1,485 & 1,397 & 1,407 \\
8,16 & 1,456 & 1,462 & 1,507 & 1,628 & 1,546 & 1,526 & 1,531 \\
10,00 & 1,555 & 1,558 & 1,581 & 1,653 & 1,720 & 1,625 & 1,653
\end{tabular}


Tabela 15 - Valores de $\left(\phi^{\circ}\right.$ em/ $\phi$ em) D para supressão de fluorescência de Ru(bipy) $3_{3}^{2^{+}}\left(-4 \times 10^{-5} \mathrm{M}\right)$ por $\mathrm{C}_{12} \mathrm{CP}\left(1,00 \times 10^{-3} \mathrm{M}\right)$ em presença de $\mathrm{CTAB}$ e $\mathrm{KBr}\left(30^{\circ} \mathrm{C}\right)$.

\begin{tabular}{c|cccccccc}
${$\cline { 2 - 4 }$} }$ & $10 \mathrm{mM} \mathrm{KBr}$ & $20 \mathrm{mM} \mathrm{KBr}$ & $30 \mathrm{mM} \mathrm{KBr}$ & $40 \mathrm{mM} \mathrm{KBr}$ & $60 \mathrm{mM} \mathrm{KBr}$ & $80 \mathrm{mM} \mathrm{KBr}$ & $100 \mathrm{mM} \mathrm{KBr}$ \\
\hline & 1,555 & 1,558 & 1,581 & 1,653 & 1,720 & 1,625 & 1,653 \\
1,96 & 1,523 & 1,511 & 1,509 & 1,573 & 1,608 & 1,507 & 1,520 \\
3,92 & 1,452 & 1,438 & 1,449 & 1,510 & 1,510 & 1,432 & 1,399 \\
5,88 & 1,401 & 1,389 & 1,384 & 1,438 & 1,484 & 1,310 & 1,323 \\
7,84 & 1,348 & 1,359 & 1,333 & 1,360 & 1,387 & 1,268 & 1,280 \\
11,76 & 1,289 & 1,302 & 1,274 & 1,302 & 1,315 & 1,187 & 1,276 \\
15,68 & 1,246 & 1,236 & 1,214 & 1,232 & 1,267 & 1,150 & 1,214 \\
19,60 & 1,195 & 1,192 & 1,227 & 1,184 & 1,235 & 1,135 & 1,191 \\
23,52 & 1,170 & 1,170 & 1,158 & 1,156 & 1,199 & 1,109 & 1,121 \\
33,32 & 1,111 & 1,118 & 1,096 & 1,095 & 1,144 & 1,014 & 1,108
\end{tabular}


Tabela 16 - Valores de $y$ para supressão da fluorescēncia de $R u(b i p y) 2_{3}^{+}\left(4 \times 10^{-5} \mathrm{M}\right)$ por $C_{12^{C P}}$ $\left(1 \times 10^{-3} \mathrm{M}\right)$ em presença de CTAB e $\mathrm{KBr}\left(30^{\circ} \mathrm{C}\right)$.

Y

\begin{tabular}{|c|c|c|c|c|c|c|c|}
\hline$|C T A B|, M \times 10^{3}$ & $10 \mathrm{mM} \mathrm{KBr}$ & $20 \mathrm{mM} \mathrm{KBr}$ & $30 \mathrm{mM} \mathrm{KBr}$ & $40 \mathrm{mM} \mathrm{KBr}$ & $60 \mathrm{mM} \mathrm{KBr}$ & $80 \mathrm{mM} \mathrm{KBr}$ & $100 \mathrm{mM} \mathrm{KBR}$ \\
\hline 0 & 0 & 0 & 0 & 0 & 0 & 0 & 0 \\
\hline 1,96 & 0,061 & 0,092 & $0,14.1$ & 0,140 & 0,184 & 0,233 & 0,256 \\
\hline 3,92 & 0,227 & 0,274 & 0,294 & 0,280 & 0,412 & 0,447 & 0,637 \\
\hline 5,88 & 0,384 & 0,434 & 0,513 & 0,491 & 0,488 & 1,016 & 1,022 \\
\hline 7,84 & 0,595 & 0,554 & 0,745 & 0,814 & 0,860 & 1,332 & 1,332 \\
\hline 11,76 & 0,920 & 0,848 & 1,120 & 1,162 & 1,286 & 2,342 & 1,366 \\
\hline 15,68 & 1,256 & 1,364 & 1,715 & 1,814 & 1,697 & 3,167 & 2,051 \\
\hline 19,60 & 1,846 & 1,906 & 1,559 & 2,549 & 2,064 & 3,630 & 2,479 \\
\hline 23,52 & 2,265 & 2,282 & 2,677 & 3,189 & 2,618 & 4,734 & 4,352 \\
\hline 33,32 & 4,000 & 3,729 & 5,052 & 5,874 & 4,000 & 6,643 & 5,046 \\
\hline
\end{tabular}




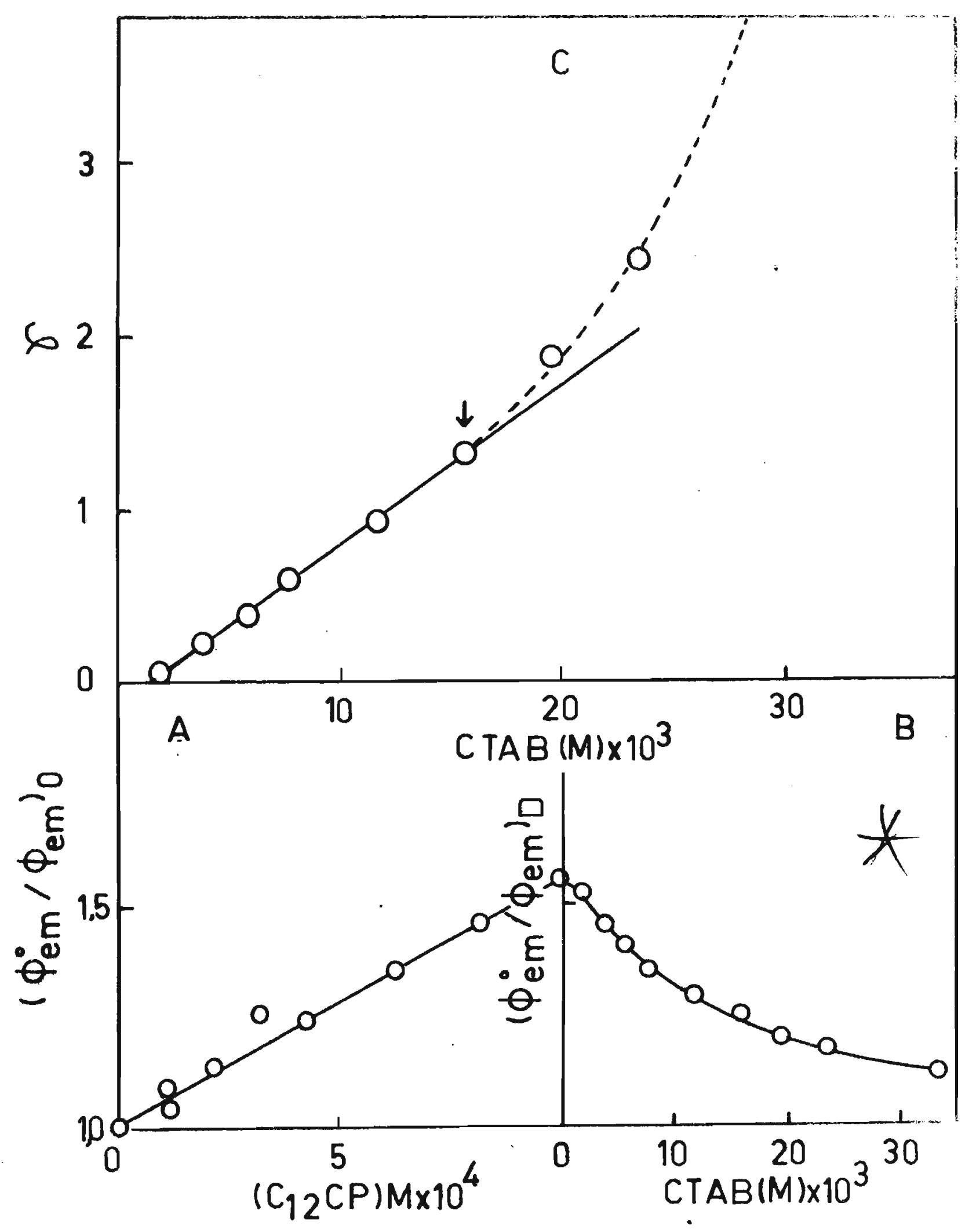

Figura 24 - Supressão da emissão do ĩon Ru(bipy) $2_{3}^{+}\left(-4 \times 10^{-5} \mathrm{M}\right)$ $C_{12} C P$, à $30^{\circ} \mathrm{C}$ em presença de $C T A B$ e $K B r 10 \mathrm{mM}$. (A) Supressão por $C_{12} C P$ na ausēncia de CTAB(eq. 74. (B) Efeito da adição de CTAB ao sistemaleq. 75. (C) $\gamma$ em função de CTAB (eq. 80). 


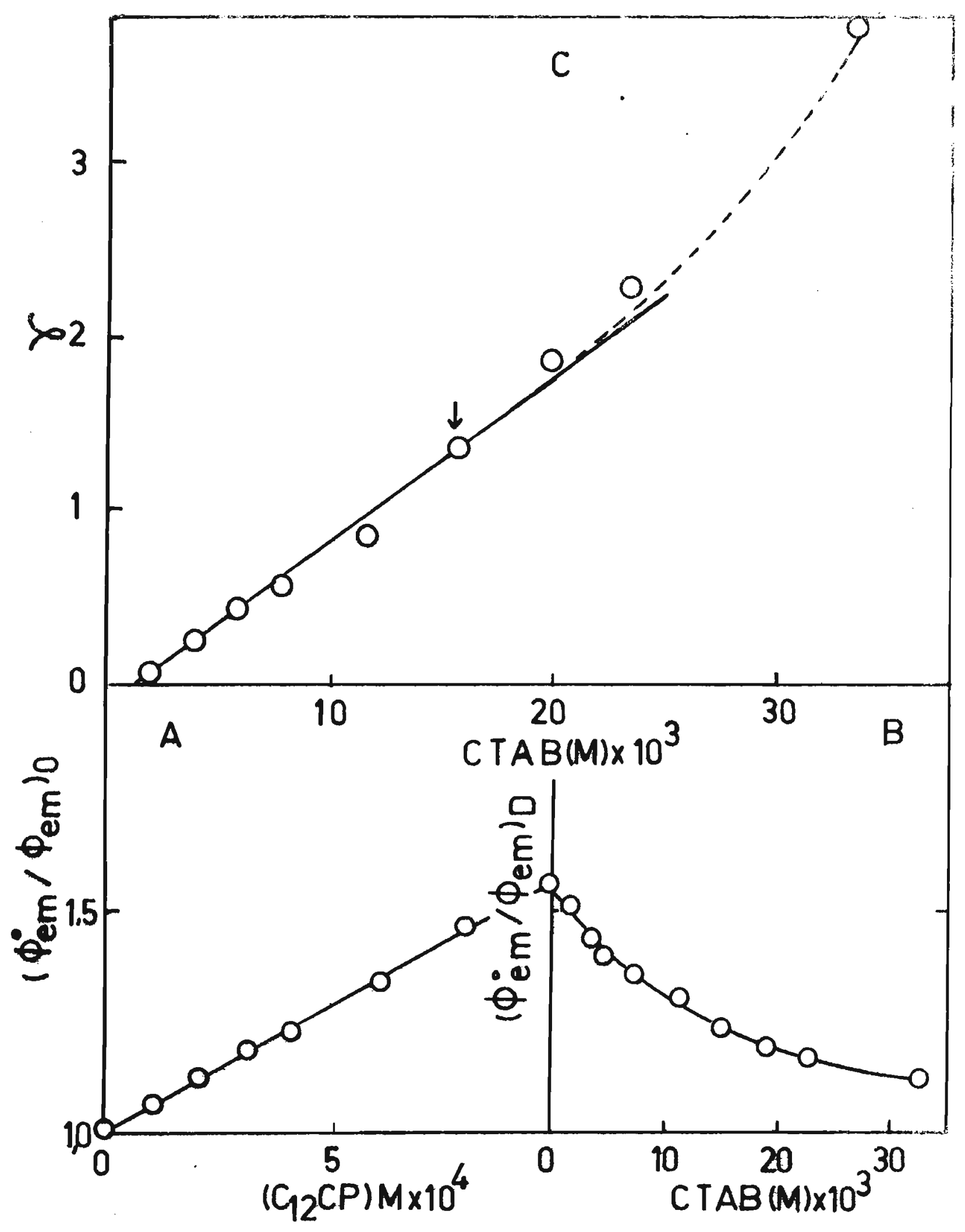

Figura 25 - Supressão da emissão do ion Ru(bipy) $2_{3}^{+}\left(-4 \times 10^{-5} \mathrm{M}\right) \mathrm{C}_{12} \mathrm{CP}$, à $30^{\circ} \mathrm{C}$ em presença de $C T A B$ e $\operatorname{KBr} 20 \mathrm{mM}$. (A) Supressão por $C_{12} C P$ na au séncia de CTAB (eq.74). (B) Efeito da adição de CTAB ao sistema (eq.75). (C) $\gamma$ en função de CTAB (eq.80). 


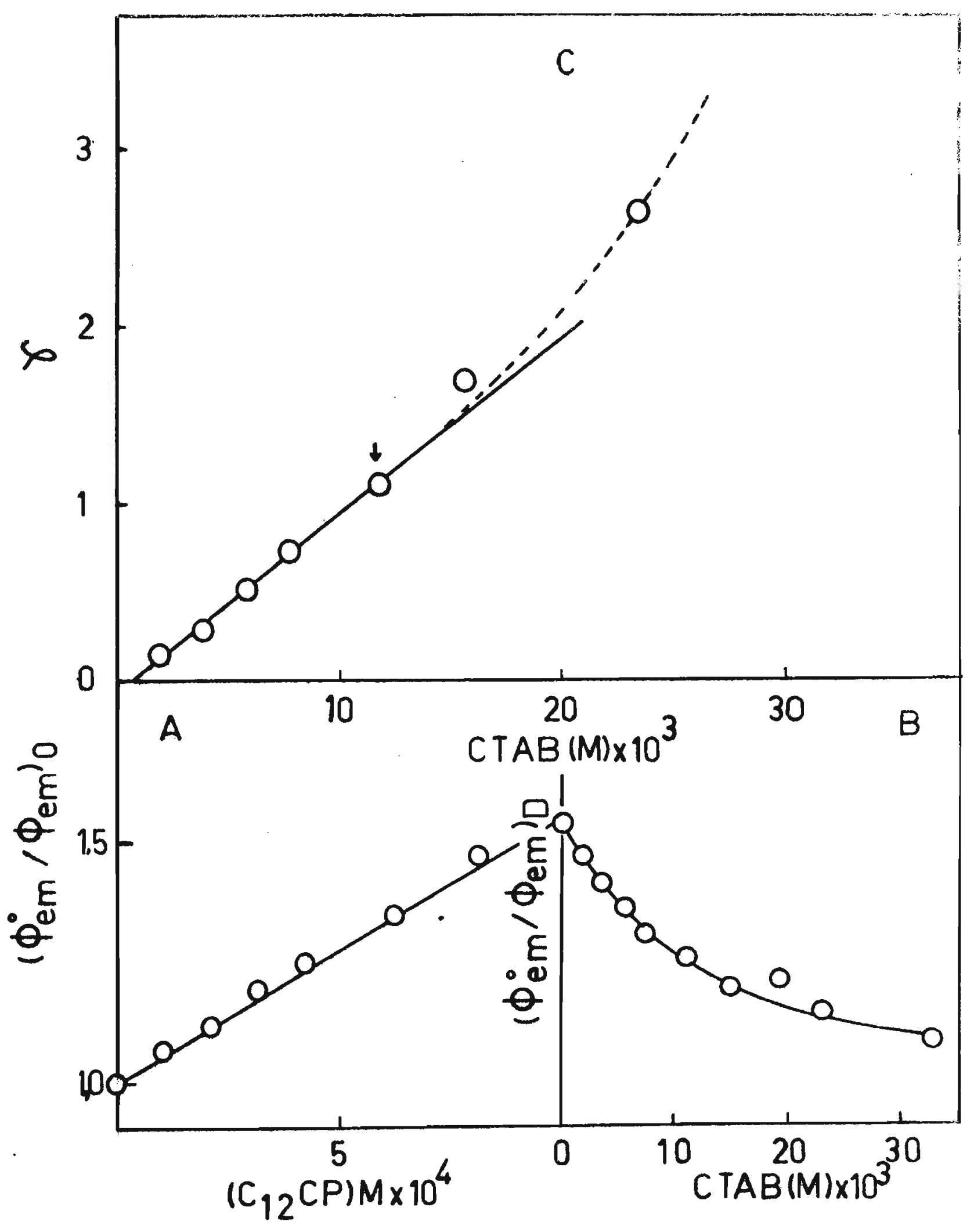

Figura 26 - Supressão da emissão do ion $R u(\text { bipy })_{3}^{2^{+}}\left(-4 \times 10^{-5} \mathrm{M}\right) \mathrm{C}_{12} \mathrm{CP}$, à $30^{\circ} \mathrm{C}$. em presença de $C T A B$ e $\mathrm{KBr} 30 \mathrm{mM}$. (A) Supressão por $C_{12} \mathrm{CP}$ na au sência de CTAB (eq. 74). (B) Efeito da adição de CTAB ao siste ma (eq.75. (C) r em função de CTAB (eq.80). 


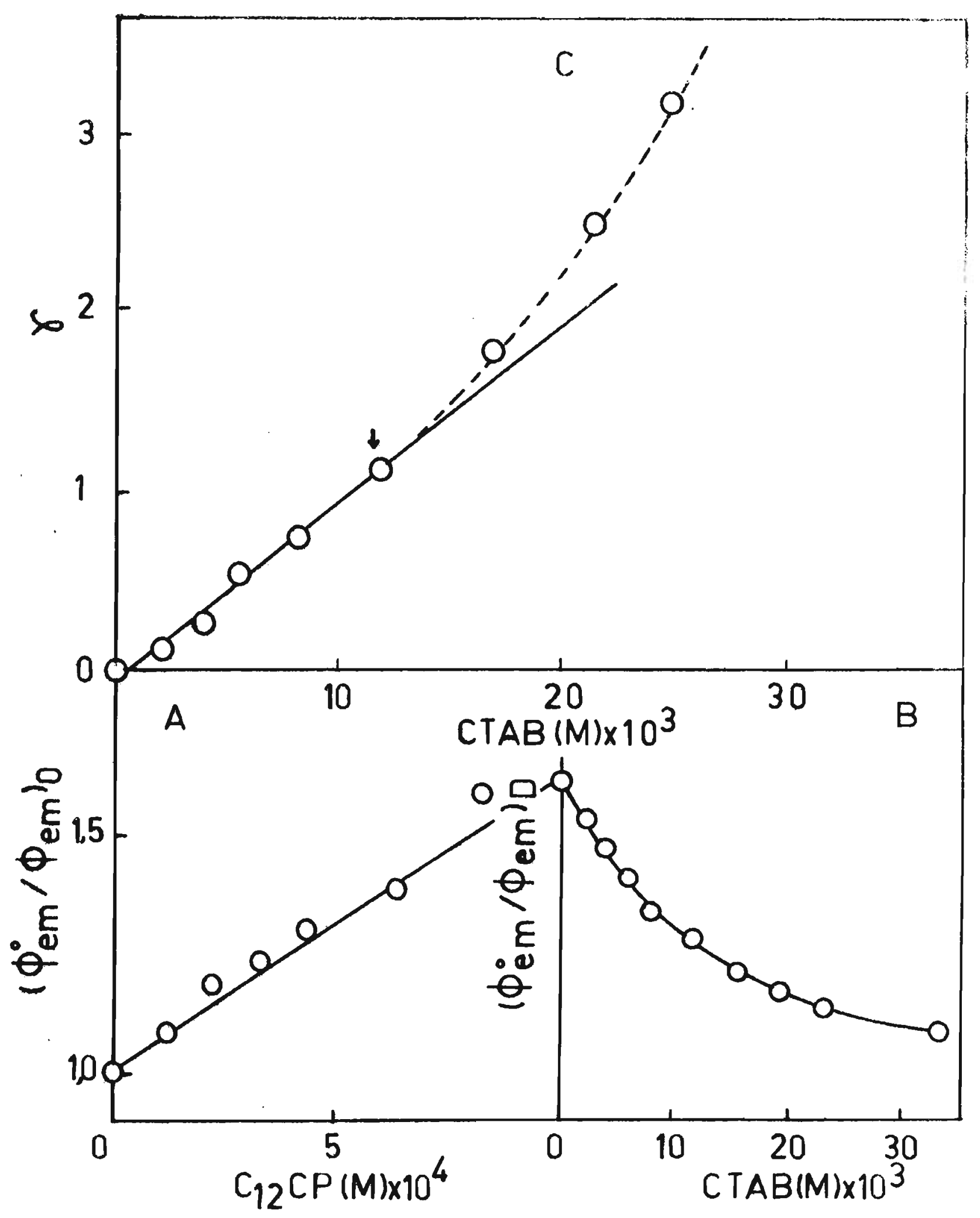

Figura 27 - Supressão da emissão do ion Ru(bipy) $2_{3}^{2+}\left(-4 \times 10^{-5} \mathrm{M}\right) \mathrm{C}_{12} \mathrm{CO}, \overline{\mathrm{a}} 30^{\circ} \mathrm{C}$ em presença de CTAB e $\mathrm{KBr} 40 \mathrm{mM}$. (A) Supressão por $C_{12} C P$ na au sência de CTAB (eq.74). (B) Efeito da adição de CTAB ao sistema (eq.75) (C) $\gamma$ em função de CTAB (eq.80). 


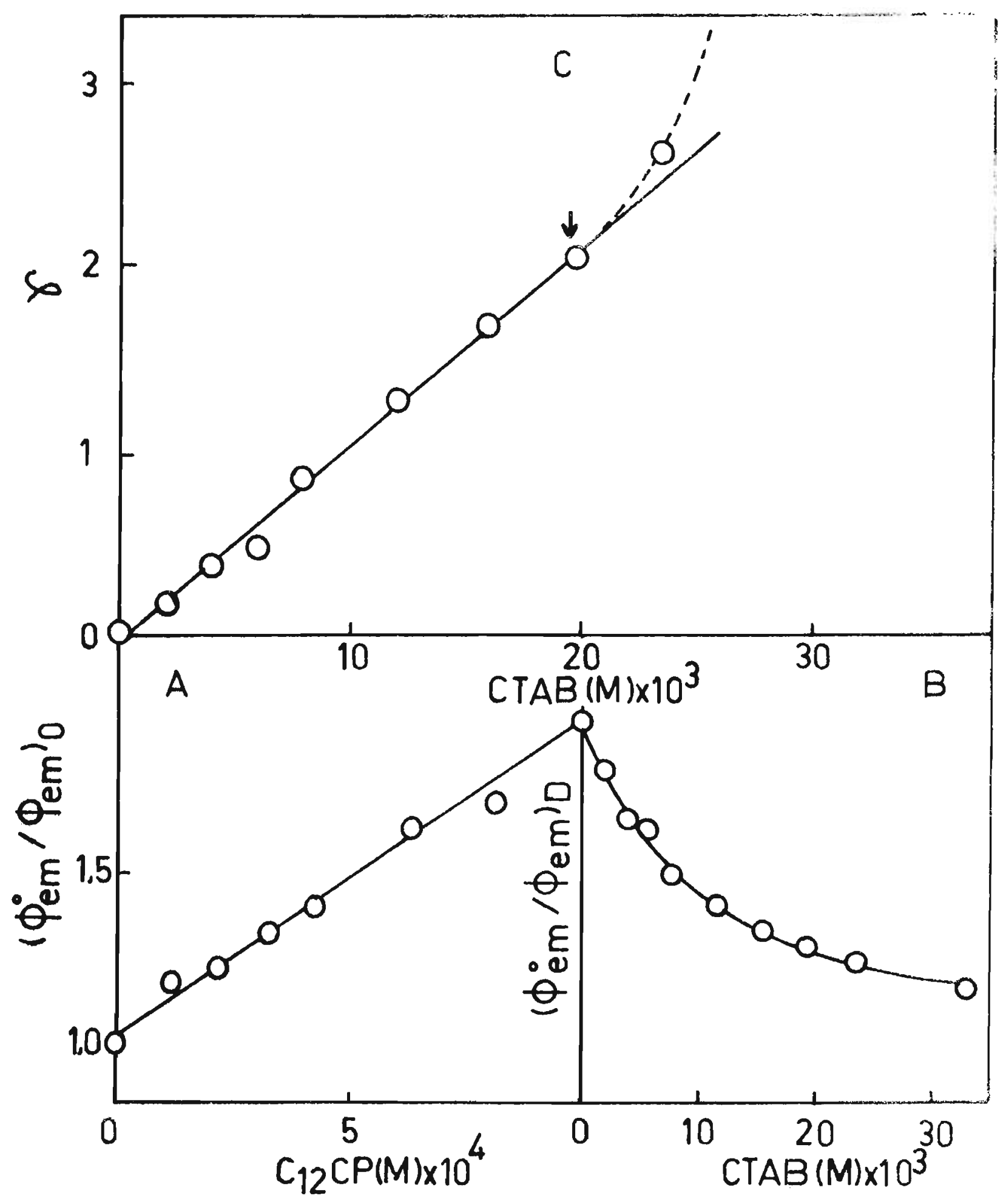

Figura 28 - Supressão da emissão do Ton Ru(bipy) $3_{3}^{2+}\left(-4 \times 10^{-5} \mathrm{M}\right) \mathrm{C}_{12} \mathrm{CP}, \overline{\mathrm{a}} 30^{\circ} \mathrm{C}$ em presença de CTAB e $K B r 60 \mathrm{mM}$. (A) Supressão por $C_{12} C P$ na ausēncia de CTAB (eq.74). (B) Efeito da adição de CTAB ao sistema (eq.75). (C) $\gamma$ em função de CTAB (eq.80). 


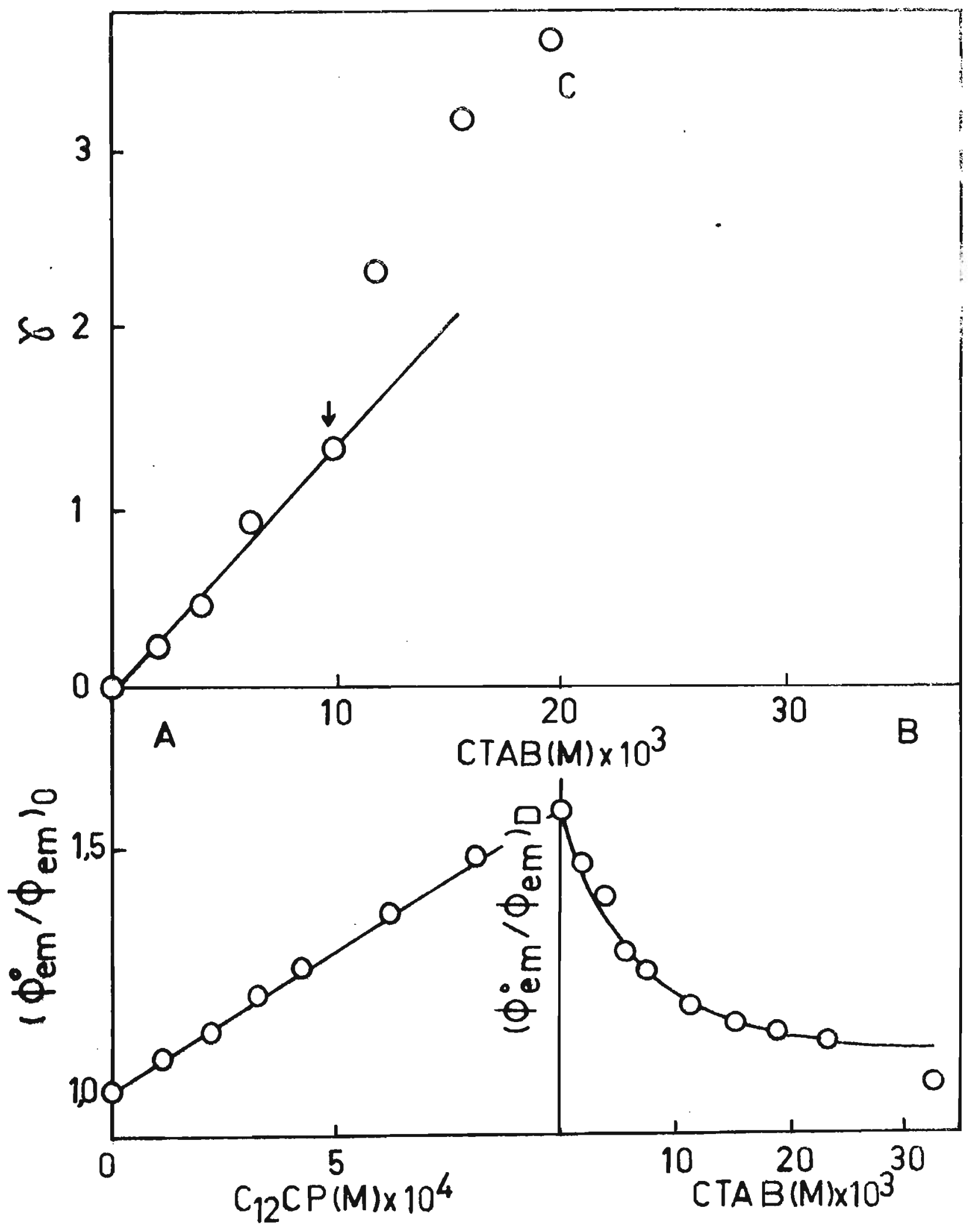

Figura 29 - Supressão da emissão do Ton Ru(bipy) $3_{3}^{2+}\left(-4 \times 10^{-5} \mathrm{M}\right) \mathrm{C}_{12} \mathrm{CP}$, à $30^{\circ} \mathrm{C}$ em presença de CTAB e $\mathrm{KBr} 80 \mathrm{mM}$. (A) Supressão por $C_{12} \mathrm{CP}$ na au séncia de CTAB (eq.74). (B) Efeito da adição de CTAB ao sistema (eq.75). (C) Y en função de CTAB (eq. 80). 


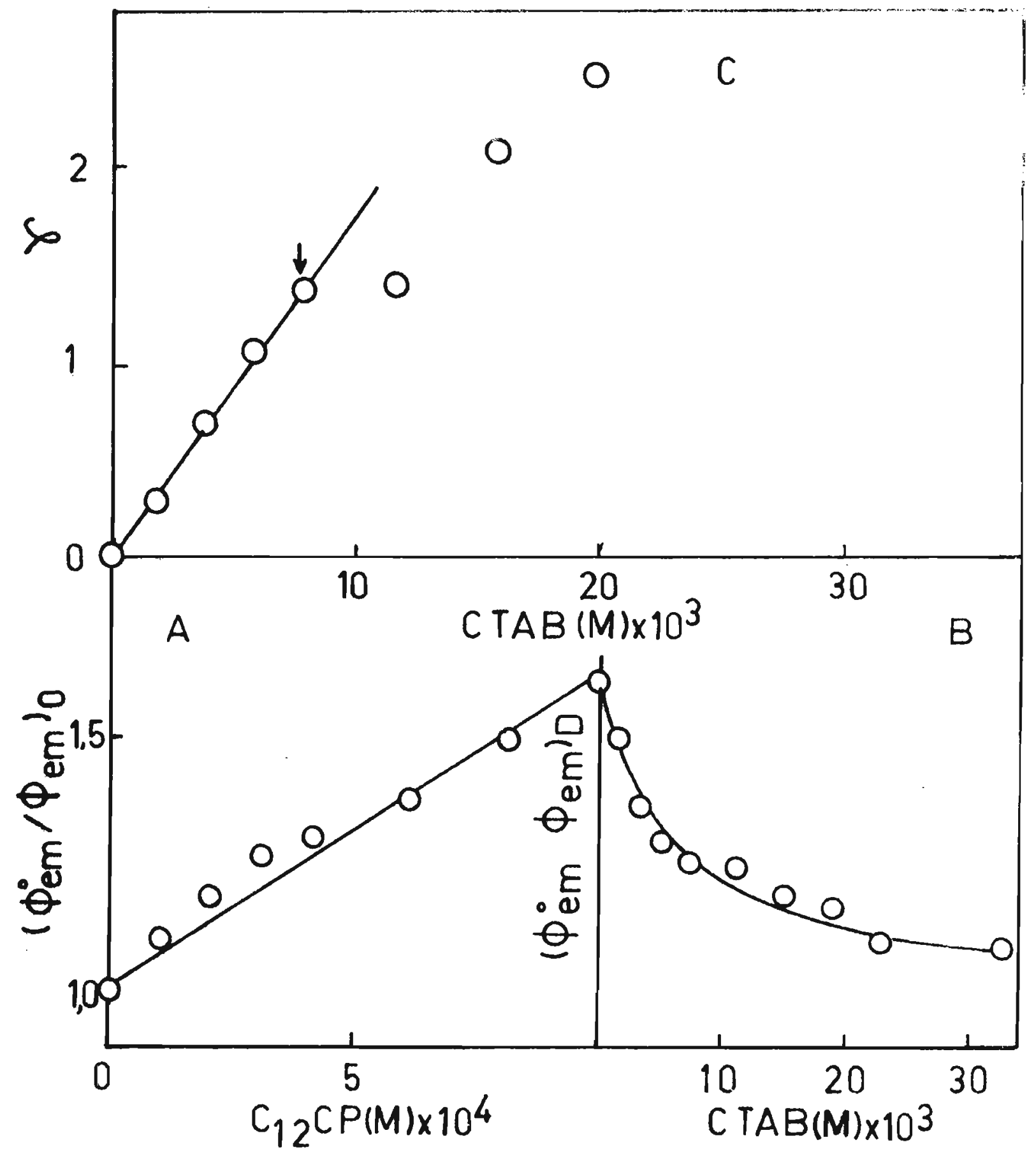

Figura 30 - Supressão da emissão do ion Ru(bipy) $2_{3}^{2^{+}}\left(4 \times 10^{-5} \mathrm{M}\right) \mathrm{C}_{12} \mathrm{CP}$, à $30^{\circ} \mathrm{C}$ em presença de CTAB e $\mathrm{KBr} 100 \mathrm{mM}$. (A) Supressão por $C_{12} C P$ na ausēncia de CTAB (eq.74). (B) Efeito da adição de CTAB ao sis tema (eq.75. (C) $\gamma$ em função de CTAB (eq.80). 
ki, 1979); uma vez que CT> $1 \mathrm{mM}$ podemos negligenciar os valo res de CMC sem acarretar grandes desvios.

Empregando a equação 80 obtemos o valor de $\mathrm{Keq} / \mathrm{N}$ di retamente da inclinação das Figuras 24 a 30 . Os valores de Keq/N em função de sal para o DCP são apresentados na Tabe1 a 17.

Tabela 17 - Valores de $($ Keq/N $)$ de DCP em CTAB

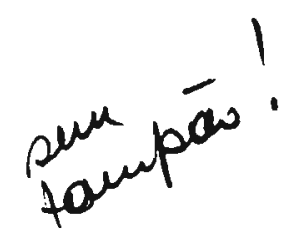

\begin{tabular}{c|c|c|c}
$\mathrm{KBr}, \mathrm{mM}$ & $\log \mathrm{KBr}$ & $\mathrm{Keq} / \mathrm{N}^{*}$ & $\operatorname{log~Keq} / \mathrm{N}$ \\
\hline 10 & $-2,000$ & 87,6 & 1,942 \\
20 & $-1,699$ & 88,4 & 1,946 \\
30 & $-1,523$ & 102,3 & 2,001 \\
40 & $-1,398$ & 109,1 & 2,038 \\
60 & $-1,222$ & 107,2 & 2,030 \\
80 & $-1,097$ & $192,5 \mathrm{~K}$ & 2,284 \\
100 & $-1,000$ & $184,0 \mathrm{~K}$ & 2,265
\end{tabular}

*As inclinaçōes foram obtidas por regressão linear simples das Figuras 24 a 30 até o ponto indicado pela seta

Analogamente para o DeCP temos as Tabelas $18,19,20$ e 21 .

Pelos valores das Tabela $18,19,20$ e 21 construimos as Figuras 31 a 38 (ver equações 74,75 e 80 ).

Aplicando-se a equação 80 obtem-se das inclinaçães das Fi guras 31 a 38 os valores dekeq/N em função de sal os quais são apresentados na Tabela 22. 
Tabela 18 - Valores de $\left(\phi^{0}\right.$ em/ $\phi$ em) o para supressão da fluorescéncia de Ru(bipy) $2_{3}^{+}\left(\sim 4 \times 10^{-5} M\right)$ por $C_{10} C P$ em $\mathrm{H}_{2} \mathrm{O}\left(30^{\circ} \mathrm{C}\right)$ na presença de värias concentraçōes de $\mathrm{KBr}$.

\begin{tabular}{|c|c|c|c|c|c|c|c|}
\hline \multicolumn{8}{|c|}{$\left(\phi^{\circ} \mathrm{em} / \phi \mathrm{em}\right)_{0}$} \\
\hline$\left|C_{10} C P\right|, M \times 10^{4}$ & $10 \mathrm{mM} \mathrm{KBr}$ & $20 \mathrm{mM} \mathrm{KBr}$ & $30 \mathrm{mM} \mathrm{KBr}$ & $40 \mathrm{mM} \mathrm{KBr}$ & $60 \mathrm{mM} \mathrm{KBr}$ & $80 \mathrm{mM} \mathrm{KBr}$ & $100 \mathrm{mM} \mathrm{KBr}$ \\
\hline 0 & 1 & 1 & 1 & 1 & 1 & 1 & 1 \\
\hline 2,05 & 1,080 & 1,115 & 1,145 & 1,076 & - & - & - \\
\hline 4,09 & 1,195 & 1,255 & 1,273 & 1,215 & 1,290 & 1.293 & 1,307 \\
\hline 6,12 & 1,276 & 1,353 & 1,406 & 1,337 & - & - & - \\
\hline 8,14 & 1,416 & 1,492 & 1,560 & 1,462 & 1,572 & 1,587 & 1,616 \\
\hline 12,17 & 1,603 & 1,763 & 1,614 & 1,714 & 1,670 & 1,867 & 1,901 \\
\hline 16,16 & 1,664 & 2,039 & 2,004 & 1,988 & 1,910 & 2,175 & 2,198 \\
\hline 20,12 & 2,090 & 2,302 & 2,311 & 2,246 & 2,176 & 2,464 & 2,530 \\
\hline
\end{tabular}


Tabela 19 - Valores de $\left(6^{0} \mathrm{em} / \phi \mathrm{em}\right)_{D}$ para supressão da fluorescéncia de Ru(bipy) ${ }_{3}^{2^{+}}\left(\sim 4 \times 10^{-5} \mathrm{M}\right)$ por $\mathrm{C}_{10} \mathrm{CP}$ $\left(2,012 \times 10^{-3} \mathrm{M}\right)$ em presença de CTAB e $\operatorname{KBr}\left(30^{\circ} \mathrm{C}\right)$

\begin{tabular}{|c|c|c|c|}
\hline $\mid$ CTAB $\mid, M \times 10^{3}$ & $\frac{\left(\phi^{\circ} \mathrm{em} / \phi \mathrm{em}\right)_{\mathrm{D}}}{10 \mathrm{mM} \mathrm{KBr}}$ & $\mid$ CTAB $\mid, M \times 10^{3}$ & $\frac{\left(\phi^{\circ} \mathrm{em} / \phi \mathrm{em}\right)_{\mathrm{D}}}{20 \mathrm{mM} \mathrm{KBr}}$ \\
\hline 0 & 2,090 & 0 & 2,302 \\
\hline 2,94 & 2,116 & 3,92 & 2,227 \\
\hline 5,77 & 2,050 & 7,69 & $"$ \\
\hline 8,49 & 2,012 & 11,32 & $"$ \\
\hline 11,11 & 2,036 & 14,81 & 2,191 \\
\hline 16,07 & 2,002 & 21,43 & $"$ \\
\hline 20,69 & 1,957 & 27,59 & 2,126 \\
\hline 25,00 & 1,921 & 33,33 & 2,067 \\
\hline 29,03 & 1,900 & 38,71 & 1,972 \\
\hline 38,06 & 1,789 & 48,48 & 1,896 \\
\hline 44,37 & 1,697 & 59,15 & 1,787 \\
\hline
\end{tabular}


Tabela 20 - Valores de $\left(\phi^{\circ} \mathrm{em} / \phi \mathrm{em}\right)_{D}$ para supressão da fluorescência de Ru(bipy $)_{3}^{2^{+}}\left(-4 \times 10^{-5} \mathrm{M}\right)$ por $C_{10^{C P}}$ $\left(2,012 \times 10^{-3} \mathrm{M}\right)$ em presença de CTAB e $\operatorname{KBr}\left(30^{\circ} \mathrm{C}\right)$

\begin{tabular}{c|ccccc}
\multicolumn{1}{c}{$|C T A B|, M \times 10^{3}$} & $30 \mathrm{mM} \mathrm{KBr}$ & $40 \mathrm{mM} \mathrm{KBr}$ & $60 \mathrm{mM} \mathrm{KBr}$ & $80 \mathrm{mM} \mathrm{KBr}$ & $100 \mathrm{mM} \mathrm{KBr}$ \\
\cline { 2 - 6 } 0 & 2,311 & 2,246 & 2,176 & 2,464 & 2,530 \\
14,9 & 2,211 & 2,109 & 2,008 & 2,264 & 2,279 \\
27,7 & 2,038 & 1,932 & 1,900 & 2,099 & 2,114 \\
38,9 & 1,894 & 1,823 & 1,762 & 1,969 & 1,975 \\
48,7 & 1,794 & 1,724 & 1,661 & 1,860 & 1,865 \\
57,4 & 1,729 & 1,647 & 1,603 & 1,769 & 1,778
\end{tabular}


Tabela 21 - Valores de $\gamma$ para supressão da fluorescéncia de Ru(bipy) ${ }_{3}^{2^{+}}$ $\left(\sim 4 \times 10^{-5} \mathrm{M}\right)$ por $C_{10} C P\left(2,012 \times 10^{-3} \mathrm{M}\right)$ em presença de CTAB $e$ $\operatorname{KBr}\left(30^{\circ} \mathrm{C}\right)$

\begin{tabular}{|c|c|c|c|c|c|c|c|}
\hline $\operatorname{CTAB}(M) \times 10^{3}$ & $\begin{array}{l}\mathrm{KBr} \\
10 \mathrm{mM}\end{array}$ & $\begin{array}{c}\mathrm{KBr} \\
20 \mathrm{mM}\end{array}$ & $\begin{array}{c}\mathrm{KBr} \\
30 \mathrm{mM}\end{array}$ & $\begin{array}{c}\mathrm{KBr} \\
40 \mathrm{mM}\end{array}$ & $\begin{array}{c}\mathrm{KBr} \\
60 \mathrm{mM}\end{array}$ & $\begin{array}{c}\mathrm{KBr} \\
80 \mathrm{mM}\end{array}$ & $\begin{array}{c}\mathrm{KBr} \\
100 \mathrm{mM}\end{array}$ \\
\hline 0 & 0 & 0 & 0 & 0 & 0 & 0 & 0 \\
\hline 2,94 & 0 & & & & & & \\
\hline 3,92 & & 0,061 & & & & & \\
\hline 5,77 & 0,038 & & & & & & \\
\hline 7,68 & & 0,061 & & & & & \\
\hline 8,49 & 0,074 & & & & & & \\
\hline 11,1 & 0,052 & & & & & & \\
\hline 11,32 & & 0,061 & & & & & \\
\hline 14,81 & & 0,093 & & & & & \\
\hline 14,90 & & & 0,083 & 0,123 & 0,173 & 0,153 & 0,191 \\
\hline 16,07 & 0,088 & & & & & & \\
\hline 20,69 & 0,139 & & & & & & \\
\hline 21,43 & & 0,093 & & & & & \\
\hline 25,00 & 0,183 & & & & & & \\
\hline 27,59 & & 0,156 & & & & & \\
\hline 27,7 & & & 0,283 & 0,339 & 0,313 & 0,326 & 0,367 \\
\hline 29,03 & 0,211 & & & & & & \\
\hline 33,33 & & 0,221 & & & & & \\
\hline 38,06 & 0,381 & & & & & & \\
\hline 38,71 & & 0,339 & & & & & \\
\hline 38,9 & & & 0,466 & 0,514 & 0,551 & 0,504 & 0,562 \\
\hline 44,37 & 0,564 & & & & & & \\
\hline 48,48 & & 0,453 & & & & & \\
\hline 48,7 & & & 0,651 & 0,721 & 0,788 & 0,694 & 0,761 \\
\hline 57,4 & & & 0,798 & 0,926 & 0,963 & 0,895 & 0,958 \\
\hline 59,15 & & 0,654 & & & & & \\
\hline
\end{tabular}




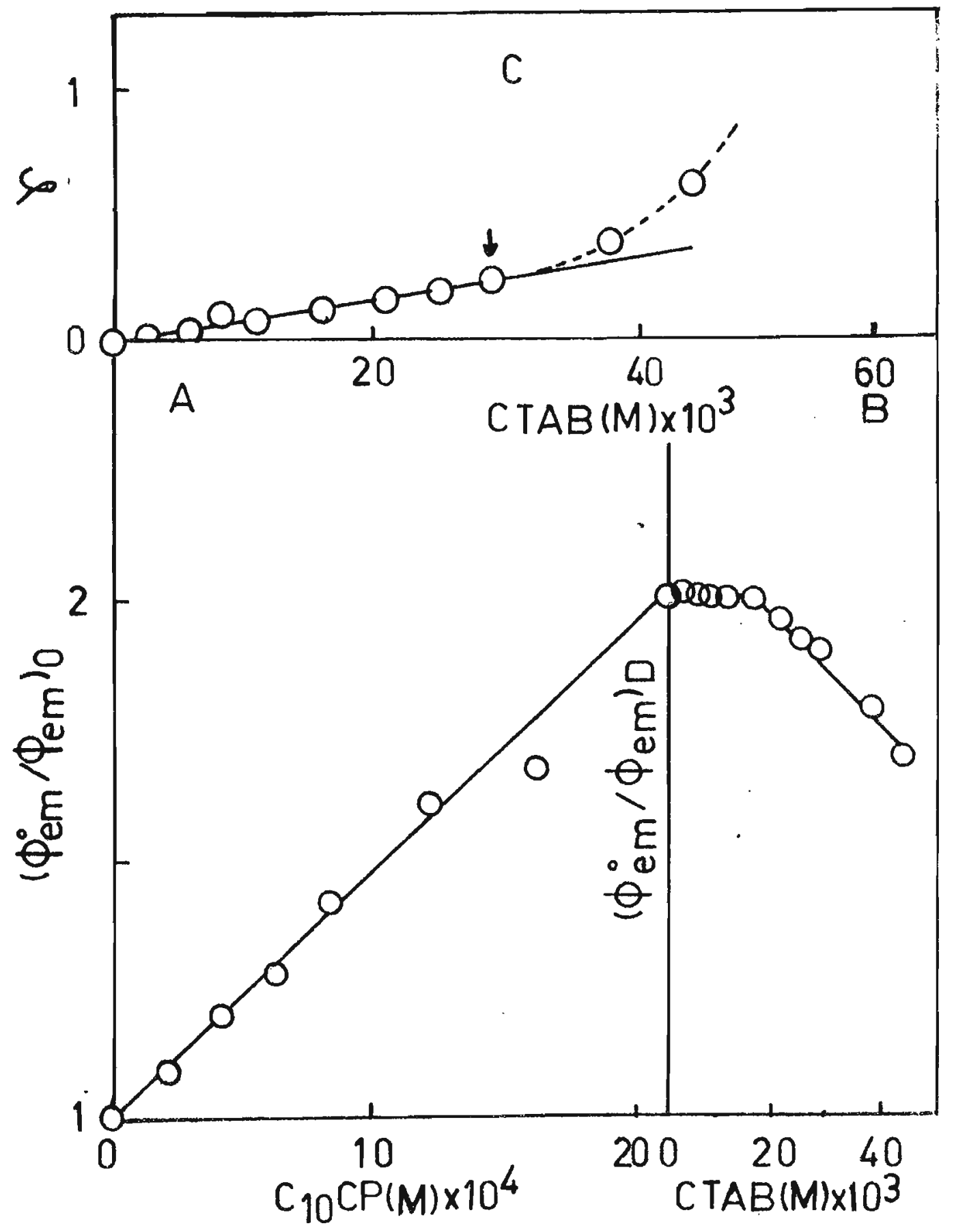

Figura 31 - Supressão da emissão do ion $\operatorname{Ru(bipy)})_{3}^{+}\left(4 \times 10^{-5} M\right)$ por $C_{10} C P$, à $30^{\circ} \mathrm{C}$ em presença de CTAB e $\mathrm{KBr} 10 \mathrm{mM}$. (A) Supressão por $\mathrm{C}_{10}$ $C P$ na auséncia de CTAB (eq.74). (B) Efejto da adiçäo de CTAB (eq.75). (C) $\gamma$ em função de CTAB (eq.80). 


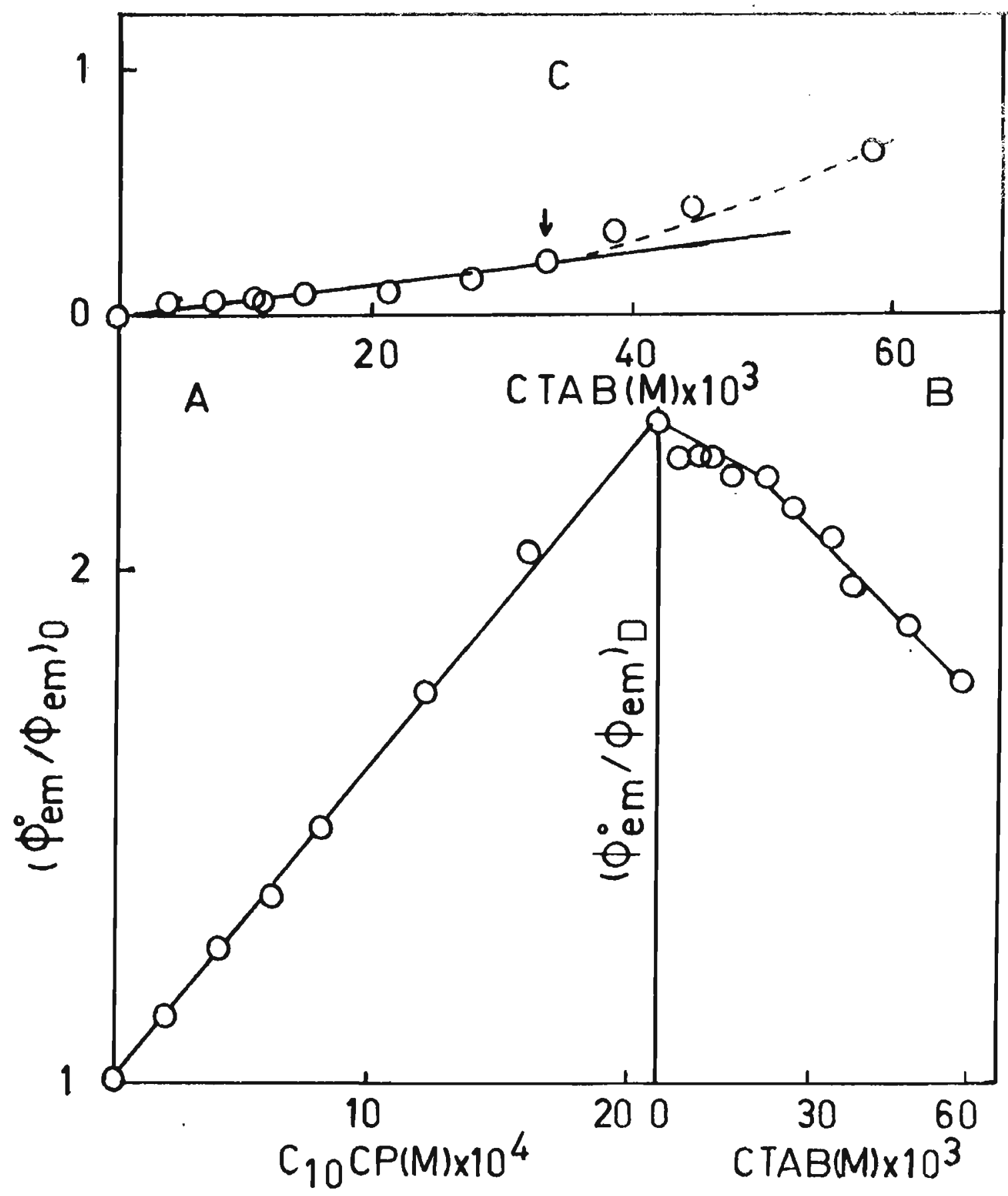

Figura 32 - Supressão da emissão do ion Ru(bipy) $2_{3}^{2^{+}}\left(4 \times 10^{-5} M\right)$ por $C_{10} C P$, à $30^{\circ} \mathrm{C}$ em presença de $\mathrm{CTAB}$ e $\mathrm{KBr} 20 \mathrm{mM}$. (A) Supressão por $C_{10}$ $C P$ na ausência de CTAB (eq.74). (B) Efeito da adição de CTAB ao sistema (eq.75). (C) $r$ em função de CTAB (eq.80). 


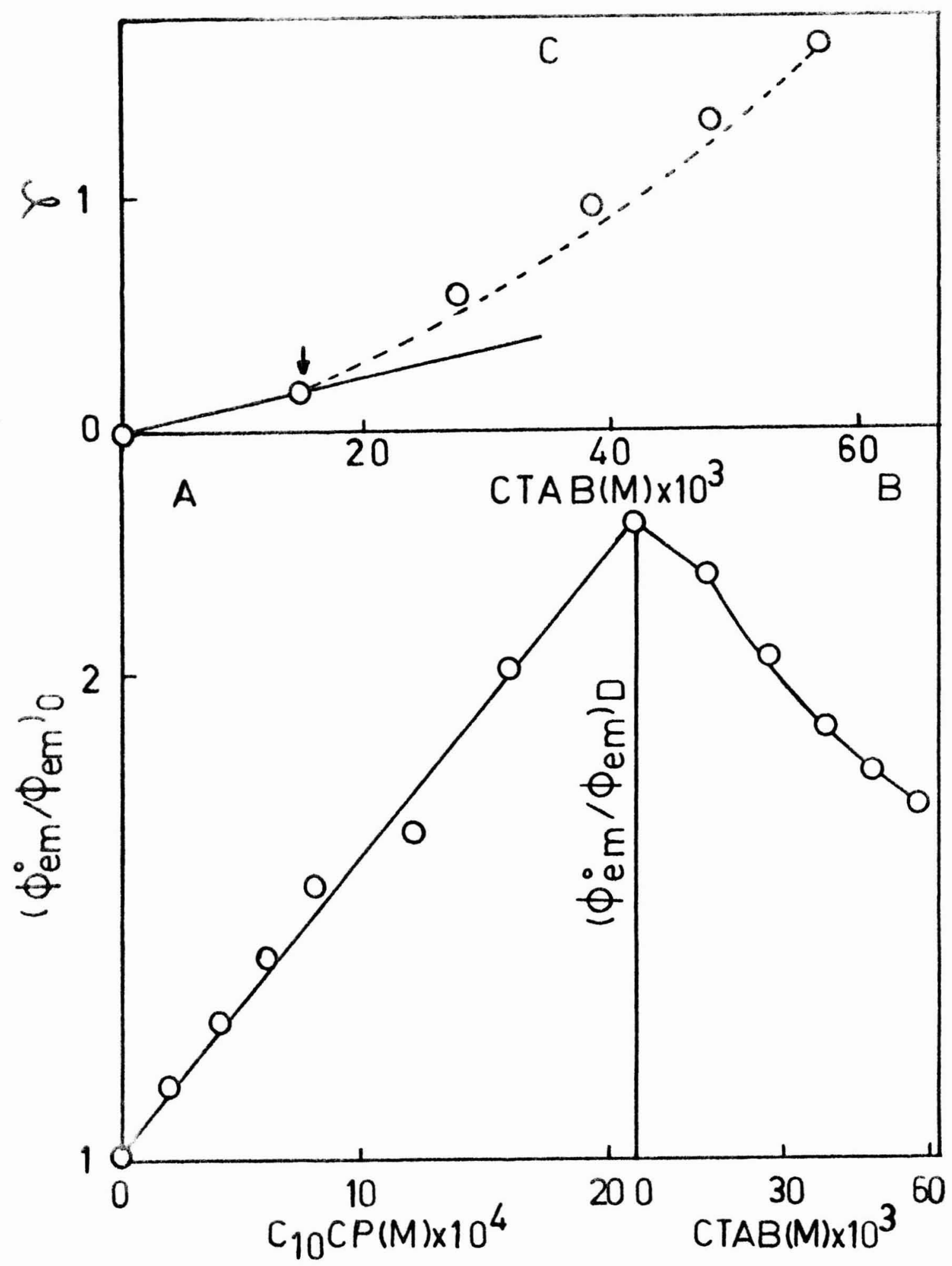

Figura 33 - Supressão da emissão do ion Ru(bipy $)_{3}^{2^{+}}\left(4 \times 10^{-5} \mathrm{M}\right)$ por $C_{10} C P, \bar{a}$ $30^{\circ} \mathrm{C}$ em presença de $C T A B$ e $\mathrm{KBr} 30 \mathrm{mM}$. (A) Supressão por $C_{10}$ $C P$ na ausēncia de CTAB (eq.74). (B) Efeito da adição de CTAB ao sistema (eq.75). (C) $\gamma$ em função de CTAB (eq.80). 


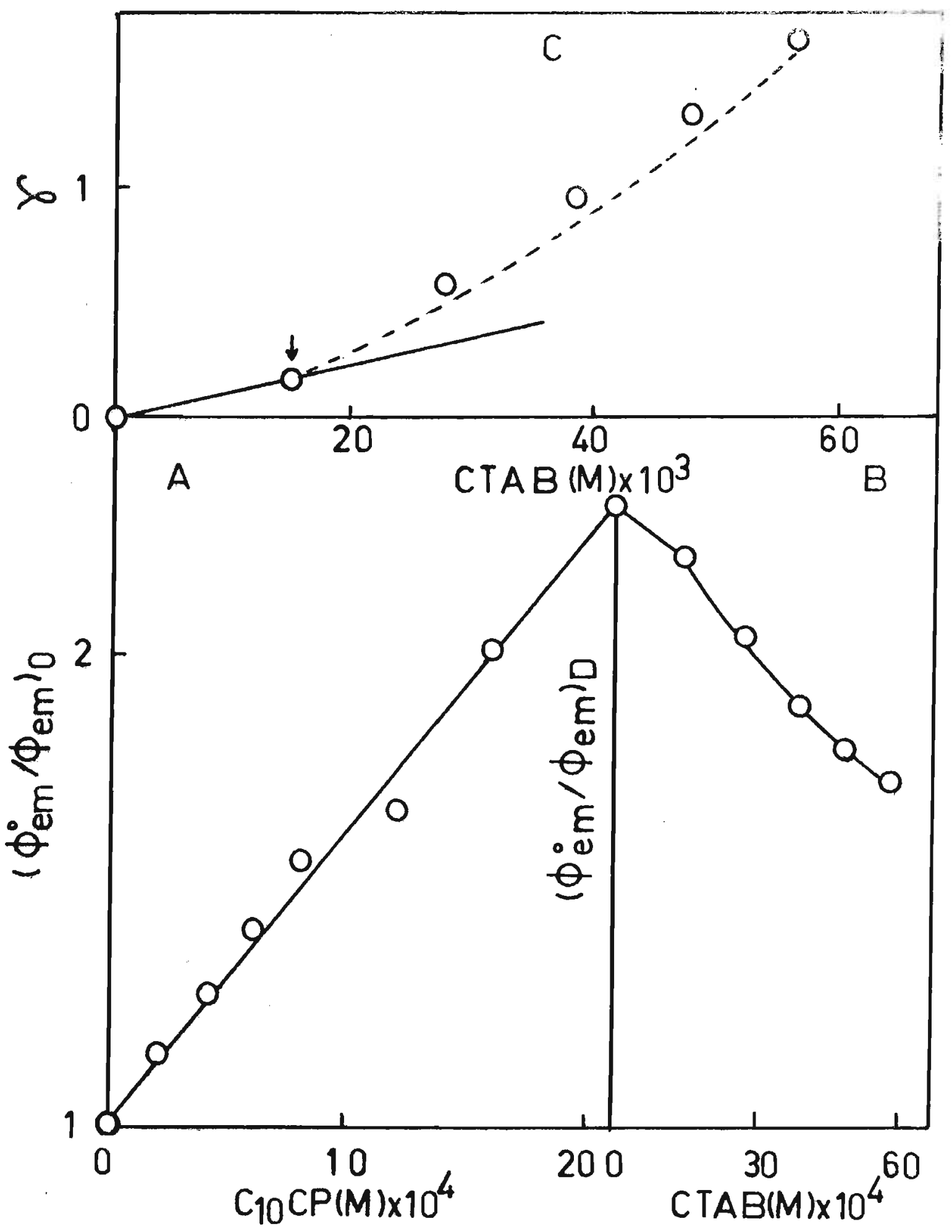

Figura 34 - Supressão da emissão do ion Ru(bipy) $2_{3}^{2^{+}}\left(4 \times 10^{-5} \mathrm{M}\right)$ por $C_{10} \mathrm{CP}$, à $30^{\circ} \mathrm{C}$ em presença de CTAB e $\mathrm{KBr} 30 \mathrm{mM}$. (A) Supressão por $C_{10}$ $C P$ na ausência de CTAB (eq.74). (B) Efeito da adição ce CTAB ao sistema (eq. 75). (C) $\gamma$ em função de CTAB (eq.80). 


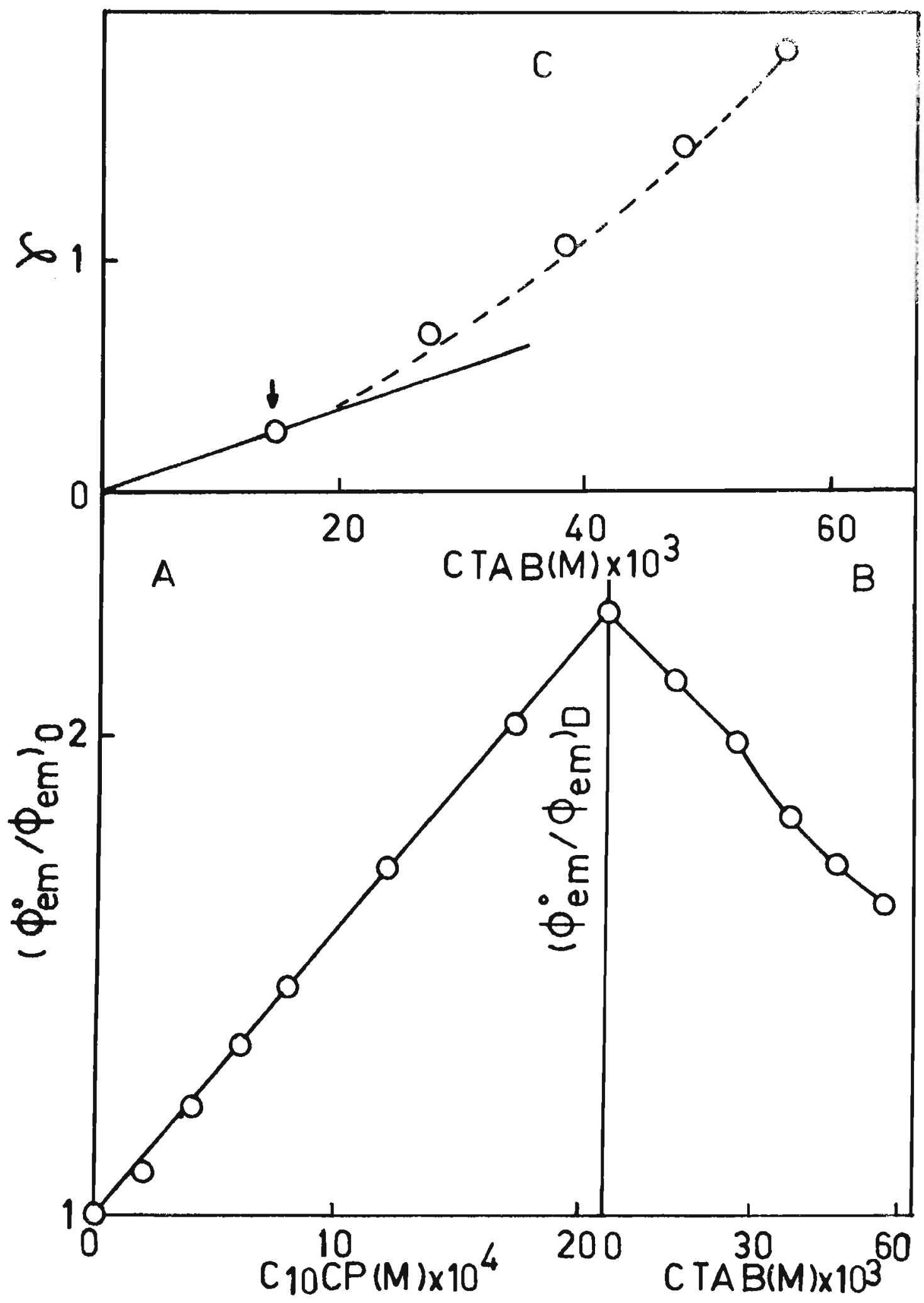

Figura 35 - Supressão da emissão do ion Ru(bipy) $2_{3}^{2^{+}}\left(4 \times 10^{-5} \mathrm{M}\right)$ por $\mathrm{C}_{10^{C}} \mathrm{CP}, \bar{a}$ $30^{\circ} \mathrm{C}$ em presença de CTAB e $\mathrm{KBr} 40 \mathrm{mM}$. (A) Supressão por $C_{10} \mathrm{CP}$ na ausência de CTAB (eq.74). (B) Efeito da adição de CTAB ao sistema (eq.75). (C) y em função de CTAB (eq.80). 


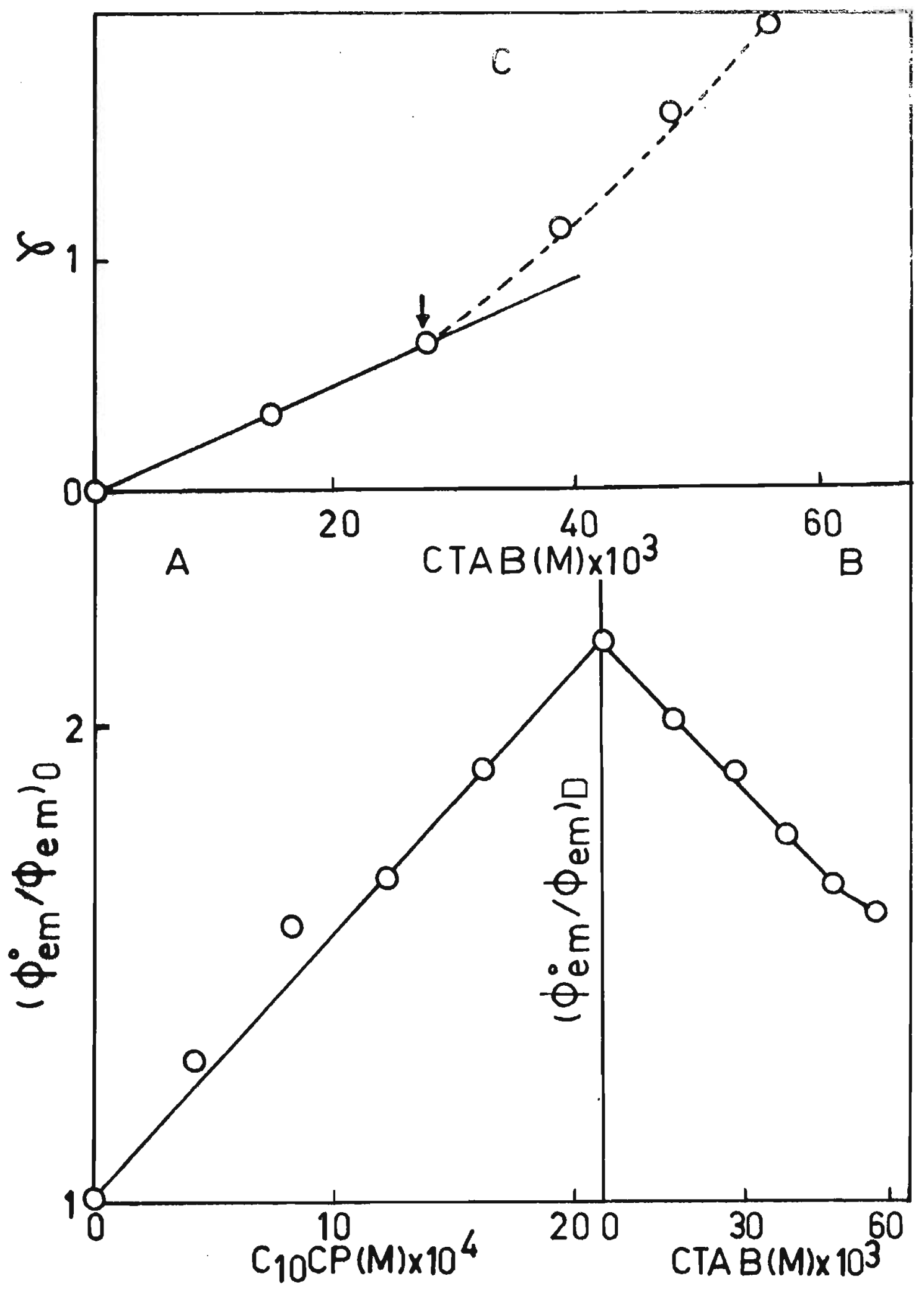

Figura 36 - Supressão da emissão do ion Ru(bipy) $2_{3}^{2^{+}}\left(4 \times 10^{-5} \mathrm{M}\right)$ por $\mathrm{C}_{10} \mathrm{CP}$, à $30^{\circ} \mathrm{C}$ em presença de CTAB e $\mathrm{KBr} 60 \mathrm{mM}$. (A) Supressão por $C_{10}$ $C P$ na auséncia de CTAB (eq.74). (B) Efeito da adição de CTAB ao sistema (eq.75). (C) y em funçäo de CTAB (eq.80). 


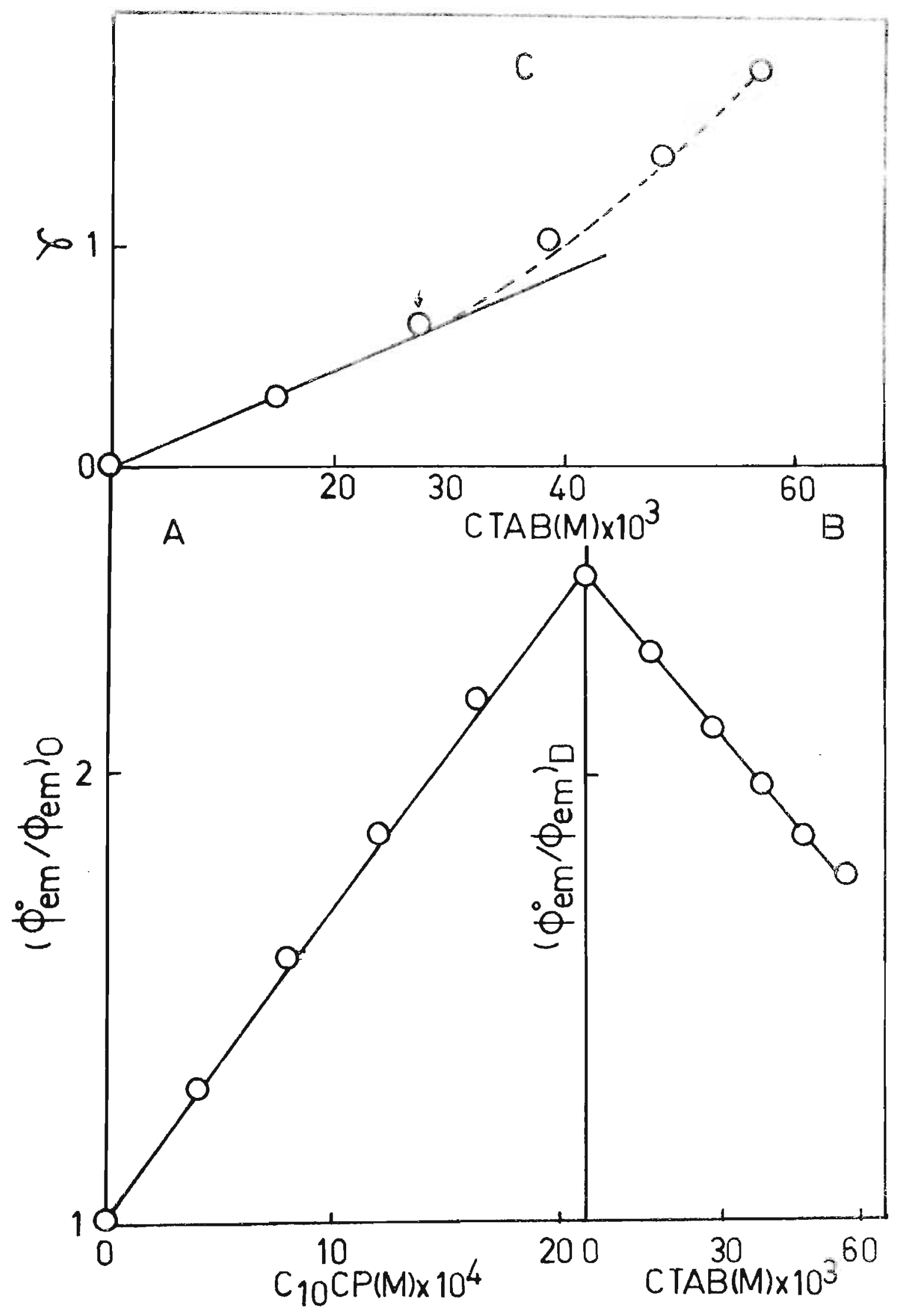

- Figura 37 - Supressão da emịssão do Ton Ru(bipy) $2_{3}^{+}\left(4 \times 10^{-5} M\right)$ por $C_{10} C P$, à $30^{\circ} \mathrm{C}$ em presença de CTAB e $\mathrm{KBr} 80 \mathrm{mM}$. (A) Supressão por $C_{10}$ $C P$ na ausência de CTAB $(e q, 74)$. (B) Efeito da adiçâa de CTAB ao sistema $($ eq.75). (C) $\gamma$ em função de CTAB (eq.80). 


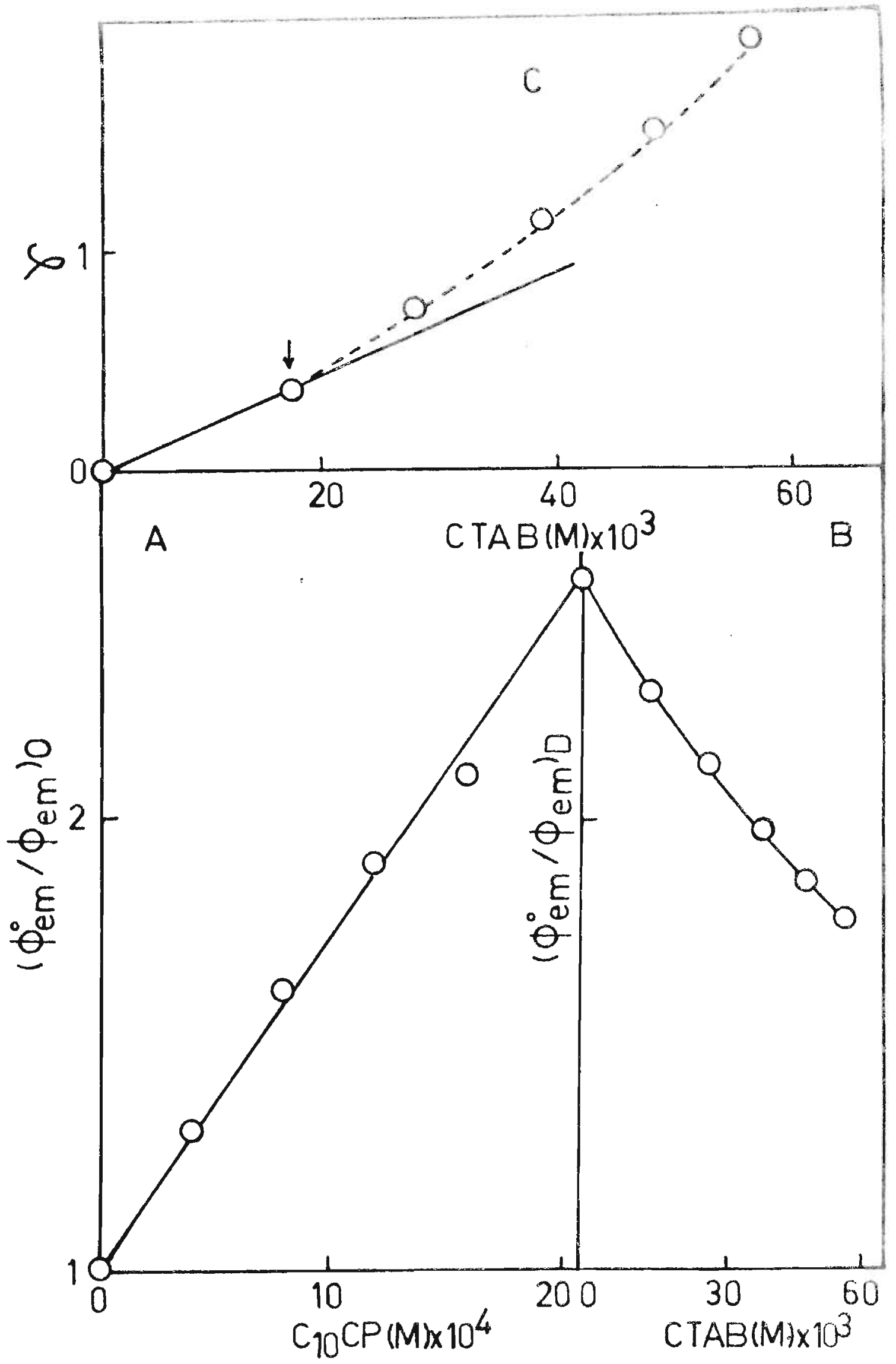

- Figura 38 - Supressão da emissão do Fon Ru(bioy) $)_{3}^{2^{+}}\left(4 \times 10^{-5} \mathrm{M}\right)$ por $\mathrm{C}_{70} \mathrm{CP}$, à $30^{\circ} \mathrm{C}$ em presença de CTAB e $\mathrm{KBr} 100 \mathrm{mM}$. (A) Supressäo por $\mathrm{C}_{10}$ CP na auséncia de CTAB (eq.74). (B) Efeito da adição de CTAB (eq.75). (C) rem função de CTAB (eq.80). 
Tabela 22 - Valores de $\mathrm{Keq} / \bar{N}$ para DeCP em CTAB

\begin{tabular}{c|c|c}
$|\mathrm{KBr}| \mathrm{mM}$ & $\mathrm{Keq} / \mathrm{N}$ & $\log \mathrm{Keq} / \bar{N}$ \\
\hline 10 & 7,4 & 0,869 \\
20 & 5,3 & 0,724 \\
30 & 5,6 & 0,748 \\
40 & 8,3 & 0,919 \\
60 & 11,3 & 1,053 \\
80 & 11,7 & 1,068 \\
100 & 13,2 & 1,121
\end{tabular}

*As inclinações foram obtidas por regressão linear simples das figuras 31 a 38 até o ponto indicado pela seta

Modēlo teórico para tratamento do efeito de CTAB sobre a constante de velocidade da hi drólise alcalina dos ions DCP

A expressão de velocidade entre ions na presença de micelas é dada pela equação 34. Aplicada ao DCP teremos:

$$
k \psi=k_{2}^{0} O H_{f} \frac{D C P_{f}}{D C P_{t}}+k_{2}^{m} \quad \overline{O H_{b}} \frac{D C P_{b}}{D C P_{t}}
$$

Uma vez que o ion DCP $\bar{e}$ um anfifīlico anălogo aomo nômero de CTAB, isto ē, ambos são sais de amônio quaternārio' com cadeia hidrocarbōnica longa $(12$ e 16 carbonos respectiva mente), a CMC de cada sistema ē relatilamente prōxima (DCP,

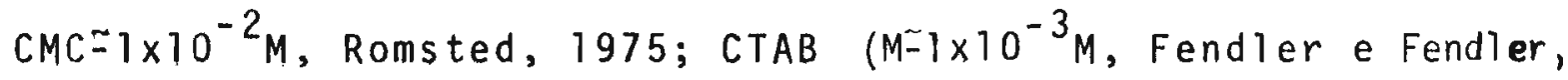
1975). Assim sendo assumimos que o DCP comporta-se como se fosse um monômero de CTAB, e portanto o equilĩbrio de troca de monômeros (equação 87) deve descrever a partição de DCP a mi 
celas de CTAB (Miola, 1979).

$$
D C P_{f}+\operatorname{micela} \stackrel{K_{T}^{m o n}}{\rightleftarrows} D C P_{b}+m_{f}
$$

londe, $K_{T}^{m o n}=$ constante de troca de monômeros

$$
m_{f}=\text { concentração de monōmero livre) }
$$

supõe-se $\bar{N}$ constante a dada concentração salina (Quina,1978).

A constante de equilībrio da equação 87 será dada

por

$$
K_{T}^{m o n}=\frac{D C P_{b} m_{f}}{D C P_{f} C D}
$$

sendo $D C P_{T}=D C P_{f}+D C P_{b}$, associando-se ã expressão de $k_{\psi}$ (equação 34 ), obtemos, substituindo os termos correspondentes:

$$
k \psi=k_{2}^{0} O H_{f}\left(1-\frac{k_{T}^{m o n} C D}{m_{f}+k_{T}^{m o n} C D}\right)+k_{2}^{m} \overline{O H}_{b}\left(\frac{k_{T}^{m o n} C D}{m_{f}+k_{T}^{m o n} C D}\right)
$$

usando-se a definição de $\overline{\mathrm{OH}_{b}}, \overline{\mathrm{OH}_{b}}=\frac{\mathrm{OH}_{\mathrm{b}}}{\mathrm{CD} \cdot \bar{V}}$ (equação 27). e aplicandose em 89 temos

$$
k \psi=k_{2}^{0} O H_{f}\left(1-\frac{K_{T}^{m o n} C D}{m_{f}+K_{T}^{m o n} C D}\right)+\frac{k_{2}^{m}}{\bar{V}} O H_{b}\left(\frac{K_{T}^{m o n}}{m_{f}+K_{T}^{m o n} C D}\right)
$$

utilizando o formalismo de troca iónica para troca de ${ }^{-} \mathrm{OH}$ por $\mathrm{Br}$

$$
K_{O H / B r}=\frac{O H_{b} \cdot B r_{f}}{O H_{f} \cdot B r_{b}}
$$

obtemos, apōs as devidas simplificações

$$
k \psi=\frac{O H_{f} \cdot k_{2}^{0} m_{f}+\left(k_{2}^{m} / \bar{V}\right) \cdot k_{O H / B r}\left(B r_{b} / B r_{f}\right) \cdot k_{T}^{m o n}}{m_{f}+k_{T}^{\text {mon }} C D}
$$

$m_{f} \vec{e}$ dado pela expressâo (Sasaki et al, 1975) 


$$
N m_{f}+\left(1-\alpha^{\prime}-\beta\right) B r_{f}+N B B_{f}^{-} \rightleftharpoons C M \text { Micela }
$$

onde $\mathrm{B}^{-}$refere-se à forma básica livre em sistema tamponado: neste estudo foi utilizado tampão borato (vide infra)

$$
C M=-K e q / \bar{N} \text { e } \alpha^{\prime} \text { e } B^{\prime} \text { säo constantes }
$$

A expressão 92 pela lei de ação das massas pode ser escrita na forma

$$
\log m_{f}=C M-\left(1-\alpha^{\prime}\right) \log B r_{f}+\beta \log \frac{B r_{f}}{B}
$$

Na C.M.C. temos a seguinte condição

$$
m_{f}=\left|B r_{f}\right|=C M C
$$

Substituindo 94 em 93 obtemos

$$
\log C M C=C M-\left(1-\alpha^{\prime}\right) \log C M C+\beta \log \frac{C M C}{B_{f}}
$$

esta expressão exprime o comportamento da CMC em função da con centração de sal, a qual $\vec{e}$ anāloga as expressōes (8,15 e 19) e as de Funasaki (1978 e 1979).

A constante de troca de Borato, Brometo $\left(K_{B / B r}\right) \bar{e}$ dada por

$$
\begin{aligned}
& \mathrm{K}_{\mathrm{B} / \mathrm{Br}} \\
& \mathrm{B}_{f}^{-}+\mathrm{BR}_{b}^{-} \rightleftharpoons \mathrm{B}_{b}^{-}+\mathrm{Br}_{f} \\
& K_{B / B r}=\frac{B_{b}^{-} \cdot B r_{f}^{-}}{B_{f}^{-} \cdot B r_{f}^{-}}
\end{aligned}
$$

na CMC temos

$$
K_{B / B r}=\frac{\beta \cdot C M C}{(1-\alpha-\beta)\left(B_{f}^{-}\right)}
$$

Associando-se $98 \bar{a}$ expressão de $m_{f}$ na CMC (equação 95) e utili zando os valores descritos de CM, CMC e 1-a' 


$$
\begin{aligned}
C M & =-4,84 \\
C M C & =5 \times 10^{-4} M \\
\left(1-\alpha^{\circ}\right) & =0,6 \quad \text { (Quina et a } 1,1980)
\end{aligned}
$$

obtemos apōs rearranjos

$$
K_{B / B r}=\frac{\beta}{0,6-\beta} \cdot 10\left(\frac{1,6 \log \left(5 \times 10^{-4}\right)+4.84}{\left(\frac{10}{\beta}\right)}\right)
$$

o valor que melhor se ajusta para $\left(K_{B / B r}=2,3 \times 10^{-2}\right.$ na $C M C$, Quina et al, 1980) e $\beta=0,28$.

As equações acima servem para estabelecer o valor de $m_{f}$ e a concentração de Borato efetiva, isto é, transformase a concentração de base livre de Borato (dependente do pH) em Brometo livre. Estes valores são então aplicados na equa-

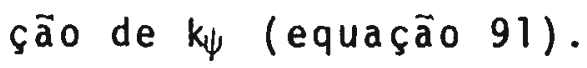

E interessante ver o limite da expressão 91 quando CD tende a zero. Utilizando-se as definiçōes de $K_{T}^{m o n}$ e $K_{e q} / N$ respectivamente temos

$$
\begin{aligned}
& K_{T}^{\text {mon }}=\frac{D C P_{b} \cdot m_{f}}{D C P_{f} \cdot C D} \\
& \frac{K_{e q}}{\bar{N}}=\frac{D C P_{b}}{D C P_{f}\left(C D+D C P_{b}\right)}
\end{aligned}
$$

combinando as equaçōes acima obtemos

$$
K_{T}^{m o n}=\frac{K_{e q}}{N} \cdot m_{f}\left(1+\frac{D C P_{b}}{C D}\right)
$$

Como a quantidade de DCP usualmente empregada é mui to pequena (em geral da ordem de $5 \times 10^{-5} \mathrm{M}$ ), mesmo no limite de $C D$ zero (lembre-se que $C D=C T-C M C$ ), $C T$ é razoavelmente maior 
que CD (o anfifilico empregado é $\operatorname{CTAB}, C M C \approx 1 \times 10^{-3} M$, na ausência de sal, Fendler e Fendler, 1975).

Assim sendo, o fator $D C P_{b} / C D$ pode ser negligenciado e a expressão 100 reduz-se para

$$
K_{T}^{\text {mon }}=\frac{k_{e q}}{N} \cdot m_{f}
$$

Aplicando-se a equação 101 em 91 temos:

$$
k \psi=\frac{k_{2}^{0} \mathrm{OH}_{f}+k_{2}^{m_{O H}}\left(\frac{1}{V}\right) k_{O H / B r}\left(B r_{b} / B r_{f}\right)\left(K_{e q} / \bar{N}\right)}{1+\left(k_{e q} / \bar{N}\right) \cdot C D}
$$

podemos então ver o 1 imite

$$
\begin{aligned}
& \lim k_{\psi}=k_{2}^{0} \mathrm{OH}_{f} \\
& C D \rightarrow 0
\end{aligned}
$$

Aplicando-se as equaçôes 95 e 99 obtemos a concentração de monómero livre $\left(m_{f}\right)$ e Borato livre $\left(B_{f}\right)$. A partir destes obtemos $k_{T}^{m o n}$ e em seguida $k \psi$ pelo uso da equaçäo 91.

\section{Efeito de CTAB sobre $k \psi$}

Vemos a seguir (Tabela 23 a 26) o efeito de CTAB sobre a constante de velocidade $(k \psi)$, relação de produtos $(P /$ A) e porcentagem de piridona formada (\%P) para a reaçäo de hi drölise alcalina dos ions RCP.

As Figuras $39,40,41$ e 42 correspondem ao efeito de CTAB sobre a constante de velocidade do DCP, OCP, BCP e MCP respectivamente. As Figuras 43,44 e 45 correspondem ao efeito de CTAB sobre a relação dos produtos da reação de $h i-$ drōlise do OCP, BCP e MCP respectivamente. Finalmente, na Fi 
Tabela 23 - Efeito de CTAB na reação de hidrōlise de $\mathrm{N}$-dodecil 4cianopiridineo ( $D C P=4,72 \times 10^{-5} \mathrm{M}$ ) em tampão borato $20 \mathrm{mM}$.

\begin{tabular}{|c|c|c|c|c|c|c|}
\hline $\begin{array}{l}\text { CTAB } \\
(M) \\
\times 10^{2}\end{array}$ & $\mathrm{pH}$ & $\begin{array}{l}\mathrm{k \psi}^{-1} \\
\left(\sec ^{-1}\right) \\
\times 10^{2}\end{array}$ & $\begin{array}{l}\text { Piridona } \\
\text { (espectro) } \\
\times 10^{5}(\mathrm{M})\end{array}$ & $\begin{array}{l}\text { Piridona } \\
\text { (DTNB) } \\
\times 10^{5}(\mathrm{M})\end{array}$ & $P / A$ & \%p \\
\hline 0,0571 & 9,10 & 0,0265 & 3,21 & 2,78 & 1,737 & 63,46 \\
\hline 0,0571 & 9,22 & 0,0112 & 3,36 & - & 2,471 & 71,19 \\
\hline 0,0951 & 9,10 & 0,0310 & 4,38 & - & 12,882 & 92,80 \\
\hline 0,0951 & 9,20 & 0,0456 & 4,53 & - & 23.842 & 95,97 \\
\hline 0,190 & 9,10 & 0,0966 & 4,52 & 3,11 & 4,215 & 80,82 \\
\hline 0,190 & 9,10 & 0,136 & - & - & - & - \\
\hline 0,38 & 9,13 & 0,266 & 4,49 & 3,71 & 6,613 & 86,86 \\
\hline 0,761 & 9,15 & 0,440 & 4,70 & 3,63 & 7,505 & 88,24 \\
\hline 1,90 & 9,10 & 0,501 & 4,65 & 4,23 & 15,857 & 94,07 \\
\hline 3,80 & 9,10 & 0,385 & 4,55 & 4,63 & 35,308 & 97,24 \\
\hline 0,0266 & 9,65 & 0,0120 & 0,503 & 0,534 & 0,123 & 10,95 \\
\hline 0,038 & 9,65 & 0,0121 & 0,642 & 1,04 & 0,217 & 17,83 \\
\hline 0,0517 & 9,65 & 0,0510 & 3,71 & 3,31 & 2,901 & 74,36 \\
\hline 0,0951 & 9,65 & 0,158 & 4,17 & 3,39 & 3,957 & 79,83 \\
\hline 0,190 & 9,65 & 0,501 & 4,21 & 3,44 & 4,274 & 81,04 \\
\hline 0,380 & 9,65 & 0,865 & 4,43 & 3,41 & 4,900 & 83,05 \\
\hline 0,761 & 9,58 & 1,22 & 4,51 & 3,86 & 5,601 & 84,85 \\
\hline 1,90 & 9,55 & 1,55 & 4,25 & 4,14 & 7,990 & 88,88 \\
\hline 3,80 & 9,50 & 1,20 & 0,463 & - & 51,444 & 98,09 \\
\hline 0,0571 & 9,85 & 0,146 & 4,08 & 3,56 & 4,244 & 80,93 \\
\hline 0,0951 & 9,88 & 0,382 & 4,50 & 3,71 & 6,675 & 86,97 \\
\hline 0,19 & 9,98 & 1,11 & 4,55 & 3,93 & 8,833 & 89,83 \\
\hline 0,761 & 9,92 & 2,94 & 4,70 & 3,95 & 10,949 & 91,63 \\
\hline 1,90 & 9,89 & 4,19 & 4,99 & 4,32 & 16,811 & 94,38 \\
\hline 3,80 & 9,85 & 2,75 & 4,71 & - & 471,000 & 99,79 \\
\hline
\end{tabular}


Tabela 24 - Efeito de CTAB na reaçäo de hidrölise de N-octil-4-cianopiridineo $\left(O C P=4,80 \times 10^{-5} \mathrm{M}\right)$

\begin{tabular}{|c|c|c|c|c|c|c|c|}
\hline $\begin{array}{l}\text { Tampäo } \\
20 \mathrm{mM}\end{array}$ & $\begin{array}{l}\text { CTAB } \\
(M) \\
\times \quad 10^{2}\end{array}$ & $\mathrm{pH}$ & $\left.\begin{array}{l}k \psi\left(\sec ^{-1}\right) \\
\times 10^{3} \\
x \\
10\end{array}\right) !$ & $\left\{\begin{array}{l}\text { Piridona } \\
\text { (espectro) } \\
\text { (M) } \times 10^{5}\end{array}\right.$ & $\begin{array}{l}\text { Piridona } \\
\text { (DTNB) } \\
\text { (M) } \times 10^{5}\end{array}$ & $P / A$ & $\% p$ \\
\hline borato & 0,102 & 9,95 & 0,256 & 0,968 & 0,956 & 0,251 & 20,06 \\
\hline$"$ & 0,190 & 9,70 & 0,212 & 2,48 & 1,89 & 0,836 & 45,53 \\
\hline$"$ & $2,040,204$ & 9,95 & 0,322 & 1,81 & 1,62 & 0,556 & 35,73 \\
\hline$"$ & 0,380 & 9,80 & 0,345 & 3,08 & 2,41 & 1,336 & 57,19 \\
\hline$"$ & 0,41 & 9,90 & 0,456 & 2,92 & 2,68 & 1,400 & 58,33 \\
\hline$"$ & 0,761 & 9,80 & 0,466 & 3,45 & 2,98 & 2,028 & 66,97 \\
\hline$"$ & 0,907 & 9,98 & 0,722 & 3,45 & 2,85 & 1,443 & 59,07 \\
\hline$"$ & T,90 pHup & 9,70 & 0,585 & 3,81 & 3,36 & 2,951 & 74,69 \\
\hline$"$ & 2,04 & 9,90 & 1,03 & 3,99 & 3,68 & 3,974 & 79,89 \\
\hline$"$ & 3,80 & 9,85 & 1,21 & 3,94 & - & 4,581 & 82,08 \\
\hline$"$ & 4,08 & 9,85 & 1,18 & 4,11 & 3,94 & 5,193 & 83,85 \\
\hline$"$ & 5,10 & 9,80 & 1,19 & 3,93 & 4,04 & 4,828 & 82,84 \\
\hline bicarbonato & 0,0408 & 10,60 & 1,23 & 1,56 & 1,42 & 0,450 & 37,03 \\
\hline$"$ & 0,0612 & 10,62 & 1,38 & 1,82 & 1,62 & 0,558 & 35,82 \\
\hline$"$ & 0,102 & 10,52 & 1,62 & 2,16 & 1,78 & 0,696 & 41,04 \\
\hline$"$ & 0,204 & 10,58 & 1,73 & 2,59 & 2,29 & 1,034 & 50.84 \\
\hline$"$ & 0,408 & 10,55 & 2,08 & 3,05 & 2,75 & 1,526 & 60,41 \\
\hline$"$ & 0,816 & 10,58 & 2,54 & 3,36 & 3,09 & 2,048 & 67,19 \\
\hline$"$ & 2,04 & 10,50 & 3,37 & 3,78 & 3,67 & 3,465 & 77,60 \\
\hline$"$ & 4,08 & 10,40 & 3,74 & 3,90 & 3,75 & 3,923 & 79,69 \\
\hline
\end{tabular}


Tabela 25 - Efeito de CTAB na reação de hidrōlise de $N$-butil-4-cianopiridineo (BCP $\left.\approx 4,80 \times 10^{-5} \mathrm{M}\right)$.

\begin{tabular}{|c|c|c|c|c|c|c|c|}
\hline $\begin{array}{l}\text { Tampão } \\
20 \mathrm{mM}\end{array}$ & $\begin{array}{l}\text { CTAB } \\
(M) \\
\times 10^{2}\end{array}$ & $\mathrm{pH}$ & $\begin{array}{l}k\left(\sec ^{-1}\right) \\
\times 10^{3}\end{array}$ & $\begin{array}{c}\text { Piridona } \\
\text { (espectro) } \\
\text { (M) } \\
\times 10^{5} \\
\end{array}$ & $\begin{array}{l}\text { Piridona } \\
\text { (DTNB) } \\
\text { (M) } \\
\times 10^{5} \\
\end{array}$ & $\mathrm{P} / \mathrm{A}$ & $\% P$ \\
\hline bicarbonato & 0,0408 & 10,82 & 1,55 & 1,04 & 1,00 & 0,270 & 2,26 \\
\hline$"$ & 0,0612 & 10,83 & 1,60 & 1,16 & 1,08 & 0,304 & 23,31 \\
\hline$"$ & 0,102 & 10,75 & 1,47 & 1,75 & 1,03 & 0,294 & 22,72 \\
\hline$"$ & 0,204 & 10,78 & 1,46 & 1,40 & 1,26 & 0,383 & 27,69 \\
\hline$"$ & 0,408 & 10,70 & 1,31 & 1,37 & 1,23 & 0,371 & 27,06 \\
\hline$"$ & 0,816 & 10,75 & 1,54 & 1,67 & 1,40 & 0,470 & 31,97 \\
\hline$"$ & 2,04 & 10,63 & 1,55 & 2,03 & 2,47 & 0,882 & 46,86 \\
\hline$"$ & 4,08 & 10,51 & 1,13 & 2,12 & 2,22 & 0,825 & 45,20 \\
\hline Fosfato & 0,04 & 10,85 & 2,11 & 1,35 & - & 0,391 & 28,11 \\
\hline$"$ & 0,100 & 10,85 & 2,23 & 1,44 & 1,50 & 0,441 & 30,60 \\
\hline$"$ & 0,102 & 10,83 & 1,73 & 1,58 & 1,26 & 0,420 & 29,58 \\
\hline$"$ & 0,102 & 10,83 & 1,96 & 1,64 & 1,55 & 0,498 & 33,24 \\
\hline$"$ & 0,200 & 10,85 & 2,17 & 1,59 & 1,53 & 0,481 & 32,48 \\
\hline$"$ & 0,204 & 10,82 & 2,00 & 1,78 & 1,48 & 0,514 & 33,95 \\
\hline$"$ & 0,400 & 10,85 & 2,14 & 1,76 & 1,63 & 0,546 & 35,32 \\
\hline$"$ & 0,408 & 10,81 & 2,01 & 1,91 & 1,67 & 0,595 & 41,04 \\
\hline$"$ & 0,800 & 10,82 & 2,05 & 1,64 & 1,51 & 0,488 & 32,80 \\
\hline$"$ & 0,816 & 10,75 & 1,70 & 2,02 & 1,86 & 0,678 & 40,40 \\
\hline$"$ & 0,816 & 10,83 & 1,43 & 2,11 & 1,92 & 0,723 & 41,96 \\
\hline$"$ & 2,00 & 10,78 & 2,16 & 2,22 & 2,27 & 0,879 & 46,78 \\
\hline$"$ & 0,0408 & 11,47 & 10,4 & 2,27 & 2,15 & 0,897 & 47,28 \\
\hline$"$ & 0,0612 & 11,49 & 10,6 & 2,26 & 2,23 & 0,879 & 46,78 \\
\hline$"$ & 0,102 & 11,49 & 11 & 2,35 & 2,22 & 1,123 & 52,90 \\
\hline$"$ & 0,204 & 11,48 & 10,7 & 2,39 & 2,27 & 0,943 & 48,53 \\
\hline$"$ & 0,408 & 11,48 & 10,6 & 2,44 & 2,58 & 1,096 & 52,29 \\
\hline$"$ & 0,816 & 11,40 & 9,49 & 2,53 & 2,68 & 1,187 & 54,27 \\
\hline$"$ & 2,04 & 11,35 & 7,96 & 2,61 & 2,65 & 1,212 & 54,79 \\
\hline$"$ & 4,08 & 11,18 & 6,04 & 2,69 & 2,87 & 1,376 & 57,91 \\
\hline
\end{tabular}


Tabela 26 - Efeito de CTAB na reação de hidrölise de N-metil-4-cianopiridineo ( $M C P=4,70 \times 10^{-5} M$ )

\begin{tabular}{|c|c|c|c|c|c|c|c|}
\hline $\begin{array}{l}\text { Tampão } \\
20 \mathrm{mM}\end{array}$ & $\begin{array}{l}\text { CTAB (M) } \\
\times 10\end{array}$ & $\mathrm{pH}$ & $\begin{array}{c}k_{\psi}\left(\sec ^{-1}\right) \\
\times 10^{2}\end{array}$ & \begin{tabular}{|c|} 
Piridona \\
espectro) \\
$\times 10^{5}(\mathrm{M})$
\end{tabular} & $\begin{array}{c}\text { Piridona } \\
\text { (DTNB) } \\
\times 10^{5}(M)\end{array}$ & $P / A$ & $\% P$ \\
\hline bicarbonato & 0,004 & 10,80 & 0,219 & 0,888 & - & 0,227 & 18,50 \\
\hline$"$ & 0,006 & 10,85 & 0,224 & 1,02 & - & 0,270 & 21,26 \\
\hline$"$ & 0,01 & 10,82 & 0,219 & 1,02 & - & 0,270 & 21,26 \\
\hline$"$ & 0,02 & 10,82 & 0,218 & 1,02 & - & 0,270 & 21,26 \\
\hline$"$ & 0,04 & 10,82 & 0,192 & 10,6 & - & 0,283 & 22,06 \\
\hline$"$ & 0,08 & 10,84 & 0,208 & 1,15 & - & 0,315 & 23,95 \\
\hline$"$ & 0,20 & 10,78 & 0,172 & 1,13 & - & 0,308 & 23,55 \\
\hline$"$ & 0,40 & 10,73 & 0,164 & 1,16 & - & 0,319 & 24,18 \\
\hline$"$ & 0,80 & 10,45 & 0,0642 & 0,803 & - & 0,201 & 16,74 \\
\hline$"$ & 0,80 & 10,43 & 0,118 & 1,09 & - & 0,294 & 22,72 \\
\hline$"$ & 1,00 & 10,45 & 0,0709 & 0,862 & - & 0,219 & 17,97 \\
\hline$"$ & 1,00 & 10,65 & 0,110 & 1,16 & - & 0,319 & 24,18 \\
\hline fosfato & 0,00408 & 11,49 & 1,09 & 2,16 & 2,03 & 0,774 & 43,63 \\
\hline$"$ & 0,00612 & 11,50 & 1,05 & 2,18 & 2,05 & 0,788 & 44,07 \\
\hline$"$ & 0,0102 & 11,50 & 1,07 & 2,16 & 2,03 & 0,774 & 43,63 \\
\hline$"$ & 0,0204 & 11,51 & 1,06 & 2,13 & 2,01 & 0,758 & 43,12 \\
\hline$"$ & 0,0408 & 11,48 & 1,04 & 2,08 & 1,96 & 0,727 & 42,10 \\
\hline$"$ & 0,0816 & 11,48 & 9,04 & 2,14 & 2,02 & 0,765 & 43,34 \\
\hline$"$ & 0,204 & 11,40 & 0,812 & 2,15 & 2,02 & 0,768 & 43,44 \\
\hline$"$ & 0,408 & 11,30 & 0,627 & 2,25 & 1,95 & 0,778 & 43,76 \\
\hline
\end{tabular}




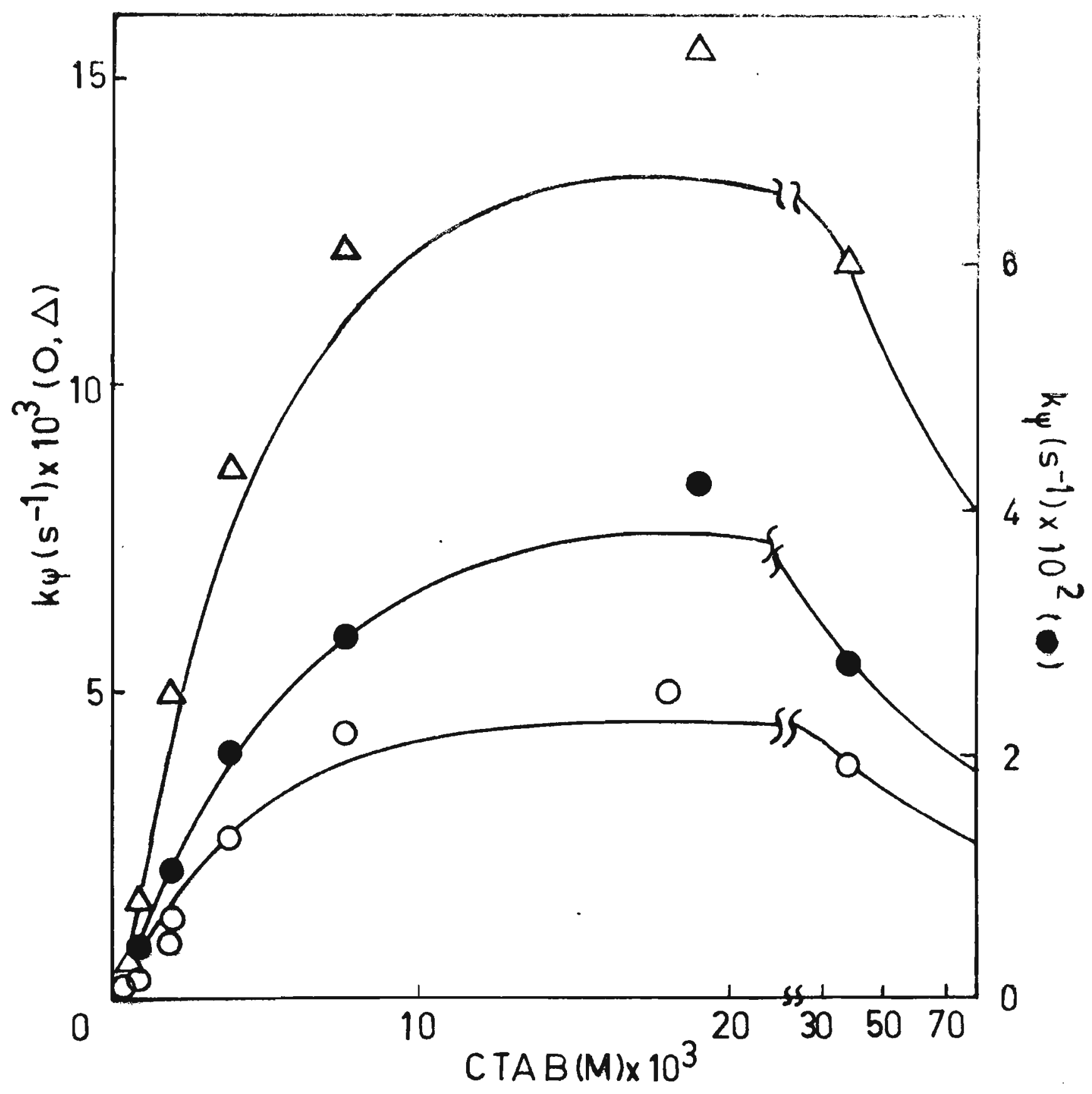

Figura 39 - Efeito de CTAB na constante de velocidade da reação de hidrōtise dq $\mathrm{N}$-dodecil-4-cianopiridīneo (DCP $\left.=4,72 \times 10^{-5 \mathrm{M}}\right) . \mathrm{O} \mathrm{pHm}\left(\mathrm{pH}\right.$ mëdio) $=9,13^{+}-0,05, \mathrm{k} \psi \times 10^{3}$ $\mathrm{S}^{-1}$ (ordenada à esquerda) $\triangle \triangle \mathrm{pHm}=9,6 \mathrm{~h}-0,06, \mathrm{k} \psi \times 10^{3} \mathrm{~s}^{-1}$ (ordenada à esquerda); $\mathrm{pHm}=9,90-0,05, \mathrm{k} \notin \times 10^{2} \mathrm{~s}^{-1}$ (ordenada à direita) (veja condiçōes na Tabela 19). As linhas foram calculadas pela equação, nas seguintes condições: $k_{2}^{m}=10 . k_{2}^{0} ; K_{0 H / B r}=0,08$ (Chaimovich et a 1, 1979); $\mathrm{V}=0,037 \mathrm{~mol}^{-1}$ (Mukerjee, 1962); as curvas foram calculadas no $\mathrm{pH}$ acima indicado; tampão borato $20 \mathrm{mM} e$ $D C P=5 \times 10^{-5} \mathrm{M}$. 


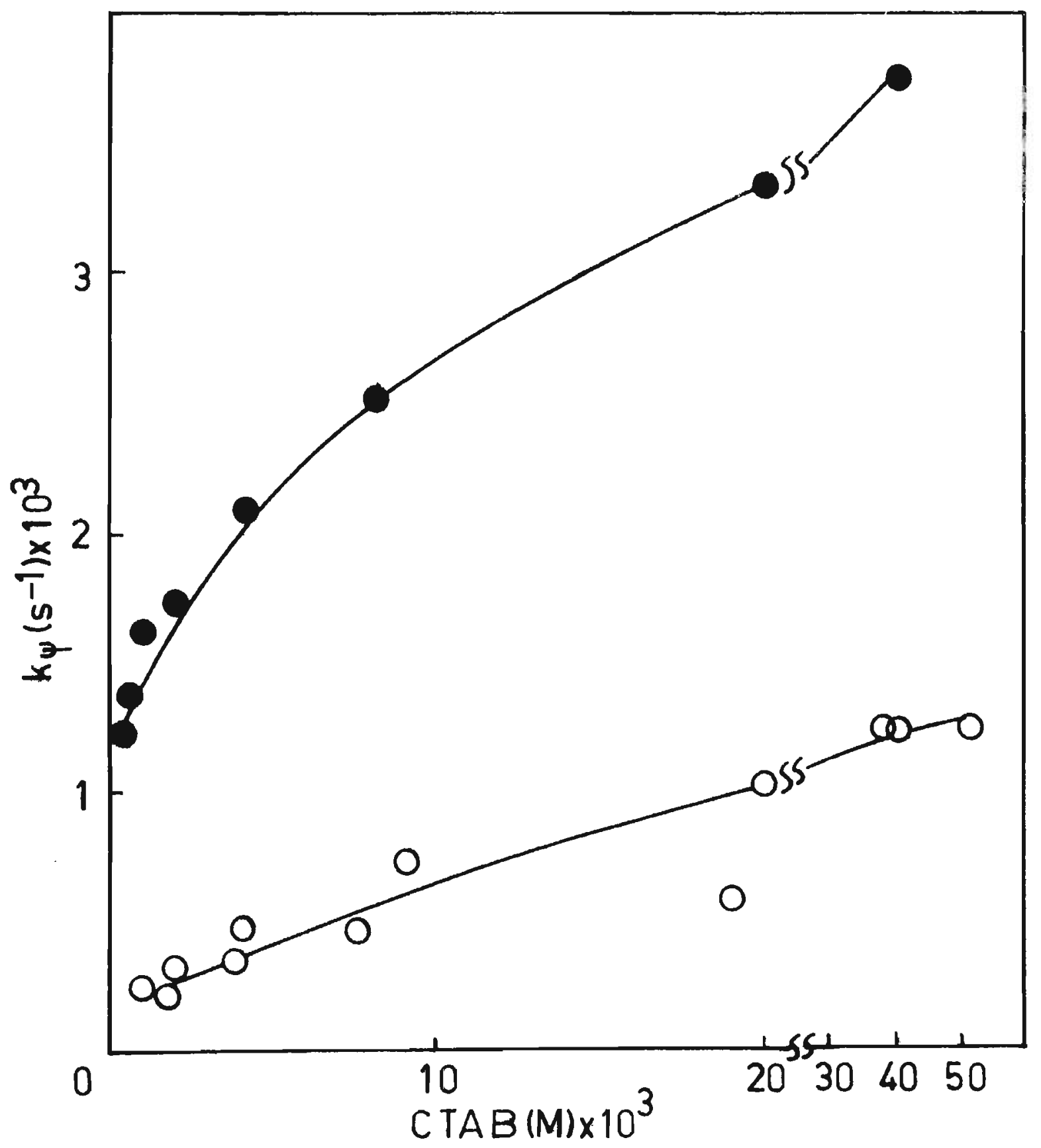

Figura 40 - Efeito de CTAB na constante de velocidade da reação de hidrōlise do $\mathrm{N}$-octil-4-cianopiridineo (OCP $=4,80 \times 10^{-5} \mathrm{M}$ ). $\mathrm{O}$ pHm $(\mathrm{pH}$ médio $)=9,84 \pm 0,09$,

$\mathrm{pHm}=$ $10,56 \pm 0,07$

(veja condições da Tabe1 a 20 ). 


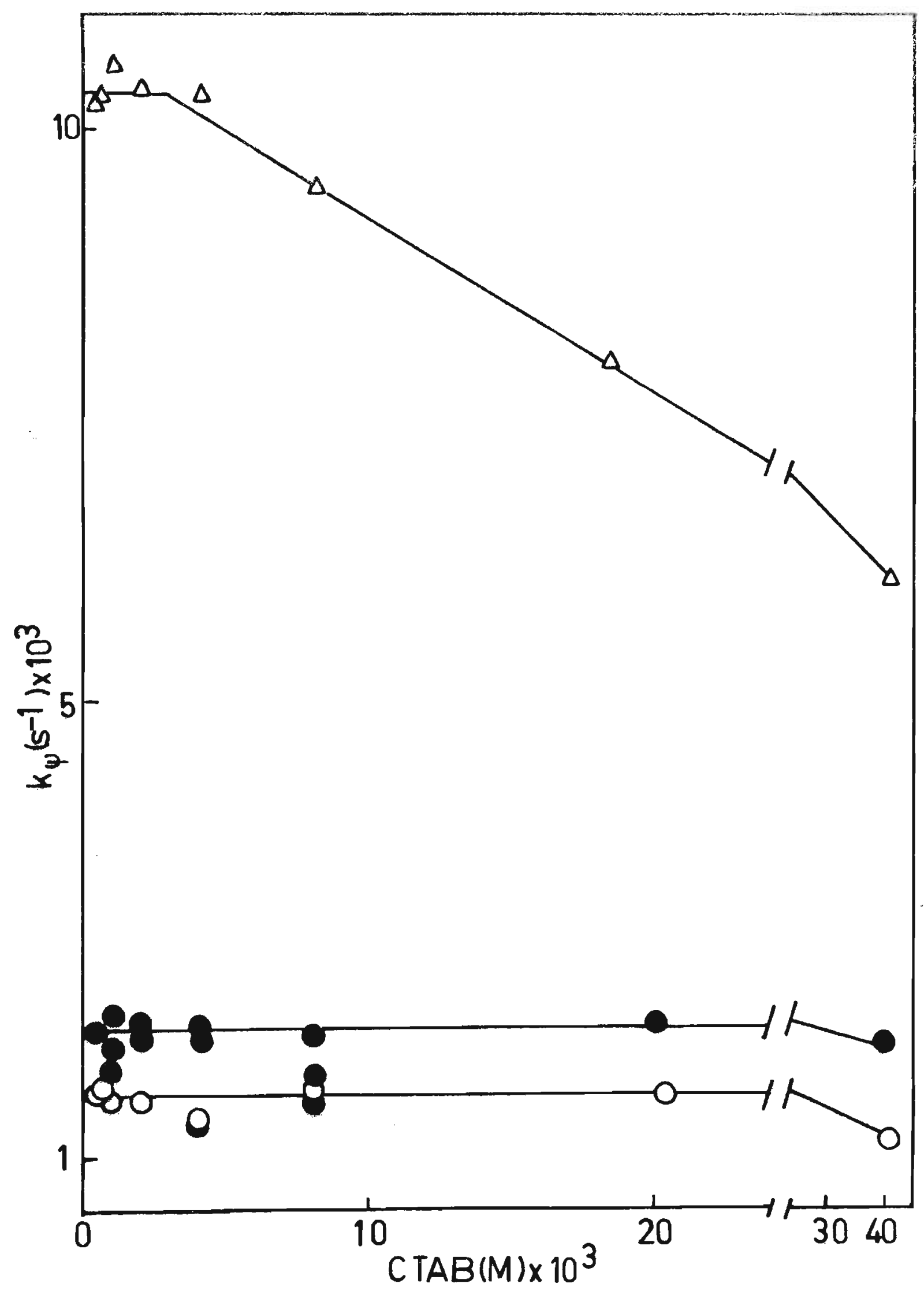

Figura 41 - Efeito de CTAB na constante de velocidade de hidró 1 ise do $\mathrm{N}$-butil-4-cianopiridineo $\left(B C P=4,80 \times 10^{-5} \mathrm{M}\right.$ ). O $\mathrm{pHm}$ ( $\mathrm{pH}$ médio $)=10,72 \pm 0,11 . \quad \mathrm{pHm}=10,8 \pm 0,04 . \Delta \mathrm{pHm}=11,42 \pm 0,17$ (veja condiçôes a Tabela 21). 


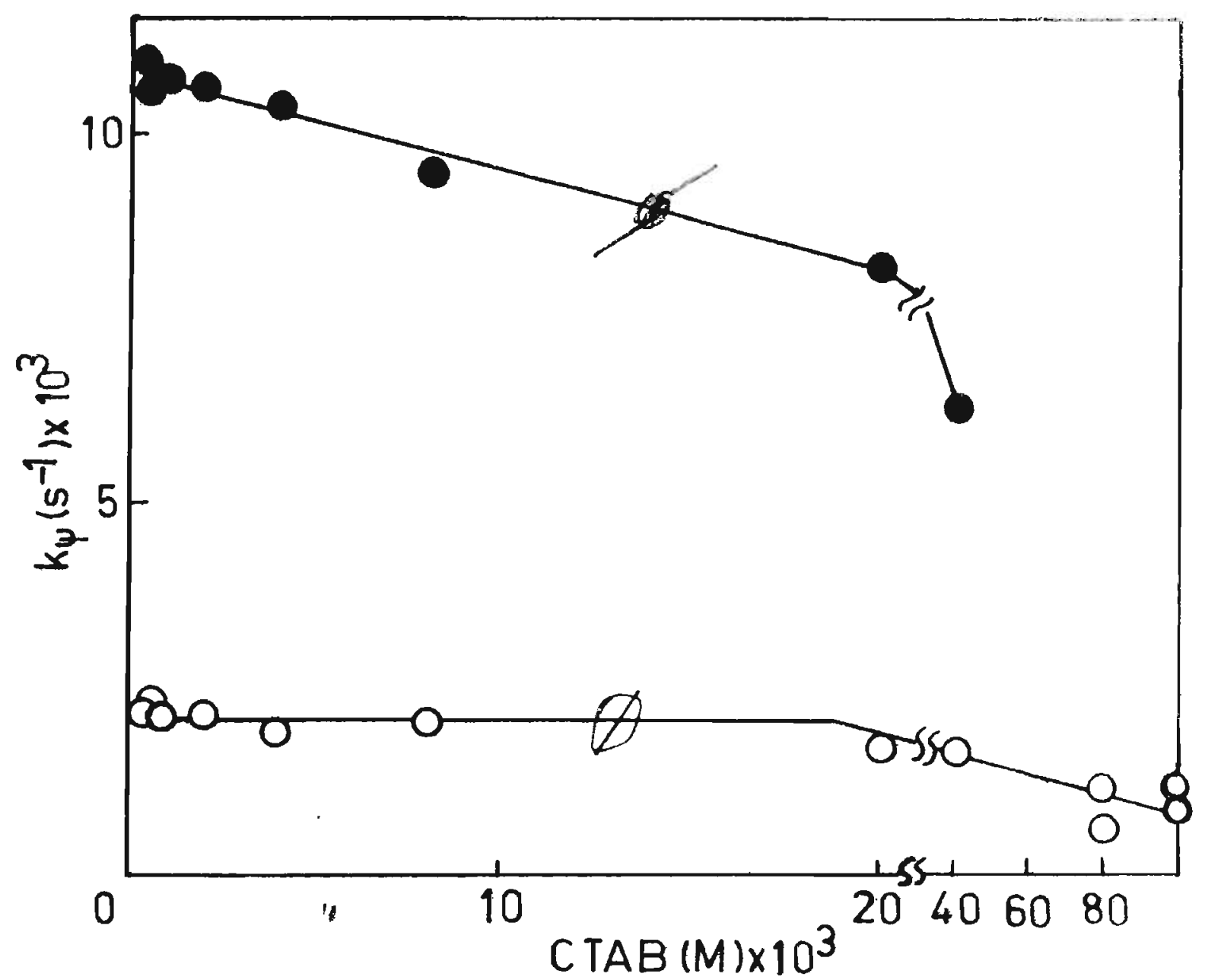

Figura 42 - Efeito de CTAB na constante de velocidade de hidró lise $N$-metil-4-cianopiridineo (MCP $=4,70 \times 10^{-5} \mathrm{M}$ ). O pHm (pHmé dio) $=10,72 \pm 0,14.0 \mathrm{pHm}=11,46 \pm 0,07$. 


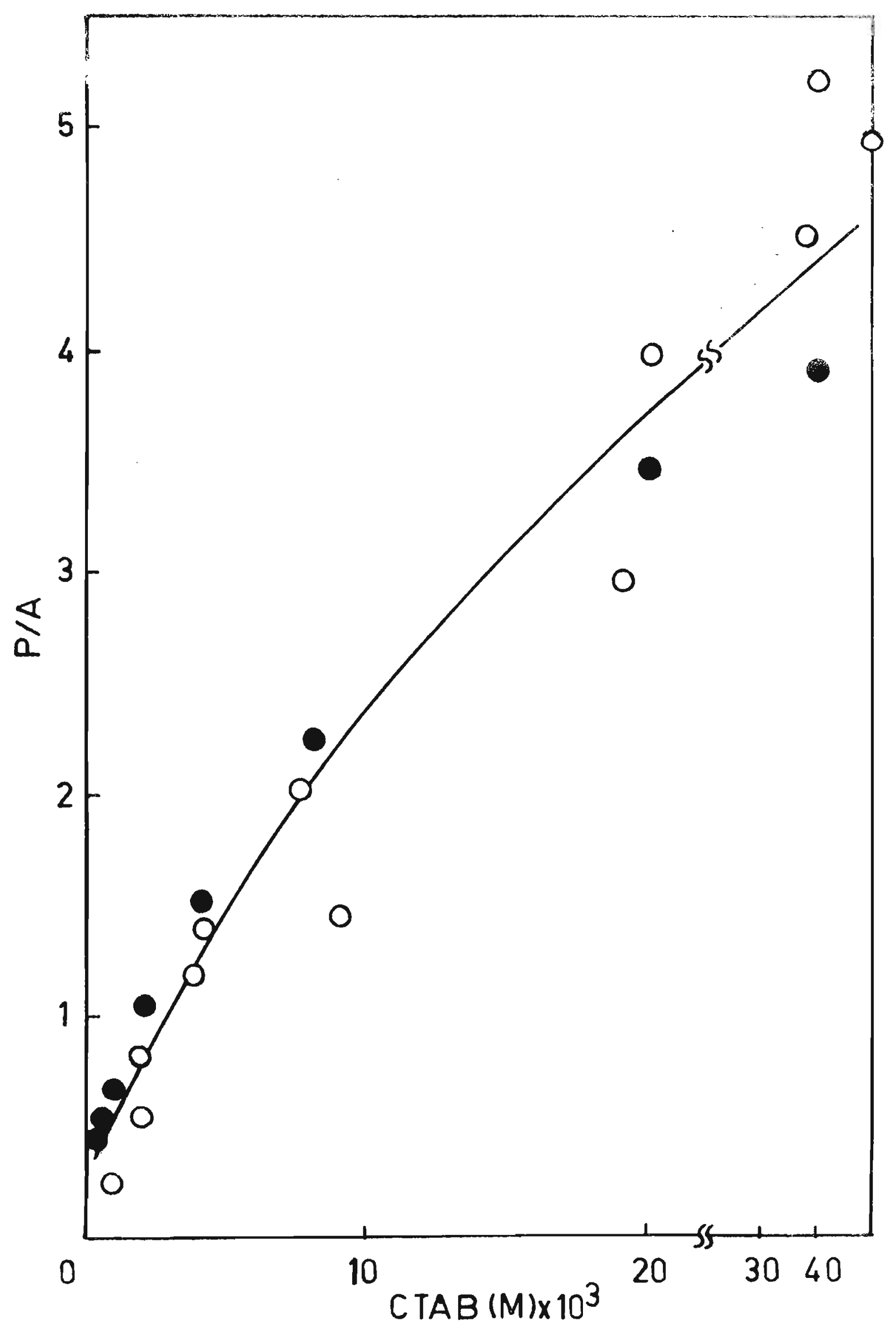

Figura 43 - Efeito de CTAB sobre a relação de produtos (P/A). Hidrólise de $\mathrm{N}$-octil-4-cianopiridineo $\left(0 \mathrm{CP}=4,80 \times 10^{-5}\right)$. O pHm $\left(\mathrm{pH}\right.$ médio) $=9,84_{-0,09}^{+} \mathrm{pHm}=10,56^{ \pm} 0,07$ (veja condições a Tabela 20). 


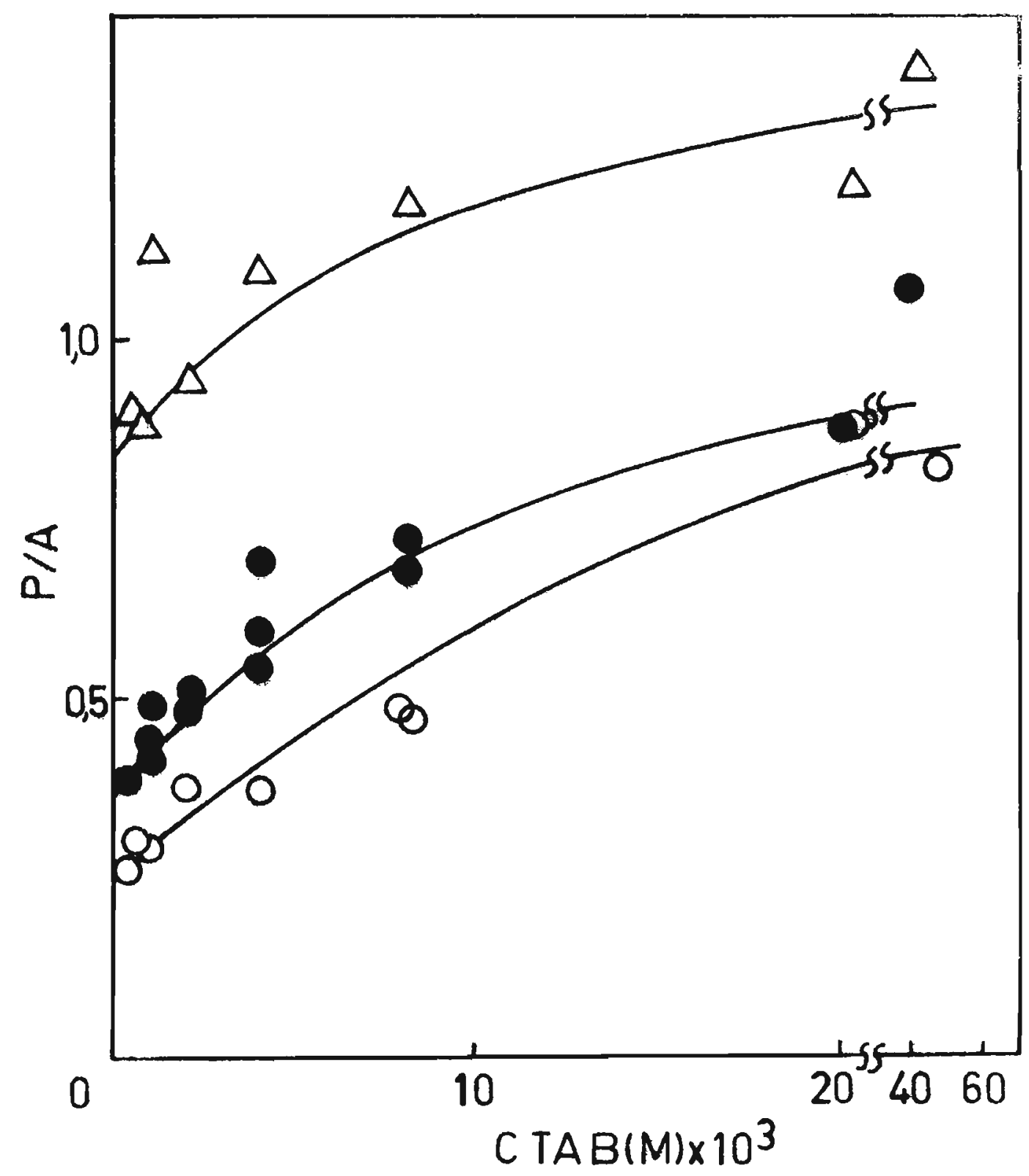

Figura 44 - Efeito de CTAB sobre a relação de produtos (P/A). Hidrōlise do $\mathrm{N}$-butil-4-cianopiridineo ( $\left.B C P=4,80 \times 10^{-5} \mathrm{M}\right)$. O pHm $($ pHmédio $)=10,72 \pm 0,11 . \quad \mathrm{pHm}=10,81 \pm 0,04 . \Delta \quad \mathrm{pH}=11,42 \pm 0,11$ (veja condiçōes a Tabela 21 ). 


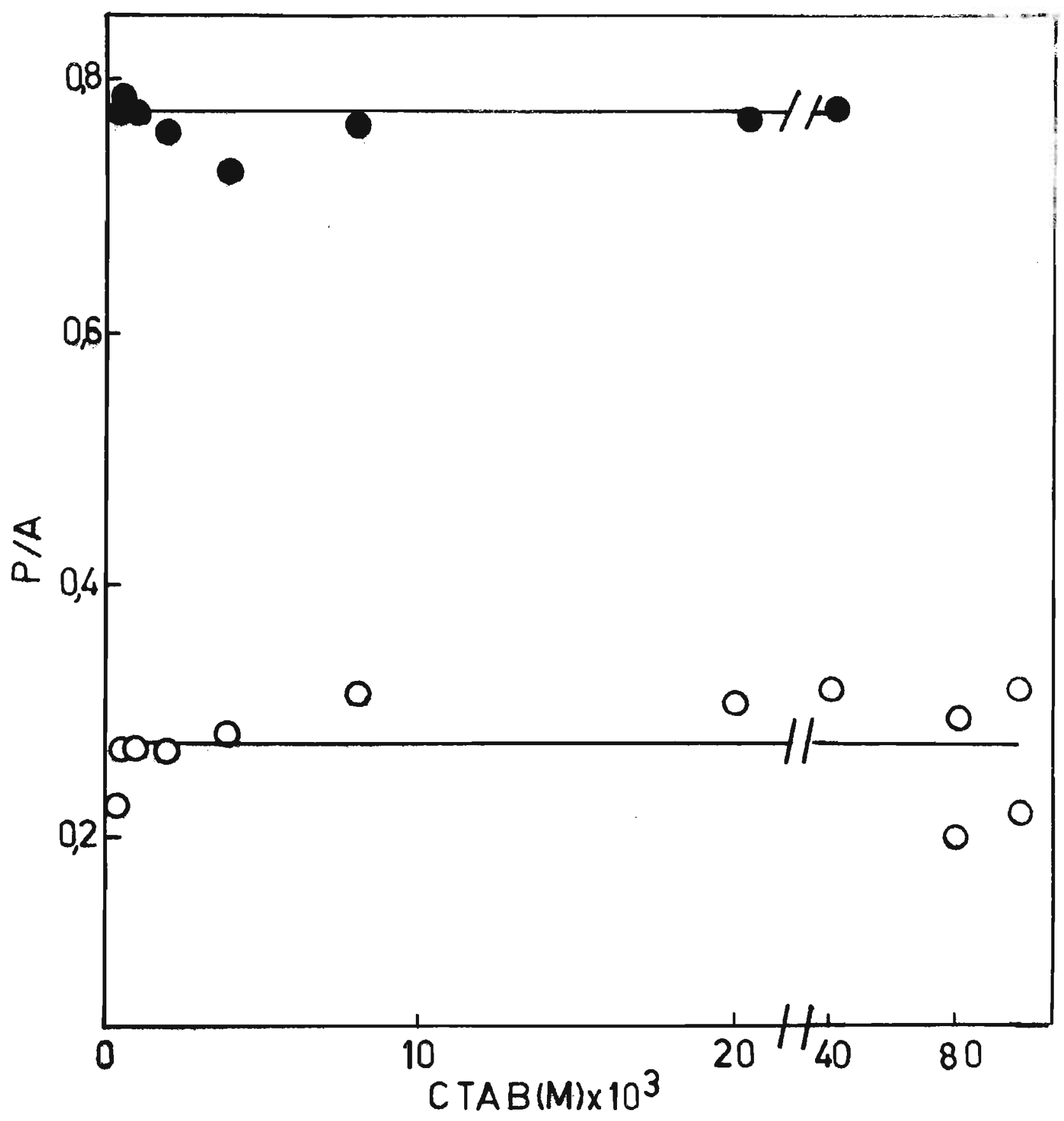

Figura 45 - Efeito de CTAB na relação de produtos (P/A). Hidró lise do $\mathrm{N}$-meti1-4-cianopiridíneo ( $\left.\mathrm{ACP} \simeq 4,70 \times 10^{-5} \mathrm{M}\right)$. O pHm(pH mé dio) $=10,72 \pm 0,14 . \quad \mathrm{pHm}=11,46^{ \pm}-0,07$ (ve.ja condição a Tabe1 a 22 ). 


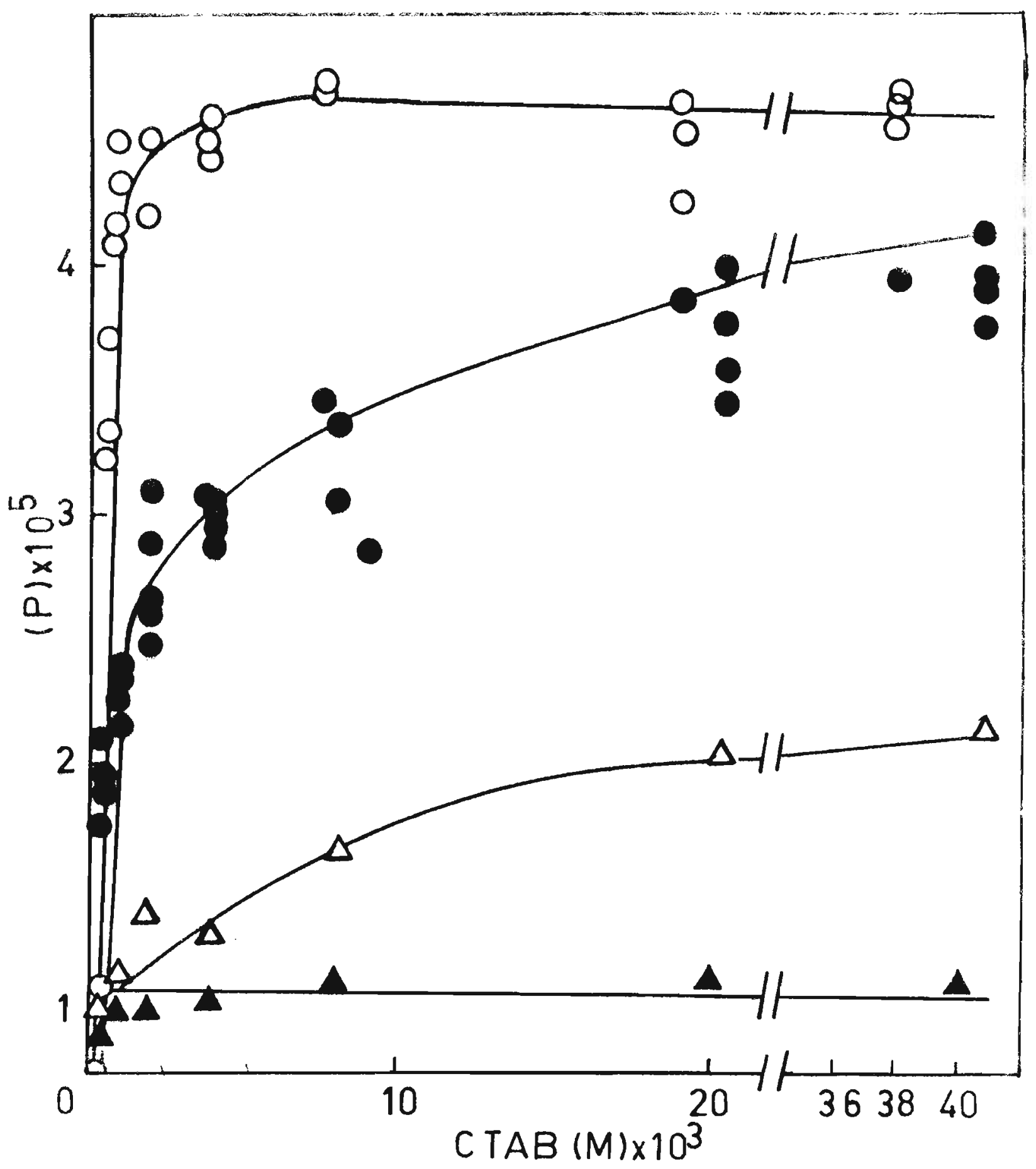

Figura 46 - Efeito de CTAB sobre a formaçäo de piridona (\%P)

Ohidrōlise do $\mathrm{N}$-dodecil-4-cianopiridineo ( $D C P=4,72 \times 10^{-5} \mathrm{M}$ ).

- hidrólise do $\mathrm{N}$-octil-4-cianopiridineo (OCP $=4,80 \times 10^{-5} \mathrm{M}$ )

$\triangle$ hidrōlise do $N$-butil-4-cianopiridíneo ( $D C P=4,80 \times 10^{-5} M$ )

A hidrōlise do $\mathrm{N}$-metil-4-cianopiridíneo (MCP $=4,72 \times 10^{-5} \mathrm{M}$ )

(veja condiçöes às Tabelas 19,20,21 e 22) 
gura 46, mostra-se a porcentagem de piridona formada para a $D C P, O C P, B C P$ e MCP em função de CTAB.

Das Tabelas 23 a 26 e Figuras 39 a 46 deve-se observar:

1 - A constante de velocidade da reação de hidrōlise do DCP (Tabela 23 e Figura 39) aumenta pela presença de CTAB. A Figura 39 mostra um mäximo na constante de velocidade (k $\psi$ ) por volta de $0,02 M$ de CTAB. Apōs o māximo observa-se diminui çäo gradativa na $k \psi$ com aumento da concentração de CTAB. Os

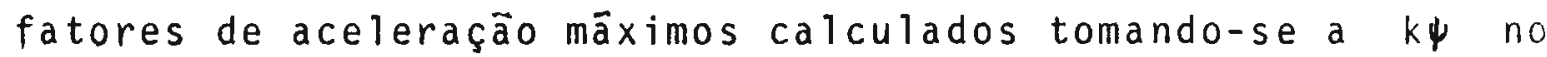
mäximo $\left(k_{\psi} \max \right)$ e dividindo pela constante de velocidade de pseudo-primeira ordem, obtida na ausência de CTAB (k市) estão' na Tabela 27.

Tabela 27 - Fatores de aceleraçäo $\left(k \psi_{\max } / k_{\psi}^{0}\right)$ para a hidrōlise do N-dodecil-4-cianopiridíneo ( $D C P=4,72 \times 10^{-5} \mathrm{M}$ ) em função do $\mathrm{pH}$.

\begin{tabular}{c|c}
$\mathrm{pH}$ & fator de aceleração \\
\hline 9,13 & 180 \\
9,61 & 270 \\
9,90 & 220
\end{tabular}

Tanto a relaçäo P/A (Tabela 19), como a \% da Figu ra 46 mostram uma formação preferencial da piridona no meio micelar (compare com a Figura 23 ). A reação de hidrölise em āgua mostra a relação $P / A$ de forma sgmoidal (Figura 17 ) enquan to que, na micela, a relação ë crescente tendendo a infinito' com aumento da concentração de CTAB. 
2- A k $\psi$ para hidrölise de OCP (Figura 40) aumenta com a concentração de CTAB e atê $40 \mathrm{mM}$ não observou-se māximos nas curvas.

A relação $P / A$ e \% é novamente maior que aquela observada em água e crescente com o aumento da concetração de CTAB (Figura 43 e 46 ).

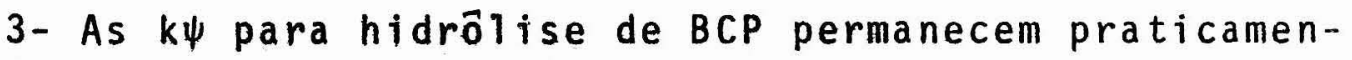
te constantes atê $0,02 \mathrm{M}$ de CTAB a pHs 10,72 e 10,81 , ocorrendo, com aumento de CTAB um ligeiro decrēscimo em $\mathrm{k} \psi$. A pH $11,4 \mathrm{k \psi}$ diminui com aumento da concentração de CTAB (Figura 41).

A relação $P / A$ e \%P é crescente com a concentraçãode detergente em todos pHs observados (Figuras 44 e 46 ).

4- Para o MCP (Figura 42) o comportamento de kqē seme Thante à de BCP. A pH 10,7 k $\psi$ ē constante (praticamente) até pelo menos 0,04 M de CTAB diminuindo com o aumento da concen tração de detergente. A pH 11,45 k $\psi$ diminui com a concentra ção de CTAB.

Uma vez que O MCP reside exclusivamente na fase aquosa em presença de CTAB, o efeito de CTAB sobre $k \psi$ dā uma in dicação direta da concetração de $\mathrm{OH}_{f}$. Na Tabela 26 ocorrem duas situações diversas, a primeira onde existe um sistema tam pão atuante ( $p H$ prōximo ao pK do tampão) e a segunda onde não hā tal sistema (veja a Tabela 26 condições a pH 10,7 e pH 11, 45). No caso de sistema tampão atuante, a constância de $\mathrm{OH}_{f}$ será dada pela contraposição de dois fatores: a concentração ' de tampäo e concentração de hidrōxido. No intuito de checar a ilanutenção do $\mathrm{pH}$ externo, estudamos o efeito sobre $k \Psi$ devido a presença de CTAB para reação de hidrôlise do MCP e do MC2P, en 
Tabela 28 - Reaçäo de hidrōlise do N-metil-4-cianopiridĩeno (MCP $4,70 \times 10^{-5} \mathrm{M}$ ) e $\mathrm{N}$-meti1-2-cianopiridineo (MC2P $9,26 \mathrm{X}$ $10^{-5} M$, em $C T A B$, com tampão borato (concentração final $20 \mathrm{mM}$ )

\begin{tabular}{|c|c|c|c|c|c|c|}
\hline $\begin{array}{c}\text { CTAB (M) } \\
\times 10\end{array}$ & $\mathrm{RCP}$ & $\mathrm{pH}$ & $\begin{array}{c}\mathrm{k}_{\psi}\left(\mathrm{sec}^{-1}\right) \\
\times 10^{3}\end{array}$ & \begin{tabular}{|c|} 
Piridona \\
(espectros) \\
$\times 10^{5}(\mathrm{M})$
\end{tabular} & $\begin{array}{c}\text { Piridona } \\
\text { (DTNB) } \\
\times 10^{5}(\mathrm{M})\end{array}$ & $P / A$ \\
\hline 0,0045 & MCP & 9,79 & 0,119 & - & 0,223 & 0,049 \\
\hline 0,010 & $"$ & 9,80 & 0,117 & 0,307 & - & 0,068 \\
\hline 0,018 & $"$ & 9,18 & 0,157 & 0,512 & 0,242 & 0,031 \\
\hline 0,08 & $"$ & 9,80 & 0,151 & 0,273 & - & 0,060 \\
\hline 0,09 & $"$ & 9,80 & 0,141 & 0,213 & 0,162 & 0,041 \\
\hline 0,18 & $"$ & 9,77 & 0,119 & 0,188 & 0,213 & 0,044 \\
\hline 0,60 & $"$ & 9,80 & 0,138 & 0,282 & - & 0,062 \\
\hline 0,80 & $"$ & 9,79 & 0,12 & 0,230 & - & 0,050 \\
\hline- & MC2P & 9,48 & 2,89 & 6,61 & 4,92 & 1,649 \\
\hline- & $"$ & 9,48 & 2,37 & 6,93 & 6,18 & 2,423 \\
\hline 0,0040 & $"$ & 9,48 & 2,82 & 6,73 & 5,92 & 2,155 \\
\hline 0,010 & $"$ & 9,48 & 2,84 & 6,95 & 6,28 & 2,501 \\
\hline 0,020 & $"$ & 9,48 & 2,89 & 6,90 & 6,31 & 2,487 \\
\hline 0,040 & $"$ & 9,48 & 2,92 & 6,92 & 6,31 & 2,501 \\
\hline 0,080 & $"$ & 9,48 & 2,72 & 6,98 & 5,39 & 2,011 \\
\hline 0,20 & $"$ & 9,47 & 2,55 & 6,97 & 6,19 & 2,455 \\
\hline 0,40 & $"$ & 9,46 & 2,39 & 6,95 & 6,51 & 2,660 \\
\hline 0,80 & $"$ & 9,46 & 2,28 & 6,95 & 6,96 & 3,087 \\
\hline 1,00 & $"$ & 9,45 & 2,50 & 7,10 & 7,97 & 4,368 \\
\hline
\end{tabular}




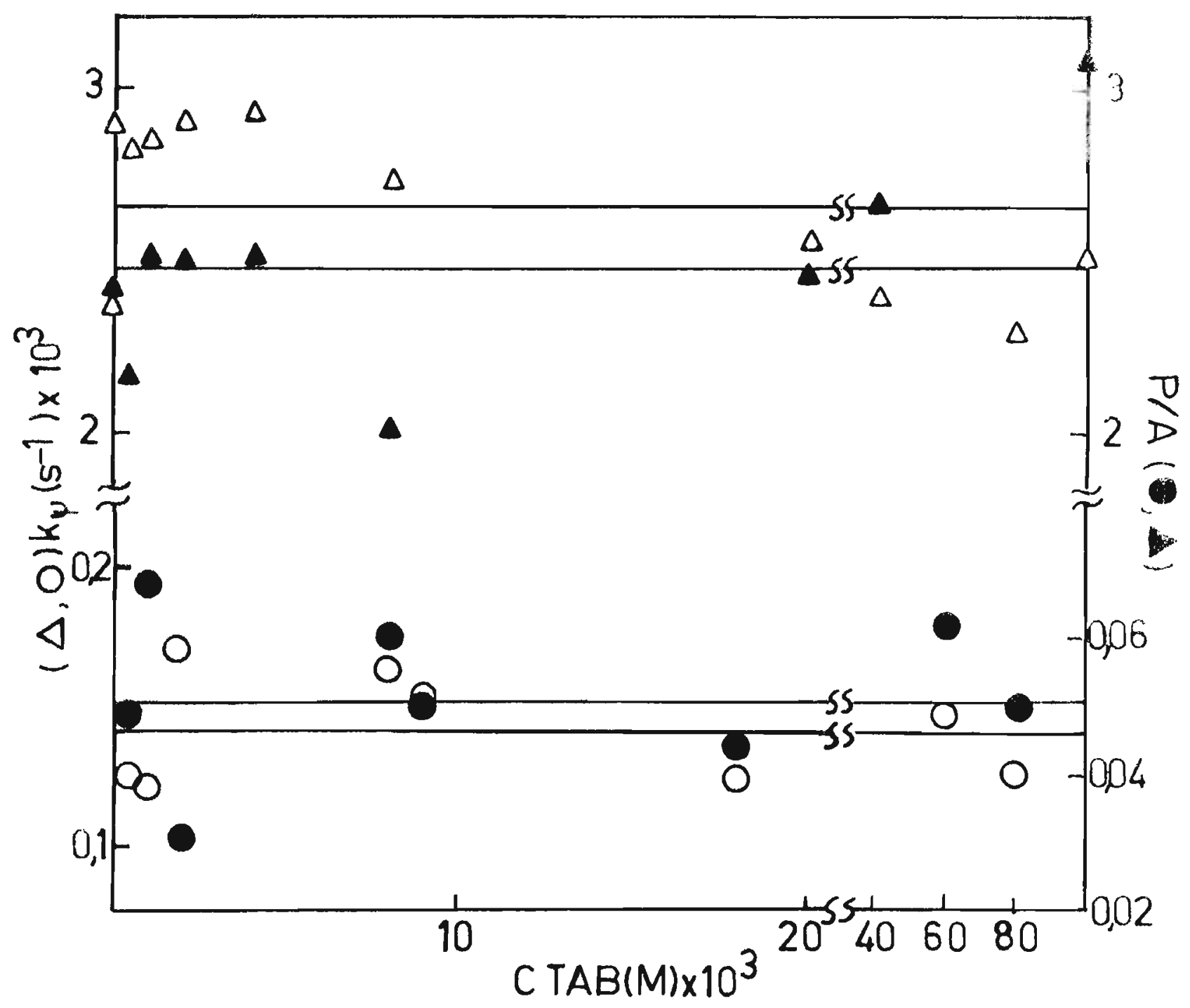

Figura 47 - Efeito de CTAB na manutençäo do pH externo (fase aquosa). $O k_{\psi}$ hidrōlise do $M C P\left(M C P=4,70 \times 10^{-5} \mathrm{M}\right) \mathrm{pH}=9,79 \pm 0,02$ tainpão borato $20 \mathrm{mM}$ relação $\mathrm{P} / \mathrm{A}$; $\Delta \mathrm{k} \psi$ da hidrōlise do MC2P ( MC2P = $\left.9,26 \cdot 10^{-5} \mathrm{M}\right) \mathrm{pH}=9,47^{+} 0,02$ tampão borato $20 \mathrm{mM} \Delta$ relação $\mathrm{P} / \mathrm{A}$. 
presença de tampão borato $20 \mathrm{mM}$ e pH entre nove e dez, pois neste caso o efeito da ligação de hidrōxido a micela näo ul trapassa a capacidade do tampão (vide infra, Tabela 39). Os resultados desse estudo estão na Tabela 28.

Atravēs dos dados da Tabela 28 construimos a Figura 47 que mostra o efeito sobre $k \psi$ e sobre a relação $P / A$.

Pode-se observar da Tabela 28 e Figura 47 quek $\psi$ per manece virtualmente constante atē $0,80 \mathrm{mM}(M C P)$ e $100 \mathrm{mM}\left(M C_{2} P\right)$, como tambēm a relação $P / A$.

- Dodecil sulfato de sōdio (SDS)

Modelo teōrico para tratamento do efeito de SDS sobre a reação de hidrólise alcalina dos ions RCP

Aplicando-se o princípio de troca iônica à superfície da micela podemos escrever para o SDS (Quina, Politi, Cuc covia, M.S. Franchetti e (haimovich):

$$
\mathrm{H}_{f}^{+}+\mathrm{Na}_{f}^{+} \stackrel{\mathrm{K}_{\mathrm{H} / \mathrm{Na}}}{\rightleftharpoons} \mathrm{H}_{\mathrm{b}}^{+}+\mathrm{Na}_{f}^{+}
$$

a constante $K_{H / N a}$ serā

$$
K_{H / N a}=\frac{H_{b} \cdot N_{f}}{H_{f} \cdot N a_{f}}=\frac{\bar{H} \cdot \mathrm{Na}}{H \cdot \overline{N a}}
$$

(onde $\mathrm{H}_{f}(\mathrm{H})$ e $\mathrm{Na}_{f}(\mathrm{Na})$ são as concentrações destes ĩons na fase aquosa e $H_{b}(H)$ e $\mathrm{Na}_{b}(\overline{N a})$ as concentrações na fase micelar). Multiplicando-se a equação 105 por um $\left(\frac{\overline{O H} . O H}{\overline{O H} . O H}\right)$ temos:

$$
K_{H / N a}=\frac{H \cdot N a \cdot \overline{O H} \cdot O H}{\overline{N a} \cdot H \cdot \overline{O H} \cdot O H}
$$


denominando

$$
\bar{H} \cdot \overline{\mathrm{OH}}=\bar{K}_{\mathrm{w}}^{-}
$$

(onde $\bar{K}_{W} \bar{e}$ o produto iōnico da àgua na interface micela/ăgua)

e $\quad H \cdot O H=K_{W}(108)$

(onde $K_{W} \bar{e}$ o produto iōnico da āgua no meio aquoso) temos

$$
K_{H / N a}=\frac{N a O H \bar{K}_{w}}{\overline{N a O H ~ K} K_{W}}
$$

ou, apōs rearranjo

$$
\overline{O H}=\frac{\mathrm{NaOH}}{\overline{\mathrm{Na}}} \cdot \frac{\mathrm{K}_{w}}{\mathrm{~K}_{w}}
$$

ou a inda

$$
\overline{O H}=\frac{\mathrm{Na}_{f} \mathrm{OH}_{f}}{\mathrm{Na}_{b}} \cdot \frac{K_{w} \cdot C D \cdot \bar{V}}{K_{w} \cdot K_{H / N a}}
$$

A resolução da equação 111 pode explicitar o valor de $\overline{\mathrm{OH}}_{b}$ em função de $\mathrm{CD}$, uma vez que $\mathrm{Na}_{f}$ e $\mathrm{Na}_{b}$ são facilmente ob tidos (equações 112 e 113)

$$
\mathrm{Na}_{f}=\mathrm{CMC}+\mathrm{C}_{D}+\mathrm{Sal}+\mathrm{H}_{\mathrm{b}}
$$

e

$$
N a_{b}=(1-a) C_{D}-H_{b}
$$

(Neste caso o sal empregado deve conter somente como cation $\left.\mathrm{Na}^{+}\right) \cdot \mathrm{K}_{\mathrm{H} / \mathrm{Na}} \overline{\mathrm{e}}$ conhecido $\left(\mathrm{K}_{\mathrm{H} / \mathrm{Na}}=1,2\right.$; Bunton et a 1 1977,1978) e $\mathrm{OH}_{f} \overrightarrow{\mathrm{e}}$ dado pelo $\mathrm{pH}$ externo, isto $\overline{\mathrm{e}}$, aquoso.

Enfocando a hidrōlise dos RCP em SDS, devemos inici 
almente tratar da partição do RCP, desde que este é um cătion e portanto sofrerá uma partição por uma equação do tipo:

$$
\begin{array}{r}
R C P_{f}+N a_{b} \stackrel{K_{R C P / N a}}{\rightleftarrows} N a_{f}+R C P_{b} \\
K_{R C P / N a}=\frac{\overline{R C P} N_{b}}{R C a_{f} N a_{b}}=\frac{R C P_{b} N a_{f}}{R C P_{f} N a_{b}}
\end{array}
$$

A expressão de pseudo-primeira ordem da constantede velocidade para a hidrōlise do RCP serā dada por:

$$
k \psi=k_{2}^{0} \mathrm{OH}_{f} \frac{\mathrm{RCP}_{f}}{\mathrm{RCP}_{T}}+k_{2}^{m}{\overline{O H_{b}}}_{\frac{R C P_{b}}{R C P_{T}}}
$$

Aplicando-se as equações 111 e 115 e utilizando do fato que RCP $=R C P_{b}+R C P_{f}$ e ainda que $R C P<<\mathrm{Na}^{+} \quad(|R C P|=$ $5 \times 10^{-5} \mathrm{M}$ e empregou-se tampão fosfato dissódico $20 \mathrm{mM}$ e assim $\mathrm{Na}^{+}=40 \mathrm{mM}$, vide infra) pode-se obter a expressão a seguir:

$$
k \psi=\frac{1}{\left(1+K_{R C P / N a} \frac{N_{b}}{N_{f}}\right)} O H_{f}\left(k_{2}^{0}+k_{2}^{m} \frac{\bar{K}_{w} \bar{V} K_{R C P / N a}}{K_{w} K_{H / N a}}\right)
$$

os termos desconhecidos na expressão 116 são $\stackrel{k_{m} K_{w}}{=}$ e e $K_{R C P / N a}$, porém tais valores podem ser estimados.

Assumindo-se, para o MCP, que $k \psi \bar{e}$ devido somente $\bar{a}$ fração aquosa, teremos: 


$$
k \psi=\frac{{ }_{f}^{O H_{f}}}{1+K_{M C P / N a} \frac{N a_{b}}{N a_{f}}}
$$

que pode ser reescrita como

$$
K_{M C P / N a}=\frac{\mathrm{OH}_{f} k_{2}^{0}-k \psi}{k \psi \frac{\mathrm{Na}_{b}}{\mathrm{Na}_{f}}}
$$

e assim podemos estimar $K_{M C P / N a}$ dos dados experimentais (vide infra).

Utilizando os valores de $k \psi($ Tabela 32) e pH (para calcular $k_{2}^{0}$ equaçäo 86 ) obtemos:

$$
K_{M C P / N a}=7,3 \pm 1,2
$$

Considerando que a diferença entre as constantes de troca do MCP para BCP,OCP e DCP são devidas a um componentenão eletrostātico ( uma vez que a parte carregada é idéntica para estes compostos) podemos escrever (Chaimovich, Cuccovia, Ale xo, Zanette, Quina):

$$
K_{B C P / N a}=K_{M C P / N a} \text { e }{ }^{\Delta \emptyset_{B, M} / R T}
$$

(onde $\Delta \emptyset_{B, M}$ é contribuição não eletrostātica ao potencial de adsorçäo, isto ē, $\emptyset_{\mathrm{BCP} / \mathrm{Na}}=\phi_{\mathrm{BCP}}-\phi_{\mathrm{Na}} ; \phi_{\mathrm{MCP} / \mathrm{Na}}=\phi_{\mathrm{MCP}}-\phi_{\mathrm{Na}}$ e $\left.\Delta \phi_{B, M}=\emptyset_{B C P}-\phi_{M C P}\right)$.

Relacionando-se $0 \Delta \phi_{B, M}$ ao $\Delta G$ de transferéncia por grupo metilénico da água para o interior da micela $\left(\Delta G / C_{2}=0,79\right.$, vide infra, Tanford, 1973, 1980) obtemos

$$
\mathrm{K}_{\mathrm{BCP} / \mathrm{Na}}=78,1 \pm 12,8
$$


analogamente obtemos para O OCP e DCP

$$
\begin{gathered}
K_{O C P / N a}=1840,6 \pm 302,5 \\
K_{D C P / N a}=43.385,2 \pm 7.131,8 \\
0 \text { outro fator desconhecido } \frac{{ }^{K_{m}} \overline{K_{W}}}{\text { è estimado utili }}
\end{gathered}
$$

zando a curva de constante de velocidade vs SDS da hidrōlise' do DCP (Figura 48, Tabela 29), na qual assume-se que a contribuição, à constante de velocidade, devido ao DCP aquosó ē des prezivel (K $K_{D C P / N a} \bar{e}$ muito grande). Assim a expressão 116 pode ser simplificada para:

$\begin{aligned} & k_{\psi}=\frac{\mathrm{OH}_{f} k_{2}^{m} \bar{K}_{w} \bar{V} K_{D C P / N a} C D}{\left(1+K_{D C P} / N a \frac{N a_{f}}{N a_{f}} K_{w} K_{H / N a}\right.} \\ & \text { designando-se } \frac{k_{2}^{m} \overline{K_{w}}}{K_{w}} \text { de } f k_{2}^{0} \text {, teremos } \\ & f=\frac{k \psi\left(1+K_{D C P / N a} \frac{N_{b}}{N a}\right) K_{H / N a}}{{ }_{f} k_{2}^{0} \bar{V} K_{D C P / N a} C D}\end{aligned}$

Aplicando-se os valores da Tabela 29 , obtemos

$$
f=0,45 \pm 0,02
$$

Efeito de SDS sobre $k \psi$

Vemos a seguir o efeito da adição de SDS sobre a velocidade de hidrōlise dos RCP. Nas Tabelas 29 a 32 encontramse os resultados relativos a reação de hidrōlise do MCP, BCP. OCP e DCP respectivamente. 
Tabela 29 - Efeito de SDS na constante de velocidade da reaçäo de hidrölise do $\mathrm{N}$-me ti 1-4-cianopiridineo( $M C P=6,25 \times 10^{-5 M}$ )

\begin{tabular}{ccccc} 
SDS ,M & $\mathrm{pH}^{*}$ & $k \psi, \mathrm{sec}^{-1}$ & $\begin{array}{r}\mid \text { piridona| } \\
M \times 10^{5}\end{array}$ & $\mathrm{P} / \mathrm{A}$ \\
\hline 0,010 & " & 0,0353 & 3,59 & 1,35 \\
$"$ & 12,35 & 0,0390 & 3,89 & 1,65 \\
0,018 & 12,40 & 0,0260 & 3,75 & 1,50 \\
$"$ & $"$ & 0,0272 & 2,86 & 1,62 \\
0,020 & $"$ & 0,0263 & 3,68 & 1,43 \\
$"$ & 12,35 & 0,0129 & 3,76 & 1,51 \\
0,050 & 12,40 & 0,0149 & 3,78 & 1,53 \\
$"$ & 12,35 & 0,0116 & 3,42 & 1,21 \\
0,080 & $"$ & 0,0112 & 3,85 & 1,60 \\
$"$ & & 0,0288 & - &
\end{tabular}

\section{*tampão fosfato $20 \mathrm{mM}$}

piridona calculada pela média entre espectro e daosagem de cianeto (veja materiais e mêtodos) 
Tabela 30 - Efeito de SDS na constante de velocida de da reação de hidrôlise do $\mathrm{N}$-butil-4-cianopiridĩ neo $\left(B C P=6,32 \times 10^{-5} \mathrm{M}\right)$

\begin{tabular}{|c|c|c|c|c|}
\hline$S D S, M$ & $\mathrm{pH}^{*}$ & $k \psi, \sec ^{-1}$ & $\begin{array}{l}\text { Piridona } \\
\text { Mx } 10^{5}\end{array}$ & $P / A^{\star \star}$ \\
\hline 0,010 & 12,35 & 0,0133 & 3,74 & 1,45 \\
\hline$"$ & $"$ & 0,0144 & 3,70 & 1,41 \\
\hline 0,020 & $"$ & 0,00765 & 4,10 & 1,85 \\
\hline$"$ & $"$ & 0,00795 & 3,99 & 1,71 \\
\hline 0,050 & $"$ & 0,00339 & 4,11 & 1,86 \\
\hline$"$ & $"$ & 0,00409 & 4,28 & 2,10 \\
\hline 0,080 & $"$ & 0,00328 & 4,07 & 1,81 \\
\hline$"$ & $"$ & 0,00321 & 3,97 & 1,69 \\
\hline
\end{tabular}

* tampäo fosfato $20 \mathrm{mM}$

**piridona calculada pela mëdia entre espectro e dosagem de cianeto (veja Materiais e Mëtodos) 
Tabela 31 - Efeito de SDS na constante de velocidade da reação de hidrôlise do $\mathrm{N}-\mathrm{oc}$ ti $1-4-c i a n o p i r i d i n e o\left(O C P=5 \mathrm{~m} 74 \times 10^{-5} \mathrm{M}\right)$.

\begin{tabular}{ccccc}
$|S D S|, M$ & $\mathrm{pH}^{*}$ & $\mathrm{k \psi}, \mathrm{sec}^{-1}$ & $\begin{array}{c}\mid \text { Piridona } \\
M \times 10^{-5}\end{array}$ & $\mathrm{P} / \mathrm{A}$ \\
\hline 0,0096 & 12,35 & 0,000891 & 2,91 & 1,03 \\
$"$ & 12,30 & 0,000917 & 2,98 & 1,08 \\
0,010 & $"$ & 0,001158 & 2,10 & 0,58 \\
0,020 & $"$ & 0,000824 & 2,70 & 0,89 \\
$"$ & $"$ & 0,001054 & 3,05 & 1,13 \\
$"$ & $"$ & 0,001015 & 3,04 & 1,13 \\
0,040 & $"$ & 0,000774 & 2,43 & 0,73 \\
0,050 & 12,35 & 0,000866 & 2,78 & 0,94 \\
$"$ & $"$ & 0,000947 & 2,85 & 0,99 \\
0,072 & $"$ & 0,000880 & 2,52 & 0,78 \\
$"$ & $"$ & 0,000882 & 2,60 & 0,83
\end{tabular}

*tampão fosfato $20 \mathrm{mM}$

* piridona calculada pela média entre espectro e dosagem de cianeto (veja Materiais e Métodos) 
Tabela 32 - Efeito de SDS na constante de velocidade da reação de hidrōlise do $\mathrm{N}$-do deci1-4-cianopiridineo (DCP $(1)=5,36 \times 10^{-5}$ $M ;(2)=4,75 \times 10^{-5} M ;(3)=5,72 \times 10^{-5} M$

\begin{tabular}{|c|c|c|c|c|}
\hline SDS $\mid, M$ & $\mathrm{pH}^{*}$ & $k \psi, \sec ^{-1}$ & $|\operatorname{Piridona}| * *$ & $P / A$ \\
\hline 0,010 & 12,35 & 0,000448 & $0,98(3)$ & 0,21 \\
\hline$"$ & 12,40 & 0,000508 & $1,20(3)$ & 0,38 \\
\hline 0,020 & 12,35 & 0,000439 & $1,69(1)$ & 0,46 \\
\hline$"$ & $"$ & 0,000464 & $1,59(1)$ & 0,42 \\
\hline 0,050 & $"$ & 0,000450 & $1,57(3)$ & 0,38 \\
\hline$"$ & 12,30 & 0,000438 & - & - \\
\hline$"$ & $"$ & 0,000470 & $1,05(3)$ & 0,22 \\
\hline 0,080 & 12,35 & 0,000585 & $1,37(2)$ & 0,40 \\
\hline$"$ & $"$ & 0,000561 & $1,54(1)$ & 0,48 \\
\hline$"$ & $"$ & 0,000518 & $1,49(1)$ & 0,38 \\
\hline$"$ & $"$ & 0,000518 & $1,63(1)$ & 0,44 \\
\hline
\end{tabular}

* tampão fosfato

**piridona calculada pela média entre espectro e dosagem de cianeto (veja Materiais e Métodos) 
Segundo os dados das Tabelas 29 a 32 , construimos a Figura 48 que corresponde ao efeito de SDS sobre $k \psi$ da reaçăo de hidrōlise alcalina dos íns MCP, BCP, OCP e DCP.

Deve-se notar da Figura 48, a existéncia de mínimos nas curvas relativas ao OCP e DCP.

No intuito de esclarecer o comportamento de hidrōxi do na superficie de SDS, estudamos o efeito de pH (Tabela 33 e Figura 49) como tambēm o efeito de sal adicionado (Tabela34 e Figura 50).

Graficando-se os dados da Tabela 33 em função da concentração de $\mathrm{NaOH}$ e do quadrado da concentração de $\mathrm{NaOH}$ ve mos o aspecto representado na Figura 49. Pode-se notar que 0 $k_{\psi}$ em função do quadrado de $\mathrm{NaOH}$ apresenta uma função linear (vide discussão).

0 efeito de concentração de $\mathrm{NaCl}$, ou melhor, de $\mathrm{Na}^{+}$ (Tabela 34 ) com consequente aumento do $\mathrm{pH}$ interfacial é visto na Figura 50. Observa-se tambēm uma funęão jinear 


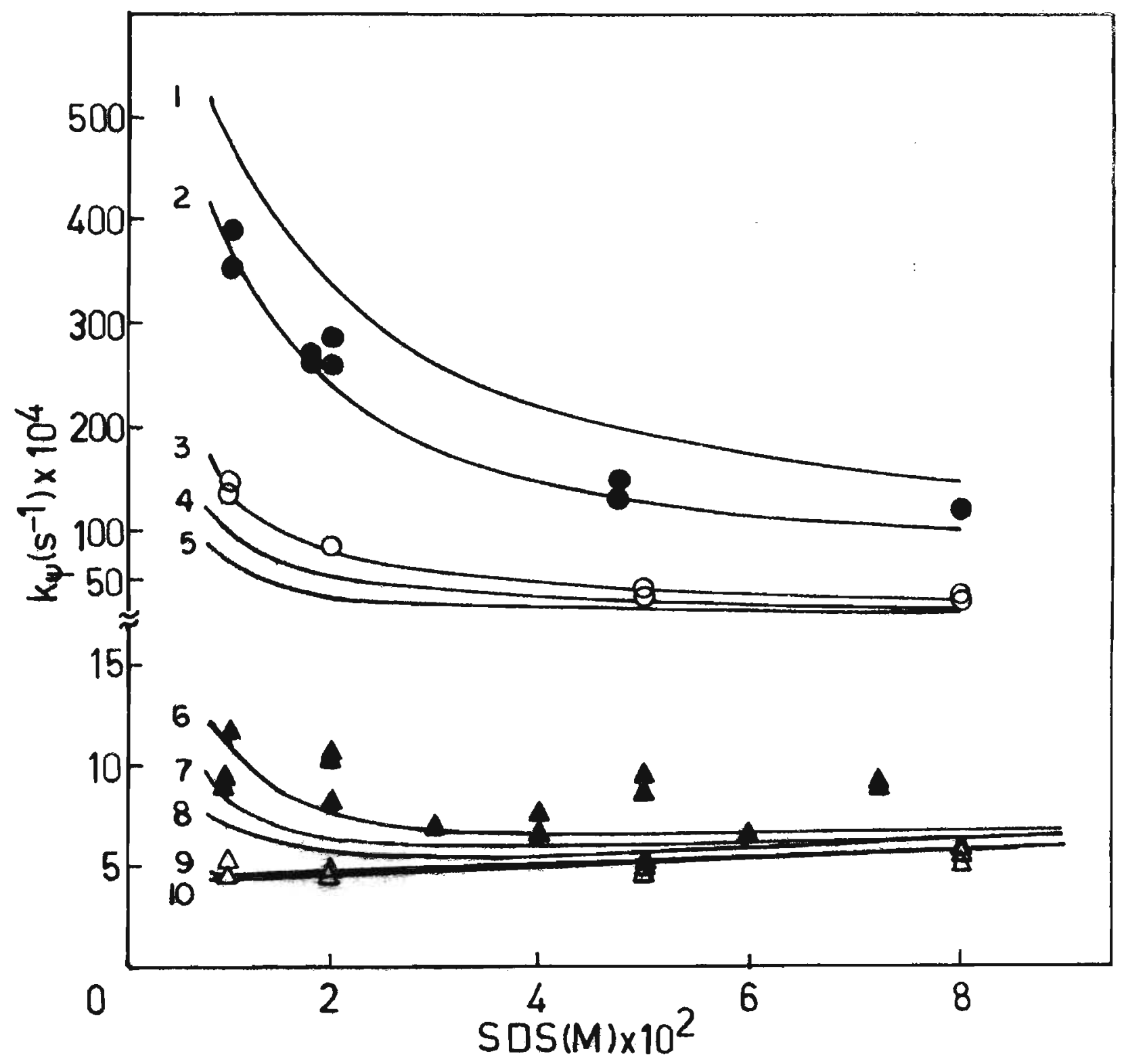

Figura 48 - Efejto de SDS na constante de velocidade da reação de $h i d r o ̄ l i s e ~ d e:-N-m e t i 1-4-c i a n o p i r i d i n e o ~(M C P)=6,25 \times 10^{-5} \mathrm{M}$ ) O-N-buti 1-4-cianopiridineo (BCP $=6,32 \times 10^{-5} M$ )

$\triangle-N-o c t i 1-4-C i a n o p i r i d i n e o\left(O C P=5,74 \times 10^{-5 M}\right)$

- N-dodecil-4-cianopiridíneo (DCP-veja Tabela 32)

As linhas foram calculadas utilizando a equação 116 com:

$\mathrm{f}=0,45 ; \mathrm{K}_{\mathrm{MCP} / \mathrm{Na}}=4,5 ; 7,5-\mathrm{K}_{\mathrm{BCP} / \mathrm{Na}}=30 ; 50 ; 78$

$K_{O C P / N a}=750 ; 1200 ; 1850-K_{D C P / N a}=18.200 ; 43.500 \quad \mathrm{pH}=12,35$ 
Tabela 33 - Efeito de SDS na constante de velocidade da reação de hidrölise de $\mathrm{N}$-do decil-4-cianopiridineo ( $D C P=5,80 \times 10-5 \mathrm{M})$ a vārios $\mathrm{pHs}^{\star}$ e a respectiva distribuição de produtos

\begin{tabular}{c|c|c|c|c|c}
$\begin{array}{c}|S D S| \\
M\end{array}$ & $\mathrm{pH}$ & $\mathrm{k \psi sec}-1$ & $-10 \mathrm{~g} \psi$ & $\begin{array}{c}\text { Piridgna } \\
\text { Mxi0 }\end{array}$ & $\mathrm{P} / \mathrm{A}$ \\
\hline 0,010 & 11,80 & 0,0000785 & 4,106 & 0,76 & 0,15 \\
$"$ & 11,77 & 0,0000628 & 4,202 & 0,76 & 0,15 \\
$"$ & 12,04 & 0,000195 & 3,710 & 0,88 & 0,18 \\
$"$ & 12,02 & 0,000196 & 3,710 & 1,42 & 0,32 \\
$"$ & 12,33 & 0,000751 & 3,124 & 2,77 & 0,91 \\
$"$ & 12,32 & 0,000725 & 3,140 & 2,68 & 0,86 \\
$"$ & 12,33 & 0,000935 & 3,029 & 2,90 & 1,00 \\
0,040 & 11,95 & 0,000113 & 3,947 & 0,77 & 0,17 \\
$"$ & 12,22 & 0,000889 & 3,051 & 2,77 & 0,91 \\
0,050 & 11,82 & 0,000878 & 4,056 & 0,63 & 0,12 \\
$"$ & 12,32 & 0,000904 & 3,344 & 2,76 & 0,91 \\
$"$ & 12,37 & 0,000911 & 3,040 & 2,71 & 0,88 \\
& & & & &
\end{tabular}

*não se utilizou solução tampão, adicionou-se $\mathrm{NaOH}$ medindo-se o pH imediatamente apōs a reação em cela sob a atmosfera de argó nio

**piridona calculada pela mëdia entre espectro e dosagem de cia neto (veja Materiais e Métodos) 


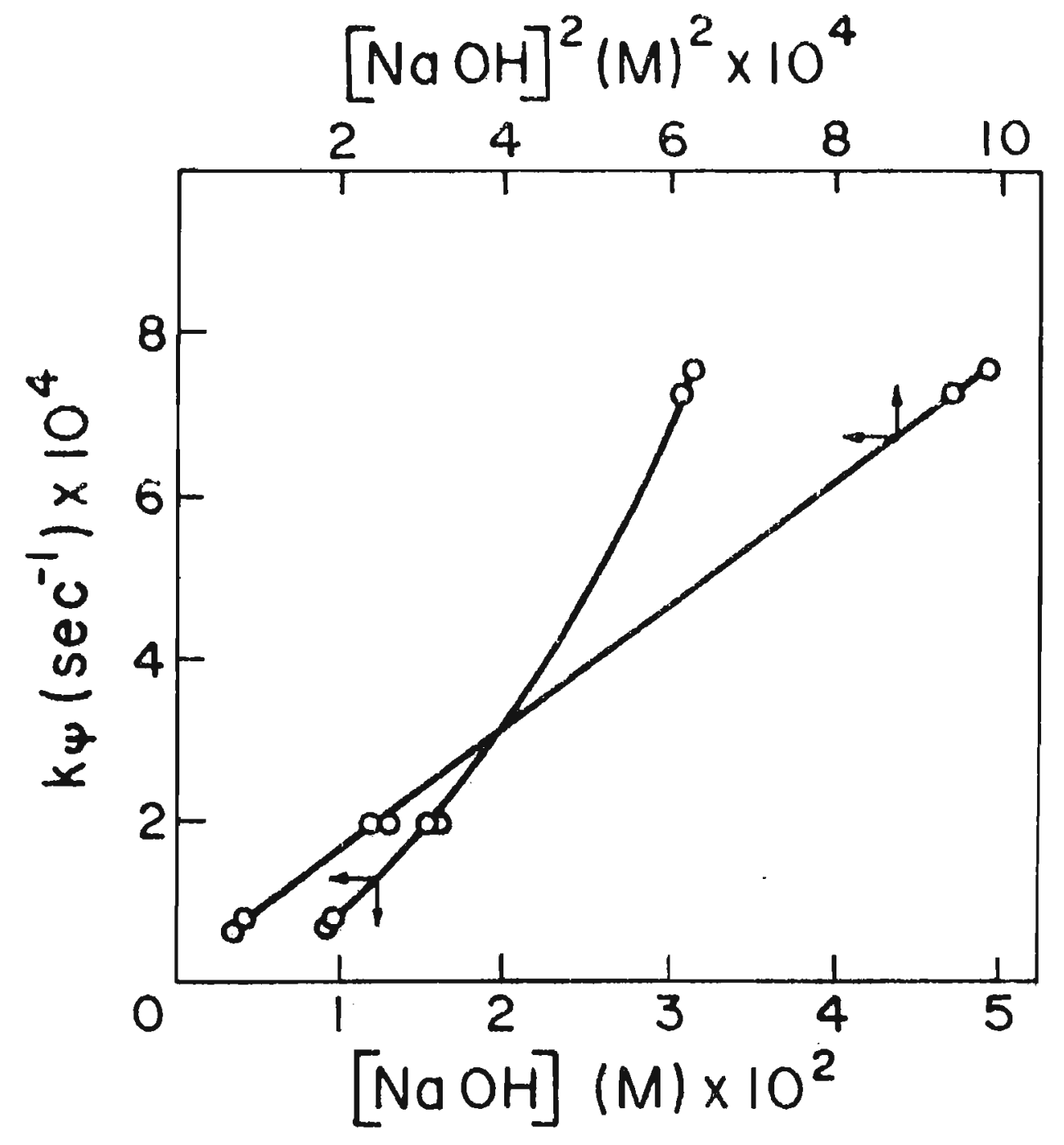

Figura $49-\quad k \psi$ vs $|\mathrm{NaOH}|$ e $\mathrm{k}_{\psi} v \mathrm{~s}|\mathrm{NaOH}|^{2}$, hidrölise de $\mathbf{N}$ dodecil-4-cianopiridineo (DCP $5,80 \times 10^{-5} \mathrm{M}$ ), SDS $40 \mathrm{mM}$. 
Tabela 34 - Efeito da adição de NaCl na constante de velocidade da reação de hidfólise do $\mathrm{N}$-dodecil 4-cianopiridīneo ( $D C P=5,80 \times 10^{-5} M$ ) em meio de SDS a $\mathrm{pH} 11,85$.

\begin{tabular}{c|c|c|c|c|c}
\multicolumn{1}{c}{$A|S D S|=10 \mathrm{mM}$} \\
$\mathrm{pH}$ & $\begin{array}{c}|\mathrm{NaCl}| \\
\mathrm{M}\end{array}$ & $\mathrm{k} \psi, \mathrm{sec}^{-1}$ & $-10 \mathrm{~g} \psi$ & $\begin{array}{c}\mid \text { piridona } \\
M \times 10^{5}\end{array}$ & $P / \mathrm{A}$ \\
\hline 11,92 & - & 0,0000643 & 4,192 & 0,65 & 0,13 \\
11,90 & 0,010 & 0,0000943 & 4,025 & 0,77 & 0,14 \\
11,85 & 0,020 & 0,000111 & 3,955 & 0,88 & 0,18 \\
11,80 & 0,040 & 0,000143 & 3,845 & 1,93 & 0,50
\end{tabular}

$B|S D S|=40 \mathrm{mM}$

\begin{tabular}{c|c|c|c|c|c}
$\mathrm{pH}$ & $\begin{array}{c}|\mathrm{NaCl}| \\
\mathrm{M}\end{array}$ & $k \psi, \mathrm{sec}^{-1}$ & $-\log k \psi$ & $\begin{array}{c}\mid \text { piridona } \\
\text { Mx } 105\end{array}$ & $P / A$ \\
\hline 11,95 & - & 0,000113 & 3,947 & 0,77 & 0,13 \\
11,90 & 0,010 & 0,000129 & 3,889 & 0,85 & 0,15 \\
11,83 & 0,040 & 0,000184 & 3,735 & 0,81 & 0,14
\end{tabular}




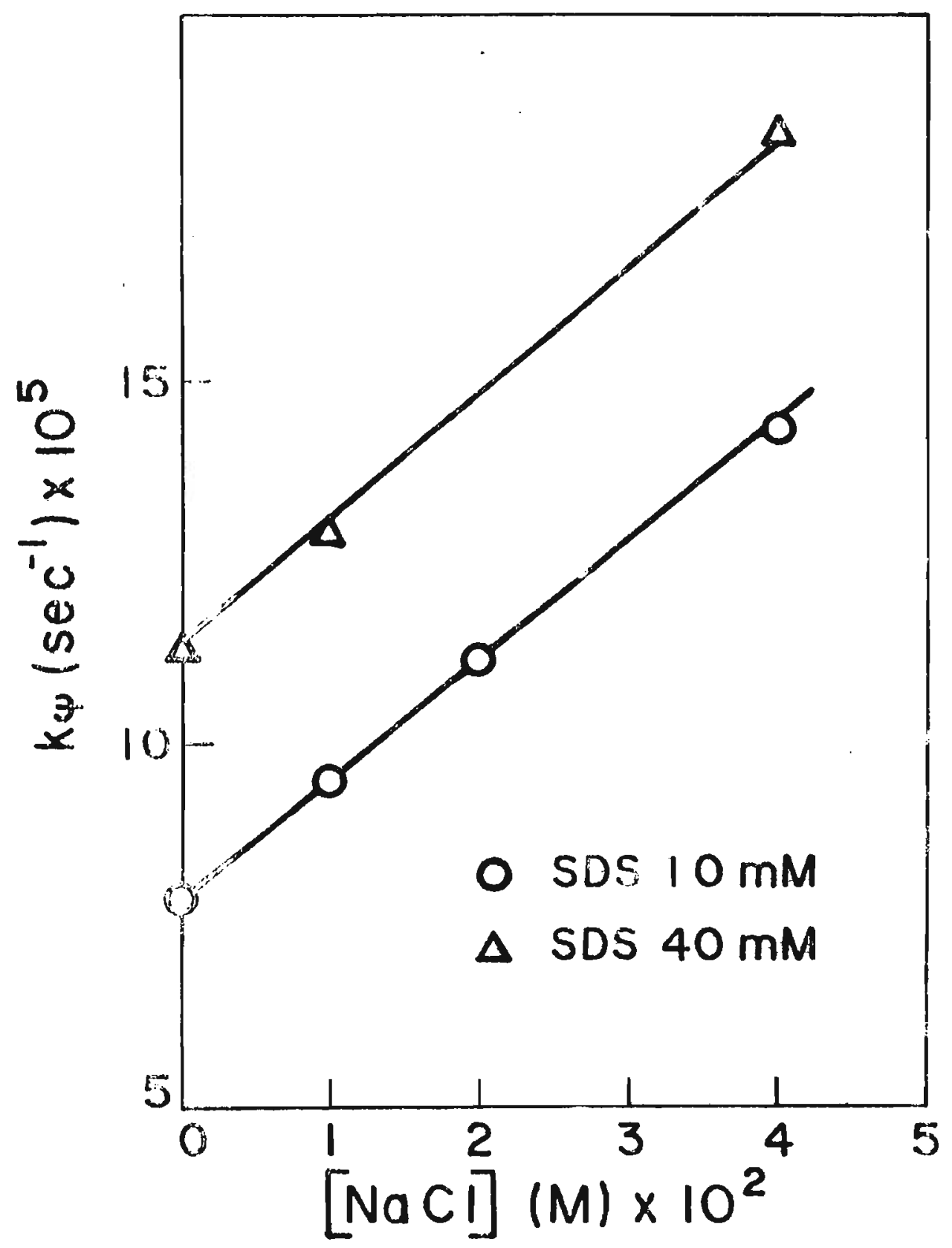

Figura 50 - Efeito de NaCl na constante de velocidade (k $\psi$ ) da reação de hidrōlise de $\mathrm{N}$-dodecil-4-cianopiridineo $10^{-5} \mathrm{M}$

O SDS $10 \mathrm{mM}, D C P=5,80 \times 10^{-5} \mathrm{M} ; \triangle \mathrm{SDS} 40 \mathrm{mM}, D C P=6,56 \times$ 
3-(N,N-dimetilalquilamōnio) propano-l sulfonato

(SDP)

O efeito de SDP sobre a constante de velocidade do reação de hidrōlise do DCP e porcentagem de piridona formada, estäo apresentados na Tabela 35 e Figura 51.

Na Figura 51 observa-se um māximo em $k \psi$, por volta de $20 \mathrm{mM}$ de SDP. 0 fator de aceleração mâximo $\left(k \psi_{\max } / k_{\psi_{0}}\right)$ $\overrightarrow{\mathrm{e}}=$

$$
\frac{k \psi_{\max }}{k_{\psi_{0}}}=14,4
$$

Deve-se notar ainda um aumento da porcentagem de $p \underline{i}$ ridona formada, com aumento da concentração de SDP, atinge-se 0 mäximo (cerca de $100 \%$ de P) a $20 \mathrm{mM}$ de SDP.

III.2. Anālise de detergentes derivados de sais de amōnio quaternārio por Hoffmann direta (Micro-Hoffmann)

Como foi discutido na Introdução (I.4.2.) a elimina ção de Hoffmann é o método de escola para analisar o comprimento de cadeia de detergentes de amōnio quaternārio.

Apresentamos a seguir sërie de resultados de cromatografia em fase gasosa obtidos por injeção (veja Mate riais, Métodos e Aparelhos) direta do detergente na forma de hidrōxido. Inicialmente aparecem os cromatogramas de padrões utilizados para poder comparar os resultados (Figuras 52 a 54) e em seguida os cromatogramas abtidos pela eliminação dos com postos em estudo, nos quais assinalamos os picos relativos aos 
Tabela 35 - Valores de constante de velocidade $(k \psi)$ en função da concentração de SDP adicionado a $\mathrm{pH}$ 10,8 e porcentagem de piridona \%P. Hidrōlise do $\mathrm{N}$-dodeci1-4-cianopiridīneo (DCP $\approx 5,00 \times 10^{-5} \mathrm{M}$ ).

\begin{tabular}{|c|c|c|}
\hline$|\mathrm{SDP}| \mathrm{mM}$ & $\mathrm{k} \psi \times 10^{3}, \mathrm{sec}^{-1}$ & $\% \mathrm{P}^{*}$ \\
\hline- & 2,16 & 27,1 \\
\hline 0,121 & 1,85 & 27,9 \\
\hline 0,202 & 1,95 & 26,7 \\
\hline 0,404 & 2,25 & 29,2 \\
\hline 0,606 & 2,38 & 30,3 \\
\hline 0,808 & 2,33 & 28,8 \\
\hline 1,010 & 2,31 & 33,1 \\
\hline 2,020 & 2,34 & 31,4 \\
\hline 2,450 & 2,34 & 31,0 \\
\hline 3,030 & 2,85 & 42,7 \\
\hline 4,040 & 13,42 & 77,2 \\
\hline 4,900 & 12,00 & 88,1 \\
\hline 8,080 & 20,67 & 93,6 \\
\hline 9,800 & 24,15 & 95,8 \\
\hline 10,100 & 24,07 & 95,3 \\
\hline 12,255 & 24,09 & 97,4 \\
\hline 20,200 & 31,09 & 96,9 \\
\hline 24,510 & 28,45 & 99,0 \\
\hline 40,400 & 27,84 & 98,0 \\
\hline 60,600 & 24,64 & 91,3 \\
\hline 80,800 & 19,22 & 99,8 \\
\hline
\end{tabular}

*piridona calculada via espectro (veja Materiais e Métodos) 


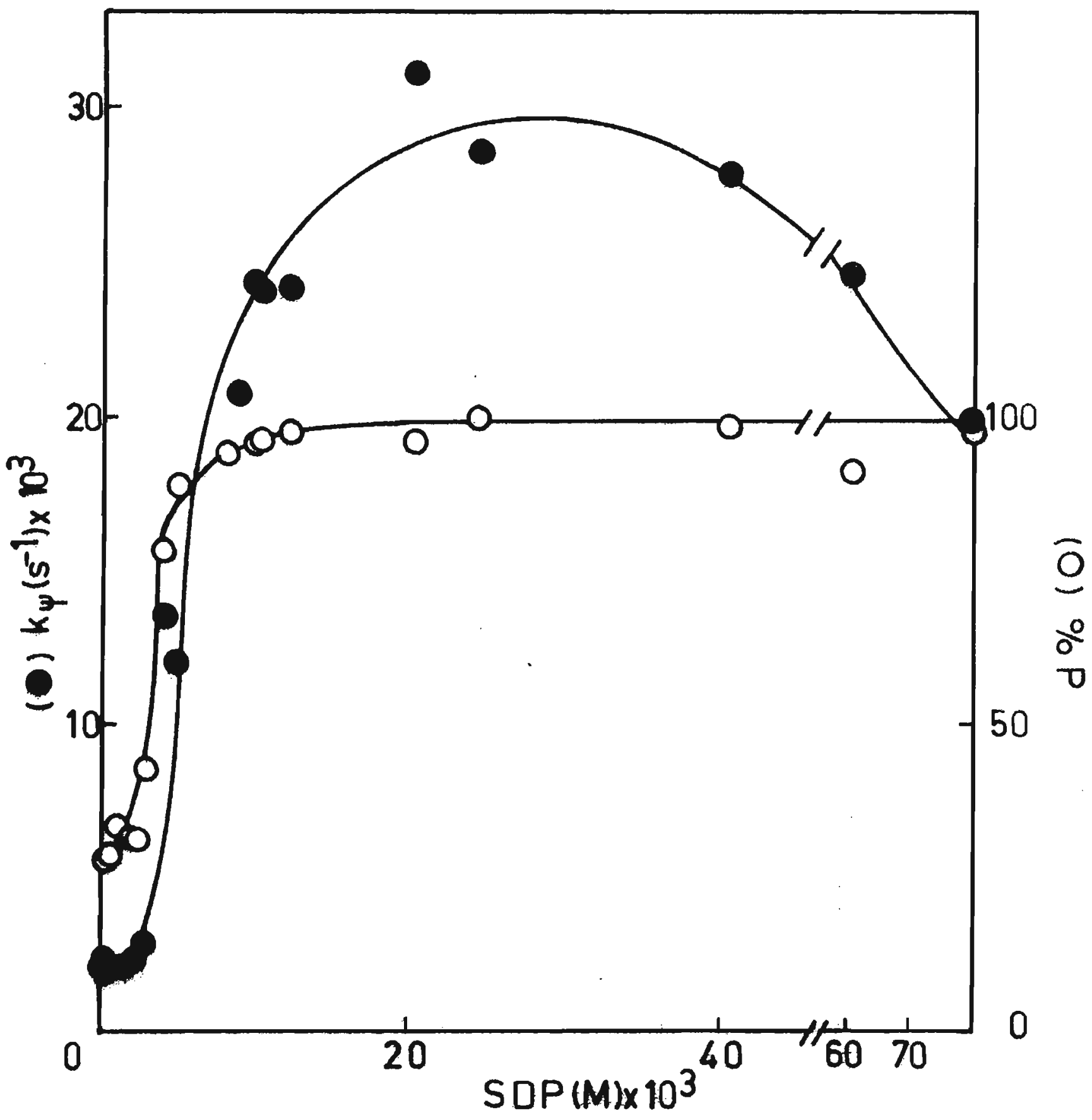

Figura 51 - Constante de velocidade ( $K \psi$ ) para hidrölise de $N$ dodecil-4-cianopiridineo (DCP $=5,00 \times 10^{-5} M$ ) e porcentagem de pi ridona formada (XP) en função da concentração de SDP. $p H=10, \overline{8}$ adição de $\mathrm{NaOH}$. 


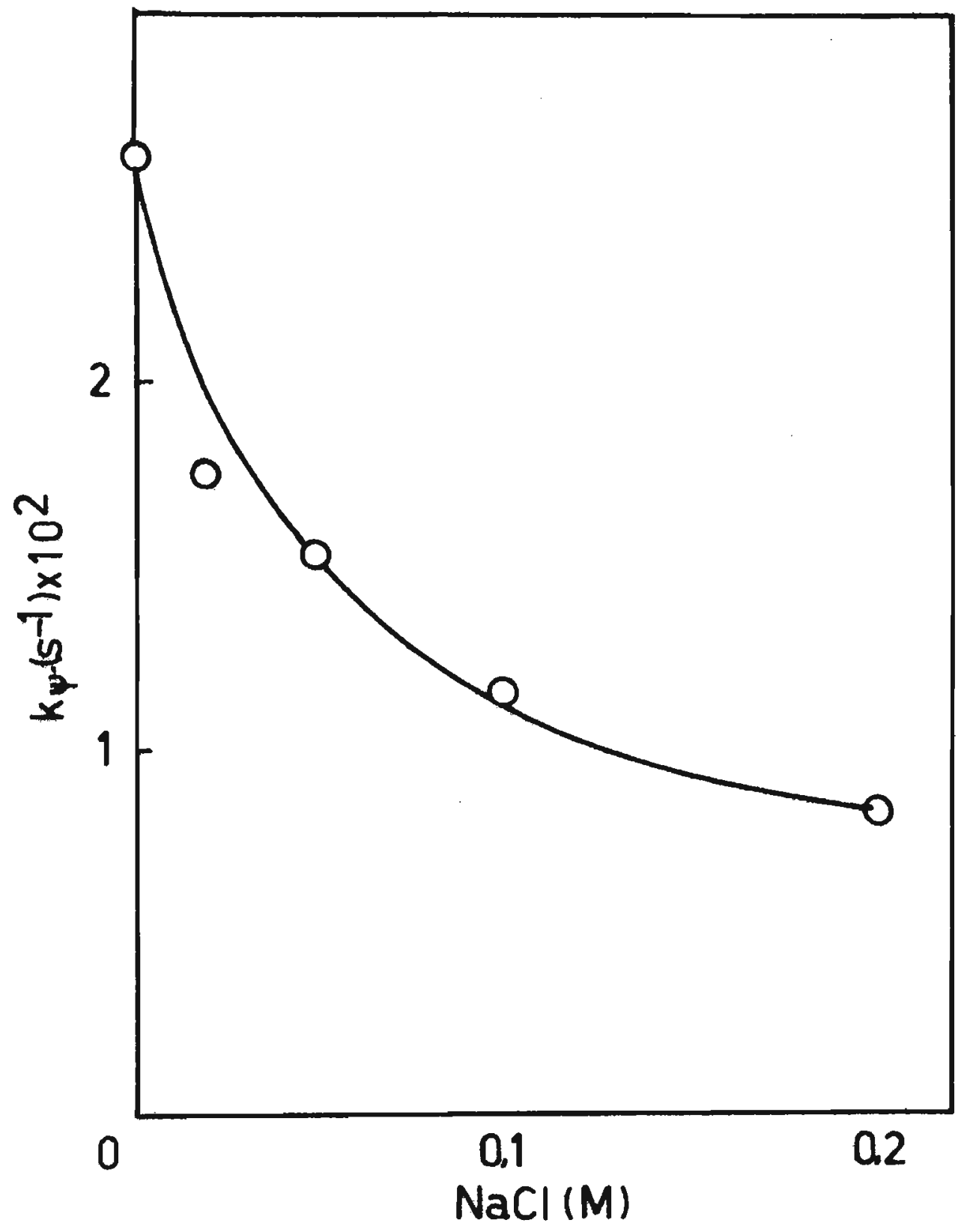

Figura 51 A - Efeito da adição de NaCl na reação de hidrôlise de $\mathrm{N}$-dodecil-4-cianopiridineo ( $O C P=5 \times 10^{-5} \mathrm{M}$ ) em presença de SDP $(0,05 M)$. 
padröes (Figuras 55 a 61 ). Devemos ressaltar que estas Figuras são amostras de uma sērle de cromatogramas.

A coluna empregada (veja Aparelhos tem a propriedade de separar homōlogos, diferentes por 2 carbonos no dobro do tempo de retenção (T.R).

Uma expressão geral deste comportamento pode ser es crita como:

$$
T R_{H S}=T \cdot R_{H . I} \cdot 2^{\frac{n}{2}}
$$

(onde HS $\vec{e}$ o homōlogo superior H.I. o inferior e $n \bar{e}$ a diferen ça no no de carbonos).

As tabelas a seguir são referentes ao tempo de reten ção (TR) dos vários padrōes e dos produtos da eliminação de Hofmann dos compostos estudados. Na Tabela 37 encontram-se os T.R. dos compostos em suequéncia idêntica àquela dos cromato gramas (Figuras 52 a 61 ).

Uma vez que a reprodutibilidade das condições experimentais (como fluxo de $\mathrm{N}_{2}$, temperatura de injeção, etc) $\bar{e}$ di fícil escolhermos um padrão interno, comum a todos os cromatogramas e relacionarmos os demais picos ao pico na Tabela 37 , o tempo de retenção do 1-hexadeceno é comum em todos os cromatogramas. Na Tabela 38 mostramos os valores de tempo de reten ção dos componentes dos värios cromatogramas relativos ao do 1-hexadeceno.

Como foi apresentado no esquema da eliminação de Hof man (Figura 8), uma vez formado o hidrōxido do detergente este decompõem-se dando origem a alcenos e aminas.

No caso de CTAOH, CTAB e CTACl empregados (vide Mate riais e Métodos Figura 55, 56 e 57; Tabelas 37 e 38) observase a existência dos seguintes componentes: 
CTAOH - (sintetizado e cedido pelo Dr. Luis Sepulveda)

1 - tetradeceno (cerca de $48 \%$ )

1 - hexadeceno (cerca de 1\%)

$N$ - dimetil-N'-tetradecilamina (cerca de 48\%)

(observe que o 1 - hexadeceno estā a nível de impureza)

CTAB - (E. Merck, Darmstadt)

1 - tetradeceno (cerca de $1 \%$ )

1 - hexadeceno (cerca de 48\%)

$N$ - dimetil-N'-tetradecilamina (cerca de 1\%)

$N$ - dimetil-N'-hexadecilamina (cerca de $48 \%$ )

CTAC1 - (sintetizado e cedico pelo Prof.Dr. J.B.S. Bonilha)

1 - tetradeceno (cerca de 1\%)

1 - hexadeceno (cerca de 48\%)

$N$ - dimetil-N'-tetradecilamina (cerca de 1\%)

N - dimetil-N'-hexadecilamina (cerca de $48 \%$ )

As porcentagens foram estimadas atravēs das āreas dos picos. Deve-se notar que o denominado CTAOH (hidrōxido de hexadeciltrimetilamōnio) é na realidade TTAOH (hidrōxido de te tradeciltrimetilamōnio).

o pico relativo a 1 -hexadeceno estā a nível de impureza (cerca de $5 \%$ ).

No caso de TTABr e STACl (figuras 58 e 59 , Tabelas 37 e 38 ), temos respectivamente:

TTABr - (sintetizado e cedido pelo Prof.Dr. J.B.S. Bonilha)

1 - tetradeceno (cerca de $48 \%$ )

1 - hexadeceno (cerca de $1 \%$ )

$N$ - dimetil-N'-decilamina (cerca de $48 \%$ ) 
STACl - (sintetizado e cedido pelo Prof.Dr. J.B.S. Bonilha)

$$
\begin{aligned}
& 1 \text { - tetradeceno (cerca de } 0,5 \% \text { ) } \\
& 1 \text { - hexadeceno (cerca de } 2 \% \text { ) } \\
& 1 \text { - octadeceno (cerca de } 45 \% \text { ) } \\
& N \text { - dimetil-N'-tetradecilamina (cerca de } 1 \% \text { ) } \\
& N \text { - dimetil-N'-hexadecilamina (cerca de } 2 \% \text { ) } \\
& N \text { - dimetil-N'-octadecilamina (cerca de } 45 \% \text { ) }
\end{aligned}
$$

No caso de Herquat na forma de cloreto (Figura 60 , Tabelas 37 e 38 ) ocorre uma cisão formando:

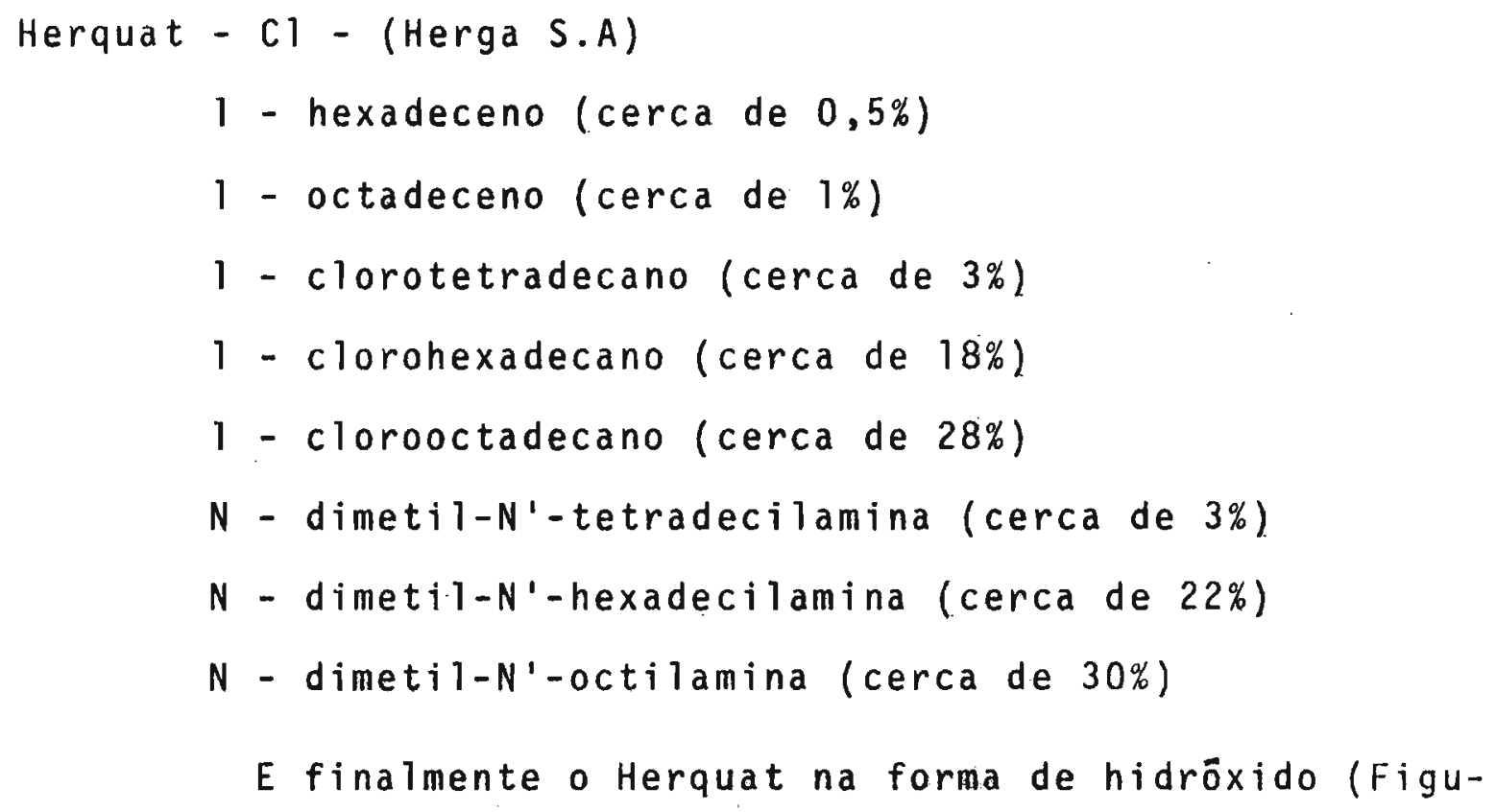




$$
\begin{aligned}
& N \text { - dimetil-N'-hexadecilamina (cerca de } 18 \% \text { ) } \\
& N \text { - dimetil-N'-octadecilamina (cerca.de } 28 \% \text { ) } \\
& \text { E interessante observar que Herquat na forma de clo }
\end{aligned}
$$
reto produz componentes em diferentes proporçôes daquela obtida com Herquat na forma de Hidróxido. 


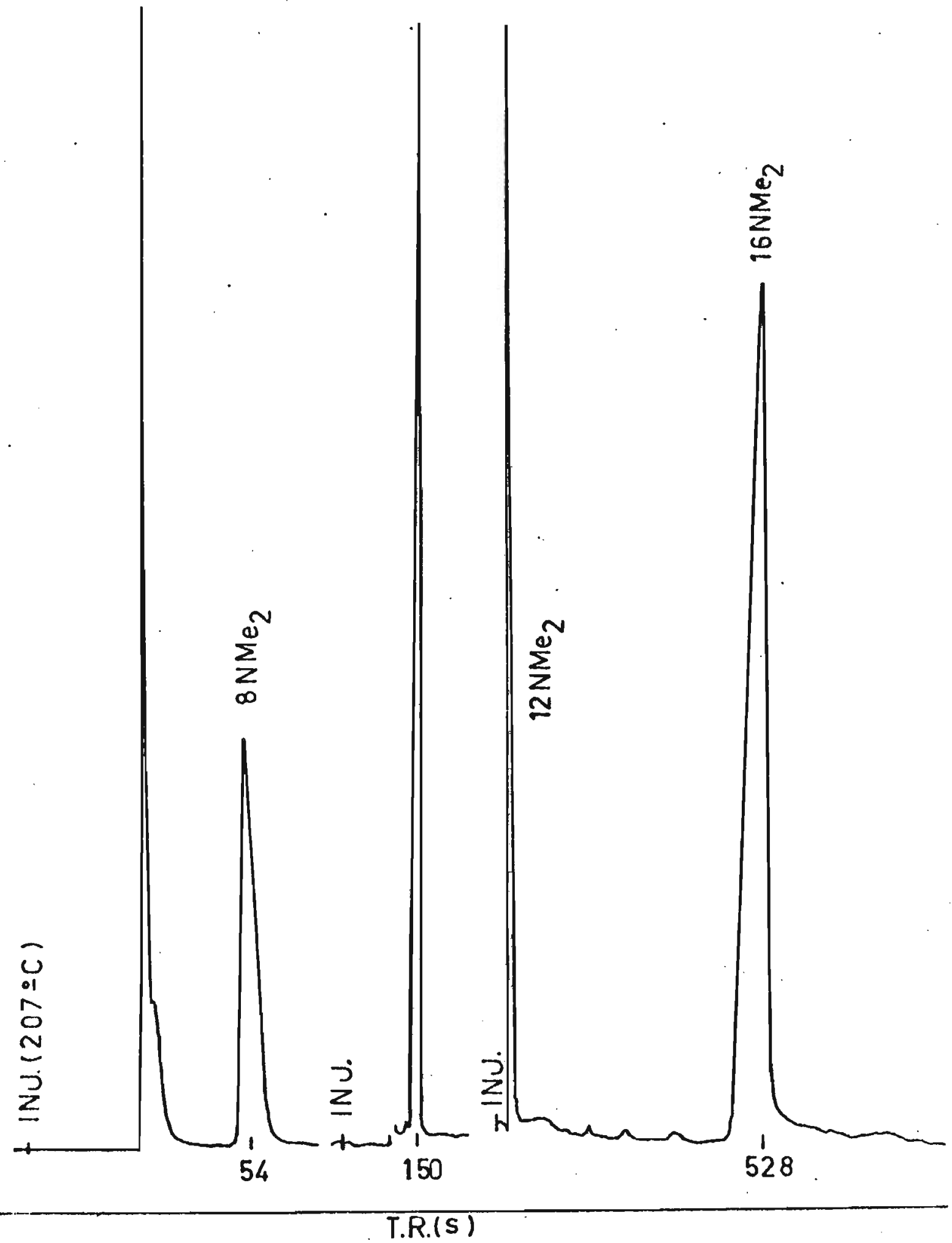

Figura 52 - Cromatogramas em fase gasosa de $N$-alquil-N'-dimetil aminas; (A) $\mathrm{N}$-octil $\left(8 \mathrm{NMe}_{2}\right) ;(\mathrm{B}) \mathrm{N}$-dodecil $\left(12 \mathrm{NMe}_{2}\right) ;$ (C) $\mathrm{N}$-hexa decil $\left(16 \mathrm{NMe}_{2}\right)$ 


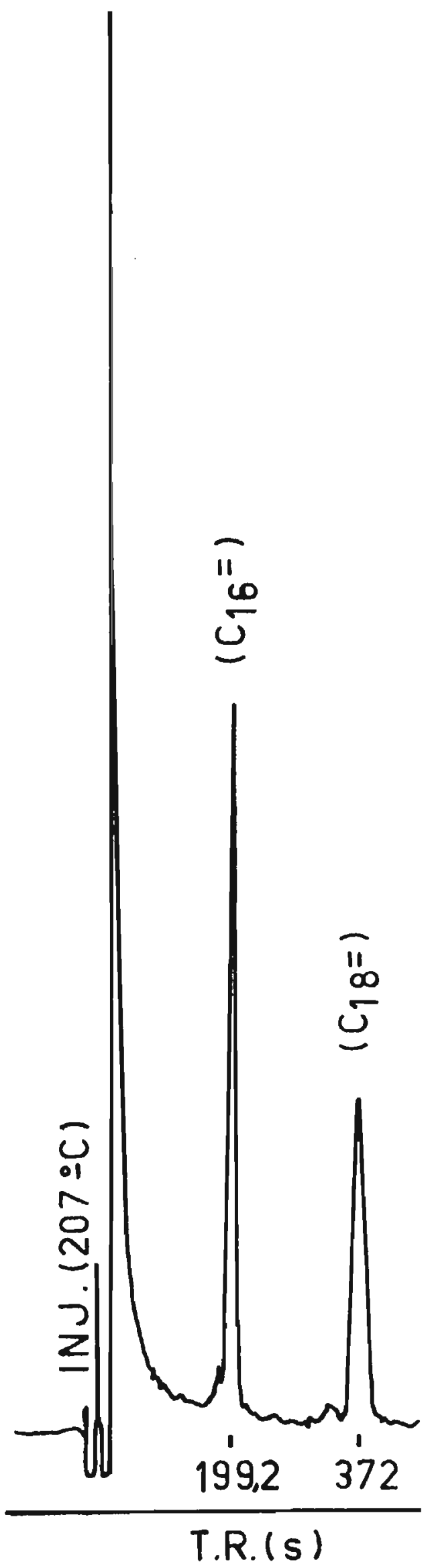

Figura 53 - Cromatogramas em fase gasosa de 1-alcenos. (A) 1hexadeceno $\left(\mathrm{C}_{16}=\right)$; (B) 1 -octadeceno $\left(\mathrm{C}_{18}=\right)$ 


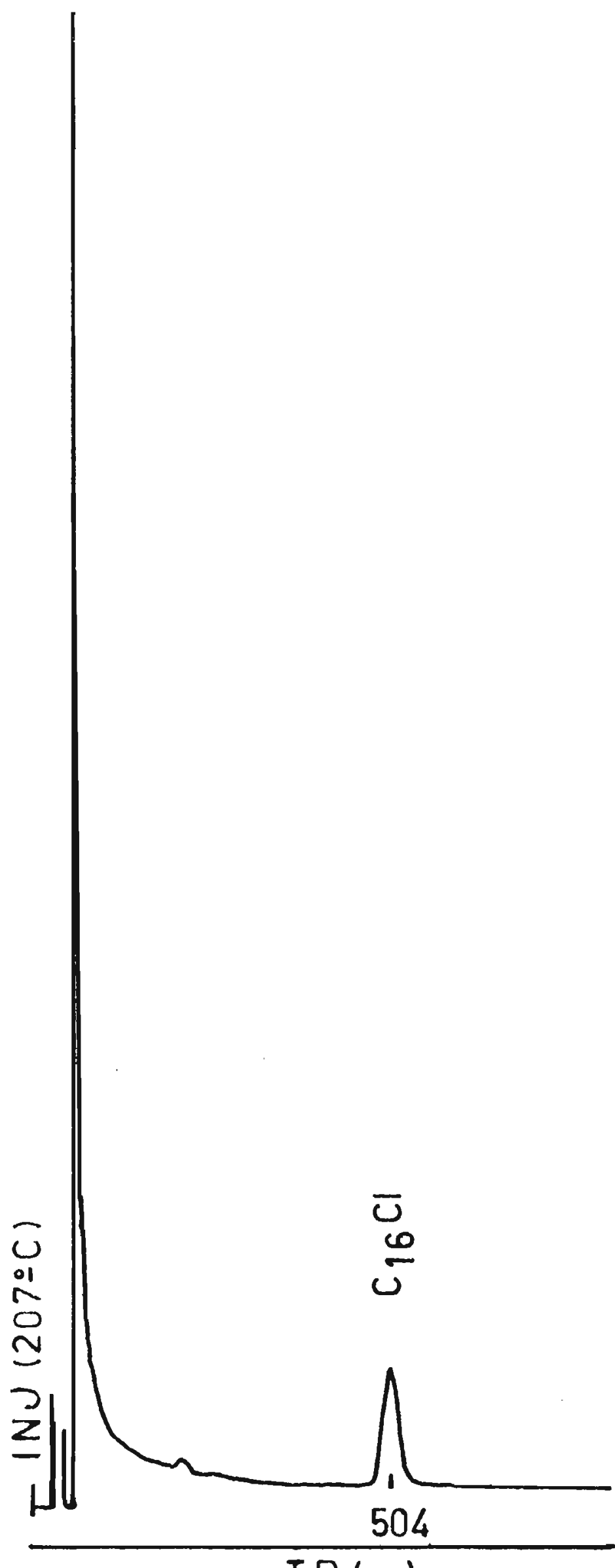

T.R.(s)

Figura 54 - Cromatograma em fase gasosa de 1-cloro-n hexadecila $\left(\mathrm{C}_{16} \mathrm{Cl}\right)$ 


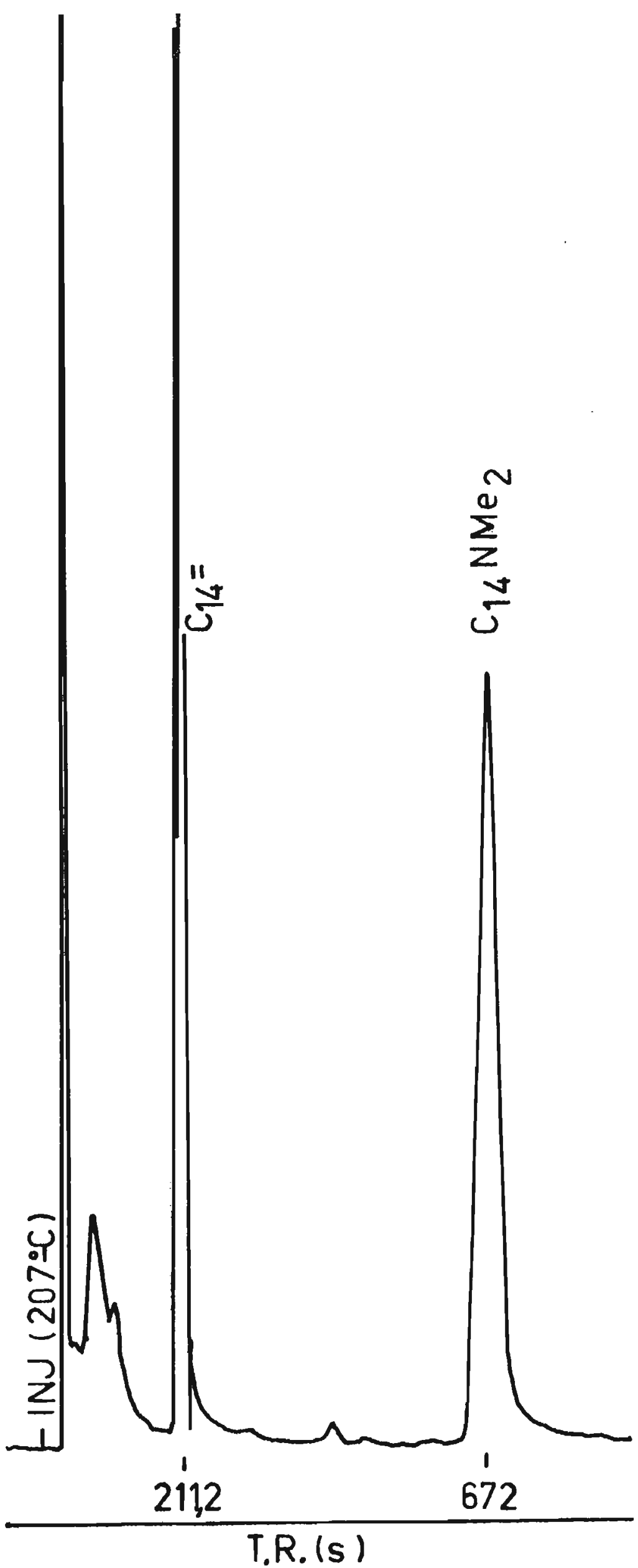

Figura 55 - Cromatograma em fase gasosa de hidróxido de $N-h e$ xadecil-N'-trimetilamōnio (CTAOH) 


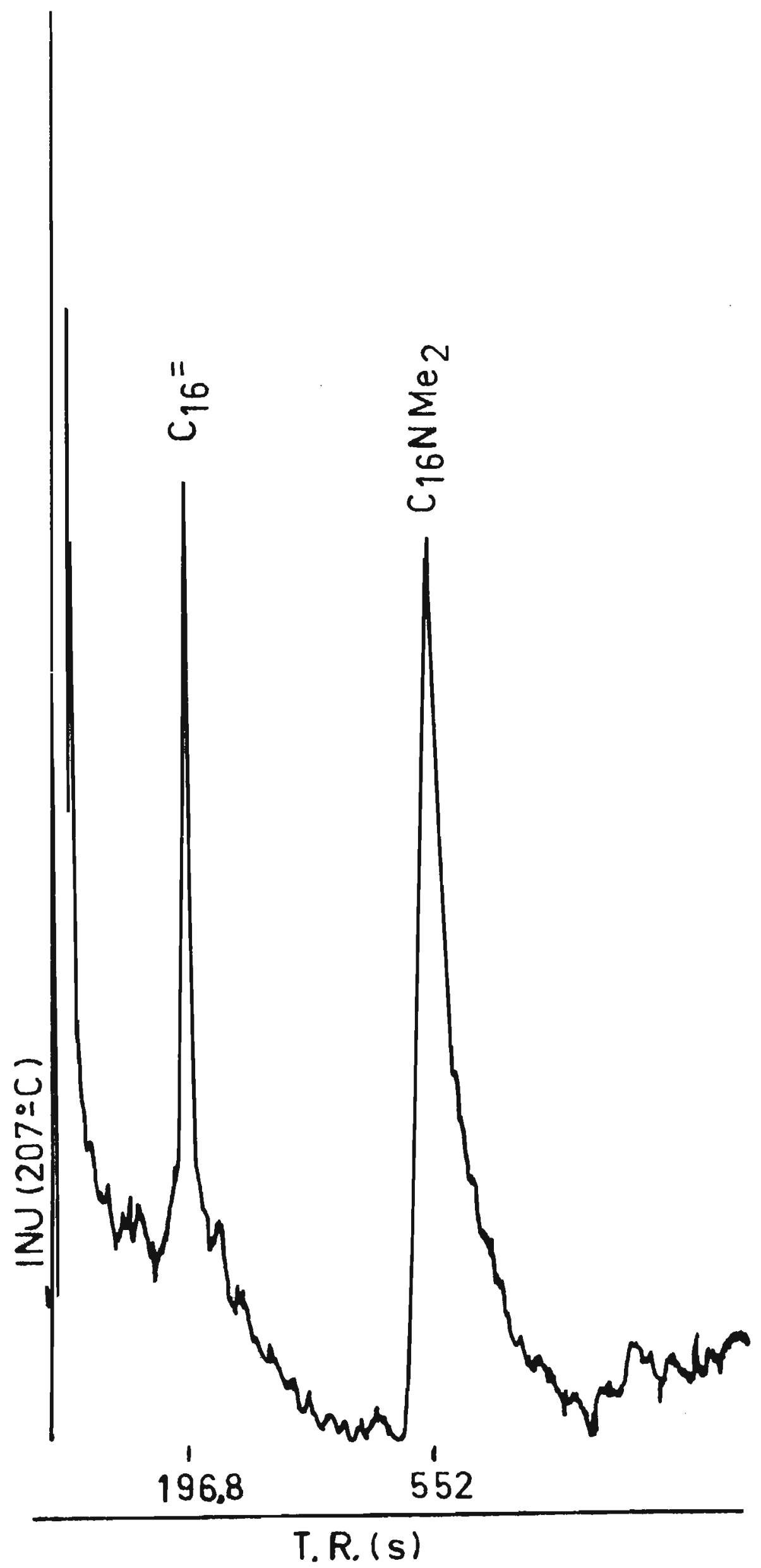

Figura 56 - Cromatograma em fase gasosa de brometo de $N$-hexade cil-N'-trimetilamónio (CTAB) 


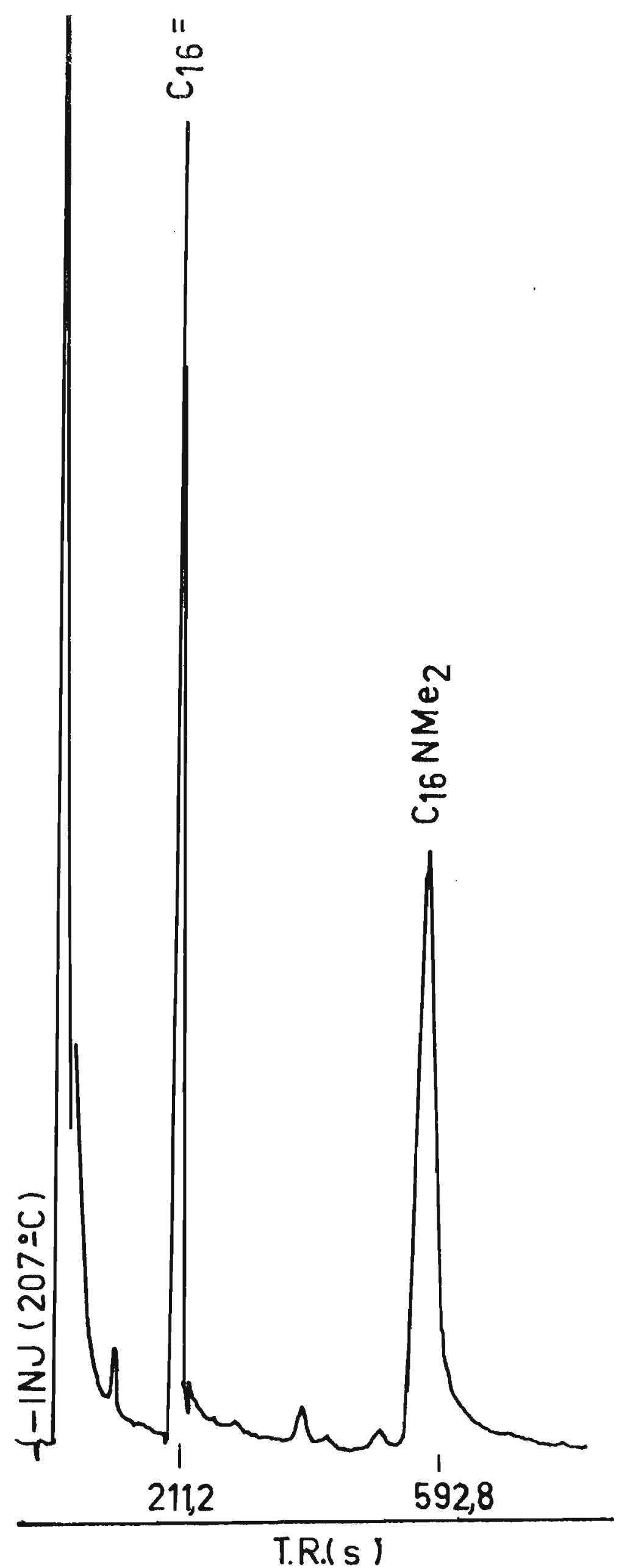

Figura 57 - Cromatograma em fase gasosa de cloreto de $\mathrm{N}$-hexade cil-N'-trimetilamónio (CTAC1) 


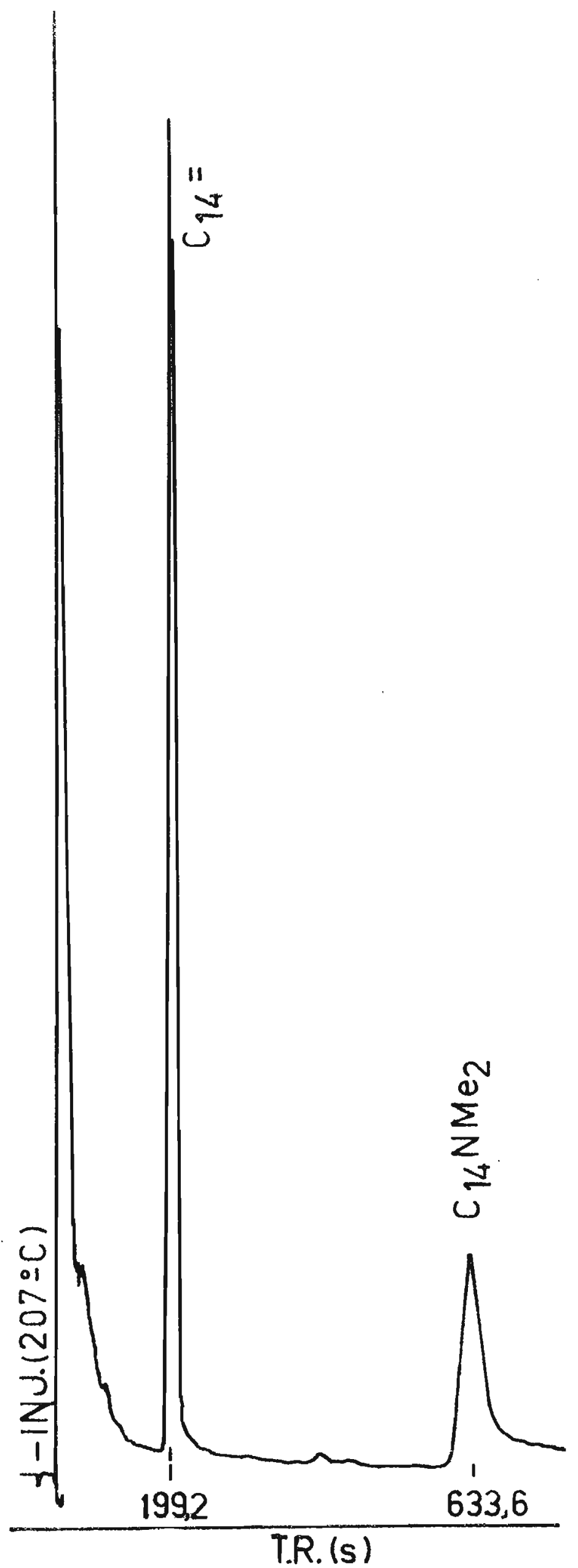

Figura 58 - Cromatograma em fase gasosa de brometo de $N$-tetradecil-N'-trimetilamónio (TTAB) 


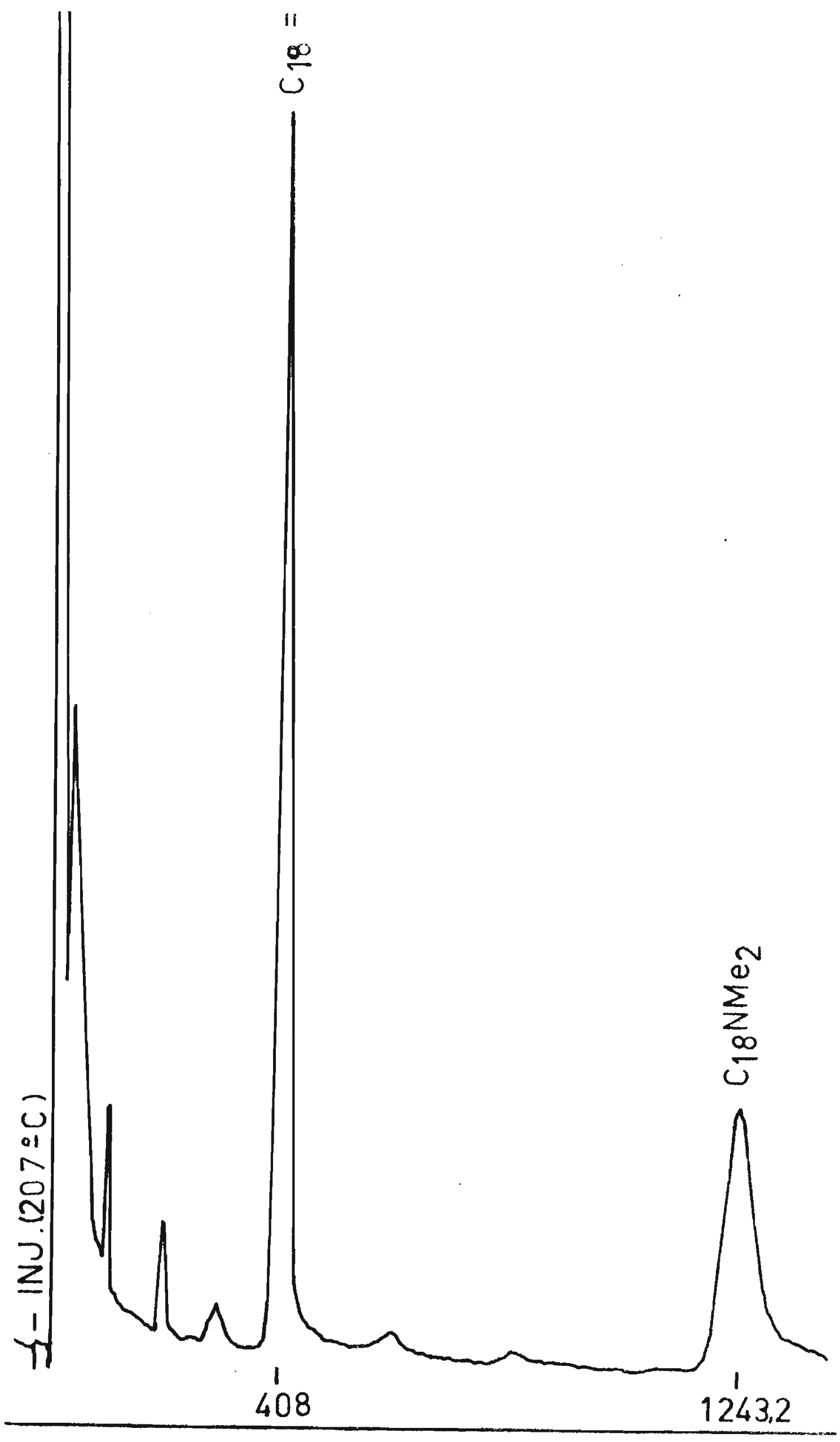

T.R.(s)

Figura 59 - Cromatograma em fase gasosa de cloreto de N-octadecil-N'-trimetilamonio (STACI) 


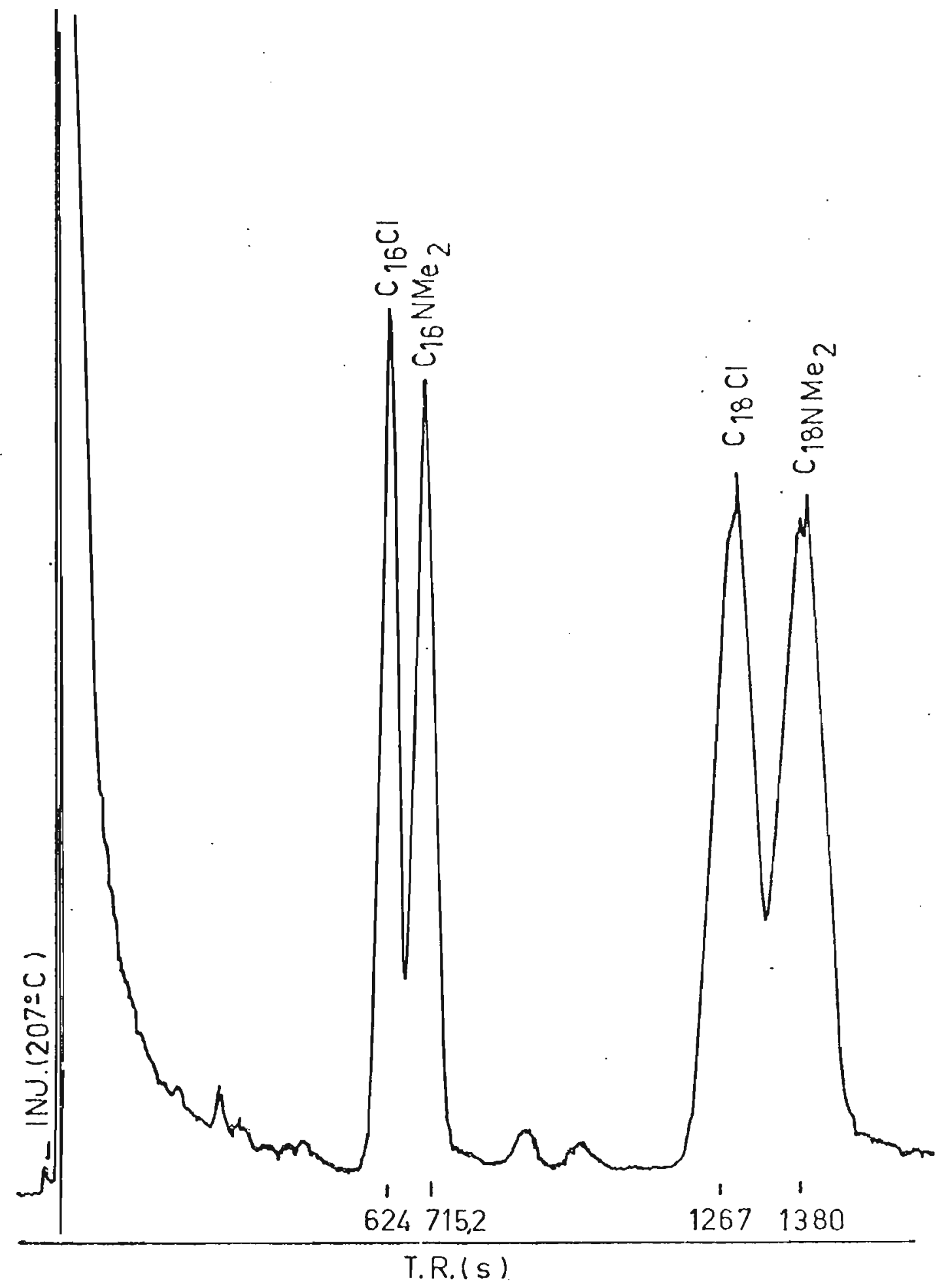

Figura 60 - Cromatograma em fase gasosa de Herquat na forma de cloreto (Herq-Cl) 


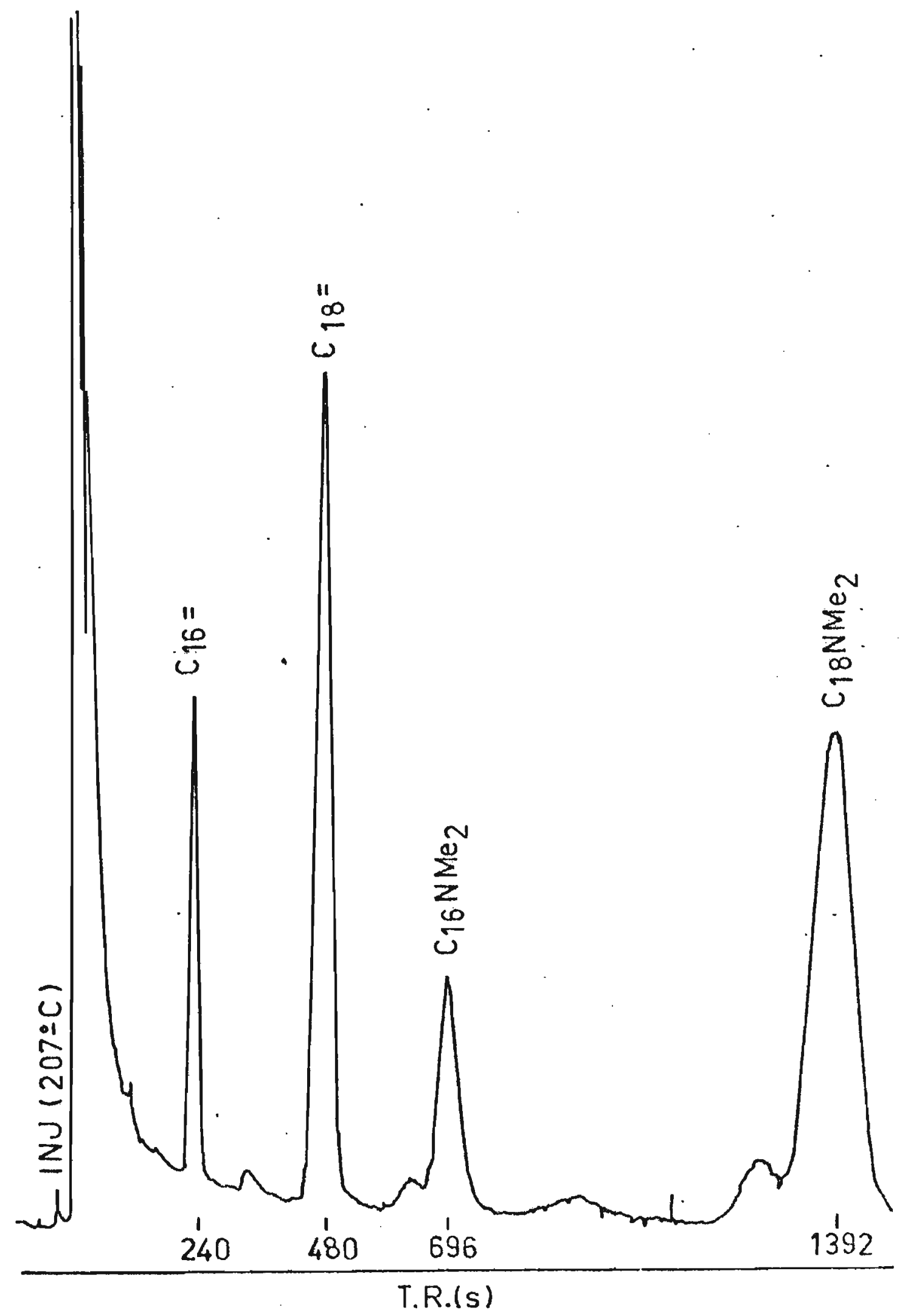

Figura 61 - Cromatograma em fase gasosa de Herquat na forma de hidróxido (Herq-OH) 


\begin{tabular}{|c|c|c|c|c|c|c|c|c|c|c|c|}
\hline \multirow[b]{3}{*}{ Compos to } & \multirow[b]{3}{*}{$t^{0}, c$} & \multicolumn{10}{|c|}{ Tempo de Retenção (segundos) } \\
\hline & & \multicolumn{5}{|c|}{ AMINAS } & \multicolumn{3}{|c|}{ ALCENOS } & \multicolumn{2}{|c|}{ CLOROALCANOS } \\
\hline & & $\mathrm{SNMe}_{2}$ & $12 \mathrm{NMe}_{2}$ & $14 \mathrm{MMe}$ & ${ }^{16 M_{2}} 2$ & ${ }_{18 \mathrm{NMe}_{2}}$ & $c_{14}=$ & $c_{16}=$ & $c_{18}=$ & $c_{16} \mathrm{Cl}$ & $\mathrm{C}_{78} \mathrm{Cl}$ \\
\hline PADROES & $\begin{array}{l}180 \\
180 \\
207\end{array}$ & $\begin{array}{l}72,0 \\
54,0\end{array}$ & $\begin{array}{l}312,0 \\
264,0 \\
150,0\end{array}$ & & $\begin{array}{l}1296,0 \\
528,0\end{array}$ & & & $\begin{array}{l}420,0 \\
199,2\end{array}$ & 372,0 & 504,0 & \\
\hline CTAOH & $\begin{array}{l}180 \\
207 \\
207\end{array}$ & & & $\begin{array}{l}672,0 \\
292,8 \\
293,0\end{array}$ & & & $\begin{array}{l}211,2 \\
115,2 \\
115,2\end{array}$ & $\begin{array}{l}410,4 \\
210,0 \\
215,2\end{array}$ & & & \\
\hline CTAB & $\begin{array}{l}207 \\
\dot{2} \\
207 \\
207\end{array}$ & & & & $\begin{array}{l}600,0 \\
552,0 \\
552,0\end{array}$ & & & $\begin{array}{l}218,4 \\
196,8 \\
196,8\end{array}$ & 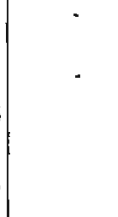 & & \\
\hline CTACI & $\begin{array}{l}207 \\
207\end{array}$ & & & & $\begin{array}{l}592,8 \\
619,2\end{array}$ & & 115,2 & $\begin{array}{l}211,2 \\
218,4\end{array} \mid$ & & & \\
\hline TTAB & $\begin{array}{l}180 \\
207\end{array}$ & & & $\begin{array}{l}633,6 \\
391,2\end{array}$ & & & $\begin{array}{l}199,2 \\
117,6\end{array}$ & $\begin{array}{l}427,2 \\
285,6\end{array}$ & & & \\
\hline STACI & $\begin{array}{l}207 \\
207\end{array}$ & & & & $\begin{array}{l}590,4 \\
516,0\end{array}$ & $\begin{array}{l}1243,0 \\
1132,8\end{array}$ & $\begin{array}{l}216,0 \\
187,2\end{array}$ & $\begin{array}{l}408,0 \\
360,0\end{array}$ & & & \\
\hline Herq-Cl & $\begin{array}{l}207 \\
207\end{array}$ & & & . & $\begin{array}{l}715,2 \\
715,2\end{array}$ & $\begin{array}{l}1428,0 \\
1380,0\end{array}$ & & $\begin{array}{l}249,6 \\
240,0\end{array} \mid$ & & $\begin{array}{l}655,2 \\
624,0\end{array}$ & $\begin{array}{l}1308,0 \\
1267,0\end{array}$ \\
\hline Herq-OH & 207 & & & & 696,0 & 1392,0 & & 240,0 & 480,0 & 628,8 & 1260,0 \\
\hline
\end{tabular}


Tabela 38 - Yalores de tempo de retenção relativos à 1 -hexadeceno Tempo de Retenção Relativo à 1-hexadeceno

\begin{tabular}{|c|c|c|c|c|c|c|c|c|c|c|c|}
\hline \multirow[b]{2}{*}{ Compos to } & \multirow[b]{2}{*}{$t^{0}, c$} & \multicolumn{5}{|c|}{ AMINAS } & \multicolumn{3}{|c|}{ ALCENOS } & \multicolumn{2}{|c|}{ CLOROALCANOS } \\
\hline & & $8 \mathrm{NMe}_{2}$ & ${ }^{12 \mathrm{NHe}_{2}}$ & $14 \mathrm{NMe}_{2}$ & $16 \mathrm{NMe}_{2}$ & $18 \mathrm{NMe}_{2}$ & $c_{14}=$ & $c_{16}=$ & $c_{18}=$ & $c_{16} \mathrm{Cl}$ & $\mathrm{C}_{78} \mathrm{Cl}$ \\
\hline \multirow{3}{*}{ PADROES } & 180 & 0,18 & 0,74 & & 3,09 & & & 1 & & & \\
\hline & 180 & & 0,63 & & & & & 1 & & & \\
\hline & 207 & 0,27 & 0,75 & & 2,64 & & & 1 & 1,87 & 2,53 & \\
\hline \multirow{3}{*}{$\mathrm{CTAOH}$} & 180 & & & 1,64 & & & 0,51 & 1 & & & \\
\hline & 207 & & & 1,39 & & & 0,55 & 1 & & & \\
\hline & 207 & & & 1,43 & & & 0,56 & 1 & & & \\
\hline \multirow{3}{*}{ CTAB } & 207 & & & & 2,75 & & & 1 & & & \\
\hline & 207 & & & & 2,80 & & & 1 & & & \\
\hline & 207 & & & & 2,80 & & & 1 & & & \\
\hline \multirow{2}{*}{ CTACl } & 207 & & & & 2,81 & & 0,54 & 1 & & & \\
\hline & 207 & & & & 2,83 & & & 1 & & & \\
\hline \multirow{2}{*}{ TTAB } & 180 & & & 1,48 & & & 0,47 & 1 & & . & \\
\hline & 207 & & & 1,37 & & & 0,41 & 1 & & & \\
\hline \multirow{2}{*}{ STACI } & 207 & & & & 2,73 & 5,75 & & 1 & 1,89 & & \\
\hline & 207 & & & & 2,76 & 6,05 & & 1 & 1,92 & & \\
\hline \multirow{2}{*}{ Herq-Cl } & 207 & & & & 2,87 & 5,72 & & 1 & & 2,62 & 5,24 \\
\hline & 207 & & & & 2,98 & 5,75 & & 1 & . & 2,60 & 5,28 \\
\hline Herq-OH & 207 & & & & 2,90 & 5,80 & & 1 & 2,00 & 2,62 & 5,25 \\
\hline
\end{tabular}


IV. DISCUSSAO

IV.I. Reaçäo de Hidrōlise Alcalina de N-alquil-4-cianopiri díneo (RCP) em ägua

E fundamental esclarecer o comportamento da reaçãode hidrōlise alcalina dos RCP em àgua a fim de podermos quantificar, posteriormente, os efeitos das micelas na velocidade des tas reaçöes.

O propōsito desta primeira parte da discussão é es clarecer os limites, as condiçōes, enfim, deixar esclarecida a reação de hidrōlise dos RCP em àgua.

Os estudos de Kosower e Patton (1966) relativos a hị drölise de MCP e MC2P, demonstraram que a hidrōlise desses com postos leva à formação de piridona e amida respectivas. Nesta dissertação retomamos o estudo da reação de hidrólise do MCP e MC2P, e estendemos o estudo para ions RCP de cadeias alquila maiores.

Os dados de coeficientes de extinção molar dos RCP (Tabela 2) e dos respectivos produtos de hidrólise (Tabela 3), não mostram uma variação significativa com a variação do com primento da cadeia (cerca de 10\%) sendo ainda bastante concordantes com os de Kosower e Patton (1966).

A equação 86 generaliza o comportamento dos RCP P rante a reação de hidrōlise alcalina en àgua. Esta expressãoé aplicada nos limites de baixa concentração de RCP ( $\leqslant 1 \times 10^{-4} \mathrm{M}$ ), em condições de pseudo primeira ordem e baixa força iōnica $(\leqslant 0,7 M)$. Sendo os RCP de cadeia $\mathrm{N}-\mathrm{a}$ lquila longa ( $\geqslant$ oito carbonos) capa zes de formar micelas, a alta concentração de RCP, cerca de 
0,08M para o OCP e 0,01M para O DCP, atinge-se a concentração crítica de micelização destes compostos (Fendler e Fendler, 1975;Romsted, 1975) e com isso a equação 86 não pode mais ser aplicada, pois o comportamento desta reação em presença de mi celas é diverso do em àgua. O limite de baixa forma iónica para a aplicação da equação é devido à CMC ser função decres cente com a concentração de sal adicionado (Shinoda 1963; Sa saki et al, 1975; Funasaki, 1978, 1979) e desta forma em meios de alta força iónica poderíamos atingir a CMC dos RCP.

Pela anālise do efeito de força iōnica na constante de velocidade e relação de produtos da reação (Tabelas 10 e 11) podemos avaliar e tecer comparações relativas às constantes $k_{4}$, $k_{5}$ e $k_{-2}$, relativas aos passos intermediārios na direção da formação de piridona (vide Figura 6) (as constantes $k_{1}$ e $k_{2}$ são obtidas nos limites de alta e baixa concentração de hidrō xido Tabelas 9 e 11 .

A anālise dos dados de hidrōlise em àgua segundo o formalismo da equação 52 indica que $k_{4} \bar{e}$ muito menor que $k_{-}{ }_{2}$, isto é, o passo de transformação direta da cianohidrona inter mediāria (H) tem uma constante de velocidade intrínseca menor que a do passo de liberação do hidrōxido do carbono 4 do anel piridineo (intercepto da Figura 19). Pode-se estimar o valor de $K_{3}(14)\left(K_{3}=10^{-12} M\right)$ e assim,pelo valor da inclinaçāo (Figura 19), vemos que $k_{5} \bar{e}$ muito maior que $k_{-2}$. Associando-se estes fatos fica claro que as espécies cianohidrīnicas $\left(\mathrm{H} \mathrm{e}^{-}\right.$) de vem estar presentes como intermediārios da reação e que a transformação direta da cianohidrina (H) não ocorre, ou ocor re a velocidade baixa. Uma vez que o pk de derivados cianohi drinicos é alto (por volta de 12), a curva de relação de pro 
dutos ou de constante de velocidade de segunda ordem em fun çäo do pH (Figuras 14 a 18 ) deve ter um perfil similar ao da titulação de äcidos fracos, com o ponto de inflexäo do pk do $\vec{a} c i d o$. Analisando as figuras 14 a 18 temos que o $p H$ no pon to de inflexão é 11,4 , consequentemente a constante de equilibrio $K_{3} \bar{e} 3,98 \times 10^{-12} \mathrm{M}$. Este valor condiz com a estimati va de $k_{3}(14)$.

Estabelecido o valor de $k_{3}$ temos que $k_{5}=8,5 \times 10^{13}$. $k_{-2}$, ou seja, $k_{5} \bar{e}$ muito maior que $k_{-2}$. 0 alto valor de $k_{5}$ relativo a $k-2$ pode ser considerado em termos da seguinte trans formação molecular (Figura 62):

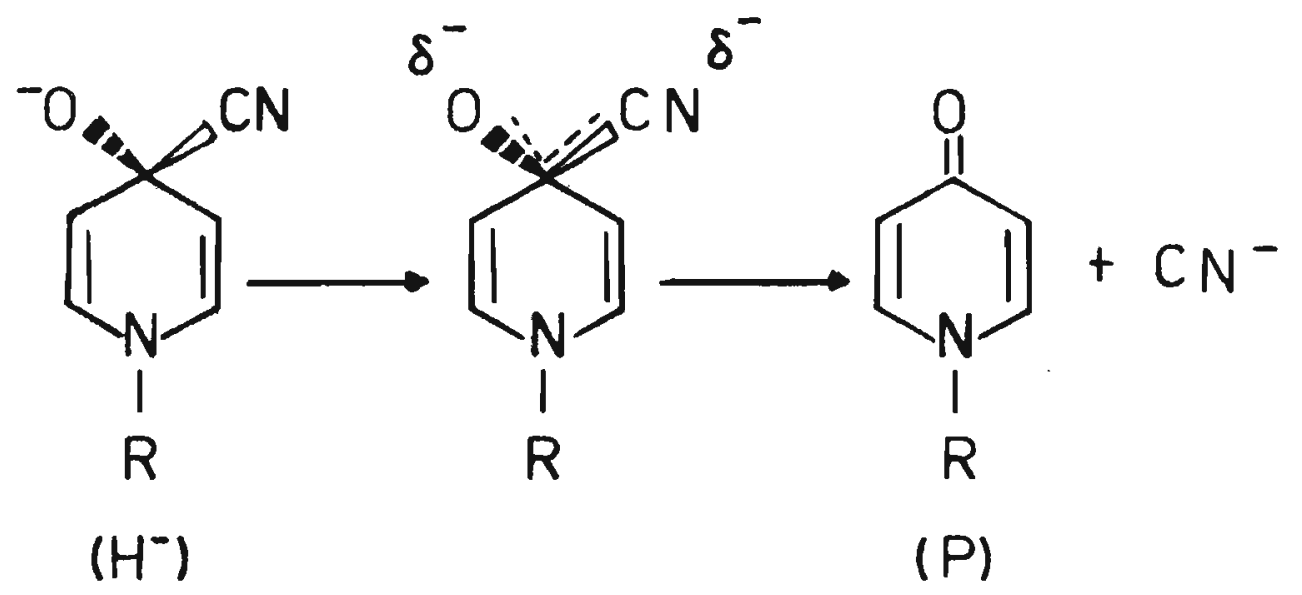

Figura 62 - Vibração de estiramento da liga ção carbono do anel piridíneo - carbono cia nĩdrico.

0 tratamento usual para constantes de transformação química devido ao estiramento de ligações ou devido ao acúmu10 de energia suficiente num modo crĩtico de vibração (k), PO de ser expresso por (Amdur e Hammes, 1966; Benson, 1960):

$$
k=v_{0} \cdot e^{-\varepsilon a} / k T
$$

(onde, vo è uma frequéncia, no caso, uma média particular das frequências da vibração molecular e $\varepsilon_{a} \bar{e}$ a energia de ativa - 
ção por molēcula necessāria para o processol.

o valor māximo da constante (k) è o valor vo e sendo, vo frequência vibracional, a ordem de magnitude de $k \bar{e}$ de $10^{13}$ a $10^{14} \mathrm{seg}^{-1}$ (Benson, 1960). Evidentemente $k-2$ envolve frequências de estiramento tambëm, porém o que queremos frisar è que $k_{5}$ é essencialmente uma transformação do tipo acima cita do, enquanto $k_{-2}$ deve ser mais complexa.

Pode-se apreciar finalmente que a reação em āgua (ba se deste estudo) ē perfeitamente descrita pelos parāmetros e funções apresentados, ou seja:

i) expressão geral de $k \psi$

ii) comportamento da relação $P / A$ e $k_{2} \psi$

iii) efeito de força iônica

iv) valores de $k_{1}, k_{1}^{0}, k_{2}$ e $k_{2}^{0}$

v) valores de $\delta$

vi) valores de $\mathrm{K}_{3}$

vii) relaçöes entre $k_{4}, k_{-2}$ e $k_{5}, k-2$

Vale salientar que, independente das interpretações, a correlação entre os pontos da Figura 19 é consistente com 0 tratamento numērico apresentado.

Outro fenómeno estudado foi o efeito da diminuição da constante dielētrica na reação em ägua, (1,4-dioxana, Figu ras 20 a 21 ).

0 modelo teórico apresentado (equações 53 a 73 ) des creve bastante bem o comportamento observado (Figuras 20 a 21 ). Vale assinalar (uma vez mais), que a concentraçăo crescente de hidróxidoe, consequente, aumento de força iônica, o desviodos pontos experimentais da curva teörica $\bar{e}$ maior. Este desvio po 
deria ser minimizado se utilizässemos formas estendidas da equeação de Debye-Huckel (equação65 e 66), pois neste caso té ríamos um fator empirico adicional, dependente de $\mu$, o qual implicaria numa rotação da reta teōrica para valóres de àngulo de inclinação maiores. Contudo uma vez que este fator empirico näo tem um sentido fïsico definido, representando uma soma tōria de contribuições ao potencial interiōnico, da qual a con tribuição de cada termo da somatōria (como raio hidratado dos ions, potenciais de curto alcance, etc) è desconhecida atē a presente data (Pitzer, 1979). Optamos então, por restringir o tratamento invēs de procurar um valor qualquer para que ajustasse melhor os dados experimentais ao modelo teórico, mesmo porque a extrapolação que pretendemos (vide infra) serā feita a uma região inacessĩvel experimentalmente.

Um resultado que merece detaque è o aumento do valor da relação P/A com a diminuição da constante dielétrica do meio, isto ē, a formação de piridona ē preferencial em meio de constante dielétrica menor. Para explicar este fato utiliza mos os estados de transição provāveis na direção da formação de piridona e na da amida, a seguir representados:

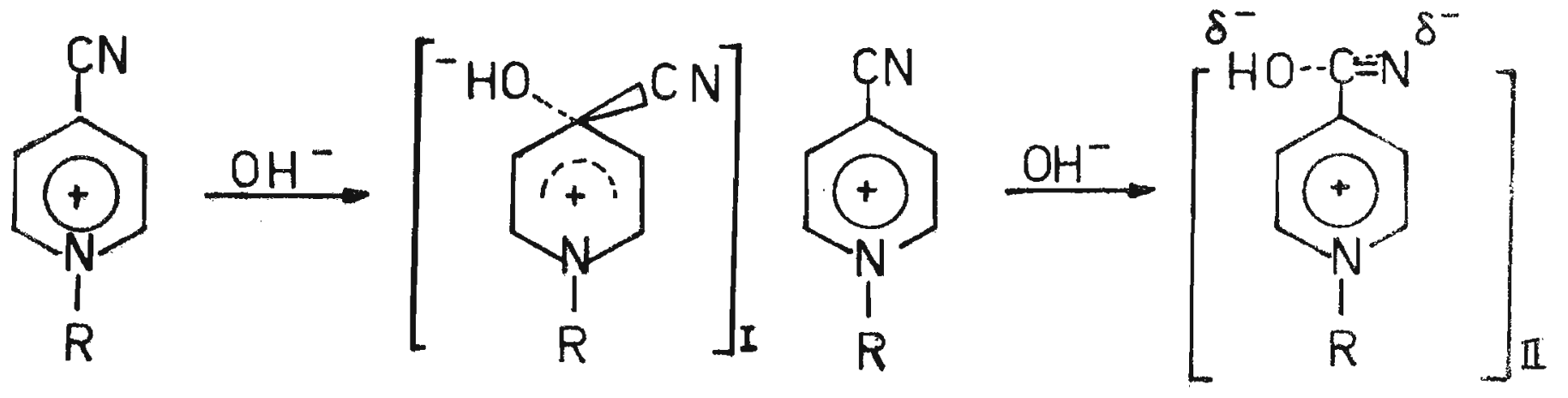

Figura 63 - Estado de transição provãveis de ataque de hidrōxido na direção de formação de piridona (I) e amida (II). 
Pode-se apreciar da Figura 63 que o passo relativo a formação de piridona (I) implica no cancelamento da carga, en quanto no passo I forma-se uma espécie zwitteriónica. Desde que uma diminuiçäo na constante dielētrica, sabidamente, acele ra reaçōes onde se produz uma diminuição na carga do estado de transição, o passo I será favorecido. Podemos dizer que nes te caso ocorre uma diminuição no $\Delta G^{f}$ do passo I por estabiliza ção do estado de transição respectivo. Poderíamos imaginar o seguinte diagrama energētico da reação:

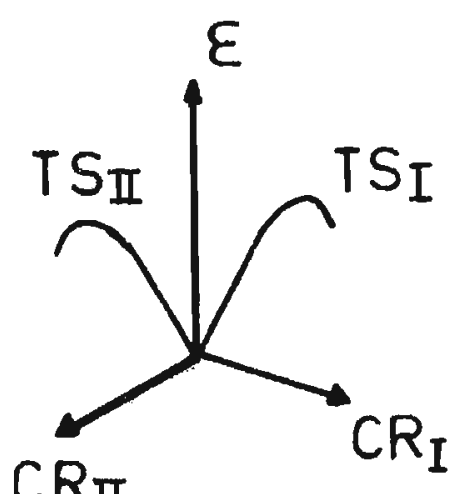

$A$

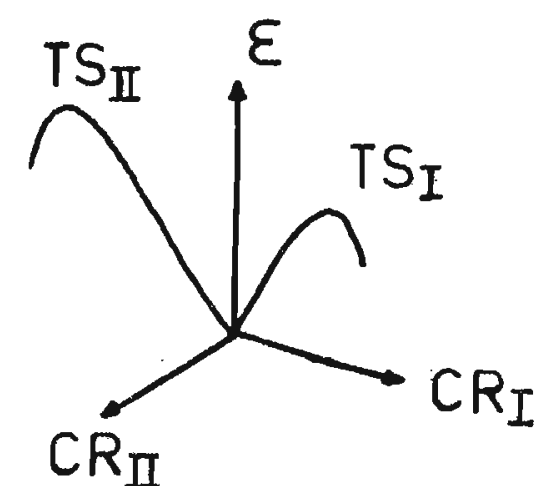

B

Figura 64 - Diagrama energético do passo I e passo II (veja legenda da Figura 63). A, $D=80 ; B, D=32, \quad$ onde $\varepsilon=$ energia, Ts=es tado de transição; CR=caminho da reação.

Visto que $k_{-2}$ è muito pequena e k-1 não existe (ve ja Figura 6 , onde $k_{-1}$ seria a suposta volta do ataque de $\mathrm{OH}^{-}$ no caminho de formação de amida), uma vez formados os intermediārios, apōs o ataque de hidrōxido, a volta para a formação de reagente praticamente inexiste. 
0 passo seguinte na formação de piridona, que repre senta a reação de ida do equilíbrio $k_{3}$, deve ser energetica mente desfavorāvel. Contudo existe uma via alternativa $\left(k_{4}\right)$ que no caso de baixa constante dielētrica pode ser viāvel.Por outro lado, os passos de formação de amida apōs a formação do primeiro intermediārio (Figura 63, II), os quais envolvem adi ção de āgua e liberação, por fim, de $\mathrm{OH}^{-}$, não devem ser, em termos energēticos muito diferentes daqueles da formação de piridona.

IV.2. Em Micelas

\section{$\underline{C T A B}$}

Analisaremos primeiramenre os dados relativos a cons tante de partição (Keq/N $)$ de DCP e DeCP. Estudos quantitativos de wishnia (1963), relativos a medida de solubilidade de hidrocarbonetos en micelas de SDS com $0,1 \mathrm{M}$ de $\mathrm{NaCl}$, permitem ob ter a energia livre de transferência do hidrocarboneto da ägua $\left(\mu^{0}{ }_{w}\right)$ para o interior da micela $\left(\mu_{\text {mic }}^{0}\right)$ (veja Tanford, 1980). A equação obtida por regressão linear simples é (assumida con dições ideais para a solução aquosa e do interior da micela):

$$
\mu_{\text {mic }}^{0}-\mu_{W}^{0}=-1934-771 \mathrm{nc}
$$

(onde nc è o no de grupos metilênicos). A expressãol22mostra que $\Delta^{0}$ ou $\Delta \Delta G / \mathrm{mol}$ de $\mathrm{CH}_{2} \bar{e} 0,771 \mathrm{Kcal} / \mathrm{mol}$. Comparando-seas $\mathrm{Keq} / \overline{\mathrm{N}}$ de DCP e DeCP (Tabela 17 e 22 e Figuras 24 a 38 ) a uma mesma concentração salina, podemos obter o valor de $\Delta \Delta G^{0}$ de transferència por grupo metilènico $\left(\Delta \Delta G^{0}\right.$ trans/CH$\left.H_{2}\right)$ uma vez 
que a energia livre de transferência (Gtrans) è relacionada a Keq/N na maneira usual, isto é:

$$
\Delta G_{\text {trans }}^{0}=-R T \ln \frac{\text { Keq }}{N} \text { (Tanford, 1973) }
$$

Utilizando os valores de $\frac{\text { Keq }}{\bar{N}}$ (Tabelas 17 e 22 ), ob temos primeiramente $O \quad \triangle \triangle G^{0}$ entre $D C P$ e DeCP. Uma vez que a diferença entre estes compostos é dois grupos metilênicos o $\Delta \Delta^{0} G / C_{2}$ ou $\Delta \mu^{0}$ será o valor de $\Delta \Delta G^{0}$ dividido por dois, como mostramos na Tabela 38.

Tabela 38 - Valores de $\Delta \Delta G^{0} / \mathrm{CH}_{2}$ de transferência de RCP da àgua para micelas de CTAB

\begin{tabular}{c|c|c}
$\begin{array}{c}\text { Concentração salina } \\
(K B r), m M\end{array}$ & $\mid \Delta G^{0}(D C P)-\Delta \Delta^{0} G(K C a l / m o l)$ \\
10 & $-1,48$ & $\frac{\Delta \Delta G^{0}}{C H_{2}}(K c a l / m o l)$ \\
20 & $-1,69$ & $-0,74$ \\
30 & $-1,74$ & $-0,84$ \\
40 & $-1,54$ & $-0,87$ \\
60 & $-1,35$ & $-0,77$ \\
80 & $-1,68$ & $-0,67$ \\
100 & $-1,58$ & $-0,84$
\end{tabular}

0 valor médio de $\Delta \Delta G^{0} / \mathrm{CH}_{2}\left(\overline{\Delta \Delta G^{0}} / \mathrm{CH}_{2}\right) \overline{\mathrm{e}} \overline{\Delta \Delta G^{0}} / \mathrm{CH}_{2}=$ $(0,79 \pm 0,06) \mathrm{Kcal} / \mathrm{mol}$.

Deve-se notar a semelahnça deste valor ao da expres são 122. Embora os dados de Wishnia refiram-se a transferên. cia de $\mathrm{CH}_{2}$ a micelas de SDS, valores de $\Delta \mu^{0}$ de outros autores como Tanford (1980), Almgreen e colaboradores (Almgreen et al, 
1979), para CTAB e outros sistemas micelares, indicam que nosso valor situa-se na faixa dos valores publicados $\left(\Delta \mu{ }^{0}\right.$ situa se entre $\mathrm{Kcal} / \mathrm{CH}_{2}$ a $-600 \mathrm{Kcal} / \mathrm{CH}_{2}$ ).

Utilizamos para medida de $\mathrm{Keq} / \bar{N}$ a supressão da emissäo de fluorescéncia de Ru(bipy) ${ }_{3}^{2+}$ pelos RCP. Residindo o Ru (bipy) ${ }_{3}^{2+}$ exclusivamente na fase aquosa, a medida que adicionamos o detergente (CTAB no caso) os RCP são incorporados (parti cionam-se) às micelas, com consequente diminuição da supressão. Medimos, portanto, a quantidade de supressor livre. Para os $R C P$ de cadeia alquila menor (OCP, BCP e MCP) seria necessārio uma quantidade muito grande de CTAB, para ocasionar uma queda na quantidade de supressor livre que permitisse a medida de $\mathrm{Keq} / \bar{N}$. Estes valores (Keq/N de OCP, BCP e MCP) podem, no entanto, ser estimados a partir dos valores de Keq/N de DCP ou DeCP, a dada concentração salina. A partir do valor de $\Delta \mu^{0}$ e da diferença em nọ de $\mathrm{CH}_{2}$ do RCP de referēncia (DCP ou DeCP) e do que se se deseja calcular, calcula-se o Keq/N.

Discutida a partição dos RCP em micelas de CTAB, po demos tentar entender o efeito de CTAB sobre a constante de $\underline{e}$ feito de CTAB sobre a constante de velocidade da reaçäo de $h \underline{i}$ drölise de RCP e relação $P / A$.

0 efeito de micelas sobre a constante de velocidade pode ser explicada como sendo devida, basicamente, à concentra ção das espēcies reagentes na interface (Berezin 1973; Romsted, 1975; Chaimovich, 1979). A adição de CTAB, em concentra ções acima da CMC, ao sistema de reação dos RCP implica nos se guintes fenômenos:

- ligação de hidróxido à superfície positiva da micela 
(Chaimovich et a1, 1979)

- partição dos RCP entre as fases micelar e aquosa ( de supra).

Iniciando a anālise para a reação do DCP (Tabela 23 e Figura 39 ) vemos que o fator māximo de aceleração ( $k_{\psi_{\max }}$ / $\left.k \psi \mathrm{H}_{2} \mathrm{O}\right) \overline{\mathrm{e}}$ da ordem de 200 vezes (Tabela 27). Este māximo $\bar{e}$ ré sultante de dois fatores, quais sejam, a partição do DCP (cuja Keq/N $\overline{\mathrm{N}}$ bastante grande, veja Tabela 17) e a diluição de hidró xido na superficie da micela como se pode ver na figura 65.

As curvas da figura 65 são calculadas a baixa concen tração salina (cerca de $10 \mathrm{mM}$ de KBr). Pode-se notar que as du as componentes $\left(\overline{O H_{b}}\right.$ e $\left.D C P_{b}\right)$ obtem-se um perfil similar ao da Figura 39 (compare com a Figura 5) Devemos notar ainda que a presença de sistema tampão atuante, isto $\bar{e}$ em pH prōximo a pK do tampão (vide infra), implicando em con centração de hidrōxido livre $\left(\mathrm{OH}_{f}\right)$ constante e uma vez que rea çäo é feita em condições de pseudo-primeira ordem ( $D C P \ll \mathrm{OH}^{-}$), a fração da reação que ocorre na āgua (na região extramicelar) e constante, Queremos dizer com isso que a composição feita 


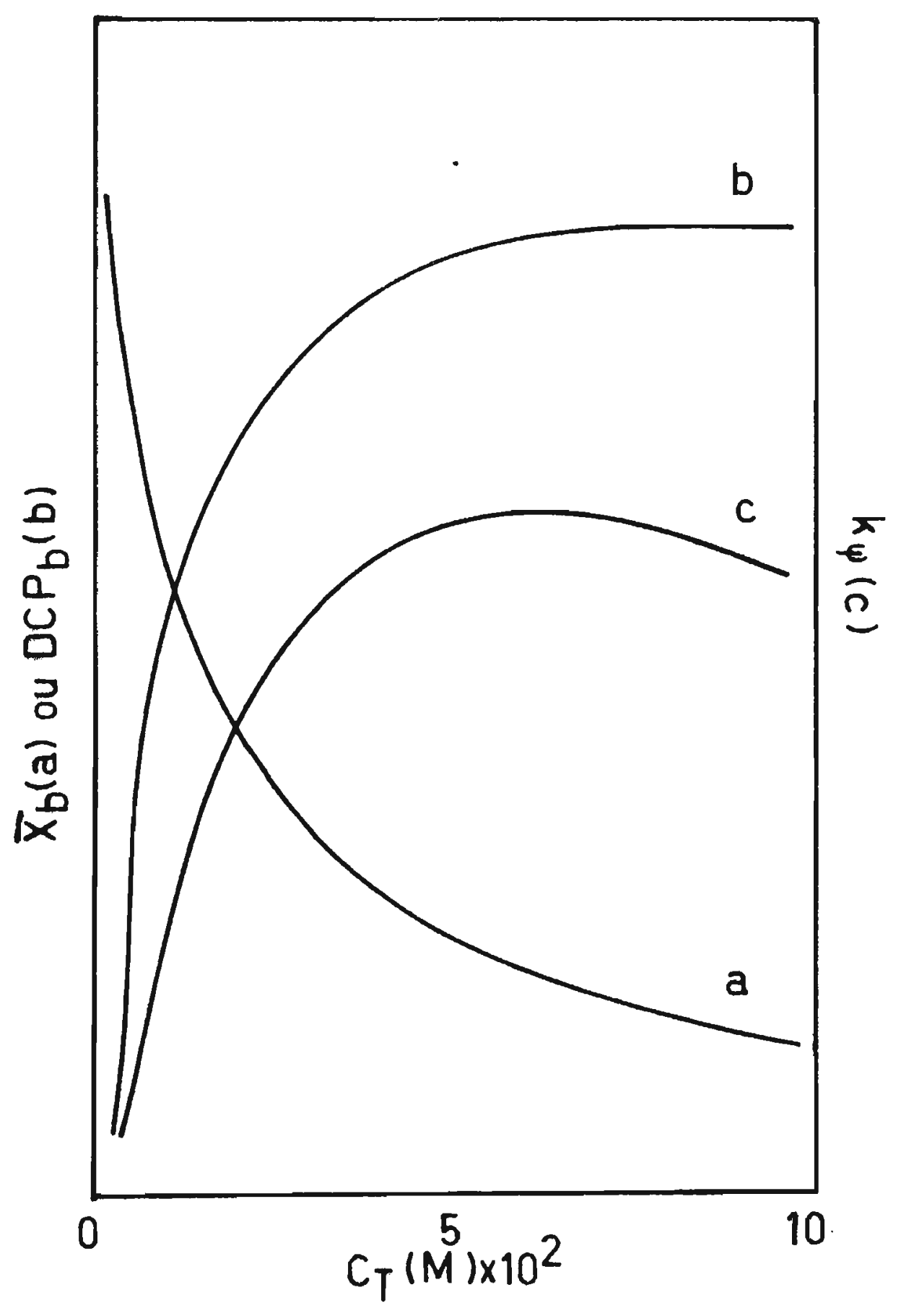

Figura 65 - Variação de $\overline{\mathrm{OH}_{b}}$ e $D C P_{b}$ em função da concentração de CTAB (veja Quina e Chaimovich, 1979). 
na Figura $65(\mathrm{DCP}+\overline{\mathrm{OH}})$ será pouco alterada, exceto por um au mento constante no eixo da ordenada, aumento este pequeno pois $\mathrm{Keq} / \overline{\mathrm{N}} \overline{\mathrm{e}}$ grande (veja Tabela 17). Ressaltamos esta condição $\left(\mathrm{OH}_{f}\right.$ constante), visto que simplifica em muito a anāise quantitativa do sistema.

Na Figura 39 as linhas foram simuladas seguindo a equação 91 . O melhor ajuste da linha teóri ca aos dados experimentais foi obtido na condição $k_{2}^{m}=10 k_{2}^{0}$, is to $\bar{e}$, a constante de velocidade de segunda ordem na micela $\left(k_{2}^{m}\right)$ é uma ordem de magnitude superior a da āgua $\left(k_{2}^{0}\right)$. E inte ressante observar que este fator $\left(k_{2}^{m}=10 \cdot k_{2}^{0}\right)$ pode ser obtido da outra forma. Como foi mostrado na introdução o modelo micelar assumido tem as seguintes características: 1) constante dieletrica da camada de Stern da ordem de 32 , isto $\bar{e}$, semelhante a de metano1; 2) força iônica da camada de Stern da ordem de $3 M$. Assume-se ainda que a reação ocorre na camada de Stern, visto que o DCP é semelhante ao monōmero de CTAB (vide equação 87 ). A posição deste na micela deve ser anāloga a do monômero, isto é, com o nitrogênio do anel piridíneo à mesma distáncia do centro que o nitrogēnio dos monōmeros de CTAB.

Aplicando esta condição nas equações 67 e $73\left(r_{A}+r_{B}=\right.$ $4,5 \mathrm{~A}(15)$ Weller, 1961) obtemos $k_{2}^{32 ; 3 M}=8 k_{2}^{0}$, isto é, a cons tante de velocidade de segunda ordem para reação de RCP em meio de constante dielëtrica 32 e força iōnica $3 \mathrm{M}$ (analogamente ao modelo de (TAB) é uma ordem de magnitude superior a constante de velocidade de segunda ordem a força ionnica usual (cerca de $20 \mathrm{mM})$. 
Este fator esta em perfeito acordo com o obtido por simulação (Figura 39 ). Podemos acrescentar ainda que caso fos sem utilizadas expressões extendidas de Debye-Hüokel (vide su pra), do efeito em $k \psi$ na presença de dioxana, o ajuste poderia ser melhor ainda, isto $\bar{e}$, o fator $f$ seria maior que 8 como acima apresentado.

A comparação entre a curva obtida por simulaçao

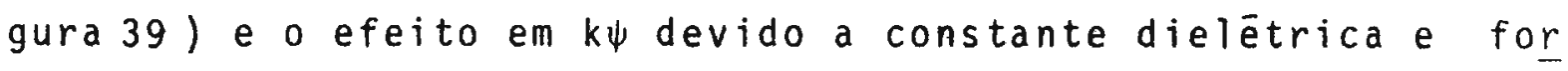
ça iōnica, está sujeita a várias críticas. Primeiramente a própria simulação onde se ajustou um valor $f$ manteve-se o volume molar parcial do detergente (V) como um valor definido e conhecido. E claro que a reação deve ocorrer num volume re lativamente menor e com isso $\bar{V}$ está super estimado. Por outro lado as curvas relativas ao efeito em $k \psi$ devido aconstante die lētrica e força iōnica foram obtidas a baixa força iōnica. A extra polação para concentrações iônicas da ordem de $3 M$ é algo duvi dosa (Pitzer, 1979). Contudo, em virtude da falta de parāmetros e equaçöes definidas que estipulem o valor do coeficiente de atividade de espécies como N-trimetil-N-hexadecilamónio e outros, a comparação é bastante sugestiva, fornecendo, pela primeira vez, uma descrição completa do efeito de micelas so bre velocidade de reações. Estes efeitos por muitas vêzes têm sido associados a constante dielétrica da interface, for ça iōnica, etc (Fendler \& Fendler, 1975).

Prosseguindo a anālise do efeito de CTAB sobre a constante de velocidade da reação de hidrólise alcalina dos RCP, enfocamos a seguir a hidrōlise de OCP, BCP e MCP (Figu $\operatorname{ras} 40,41$ e 42 ). 
Para o caso da hidrólise de OCP, como năo se atingiu o māximo na cruva de $k \psi \times$ CTAB, achamos incoveniente a si mulação das curvas, principalmente porque os principais pon tos de ajuste são o inicio (isto $\left.\bar{e} k \psi^{0}\right)$, o māximo (k $\psi_{\max }$ ) e a posterior diluição. A visão qualitativa do efeito é, entretanta bastante clara.

Sendo a constante de partição de OCP cerca de 100 vezes menor que DCP (vide supra) a uma mesma concentração sa lina o māximo da curva deve estar deslocado para regiōes de alta concentração de CTAB (veja Figura 40). Não é necessārio aprofundar mais a anāise deste composto pois não traríamos ne nhum componente adicional que a justificasse.

Para os RCP menores ( $B C P, \mathrm{Keq} / \bar{N}=0,06 \mathrm{M}^{-1}, \mathrm{KBr}=10$ mM, extrapolado como anteriormente citado (vide supra) e MCP, $\mathrm{Keq} / \mathrm{N} \ll 1 \times 10^{-4} \mathrm{M}^{-1}=0$, O MCP reside exclusivamente na fase. ex tramicelar, isto é, aquosa, Quina, 1978) a pequena constante de incorporação implica que a totalidade da reaça ocorre na fase aquosa. As curvas das Figuras 41 e 42 podem ser separa das em duas partes:

- aquelas obtidas na presença de tampão (em pH próximo ao pk e concentração suficiente, para evitar que a ligação de hidrōxido à micela positiva exceda a capacidade de manuten çäo do pH do sistema tampão, Quina et al, 1980) onde a concen tração de hidrōxido externa ē constante.

- aquelas onde não se adicionou tampão. Deve-se notar que neste caso foi adicionado erradamente o sistema tampão $\mathrm{HPO}_{4}=\mathrm{PO}_{4} \equiv$ num pH muito longe do seu pK (cerca de 12,50 à $25^{\circ} \mathrm{C}$, veja Tabela 25 e 26 ). Como os dados indicam fraca liga- 
ção destas espécies à micelas de CTAB, KPO $4 / B r \simeq 0,75$ (Barret et al, 1980) considera-se simplesmente a adição de hidrōxido ao sistema.

Enfocando-se inicialmente a hidrōlise onde não há sistema tampão atuante, pode-se apreciar que:

- a hidrōlise do MCP é proporcional ao pH externo, is to é, aplicando-se a equacăo experimental obtem-se exatamente a $k \psi$ de āqua (basta substituir o pH constante da Tabela 26 e obtem-se $k \psi$, enquanto que aplicando-se o mesmo procedimento para BCP observa-se que a velocidade é cerca de $10 \%$ a $20 \%$ maior do que aquela em āgua. Este fato estā perfeitamente de acordo com uma pequena incoporação de BCP. Pode-se notar ainda um aumento gradativo de $k \psi$ à medida que a concentração de CTAB cresce,em bora a sensibilidade experimental alinhe-se ā gradação obser vada.

Relativo ao meio tamponado (Figuras 41 e 42 e Tabelas 25 e 26 ), pode-se notar que $k \psi \bar{e}$ virtualmente constante com o aumento da concentração de CTAB, tanto para o BCP como O- BEP Como MCP. Deve-se reparar que a altas concentraçöes de CTAB (CTAB > 40mM) a ligação de hidrōxido começa a exceder a capacidade do tampão, implicando numa ligeira diminuição de $k \psi$. Tal efeito pode ser visualizado através do formalismo de troca iônica, ou seja:

- considerando-se o equilíbrio de troca de hidrōxido e admitindo-se a não ligação das espécies do tampão temos que

$$
K_{O H / B r}=\frac{O H_{b} \cdot B r_{f}}{O H_{f} \cdot B r_{b}}
$$


substituindo-se as expressões analiticas de brometo ligado $e$ livre (equações 29 e 30 ) e, considerando-se o limite de a)ta concentração de detergente, pode-se demonstrar facilmente que:

$$
\lim _{C T \rightarrow \infty} K_{O H / B r}=\frac{O H_{b}}{O H_{f}} \frac{\alpha}{(1-\alpha)}
$$

substituindo-se o valor de $\left(\alpha=0,2\right.$, Romsted, 1975)e $\mathrm{K}_{\mathrm{OH} / \mathrm{Br}}$ $\left(K_{\mathrm{OH} / \mathrm{Br}}=0,08\right.$, Chaimovich et al, 1979), obtemos:

$$
\mathrm{OH}_{\mathrm{b} 1 \mathrm{im}}=0,32 \mathrm{OH}_{\mathrm{f}}
$$

Pode-se verificar o efeito de CTAB no pH neste 1 inl te, admitindo-se para tanto que:

- uma vez ligado $\mathrm{O} \mathrm{OH}^{-}$ocorre uma queda no $\mathrm{pH}$ em ägua e o sistema tampão matēm 0 pH associando protons.

- as espēcies do tampão não se ligam à interface.

- para uma primeira aproximação o hidrōxido em āgua $\vec{e}$ obtido pelo valor de $\mathrm{pH}$ nominal da solução.

os cälculos são prontamente realizados com auxilio da equação de Handerson Hasselbach. Pode-se apreciar (Tabela 39), que quanto menor a concentração do sistema tampão e quan to maior o $\mathrm{pH}$, o efeito de CTAB na variaçäo do $\mathrm{pH}$ è maior. os cálculos foram feitos sem interações ou aproximações sucessi vas, visto que pretende-se sō uma visão qualitativa. 


\section{Tabela 39 - Efeito de micelas (CT $\rightarrow \infty)$ sobre $0 \mathrm{pH}$ da fase aquosa na presença de tampão}

Tampão Conc. de Tampão (mM) pH nominal pH final*

\begin{tabular}{|c|c|c|c|}
\hline $\mathrm{HCO}_{3}^{-} \quad \mathrm{H}^{+}+\mathrm{CO}_{3}^{=}$ & 20 & 9,30 & 9,29 \\
\hline \multirow{8}{*}{$\operatorname{pK}\left(30^{\circ} \mathrm{C}\right)=10,30$} & 20 & 10,50 & 10,49 \\
\hline & 20 & 11,30 & 11,49 \\
\hline & 10 & 9,30 & 9,29 \\
\hline & 10 & 10,50 & 10,47 \\
\hline & 10 & 11,30 & 10,94 \\
\hline & 5 & 9,30 & 9,29 \\
\hline & 5 & 10,50 & 10,45 \\
\hline & 5 & 11,30 & 10,71 \\
\hline \multirow{9}{*}{$\begin{array}{l}\mathrm{H}_{3} \mathrm{BO}_{3} \quad \mathrm{H}^{+}+\mathrm{H}_{2} \mathrm{BO}_{3} \\
\mathrm{pK}\left(30^{\circ} \mathrm{C}\right)=9,20\end{array}$} & 20 & 8,20 & 8,20 \\
\hline & 20 & 9,50 & 9,50 \\
\hline & 20 & 10,20 & 10,18 \\
\hline & 10 & 8,20 & 8,20 \\
\hline & 10 & 8,90 & 8,90 \\
\hline & 10 & 10,20 & 10,16 \\
\hline & 5 & 8,20 & 8,80 \\
\hline & 5 & 9,70 & 9,69 \\
\hline & 5 & 10,20 & 10,13 \\
\hline
\end{tabular}


Comparando-se os gräficos de constante de velocidade em função de CT Figuras 41,42 e 47 , verifica-se que - pH externo é mantido atê concentrações de CTAB da ordem de $0,1 M$ (Tabela 28), quando se utiliza tampão borato (pH 9,50 e 9,80, Figura 47), ou seja $\mathrm{OH}_{f}$ è constante.

Em presença de tampão de bicarbonato nota-se um de créscimo da constante de velocidade com aumento de CTAB, devi do à diminuição do pH externo.

Outro aspecto a ser analisado da reação de hidrōlise de RCP em presença de CTAB, é a relação P/A apresentada as Figuras $43,44,45$ e 46 . Como concluimos acima (veja anālise do efeito de constante diefétrica na relação P/A, Figuras 23 e 64 ) a proporção de produtos da reação é função da polaridade do meio, efeito este que atribuimos à estabilização seletiva do estado de transição intermediārio. Vimos na introdução que a constante dielétrica da interface (camada de stern) é semelhante a de metanol, (da ordem de 32 ) (Tabela 1).Estes fatos permitem que estabeleçamos o esquema abaixo para a rea ção de hidrōlise em presença de CTAB (Figura 66).

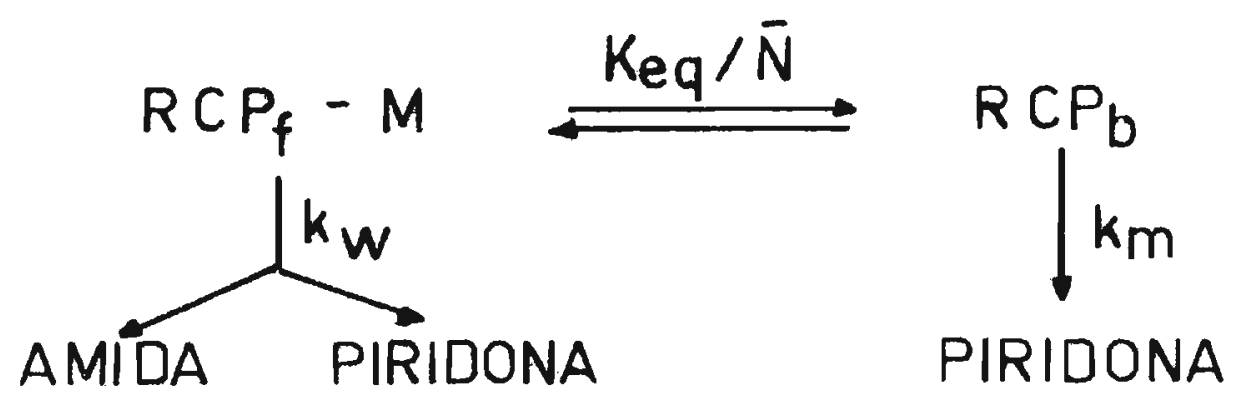

Figura 66 - Mecanismo proposto de hidrōlise de RCP em CTAB. 
onde $M=m i c e l a ; k w=$ constante de velocidade em āgua; $k m=c o n s t a n$ te de velocidade na micela. Em meio de constante dielétrica' baixa (adição de solvente inerte em āgua) a formação de piridona ē preferencial.

A expressão cinética(eq.91) associada ao valor de Keq/ $\mathbb{R}$, mostra que os resultados relativos a $P / A$ (Figuras 43 a 45 ) são coerentes com o esquema acima. 0 gráfico 46 que mostra a porcentagem de piridona formada em função da concentração de CTAB, representa melhor o que estamos analisando. Poder-se ia obter Keq/N destes gräficos, uma vez que pelo esquema a \% $P$ é função de Keq/N̄. Podemos concluir dizendo que os dados de $P / A$ em função de CTAB (ou \% P), associados aos de P/A em meio de dioxana são bastante sugestivos, garantindo assim o esquema proposto.

\section{$\underline{\text { SDS }}$}

Pode-se observar na Figura 48 que a medida que aumenta o comprimento da cadeia alquila com consequente aumento da constante de troca (KRCP/Na) (equação 116), ocorre uma diminuição na constante de velocidade. Na tentativa de promover um melhor ajuste do modelo teōrico aos dados experimentais, abaixamos empiricamente a constante de troca do MCP e aplica mos a equação 117 para obter as demais constantes, como mostra do abaixo:

$$
\begin{array}{rlrl}
K_{M C P / N a} & =4,5 & K_{M C P / N a}= & 3 \\
K_{B C P / N a}=50 & K_{B C P} / N a & =30 \\
K_{O C P / N a}=1200 & K_{O C P / N a}=750 \\
K_{D C P / N a}=26700 & K_{D C P / N a}=18200
\end{array}
$$


vas relativas a cada constante de troca ionica (vide legenda da Figura 48). Excetuando-se a curva relativa ao OCP, as de mais curvas (MCP, BCP e DCP) säo bastante concordantes aos da dos experimentais. Devemos notar ainda que para o caso do DCP a mudança da constante de troca de 18200 para 43500 pouco influencia a forma da curva. O fator $f$ (equação 120) calcula do com ambas as constantes é invariāvel, fato este que justifica a aproximação efetuada, isto ē, a constante de velocidade do DCP $\vec{e}$ devido somente à fração ligada ao SDS.

A previsäo dada pela equação 119 na condição de $K_{\mathrm{RCP} / \mathrm{Na}}$ muito grande é, portanto, amplamente obedecida.

Um aspecto importante desse estudo è a demonstração da ligação de hidróxido ao sistema micelar negativo. A medi da que adicionamos sal (Tabelas 33 e 34 , Figuras 49 e 50 ) ao sistema a concentração de sōdio livre aumenta e, pelo equilíbrio de troca (equação 104), os prōtons ligados às micelas de SDS serão deslocados.

Portanto, o pH interfacial deverā aumentar. Toman do-se a expressão 119, no limite de $\mathrm{K}_{\mathrm{RCP} / \mathrm{Na}} \rightarrow \infty$, temos:

$$
\begin{aligned}
& \mathrm{K}_{\mathrm{RCP} / \mathrm{Na}}{ }^{\rightarrow \infty} \mathrm{K}_{\mathrm{w}}=\frac{\mathrm{OH}_{f} \mathrm{~K}_{\mathrm{m}}^{2} \overline{\mathrm{K}_{w}}}{\mathrm{~K}_{\mathrm{Na}}} \frac{\mathrm{CDV}_{\mathrm{V}} \mathrm{Na}_{f}}{\mathrm{Na}_{b}} \\
& \text { ou } \\
& \lim _{R C P / N a} K_{R}=\frac{\mathrm{OH}_{f} \mathrm{~K}_{m}^{2} \overline{K_{w}}}{K_{w} K_{H / N a}} \frac{\mathrm{Na}_{f}}{\overline{N a_{b}}},
\end{aligned}
$$

podemos assumir $\overline{\mathrm{Na}_{b}}$ constante, uma vez que $\alpha \overline{\mathrm{e}}$ virtualmente. constante na faixa de concentração de detergente empregadolve 
ja Tabelas 29 a 34 ). Assim sendo, a expressão acima pode ser transformada em:

$$
\lim k \psi=\frac{\mathrm{OH}_{f} k_{m}^{2} \overline{K_{w}}}{k_{w C P / N a}{ }^{\rightarrow \infty} K_{H / N a} \cdot \overline{N a_{b}}} \cdot N a_{f}
$$

a expressão de $\mathrm{Na}_{f} \overline{\mathrm{e}}$

$$
\begin{array}{r}
\mathrm{Na}_{f}=\mathrm{CMC}+\mid \text { sal adicionado } \mid+\alpha C D \\
0 \mathrm{H}_{f} \mathrm{k}_{\mathrm{m}}^{2} \overline{\mathrm{K}_{w}}
\end{array}
$$

substituindo 126 em 125 e designando $\frac{}{k_{w} K_{H / N a} \cdot N a_{b}}$ de $\boldsymbol{\omega}$, temos

$$
\underset{\mathrm{KCP} / \mathrm{Na}^{\rightarrow \infty}}{\lim k \psi(\alpha C D+C M C+\text { sal adicionado })}
$$

A expressão 127 em função de sal adicionado $\vec{e}$ pratica mente linear, pois, we constante, a CMC è uma quantidade peque na podendo ser desprezada e $\alpha C D$ a dada concentração de deter gente é praticamente constante $(C D=C T$ - CMC e CMC ē desprezī vel). Assim, a expressão 127 pode ainda ser reduzida para

$$
\begin{aligned}
& \lim k \psi=\omega^{\cdot}(\text { sal adicionado })+\omega^{\prime} \\
& K_{R C P / N a}{ }^{+\infty}
\end{aligned}
$$

(onde $\left.\omega^{\prime}=(\alpha C D+C M C)\right)$.

A expressão 128 prevé que kঋ serā uma função linear da concentração de $\mathrm{NaCl}$ como se pode constatar na Tabela 34 e Figura 50 .

A ligação de hidrōxido ao sistema de SDS, previstope la equação 111, pode ser melhor desenvolvida utilizando-se a ex pressão de $\mathrm{Na}_{f}$ (equaçao 126), ou seja: 


$$
\overline{O H_{b}}=\frac{\mathrm{Na}_{f} \mathrm{OH}_{f}}{\mathrm{Na}_{b}} \frac{\overline{K_{w}} \mathrm{CDV}}{\mathrm{K}_{H / N a} K_{w}}
$$

ou

$$
\overline{O H_{b}}=\frac{\mathrm{Na}_{f} \mathrm{OH}_{f}}{\mathrm{Na}_{b}} \frac{\overline{K_{w}}}{K_{H / N a} K_{w}}
$$

assumindo $\overline{\mathrm{Na}_{b}}$ constante (vide supra) temos

$$
\begin{aligned}
& \overline{O H_{b}}=\frac{\overline{K_{w}}}{K_{H / N a} K_{w} N_{b}} \cdot \mathrm{Na}_{f} \cdot \mathrm{OH}_{f}, \\
& \text { designando } \frac{K_{W}}{K_{H / N a} K_{W} \overline{N_{b}}} \text { de } \Omega \text { temos } \\
& \overline{\mathrm{OH}_{\mathrm{b}}}=\Omega \mathrm{Na}_{\mathrm{f}} \cdot \mathrm{OH}_{\mathrm{f}}
\end{aligned}
$$

$$
\begin{aligned}
& \lim k \psi=\omega \cdot N a_{f} \\
& \mathrm{~K}_{\mathrm{RCP} / \mathrm{Na}}{ }^{\rightarrow \infty} \\
& N a_{f}=\alpha C D+C M C+\text { sal adicionado } \\
& \mathrm{Na}_{f}=\frac{\overline{\mathrm{OH}_{b}}}{\Omega O \mathrm{OH}_{f}} \\
& \text { temos } \overline{\mathrm{OH}_{b}}=\Omega\left(\alpha \mathrm{CDOH} \mathrm{H}_{f}+\mathrm{OH}_{f} \mathrm{CMC}+\text { sal adicionado }\right) \\
& \text { A equação } 131 \text { pode ser transformada em: } \\
& \overline{O H_{b}}=\Omega\left(\alpha \mathrm{CDOH}_{f}+\mathrm{CMCOH}_{f}+\mathrm{OH}_{f}{ }^{2}\right)
\end{aligned}
$$


expressāo esta que prevè um comportamento quadrático de $k \psi$ com $\mathrm{OH}_{f}$, explicando portanto a Figura 49 . Substituindo-se os valores experimentais em 132 , segundo os dados da Tabela 33 , a $20 \mathrm{mM}$ de hidrōxido de sōdio adicionado temos:

$$
\overline{\mathrm{OH}_{\mathrm{b}}}=\Omega(0,00004+0,00003+0,0004)
$$

da qual podemos notar que o termo dominante da expressão é $\mathrm{OH}_{f}{ }^{2}$. No caso de CD da ordem de 30 a $40 \mathrm{mM}$ o comportamento da expres são 132 será diverso. Portanto a condição de $k \psi$ proporcional ao quadrado de hidrōxido é obedecida somente a baixa concen tração de detergente (SDS) relativa à de hidrōxido (ou sal adicionado).

Haviamos obtido anteriormente $k_{m}^{2}=10 . k_{2}^{0}$ em mice las de CTAB (vide supra), e $k_{2}^{32,3 M}=8$. $k_{2}^{0}$ em meio de $50 \%$ de dioxana e força iōnica $3 M$ (vide supra). Em meio de SDS obtemos $f=\frac{k_{2}^{m} \bar{K}_{w}}{k_{2}^{0} k_{w}}$ da ordem de 0,45 . Substituindo-se o valor $k_{2}^{m} / k_{2}^{0}$ obtido com CTAB e $k_{w}=1,469 \times 10^{-14} M^{2}$ a $30^{\circ} \mathrm{C}$ obtemos $\bar{K}_{w}=6,61 x$ $10^{-16} \mathrm{M}^{2}$. 0 valor de $\bar{K}_{w}$ para misturas água dioxana, na ordem de $50 \% \mathrm{v} / \mathrm{v}, \overline{\mathrm{e}} \overline{\mathrm{K}_{\mathrm{w}}}$ Diox $50 \%=2,88 \times 10^{-16} \mathrm{M}^{2}$ (Harned e Owen, 1943). Pode-se notar que a aproximação dos valores de $\overline{K_{W}} \quad \bar{e}$ razoāvel. O efeito de força iônica em $\overline{K_{w}}$ é difícil de ser atribuido pois temos vārias espēcies iōnicas presentes, como o monōmero de CTAB, os contraions ligados, etc. Embora assumamos que a força iônica da camada de Stern ē $3 M$, não emprega mos este valor para estimar $\overline{K_{W}}$. Uma vez que $\overline{K_{w}}$ obtido $\bar{e}$ nume ricamente semelhante ao $\bar{K}_{W}$ descrito ( $50 \%$ de dioxana), podemos assumir que a constante de velocidade de segunda ordem intrín 
seca na fase micelar $\left(k_{2}^{m}\right)$ ê uma ordem de magnitude superior a de àgua $\left(k_{2}^{0}\right)$, analogamente a de dioxana $50 \%, 3 M\left(k_{2}{ }^{32,3 M}\right)$.

outro ponto de apoio a esta conclusão é a relação P/A obtida para reação de hidrölise na presença de SDS (Tabe

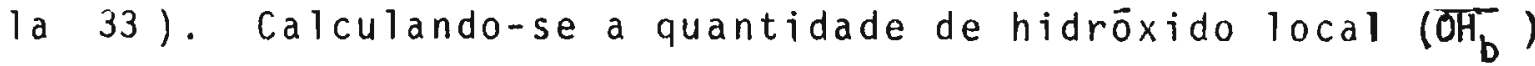
pela equação 129 , quer utilizando $\overline{K_{w}}=1,5 \times 10^{-14}$, quer ut lizando $\overline{K_{W}}=6,6 \times 10^{-16}$, obtemos respectivamente $\overline{O H_{b}}=4,6 x$ $10^{-4} \mathrm{Mw} \overline{\mathrm{OH}_{b}}=1,9 \times 10^{-5} \mathrm{M}$. A variação de $\overline{\mathrm{OH}_{b}}$ em função da concentração de SDS (entre 0,01 e $0,1 M$ ) não é muito grande. Portanto a relação P/A pode ser estimada a uma concentração in termediāria de SDS uma vez que nos limites de concentração de detergente a variação de $P / A$ é pequena. Aplicando-se os valo res de $\overline{\mathrm{OH}_{\mathrm{b}}}$ para estimar a relação P/A esperada em āgua (Figu ra 18 ), obtemos que a relação P/A em SDS è duas vezes superior a relação P/A da hidrólise em água, quando se utiliza $K_{W}$ para calcular $\mathrm{OH}_{b}$, e 25 vezes quando se utiliza $\bar{K}_{W}$ para cal cular $\mathrm{OH}_{b}$. Em qualquer caso a relação P/A em SDS é superior a de àgua.

Este fato demonstra que o esquema apresentado na $F \underline{i}$ gura 66 é bastante provāvel.

A suposição que $k_{2}^{m}$ em CTAB é semelhante a $k_{2}^{m}$ em SDS $\bar{e}$, a primeira vista, contrastante, uma vez que num casoes tamos adicionando um composto positivamente carregado (DCP) a um sistema positivo (CTAB), e no outro a um sistema negativo (SDS). E claro que o potencial químico do DCP em CTAB deve ser maior que em SDS. No entanto, não podemos esquecer que o hidroxido atua inversamente, ou seja, o potencial químico do hidröxido é menor em CTAB que em SDS. Assim devemos terum cancelamento de efeitos. Esta idéia pode ser melhor esclarec 
da monstando-se um diagrama energético como apresentado na figu ra 67 .

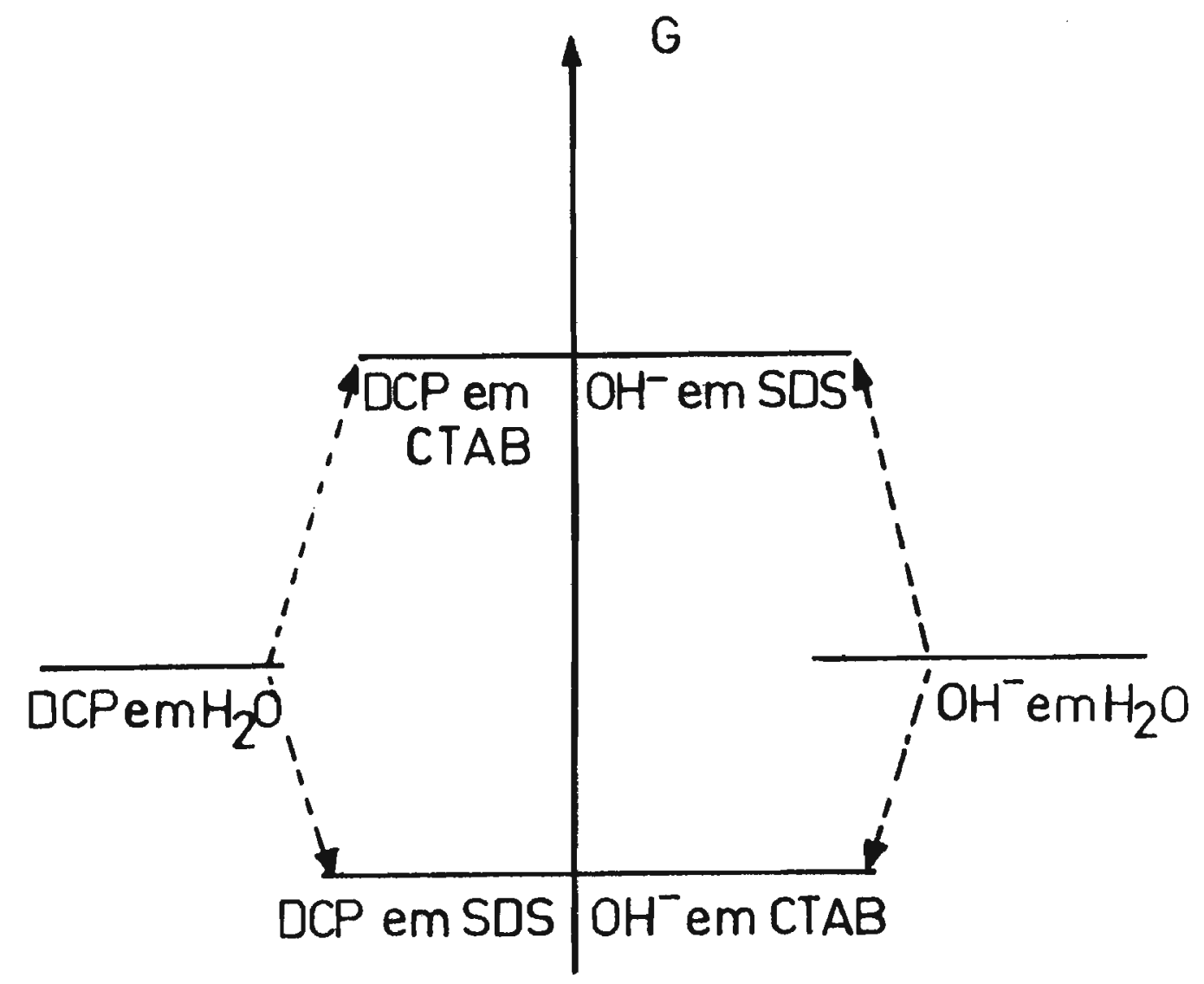

Figura 67 - Diagrama energētico de transferēncia de $D C P$ e $O H$ de àgua para CTAB e SDS. (G=energia livre)

Obviamente os valores de G de hidrōxido e DCP não de vem ser os mesmos em cada sistema $\left(\mathrm{H}_{2} \mathrm{O}\right.$, CTAB e SDS). Queremos entretanto, frisar é que o $\Delta G$ de transferencia deve ser semelhante.

Podemos concluir portanto que a reação de hidrölise alcalina dos RCP em presença de dioxana, CTAB ou SDS realiza se pelo mesmo caminho (veja Figura 66) e que a reatividade in trinseca nesses meios è superior por uma ordem de magnitude a de àgua. 
Podemos observar (Tabela 35 , Figura 5l), que o comportamento da reação de hidrōlise alcalina de DCP em pre sença de SDP é bastante semelhante ao comportamento da mesma reação em presença de CTAB (Tabela 23 , Figuras 39 e 46 ). A curva de constante de velocidade em função da concentração de SDP apresenta um máximo por volta de $20 \mathrm{mM}$ de SDP (Figura51).A porcentagem de piridona produzida atinge rapidamente o mäximo, $(100 \%$ de P) por volta de $8 \mathrm{mM}$ de SDP, indicando, mais uma vez, que a formação de piridona é preferencial em meio de constante dielētrica menor (a constante dielétrica de sistemas zwitte riônicos é também por volta de 30 , veja Tabela 1).

Os dados de $k \psi$ vs concentração de SDP indicam que ocorre concentração de hidrōxido na superfície. 0 fator de aceleração māximo $\left(k_{\psi m a x} / k_{\psi 0}\right) \bar{e}$ da de 15 vezes (a $p H=10,8$, sem sistema tampão adicionado).

0 efeito de sal adicionado ( $\mathrm{NaCl}$ ) apresentado na $\mathrm{Fi}-$ gura 51A demonstra a ligação de hidrōxido à superfície, uma vez que aumentando-se o $\mathrm{NaCl}$ externo, $k \psi$ diminui, devido ao desiocamento de hidróxido pelo cloreto adicionado.

A concentração de espēcies iōnicas num sistema mice Tar zwitteriónico é, a primeira vista, sem sentido. Contudo não podemos esquecer a existência do dipolo ( $\left.{ }^{-}-N^{+}\right)$no SDP, o qual deve gerar as condições para adsorver sais, neste caso $\mathrm{NaOH}$.

0 estudo de sistemas micelares zwitteriónicos $\overrightarrow{\mathrm{e}}$ um campo aberto para estudo de potenciais de dipolo de superficie. 
Nosso estudo com SDP e a reação de hidrólise alcal $\underline{i}$ na de DCP, restringe-se a demonstração que o comportamentada ligaçäo de hidróxido ë similar a micelas de CTAB. Se concentrarmos $\mathrm{Na}^{+}$e $\mathrm{OH}^{-}$conjuntamente ou hidrôxido isolado são con jecturas no presente momento.

IV.3. Anälise de detergentes por Micro-Hoffmann

A ocorrência da eliminação de Hoffmann (Figura 8) no interior do cromatögrafo a gās, pode ser observada nas figuras 52 a 61 . Tomando como exemplo o cromatograma de HerquatCl (Figura 60) e do Herquat-OH (Figura 61), percebe-se a variação na proporção de componentes, isto ë, no caso do Herquat Cl a de composição têrmica conduz basicamente cloretos de a cano e aminas terciārias, enquanto no caso de Herquat-OH a de composição produz alcenos, alcoōis e aminas terciärias.

A composição de cadeias do detergente è calculada levando-se em conta as āreas relativas de cada componente do cromatograma.

Não é nossa intenção um estudo metodológico profundo, que compare o método usual com o mëtodo por nós modificado. Queremos apenas ressaltar que, com a modificação proposta, eliminamos a etapa mais lenta na determinação da composição de cadeia dos detergentes examinados. 
A reação de hidrōlise alcalina em fase aquosa de' Fons N-alquil-4-cianopiridineos (RCP) foi caracterizada com relação a efeitos de $\mathrm{pH}$, força iōnica (u) e constante diéletrica do meio (D).

A hidrólise alcalina dos RCP resulta na formaçăo de do is produtos, i.e.e, a N-alquil-4-carboxiamidopiridíneo (A) e a N-alquil-4-piridona (P) correspondentes. A relação $P / A$ é função crescente de $\mathrm{pH}$ e atinge um valor limite de 1,75 para todos os RCP empregados. No entanto, em misturas āgua/dioxa na a formação de $P$ é preferencial.

A constante de velocidade observada $(k \psi)$ de pseudoprimeira ordem de hidrōlise dos RCP é função de pH. Em solução aquosa $(\mu=0,02)$ esta dependēncia pode ser expressa por : $\log k \psi=1,0702 \mathrm{pH}-14,3$

Os efeitos devidos a variações em $\mu$ e D sobre k $\psi$, foram analisados segundo os modelos de Debye-Huckel (Robinson, R.A. e Stokes, R.H. em "Electrolyte Solutions", 1955) e Bröns ted - Christiansen - Scatchard (Amis, E.S. em "Solvent Effects on Reaction Rates and Mechanisms", 1966).

Os estudos dos efeitos de $\mathrm{pH}, \mu$ e D sobre $k \psi$ servi ram como modelos de referéncia para racionalizar efeitos de' detergentes de vārios tipos estruturais tanto na velocidade, como na razão de produtos resultantes da hidrólise alcalina. dos RCP.

Em soluções tamponadas de micelas de hexadeciltrime

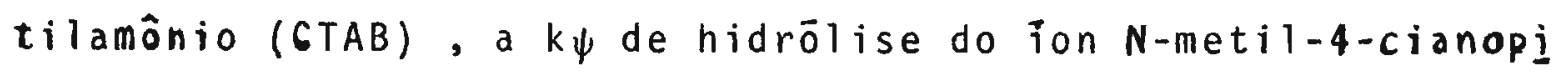


ridineo (MCP) è independente da concentração de detergente. Por outro lado, $k \psi$ aumenta com CTAB, acima da concentração crïtica de micelização (CMC) para ions N-butil (BCP), N-octil (OCP) e N-dodecil-4-Cianopiridineo (DCP). No caso do DCP o

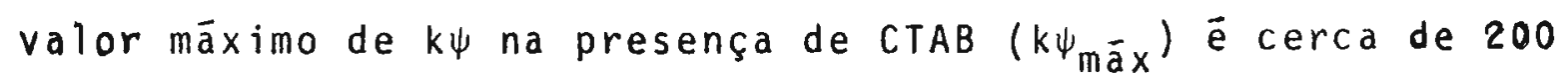
vêzes maior que $k \psi$ na ausência de $\operatorname{CTAB}\left(k \psi^{0}\right)$. os dados referentes ao efeito de CTAB para a hidrölise de DCP, foram analisados quantitativamente utilizando o modelo teōrico de Troca-Iōnica em micelas (Quina,F.H. e Chaimovich, H. J.Phys. Chem. 83,1844 (1979) ) . Os resultados desta anālise indicam que a constante de velocidade de segunda ordem na fase mice $\operatorname{lar}\left(k_{2}^{m}\right)$ è uma ordem de magnitude superior àquela na àgua $\left(k_{2}^{0}\right)$. Esta diferença pode ser reproduzida supondo a reação num ambi ente com $D=32$ e $\mu=3$.

A adição de dodecilsulfato de sōdio (SDS) acima CMC, inibe a reação. Contudo, não é observada inibição total, mesmo no caso do DCP o qual é completamente incorporado à fá se micelar. Empregando a teoria de Troca-Iônica em soluções micelares, explicitas considerações do produto iônico da $\bar{a}-$ gua na fase micelar $(\overline{K w})$, conduzem a expressões da dependēncia de concentração de $\mathrm{Na}^{+}$aquoso (livre) do pH local na superficie do SDS. Anālise quantitativa dos resultados de velo cidade de hidrōlise dos RCP, fornecem o resultado que $\overline{K W}=$ $0,025 \mathrm{kw}$ ( $\mathrm{kw}$ é o produto iōnico da āgua na fase aquosa), uma vez suposto $k_{2}^{m}=10 k_{2}^{0}$.

Em soluções micelares de $3-(N, N$-dimetil-N-dodecila-

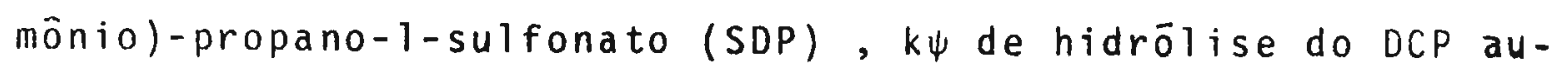


menta, a razão $k_{m a ̄ x} / k_{\psi}^{0}$ chega a cerca de 15. Esta aceleração pode ser devida a existêcia de um campo potencial dipolar na' superfície da micela de SDP.

Como no caso de misturas dioxano-āgua, a razão de' produtos P/A em presença de micelas (CTAB, SDS e SDP) refletem a formação preferencial de P. Esta preferéncia foi analisada considerando os possỉveis estados de transição envolvi-" dos.

Finalmente descreve-se uma metodologia simples para determinação rāpida da homogeneidade dos detergentes derivados de sais de amōnio (distribuição do comprimento de cadeias a)quila). Esta técnica é em essência uma eliminação micro - ' Hoffman, devido a direta injeção do detergente na forma de' hidróxido e posterior pirōlise no cromatógrafo a gās. Como tal, quantidades negligiveis de detergente são requeridas, como tam bém os passos de isolamento e manipulação (e eventuais erros' sistemáticos) associados com a eliminação de Hoffman convencional, seguidos por anālise no cromatōgrafo a gās, são evitados. 
The alkaline hydrolysis of $\mathrm{N}-a 1 k y l-4-c y a n o$ pyridi-' nium ions (RCP) in aqueous solution was characterized with respect to the eftects on $\mathrm{pH}$, ionic strength $(\mu)$ and medium dieletric constant (U) on the reaction. Alkaline hydrolysis of RCP results in the formation of two products, i.e., the ' corresponding N-alkyl-4-carboxamidopyridinium ion (A) and ' N-alkyl-4-pyricione (P). In aqueous solution the P/A product ' ratio increases with $\mathrm{pH}$, attaining a limiting value of 1,75 ' at high pH for all the RCP. In water-dioxane mixture, however, there is preferential formation of $P$.

The observed pseudo-first-order rate constant $\left(k_{\psi}\right)$ for hydrolysis of the RCP in aqueous solution $(\mu=0,02)$ va-' ries with $\mathrm{pH}$ according to:

LOG $k_{\psi}=1,0702 \mathrm{pH}-14,3$

The effect of changes in $\mu$ or $D$ on $k_{\psi}$ were analysed within the framework of the models of Debye-Huckel (Robinson, R.A. and Stockes, R.H. in "Electrolyte Solutions", 1955 ) and Bronsted-Christiansen - Scatchard (Amis, E.S. in "Solvent' Effects on Reaction Rates and Mechanisms", 1966).

These dependences of $k_{\psi}$ and of the $P / A$ product ratio on $\mathrm{pH}, \mu$ and $D$ served as a basis for rationalization of the " effects of detergents of various structural types on both the rate of alkaline hydrolysis of the RCP and the resultant produc ratio.

In Buffered micellar solutions o hexadecyltrimethy 
ammonium bromide $(C T A B), K_{\psi}$ for alkaline hydrolysis of the $N$ methyl-4-cyanopyridinium ion (MCP) is independent of detergent concentration. In contrast, $k_{\psi}$ increases with (CTAB) above the critical micelle concentration (CMC) for the N-Butil (BCP), $\mathrm{N}$-octyl (OCP) and N-dodecyl-4 cyanopyrydinium (DCP) ions. In the case of DCP, the maximum value of $k_{\psi}$ in the presence of ' $\operatorname{CTAB}\left(k_{\psi \text { max }}\right)$ is 200 times greater than $k_{\psi}$ in the absence of CTAB $\left(k_{\psi}^{0}\right)$. The effect of CTAB on $k_{\psi}$ for alkaline nydrolys is of DCP was analyzed quantitatively using the conceptual model' for ion exchange (Quina, F.H. and Chaimovich, H. J.Phys.Chem. 83, $1844(1979))$. The results of this analysis indicate that' the second order rate constant for nydrolysis in the micellar phase $\left(k_{2}^{m}\right)$ is an order of magnitude greater than that in the aqueous phase $\left(k_{2}^{0}\right)$. This difference betwen $k_{2}^{m}$ and $k_{2}^{0}$ can be" reproduced by assuming a reaction environment with $D=32$ and ' $\mu=3$.

Micellar sodium dodecyl sulfate (SDS) inhibit the ' rate of alkaline hydrolysis of all the RCP. Nonetheless, total inhibition is not observed, even in the case of DCP, which is completely incorporated into the micellar phase. Using the theory of ion exchange in micellar solutions, explicitly conside ration of the ionic product of water in the micellar phase $\left(R_{w}\right)$ leads to expression for the external (free) Nat dependence of the local pH at the SDS micellar surface. Quantitative analysis of the rate data for the alkaline hydrolysis of the RCP, assuming $k_{2}^{m}=10 k_{2}^{0}$, furnishes the result that $k w=0,025 \mathrm{kw}$, where $\mathrm{KW}$ is the product of water in the aqueous phase. 
In micellar solutions of $3-(N, N-d i m e t h y l-N-d o d e c y l-$ ammonium) propane-l-sulfonate (SDP), $k_{\psi}$ for alkalyne Hydrolysis of DCP increases, the ratio $k_{\psi m a x} / k_{\psi}^{0}$ attaining a value ' of ca. 15. The observed rate acceleration is suggested to be due to the existence of a dipolar potencial field at the SDP micellar surface.

As in the case of water-dioxane mixtures, the P/A product ratio in the presence of detergent micelles (CTAB, ' SDS and SDP) reflects preferential formation of $P$. This preference was analyzed on the basis of considerations of possible transition states involved.

Finally, a simple methodology for rapid determina-' tion of the homogeneity (distribution of alkyl chain lengths) of ammonium-derived detergents is described. This technique is in essence a micro Hoffmannelimination effected by direct injection pyrolysis glpc of the detergent in the hydroxide form.

As small negligible quantities of detergent are required and the product isolation and manipulation steps and. attendant systematic errors) associated with a conventional ' Hoffmannelimination, followed by glpc analysis of the products are circunve ted. 
1. Incluiu-se na Introdução tratamentos teōricos originais pa ra näo quebrar a fluidez do texto e facilitar a compreensão dos mesmos.

2. Esta dissertação trata unicamente de sistemas micelares î́ nicos formados em solução aquosa.

3. Estudos teōricos (Stigter, 1964) mostram que variando - se o fator de forma (designado por $S$ ), das equações que descrevem o potencial específico de absorção de contraions às micelas $\left(\Delta \mu^{0}=\mu^{0}\right.$ micela- $\left.\mu a \overline{g u a}\right)$, de um sistema esférico $(S=1)$, para um sistema elīptico $(S 21,5)$, não hä alteração signifi cativa dos resultados.

4. A estimativa do raio da esfera, nūcleo da micela, baseia-se no comprimento da cadeia alquila com as ligações $\mathrm{CH}_{2}$ em configuração trans (Tanford, 1980).

5. Impõe-se como limite de concentração de detergente atē cer ca de 100 vezes a CMC. Acima desta concentração ocorre fre quentemente a chamada segunda CMC (Shinoda et a1, 1963), onde - sistema não è mais constituĩdo de micelas, como defini das no texto, passando para estruturas mais ordenadas como cristais liquidos e outras (Fendler \& Fendler, 1975). Na condição de alta concentração de detergente o grau de dis sociação $(\alpha)$, não pode ser definido pelas equações 9 e 10 , nem tampouco è claro se a é constante (Fendler, 1980).

A outra condição indicada é referente a concentração sali na. O valor de a é dependente do contraion,como exemplo micelas de CTACl tem $\alpha$ igual a 0,20 , enquanto micelas de CTAIO $_{3}$ tem a igual a 0,24 (Romsted, 1975). A variação de $\alpha$ em função do contraion que tem sido descrita (Romsted, 1975 ) é em geral pequena, por volta de 10 a 20 por cento nos casos extremos, porën ocorre. Assim sendo adicionandose sal a dado sistema micelar, cujo contraion $\vec{e}$ dife 
rente do sal adicionado, o grau de cobertura da micela pe lo contraion da micela serā alterado. A medida que a por centagem do sal adicionado seja muito grande (Chajmorich et al, 1980) relativa ao contraion original da micela pode mos mudar de micela, passar de CTAB para CTAOH, por exemp10. Dados recentes (Lindman, 1980) indicam que micelas de CTAB são de forma elipsoidal enquanto de CTACl esféri cas, ao adicionar $\mathrm{Cl}^{-}$em sistemas de CTAB iremos a medida que $C]^{-}>\mathrm{Br}^{-}$passar de micelas elipsōides para esféricas, e vice-versa (veja tambëm Miola, 1979).

6. 0 cālculo da força iônica $3 M$ na camada de Stern, foi calcu lado para micela esfērica (Mukerjee, 1962).

7. Outra critica que pode ser feita ao modelo é a definiçäo de trēs regiões com constante dielétrica definidas $(2,32$, 80). Fica dificil de imaginar como é a fronteira de cada região.

8. 0 equilíbrio apresentado na equação 12 è um equilíbrio for mal, pois representa a somatōria do conjunto de reaçōes que conduzem à formação do agregado mais provāvel.

9. Tratando-se da adição de sal à certa quantidade de āgua, a condutividade irā inicialmente crescer linearmente com quan tidade de sal adicionado (assumindo dissociação completa), quando a concentração de saturação é alcançada a condutivi dade para de aumentar. Consequentemente o diferencial da condutāncia equivalente serā aproximadamente constante ate a concentração de saturação e a partir dai cai instantanea inente para o valor zero. A quebra aguda observada nos grä ficos de condutância especĩfica VS. concentração de soluções de detergentes (Shinoda et al, 1963) sugere uma sepa ração de fases. Uma vez que a nova fase è microscōpica in distinguivel o termo pseudo fase é preferível.

A pseudo fase micelar tem certas peculiaridades que a dis tinguem de uma separação de fases real. Considere uma mis tura āgua benzeno em um dado recipiente, a medida que au- 
menta uma das fases, a superficie de contato entre estas permanece inalterada, variando somente o volume de cada fa se. Em sistemas micelares o tamanho da micela é delimitado pelo $\bar{N}$ (Chaimovich, 1979) e consequentemente adicionando-se mais detergentes a relação ārea/volume permanece cons tante, na faixa de concentração usualmente empregada.

10. A relação $y / x$ que encontra-se na equação 8 é relacionadoà $(1-\alpha)$ (equaçōes 15 e 19) da seguinte forma. Utilizando-se da definição de $\alpha$ (equação 10): a carga da micela é p-q e - no de agregação é $p$, ou seja, $\alpha=\frac{p-q}{p}$, que $\bar{e}$ o mesmo que a fração de contraions ligados $(q / p)$, isto $\bar{e} 1-\alpha=\frac{q}{p}$.

11. Como a CMC de detergentes iônicos de $1 \times 10^{-3} \mathrm{M}$ (Fendler e Fen dler, 1975; Shinoda et a 1, 1963) o limite de CT $\rightarrow \infty$ é acessí vel experimentalmente.

12. 0 desenvolvimento usual è o seguinte:

$v=k \psi|R T|=k_{0}^{2} x_{f} R_{f}(1-C D \bar{V})+k_{m}^{2} X_{b} R_{b}(C D V)$

(onde $k \psi \bar{e}$ a constante de velocidade de pseudo primeira or dem; $R_{f}$ a fração de $R$ livre; $\overline{R_{b}}$ concentração local de $R$; $k_{0}^{2}$ e $k_{m}^{2}$ constante de velocidade de segunda ordem em àgua $e$ micela respectivamente)

como $\overline{R_{b}}=\frac{R_{b}}{C D \bar{V}}$ e $(1-C D \bar{V})=1$

$v=k \psi=k_{0}^{2} \quad x_{f} \frac{R_{f}}{R_{T}}+k_{m}^{2} X_{b} \frac{R_{b}}{R_{T}}$

13. O desvio a que nos referimos è relativo à mudança do coefí ciente de atividade da espēcie iônica.

14. A constante $K_{3}$ como pode ser visto na Figura 6 , representa o equilibrio entre as cianohidrinas ( $\mathrm{H}$ e $\mathrm{H}^{-}$). 0 valor da mesma pode ser estimada por comparação ao pk de cianohidri nas correlatas (Wiberg, 1954; Stork, 1971). 
15. Pelo modelo de esferas rigidas $a_{j}=$ raio $A+$ raio $B$ (Weston e Schawrz, 1972; Benson, 1960). 
Akerlö, G. e Short, 0.A.; 3. Amer. Chem. Soc. 58, 1241 (1936). Almgren, M., Aniansson, E.A.G. e Holmaker, K.; Chem.Phys. 19, 1 (1977).

Almgren, M., Grieser, F. e Thomas, J.K. J.Chem.Soc.Faraday.

Trans. I. 75,1674 (1979).

Amdur, I. e Hammes, G.G.; em "Chemical Kinetics" McGraw-Hill, New York (1966).

Amis, E.S.; em "Kinetics of Chemical Change in Solution" MacMillan, New York (1949)

Amis, E.S.; em "SolventEffects on Reaction Rates and Mechanisms" Academic Press, New York (1966).

Aniansson, E.A.G.; em "Chemcial and Biological Applications of relaxation Spectrometry" D: Reidel, Dordrecht, Holland (1975).

Aniansson, E.A.G. e Wa11, S.N. J. Phys. Chem. 78, 1024 (1974).

Aniansson, E.A.G. e Wa11, S.N. J. Phys. Chem. 79, 857 (1975).

Aniansson, E.A.G. e Wa11, S.N. Ber. Bunsengese11. Phys. Chem. 81 $(1977)$.

Aniansson, E.A.G., Wa11 S.N., Almgrem, M., Hoffmann, H.0., Kei1man, I.,Ulbricht, W., Zana, R., Lang, J. e Tondre, C. J. Phys.

Chem. 80, 905 (1976).

Barry, B.W. e Russel, G.F.J. J. Colloid. Interface Sci., 40, 174 (1972).

Bartet, D., Gamboa, C. e Supūlveda, L: J. Phys. Chem. 84, 272 , (1980).

Benson, S.W., em "The Foundations of Chemical Kinetics, McGraw Hil1, New York (1960).

Berezin, I.V., Martinek, K. e Yatsimirskii, Russ. Chem. Rev. (English Trans1.) 42, 487 (1973).

Bock. C.R., Tese de Doutoramento, Univ. de Carolina do Norte, Chapel Hill, M.C., U.S.A., (1974). 
Bonilha, J.B.S., Tese de Doutoramento, Universidade de São Pau 10, Instituto de Química, Brasil, (1979).

Buist, G.J., Bunton, C.A., Robinson, L., Sepūiveda, L. e Stam, M, J. Amer. Chem. Soc., 92, 4072 (1970).

Bunton, C.A. Prog. Solid State Chem. 8, 239 (1973).

Bunton, C.A., Ohmenzetter, K. e Sepülveda, L., J. Phys. Chem. $81,2000(1973)$.

Bunton, C.A., Romsted, L.R. e Smith, H.J. J. Org. Chem., 43, 4299 (1978).

Chaimovich, H., Tese de Doutoramento, Universidade de São Pau10, Instituto de Química, Brasil, (1979).

Chaimovich, H., Tese de Livre-Docēncia, Universidade de São Pau1o, Instituto de Quimica, Brasi1, (1979).

Chaimovich, H., Politi, M.J., Bonilha, J.B.S, e Quina, F.H. J. Phys. Chem. 83, 1851, (1979).

Chaimovich, H., Cuccovia, I.M., Aleixo, R.M.V., Zanette, D, e Quina, F.H. - Resumos do "International Symposium on Solution Behavior of Surfactants - Theoretical and Applied Aspects", 1980, no prelo.

Chan, S.K. e Kahlweit, M., Ber. Bunsengessel. Phys. Chem. 81 , $1294(1977)$.

Clifford, J. Trans. Faraday. Soc. 61, 1276 (1965).

Clifford, J. e Pethica, B,A., Trans. Faraday. Soc. 60, 1483, $(1964)$.

Cope, A.C. e Trumbull, E.R., Org. Reactions, 11, 317 (1960).

Corkill, J.M., Goodman, J.F. e Walker, T., Trans. Faraday Soc. $63,768(1967)$.

Corrin, M.L., J. Colloid Sci. 3, 333 (1948).

Cuccovia, I.M., Tese de Doutoramento, Universidade de Sāo Paulo, Instituto de Quimica, Brasi1, 1980.

Eisenberg, D. e Kauzmann, W., em "The Structure and Properties of Water" oxford, C1arendon Press, London, 1969. 
Elworthy, P.H, Florence, A.T. e Mac Farlane, C.B.,em "Solubjlization by Surface Active Agents and Its Applications in Chemistry and the Biological Sciences", Chapman and Hall, London, (1968).

Fendler, J.H., em "Membrane Mimetic Chemistry", a ser publicado por Wiley-Interscience (1980).

Fendler, J.H. e Fendler, J.H. em "Catalysis in Micellar and Macromolecular Systems", Academic Press, New York (1975).

Fernandez, M.S. e Fromherz, P. J, Phys. Chem. 81, 1755 (1977).

Fisher, L.R. e 0akenful1, D.G. Chem. Soc. Rev. 6, 25 (1977).

Frank, H.S., e, "Desalination Research Conference Proceedings", National Soc. of Sciences - National Research Council, Publication 942, p.141 (1963).

Frank, H.S., Fendn. Proc. (Fedn. Am. Socs-exp-Biol.) 24, Supplement $15,51(1965)$.

Frank, H.S. e Evans, M.W. J. Chem. Phys. 13, 507 (1945).

Frank, H.S. e Thompson, P.T. J. Chem. Phys, 31, 1086 (1959).

Funasaki, N. J.Colloid Interface Sci. 64. 461 (1978).

Funasaki, N. J. Phys. Chem 83,237 (1979).

Funasaki, N. J. Phys. Chem. 83, 1998 (1979).

Fuson, R.C., em "Reactions of Organic Componds", John Willey, New York (1962).

Grätzel, M. e Thomas, J.K., em "Modern Fluorescence Spectrosco py" Plenum Press, New York, (1976).

Grunhagem, H.H. J. Colloid. Interface Sci. 53, 282 (1975). Guggenheim, E.A., em "Thermodynamics", Interscience, New York $(1945)$.

Harned, H.S. e Owen, B.B., em "The Physical Chemistry of Eletrolytic Solution", Reinhold, London (1943).

Harkins, W.D., Matton, R.W. Corrin, M.L. J.:Amer. Chem. Soc.

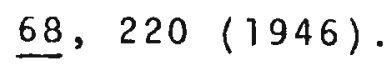

Harrold, S.P. J. Colloid. Sci. 15, 280 (1960). 
Hartley, G,S., em "Aqueous Solutions of Paraffin Chain Salts", Hermann, Paris (1936).

Hartiey, G.S. e Roe, J.W. Trans.Faraday Soc. 36, 101 (1940). Hasted, J.B., em "Aqueous Dieletrics", John Wiley; New York (1973).

Infelta, P.P. Chem. Phys. Lett 61, 88 (1979).

Jungermann, E., em "Cationic Surfactants" Marcel Dekker. New York (1970).

Kalyanasundaram, K. Chem. Soc. Rev. 7, 453 (1978).

Kalyanasundaram, K. e Thomas, J.K., J. Phys. Chem. 80, 1462 (1976).

Kavanau, J.L., em "Water and Solute - Water Interactions", Holden-Day, San Francisco (1965).

Kirschbaum, M. J,Pharm, Sci. 63, 981 (1974).

Kosower, E.M., Skarcz, J.A.Jr., Schawartz, W.M.Jr. e Patton, J. W. J. Amer. Chem. Soc. 82,2188 (1960).

Kosower, E.M. e Patton, J.W. Tetrahedron 22, 2081 (1966).

Kurz, J.L. J. Phys. Chem. 66, 2239 (1962).

Laidler, K.J., em "Reaction Kinetics", MacMillan, New York (1963).

Landquist, J.K. J. Chem. Soc. Perkin I 454 (1976).

Leffler, J.E. e Grunwald, E., e, "Rates and Equilibria of Organic Reactions", John Wiley, New York (1963).

Lindman, B. Resumos do "International Symposium on Solution Behavior of Surfactants - Theoretical and Applied Aspects" (1980) no prelo.

MacDonald, R.C. e Banghan, A.D. J. Membr. Biol. 9, 361 (1972). Maclness, D.A., em "The Principles of Eletrochemistry", Reinhold, New York (1939).

MacLaughiin, S. Current Topics in Membranes and Transport 2,71 (1977).

Martinek, K., Osipov, A.P., Yatsimirski, A.K. e Berezin, I.V. Tetrahedron 31, 709 (1975). 
Martinek, K., Yatsimirski, A.K., Levashov, A.V. e Berezin, I. V., em "Micellization, Solubilizatio and Micro.emulsions", Plenum Press, New York (1977).

McBain, J.W., em "Advances in Colloid Science" Interscience, New York (1942).

McBain, M.E.L. e Hutchinson, E., em "Solubilization and Related Phenomena", Academic Press, New York (1955).

Menger, F.M. Accounts.Chem. Res. 12, 111 (1979).

Menger, F.M. e Portnoy, C.E. J. Amer. Chem. Soc. 89,4698 (1967).

Menger, F.M., Jerkunica, J.M. e Johnston, J.C. J. Amer. Chem. Soc. $100,4676(1978)$.

Miola, L., Tese de Doutoramento, Universidade de São Paulo, Brasil (1979).

Mittal, K.L., "Micellization, Solubilization and Micro emulsions" Plenum Press, New York (1977).

Mittal, K.L. "Solution Chemistry of Surfactants" Plenum Press, New York (1979).

Mukerjee, P. J. Phys. Chem. 66, 943 (1962).

Mukerjee, P. em "Micellization, Solubilization and Micro emulsi ons", Plenum Press, New York (1977).

Mukerjee, P. e Mysels, K.J. "Critical Micelle Concentrations of Aqueous Surfactant Systems", Nat1. Stand. Ref. Data Serv. Natl. Bur. Stand (U.S.) 36 (1971).

Muller, N. J. Phys. Chem. 76, 3017 (1972).

Muller, N., em "Reaction Kinetics in Micelles" Plenum Press, New York (1973).

Muller, N., em "Solution Chemistry of Surfactants", Plenum Press, New York (1979).

Muller, N. e Birkahn, R.H. J. Phys. Chem. 71, 957 (1967).

Mysels, K.J. "Introdution to Colloid Chemistry" Interscience, New York (1967). 
Nakagawa, T. e Jizimoto, H. Kolloid. Z. Z. Polym. 250, 594 (1972).

Némethy, G. e Scheraga, H.A. J. Chem. Phys, 36, 3382 (1962). Overbeek, J. Th. G., em "Colloid Science", Elsevier, New York (1952).

Overbeek, J. Th.G. e Stigter, D. Rec. Trav. Chim. Pays.-Bas 75 , $1263(1956)$.

Patey, G.N. e Valleau, J.P. J. Chem. Phys. 63, 2334 (1975).

Pauling, L. "The Nature of the Chemical Bond", Cornell University Press, Ithaca, New York (1960).

Permutter, B. e Haugman, Proc. Reaction Kinetics 6, 239 (1972).

Pitzer, K.S. J. Phys. Chem. 77,268 (1973).

Pitzer, K.S. Accounts. Chem. Res. 10, 371 (1977).

Pitzer, K.S. J. Chem. Phys. 70, 393 (1979).

Pitzer, K.S. e Mayorga, G. J. Phys. Chem. 77, 2300 (1973).

Pitzer, K.S. e Kim, J.J. J. Amer. Chem. Sco. 96, 5701 (1974).

Podo, F., Ray, a e Némethy, G. J. Amer. Chem. Soc. 95, 6164 (1973).

Politi, M.J., Cuccovia, I.M., Chaimovich, H, Almeida, M.L.C., Bonilha, J.B.S. e Quina, F.H.-Tetrahedron Lett., 115 (1978). Pottel, R., Katze, V. e Mullier, St. Ber. Bunsenges. Phys.Chem. $82,1086(1978)$.

Quina, F.H., Tese de Livre Docēncia, Unviersidade de São Paulo, Brasil (1978).

Quina, F.H. e Toscano, V.G. j.Phys.Chem 81, 1750 (1977).

Quina, F.H. e Chaimovich, H. J. Phys. Chem. 83, 1844 (1979).

Quina, F.H., Politi, M.J., Cuccovia, I.M., Baumgarten, E., Mar tins-Franchetti, S.M. e Chaimovich, H. J. Phys. Chem. 84, 361 $(1980)$.

Quina, F.H., Politi, M.J., Martins-Franchetti, S.M., Cuccovia, I.M. e Chaimovich, H. Resumos do "International Symposium on Solution Behavior of Surfactants - Theoretical and Applied Aspects"1980, io prelo. 
Robinson, R.A. e Stokes, R.H., em "Eletrolyte Solutions", Butter Worths, London (1955).

Romsted, L.R., Tese de Doutoramento, Depto Chem., Indiana University, Bloomington, Indiana (1975).

Sasaki, T., Hattori, M., Sasaki, J. e Nukina, K. Bull. Chem. Soc. Japan 48, 1397 (1975).

Schales, 0. e Schales, S.S. J. Biol. Chem. 140,879 (1941).

Schick, M.J. "Nonionic Surfactants" Dekker, New York (1967)

Sheraga, H.A. Curr. Top. Biochem, 1 (1973).

Schinitzky, M., Dianoux, A.C., Gitler, C. e Weber, G. Biochemistry 10, 2106 (1971).

Shinoda, K. e Soda, T. J. Phys. Chem. 67, 2072 (1963).

Shinoda, K., Nakagawa, T., Tamamushi, B. e Isemura, T. "Colloidal Surfactants" Academic Press, New York (1963).

Shinoda, K. e Haruhiko, A. Nippon Kagaka Zasshi, 299 (1965).

Smoluchowski, M. in "Electrokinetic Phenomena", Reinhold, New York (1934).

Spurlin, S., Hinze, W. e Armstrong, D.W. Analytical Lett. 10, $997(1977)$.

Stigter, D. J. Phys. Chem. 68, 3603 (1964).

Stigter, D. J. Phys. Chem. 782480 (1974a).

Stigter, D. J. Colloid Interface Sci. 47, 473 (1974b).

Stigter, D. J. Phys. Chem. 79, 1008 (1975a).

Stigter, D. J. Phys. Chem. 79, 1015 (1975b).

Stigter, D. e Mysels, K.J. J. Phys. Chem. 59, 45 (1955).

Stork, G. J. Amer. Chem. Soc. 93,5286 (1971).

Tanford, C. "The Hydrophobic Effect", John Wiley, New York (1963

Tanford, C. "The Hidrophobic Effect", John Wiley, New York, $2^{\text {nd }}$ ed. $(1980)$.

Thomas, J.K. Accounts, Chem. Res. 10, 133 (1977). 
Turro, N.J., Brown, A.M. e Gratzel, M (1979). A ser publicado no Agew. Chem.

Vogel, A.I., em "Anālise Orgānica Qualitativa". Ao Livro TēcnI co, Rio de Jnaeiro (1971).

Weller, A., Prog. Reaction Kinetics 6, 239 (1972).

Weston, R.E.Jr. e Schawrz, H.A., em "Chemical Kinetics" Prentice Ha11, New Jersey (1972).

Wiberg, K.H. J: Amer. Chem. Soc. 76, 5371 (1954).

Williams, E., Sears, B., Allerhand, A. e Cordes, E.H. J. Amer. Chem.Soc. 95, 4871 (1973).

Wishinia, A. J. Phys. Chem. 67, 2079 (1963).

Yatsimirski, A.K., Martinek, K. e Berezin, I.V. Tetrahedron, 27, $2855(1971)$.

Yēkta, A., Aikawa, M. e Turro, N.J. Chem. Phys. Lett. 63,543 $(1979)$. 